\title{
WestVirginiaUniversity
}

THE RESEARCH REPOSITORY @ WVU

Graduate Theses, Dissertations, and Problem Reports

2000

\section{Process control of applied laser system for enhanced glass production}

Liyun Zheng

West Virginia University

Follow this and additional works at: https://researchrepository.wvu.edu/etd

\section{Recommended Citation}

Zheng, Liyun, "Process control of applied laser system for enhanced glass production" (2000). Graduate Theses, Dissertations, and Problem Reports. 2332.

https://researchrepository.wvu.edu/etd/2332

This Dissertation is protected by copyright and/or related rights. It has been brought to you by the The Research Repository @ WVU with permission from the rights-holder(s). You are free to use this Dissertation in any way that is permitted by the copyright and related rights legislation that applies to your use. For other uses you must obtain permission from the rights-holder(s) directly, unless additional rights are indicated by a Creative Commons license in the record and/ or on the work itself. This Dissertation has been accepted for inclusion in WVU Graduate Theses, Dissertations, and Problem Reports collection by an authorized administrator of The Research Repository @ WVU.

For more information, please contact researchrepository@mail.wvu.edu. 


\title{
Process Control of Applied Laser System for Enhanced Glass Production
}

\author{
Liyun Zheng
}

\author{
Dissertation submitted to the \\ College of Engineering and Mineral Resources \\ at West Virginia University \\ in partial fulfillment of the requirements \\ for the degree of
}

Doctor of Philosophy

in

Mechanical Engineering

John E. Sneckenberger, Ph.D., Chair

Larry Banta, PhD.

Biswajit Das, Ph.D.

Samir Shoukry, Ph.D.

Charles Stanley, Ph.D.

Steven D. Woodruff, Ph.D.

Department of Mechanical and Aerospace Engineering

\section{Morgantown, West Virginia}

2000

Keyword: Laser, Glass Cutting, Process Control, Finite Difference Method, Experiment 


\title{
Abstract \\ Process Control of Applied Laser System For Enhanced Glass Production
}

\author{
Liyun Zheng
}

\begin{abstract}
Existing glass crack-off methods often result in considerable loss of glassware and require subsequent edge finishing that is labor intensive. The main objective of this dissertation is to contribute to the development of a laser-enhanced cutting and finishing method that will decrease waste and improve productivity in the manufacturing of handblown glass.

The main objectives of this dissertation were to perform modeling and simulation of the laser glass interaction, to contribute to the lab prototype machine construction, to participate in experiments to investigate the process parameters governing successful glass cutting, and to pursue the design and validation of controls for the laser glass cutting machine.

A 3-D laser heat source model was developed. The LGCSim program based on this 3-D heat source model as well as the classical 3-D heat conduction model was developed to simulate the laser glass interaction. Results from the simulation showed that the peak glass temperature can reach $3500{ }^{\circ} \mathrm{C}$, the time constant for glass temperature decay after laser striking is 0.02 second, and the required laser power to cut typical glassware has to be around $1000 \mathrm{~W}$. Simulation-based parametric studies showed that higher laser power is significantly beneficial to the process, higher glassware rotation speed is beneficial to the process too, and larger glassware diameter and thickness have detrimental effects on the process.

It was experimentally shown that the glassware should be preheated to its annealing temperature to avoid cracking. The pulling force is necessary to enable quick and stable cutting. It is better to increase the rotation speed although it is limited mechanically. The laser power has a significant beneficial effect on the melting and a detrimental effect on the groove depth. It is best that the laser beam be kept focused on the cutting ring surface. A gas purge can help to obtain narrower and deeper grooves.

Empirical models were developed to predict the melting depth and the groove depth based on the simulation and experimental results. A system controller was developed. Four subsystem components in the control system were designed and conceptually proven to be operationally acceptable for the lab prototype machine.
\end{abstract}




\section{TABLE OF CONTENT}

Acknowledgements vii

List of Figures viii

List of Tables $\quad$ xii

Nomenclature xiii

$\begin{array}{lll}\text { Chapter } 1 \text { Introduction } & 1\end{array}$

1.1 Research Background 1

1.2 Goal and Tasks of Research 4

$\begin{array}{llr}\text { Chapter } 2 & \text { Literature Review } & 8\end{array}$

2.1 Laser and Its Application $\quad 8$

2.1.1 Laser Cutting of Metals 9

2.1.2 Laser Cutting of Non-metals 10

2.2 Glass and Glass Cutting 11

2.3 Laser Glass Cutting 15

2.3.1 Fracture Method 15

2.3.2 Refined Fracture Method 18

2.3.3 Vaporization/Melting Method 18

2.3.4 Cutting Rod-like Glass 20

2.4 Modeling/Simulation of Laser Glass Cutting 21

2.5 Cutting Quality Characterization and Experiment 24

2.6 Instrumentation and Control 27 
Chapter 3 Analytical Modeling of Laser Glass Interaction

3.0 Introduction 30

3.1 3-D Heat Conduction Model 31

3.1.1 Laser Beam 32

3.1.2 Cut Glassware 35

3.1.3 Laser Glass Interaction $\quad 38$

3.2 1-D Model and Its Application 42

Chapter 4 Simulation of Laser Glass Interaction 46

4.0 Introduction 46

4.1 Numerical Model 47

4.2 Simulation 51

4.3 Results 53

4.3.1 Single-Cycle Laser Glass Interaction 53

4.3.2 Multi-Cycle Laser Glass Interaction $\quad 58$

4.3.3 Parametric Studies $\quad 61$

4.3.3.1 Effect of Glassware Rotation Speed 65

4.3.3.2 Effect of Laser Power 66

4.3.3.3 Effect of Glassware Size $\quad 74$

4.3.3.4 Effect of Glassware Wall Thickness 77

$\begin{array}{lll}\text { 4.3.4 Discussion } & 77\end{array}$

$\begin{array}{lll}\text { Chapter } 5 & \text { Experiments on Laser Glass Cutting } & 79\end{array}$

$\begin{array}{lll}5.0 & \text { Introduction } & 79\end{array}$

$5.1 \quad$ Experiment Setup 81

5.1.1 Machine Requirements $\quad 81$

5.1.2 Machine Setup 82

5.1.3 Performance Measures 86 
5.1.4 Experiment Parameters $\quad 87$

$\begin{array}{lll}\text { 5.1.5 Glassware Samples } & 88\end{array}$

5.2 Experiment Procedure 92

5.3 Experiment Arrangement 99

5.4 Experiment Results and Analysis 105

$\begin{array}{lll}\text { 5.4.1 General Results } & 105\end{array}$

$\begin{array}{ll}\text { 5.4.2 Cutting Mechanism } & 107\end{array}$

$\begin{array}{ll}\text { 5.4.3 Cutting Characteristics } & 113\end{array}$

5.4.4 Mass Transfer 118

$\begin{array}{ll}\text { 5.4.5 Cutting Process } & 120\end{array}$

5.4.6 Effect of Laser Power 122

5.4.7 Effect of Rotation Speed 124

$\begin{array}{lll}5.4 .8 & \text { Effect of Material } & 130\end{array}$

5.4.9 Effect of Laser Focal Position 133

5.4.10 Effect of Purge 135

$\begin{array}{lll}5.4 .11 \text { Discussion } & 137\end{array}$

Chapter 6 Control of Laser Glass Cutting Process 140

$\begin{array}{lll}6.0 & \text { Introduction } & 140\end{array}$

6.1 Process Control Modeling 142

6.1.1 Model to Predict Melting Depth 144

6.1.2 Model to Track Cutting Groove Depth 150

6.2 Subsystem Implementations 152

6.2.1 Temperature Measurement Unit 152

6.2.2 Laser Power Controller 154

6.2.3 Laser Beam Positioning Controller 157

6.2.4 Pulling Force Controller 158

6.2.5 Data Acquisition Board 159

6.2.6 System Integration 160 
6.3 System Controller Implementation 161

$\begin{array}{lll}6.4 & \text { Application } & 163\end{array}$

Chapter 7 Dissertation Summary, Contribution and Future Work 165

$\begin{array}{lll}7.1 & \text { Dissertation Summary } & 165\end{array}$

$\begin{array}{lll}7.1 .1 & \text { Motivation } & 165\end{array}$

$\begin{array}{lll}7.1 .2 & \text { Objectives } & 165\end{array}$

$\begin{array}{lll}\text { 7.1.3 Approaches } & 166\end{array}$

$\begin{array}{lll}7.1 .4 & \text { Results } & 167\end{array}$

$\begin{array}{lll}7.2 & \text { Dissertation Contributions } & 168\end{array}$

$\begin{array}{lll}\text { 7.2.1 Theoretical Contributions } & 168\end{array}$

$\begin{array}{ll}\text { 7.2.2 Experimental Contributions } & 169\end{array}$

$\begin{array}{lll}7.3 & \text { Recommendations for Future Work } & 171\end{array}$

$\begin{array}{ll}\text { References } & 172\end{array}$

Appendix A 1-D Analytical Model for Laser Glass Cutting 178

Appendix B Peak Temperature and Decay Rate 185

Appendix C Energy Loss Due to Heat Convection 188

Appendix D Energy Loss Due to Heat Radiation 192

Vita 195

Dissertation Approval Page 196 


\section{ACKNOWLEDGEMENTS}

I would like to dedicate this work to my son Daniel and my wife Wenbo whose love and whole-hearted support helped me to bring this work and my degree to completion. I would also like to give thanks to my father, mother and brothers for encouraging me in pursuing my education. I love you all.

I would like to take this opportunity to express my gratitude to Dr. John E. Sneckenberger, a great man and an excellent teacher and advisor, for giving me the opportunity to work on this interesting project, and for providing me with the guidance, support and resource necessary for accomplishing my research objectives.

My sincere appreciation also goes to Dr. Steven D. Woodruff, who served as a member on my committee, for his tremendous support in doing this research. I would like to thank Dr. Larry Banta, Dr. Charles Stanley, Dr. Samir Shoukry and Dr. Biswajit Das who served as members of my committee and whose wise advice and valuable suggestions helped significantly improve the quality of my work.

I would like to acknowledge the support from US Department of Energy for funding this project. I would also like to acknowledge the support from the West Virginia Development Office's Energy Efficiency Program, for which Jeff Herholdt is the Manager. I would also like to thank Tom Fenton at the Fenton Art Glass Company, Robert Lynch and John Lynch at the Davis Lynch Glass Company, and Richard Bazelak at the Laser Processing Company for their great support in doing this research.

A special thanks goes to Dr. Keh-Minn Chang for providing the opportunity to use the Hi-Scope equipment for experimental micrograph measurement. Dr. Wanhong Yang and Ms. Jian Mao deserve thanks for their valuable instruction and help in performing the measurements with the Hi-Scope equipment. 


\section{LIST OF FIGURES}

Figure 1.1 Hand Glass Production Process using Conventional Cutting in Cold Shop..... 2

Figure 1.2 Hand Glass Production Process using Laser Cutting in Hot Shop .................. 3

Figure 3.1 Gaussian Beam and its Relative Intensity Distribution .............................. 33

Figure 3.2 Collimated Gaussian Beam brought to a Focus ......................................... 34

Figure 3.3 Geometry of Glassware in Cylindrical Coordinate System........................... 36

Figure 3.4 Approximate Geometry of Glassware in Cartesian Coordinate System ........ 37

Figure 3.5 Temperature Response with Laser Power $100 \mathrm{~W}$........................................ 45

Figure 3.6 Temperature Response with Laser Power $1000 \mathrm{~W}$..................................... 45

Figure 4.1 Resistance-Capacitance Formulations for Finite Difference Method............. 48

Figure 4.2 Control Volumes and Resistance in Different Coordinates for R-C

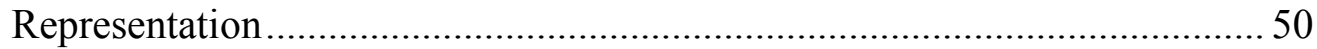

Figure 4.3 Heat Conductivity as a Function of Temperature ....................................... 52

Figure 4.4 Specific Heat as a Function of Temperature .................................................53

Figure 4.5 Temperature Response to Single-Cycle Energy Input $\left(\theta=0, r=r_{2}, z=z_{1}\right) . .55$

Figure 4.6 Temperature Profile along Direction at $\mathrm{t}=0.25$ second $\left(\mathrm{r}=\mathrm{r}_{2}, \mathrm{z}=\mathrm{z} 1\right) \ldots \ldots . .56$

Figure 4.7 Temperature Profiles along $\mathrm{z}$ Axis at $\mathrm{t}=0.25$ second and 1.0 second $(\theta=0$,

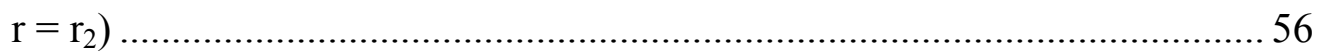

Figure 4.8 Temperature Profiles along $\mathrm{r}$ Axis at $\mathrm{t}=0.25$ second and $1.0 \operatorname{second}(\theta=0$,

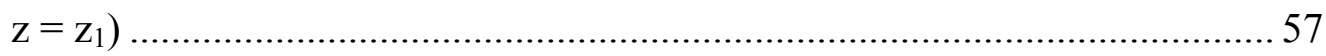

Figure 4.9 Temperature Response to Multi-Cycle Energy Input $\left(\theta=0, r=r_{2}, z=z_{1}\right) \ldots .59$

Figure 4.10 Average Temperature Response to Multi-Cycle Energy Input ( $r=r_{2}$, $\left.\mathrm{z}=\mathrm{z}_{1}\right)$

Figure 4.11 Effect of Glassware Rotation Speed on Temperature Response $\left(\theta=0, r=r_{2}\right.$, $\left.\mathrm{z}=\mathrm{z}_{1}\right)$

Figure 4.12 Effect of Laser Power on Average Temperature Response $\left(r=r_{2}, z=z_{1}\right) \ldots 64$ 
Figure 4.13 Effect of Laser Power on Average Temperature Response $\left(r=1 / 2\left(r_{1}+r_{2}\right)\right.$,

$$
\left.\mathrm{z}=\mathrm{z}_{1}\right)
$$

Figure 4.14 Effect of Laser Power on Average Temperature Response $\left(r=r_{1}, z=z_{1}\right) \ldots 65$

Figure 4.15 Temperature Image at 5 seconds $\left(P=600 \mathrm{~W}, \mathrm{D}_{0}=95 \mathrm{~mm}, \mathrm{~d}_{0}=5 \mathrm{~mm}\right) \ldots . .67$

Figure 4.16 Temperature Profile at 5 seconds $\left(P=600 \mathrm{~W}, \mathrm{D}_{0}=95 \mathrm{~mm}, \mathrm{~d}_{0}=5 \mathrm{~mm}\right) \ldots .67$

Figure 4.17 Temperature Image at 15 seconds $\left(P=600 \mathrm{~W}, \mathrm{D}_{0}=95 \mathrm{~mm}, \mathrm{~d}_{0}=5 \mathrm{~mm}\right) \ldots 68$

Figure 4.18 Temperature Profile at 15 seconds $\left(P=600 \mathrm{~W}, \mathrm{D}_{0}=95 \mathrm{~mm}, \mathrm{~d}_{0}=5 \mathrm{~mm}\right) . .68$

Figure 4.19 Temperature Image at 5 seconds $\left(P=1000 \mathrm{~W}, \mathrm{D}_{0}=95 \mathrm{~mm}, \mathrm{~d}_{0}=5 \mathrm{~mm}\right) \ldots 69$

Figure 4.20 Temperature Profile at 5 seconds $\left(P=1000 \mathrm{~W}, \mathrm{D}_{0}=95 \mathrm{~mm}, \mathrm{~d}_{0}=5 \mathrm{~mm}\right) . .69$

Figure 4.21 Temperature Image at 15 seconds $\left(P=1000 \mathrm{~W}, \mathrm{D}_{0}=95 \mathrm{~mm}, \mathrm{~d}_{0}=5 \mathrm{~mm}\right) .70$

Figure 4.22 Temperature Profile at 15 seconds $\left(P=1000 \mathrm{~W}, \mathrm{D}_{0}=95 \mathrm{~mm}, \mathrm{~d}_{0}=5 \mathrm{~mm}\right) 70$

Figure 4.23 Temperature Image at 5 Seconds $\left(P=1000 \mathrm{~W}, \mathrm{D}_{0}=80 \mathrm{~mm}, \mathrm{~d}_{0}=5 \mathrm{~mm}\right) . .72$

Figure 4.24 Temperature Profile at 5 Seconds $\left(P=1000 \mathrm{~W}, \mathrm{D}_{0}=80 \mathrm{~mm}, \mathrm{~d}_{0}=5 \mathrm{~mm}\right) .72$

Figure 4.25 Temperature Image at 15 Seconds $\left(P=1000 \mathrm{~W}, \mathrm{D}_{0}=80 \mathrm{~mm}, \mathrm{~d}_{0}=5 \mathrm{~mm}\right) 73$

Figure 4.26 Temperature Profile at 15 Seconds $\left(P=1000 \mathrm{~W}, \mathrm{D}_{0}=80 \mathrm{~mm}, \mathrm{~d}_{0}=5 \mathrm{~mm}\right) 73$

Figure 4.27 Temperature Image at 5 Seconds $\left(P=1000 \mathrm{~W}, \mathrm{D}_{0}=80 \mathrm{~mm}, \mathrm{~d}_{0}=3 \mathrm{~mm}\right) . .75$

Figure 4.28 Temperature Profile at 5 Seconds $\left(P=1000 \mathrm{~W}, \mathrm{D}_{0}=80 \mathrm{~mm}, \mathrm{~d}_{0}=3 \mathrm{~mm}\right) .75$

Figure 4.29 Temperature Image at 15 Seconds $\left(P=1000 \mathrm{~W}, \mathrm{D}_{0}=80 \mathrm{~mm}, \mathrm{~d}_{0}=3 \mathrm{~mm}\right) 76$

Figure 4.30 Temperature Profile at 15 Seconds $\left(P=1000 \mathrm{~W}, \mathrm{D}_{0}=80 \mathrm{~mm}, \mathrm{~d}_{0}=3 \mathrm{~mm}\right) 76$

Figure 5.1 Laser and Beam Delivery Subsystem .................................................... 83

Figure 5.2 Lab Prototype Laser Glass Cutting Machine .............................................. 84

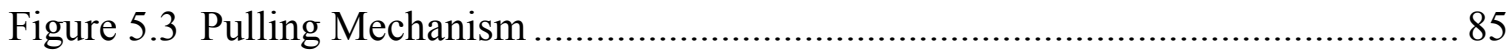

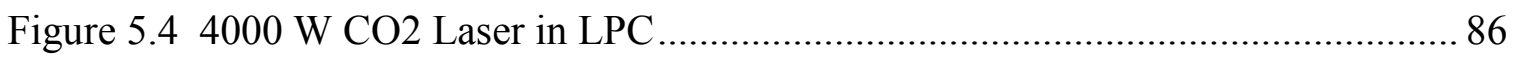

Figure 5.5 Cut Sample (Clear Cylinder) from Davis Lynch Glass Company.................. 90

Figure 5.6 Cut Sample (Opaque Cylinder) from Davis Lynch Glass Company............. 91

Figure 5.7 Cut Samples (Left: Bottom of Champagne Bottle, and Right: Bottom of

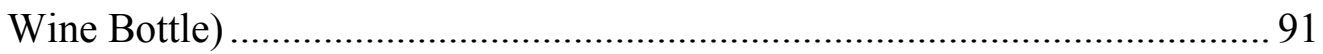

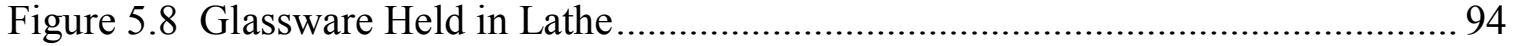

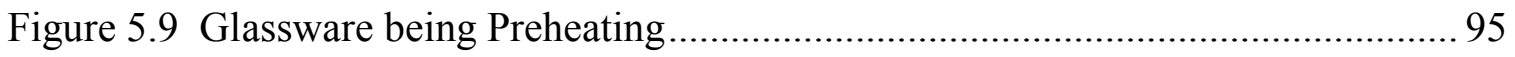




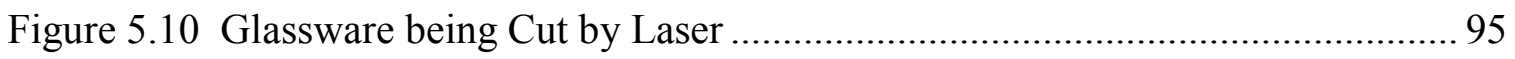

Figure 5.11 Separation of Lower Section of Glassware (Moil) Begins ......................... 96

Figure 5.12 Separation of Lower Section of Glassware (Moil) Completed.................... 96

Figure 5.13 Glassware Product Produced .................................................................... 97

Figure 5.14 Optical Equipment for Measurement of Cut Samples ............................... 97

Figure 5.15 Melting and Vaporizing Phenomena in Laser Glass Cutting ................... 108

Figure 5.16 Melting and Vaporizing Phenomena in Laser Cutting (A-A View)........... 109

Figure 5.17 Three Types of Possible Groove Geometry............................................ 111

Figure 5.18 Resealing in Laser Glass Cutting (case one) .......................................... 111

Figure 5.19 Resealing in Laser Glass Cutting (case two) .......................................... 112

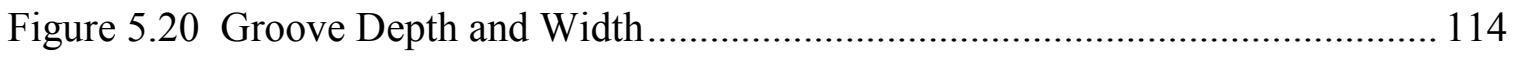

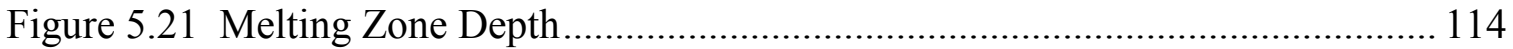

Figure 5.22 Heat Affected Zone Width.............................................................. 115

Figure 5.23 Cutting Edge Features $\left(\mathrm{P}=1000 \mathrm{~W}, \omega=1 \mathrm{r} / \mathrm{s}, \mathrm{d}_{0}=4.3 \mathrm{~mm}\right) \ldots \ldots \ldots \ldots \ldots \ldots . . . . . . . .117$

Figure 5.24 Cutting Edge Features $\left(\mathrm{P}=1000 \mathrm{~W}, \omega=1 \mathrm{r} / \mathrm{s} \mathrm{d}_{0}=3.8 \mathrm{~mm}\right) \ldots \ldots \ldots \ldots \ldots \ldots . . . \ldots 118$

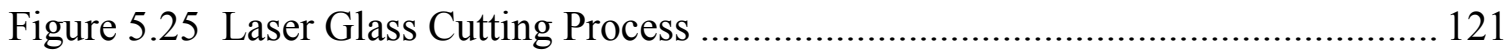

Figure 5.26 Laser Glass Cutting Process with Fitted Curves.................................... 121

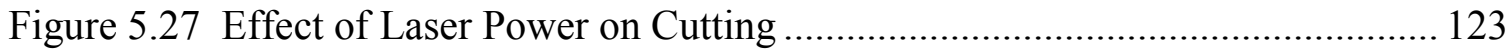

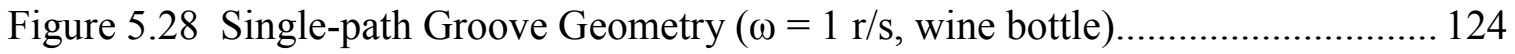

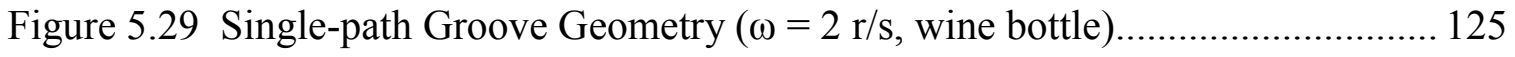

Figure 5.30 Melting Depth vs. Time at Two Levels of Rotation Speed ....................... 128

Figure 5.31 Groove Width vs. Time at Two Levels of Rotation Speed....................... 128

Figure 5.32 Heat Affected Zone Widths vs. Time at Two Levels of Rotation Speed ... 129

Figure 5.33 Groove Depths vs. Time at Two Levels of Rotation Speed ...................... 129

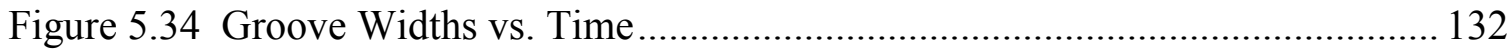

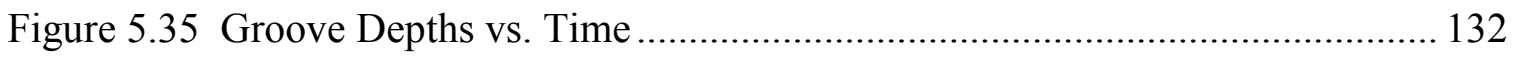

Figure 5.36 Heat Affected Zone Widths vs. Time …................................................ 133

Figure 5.37 Effect of Focal Position on Cutting Process $(\mathrm{P}=500 \mathrm{~W})$......................... 134

Figure 5.38 Effect of Focal Position on Cutting Process $(\mathrm{P}=1000 \mathrm{~W})$....................... 135 
Figure 6.1 Schematic of Laser Glass Cutting Machine with Proposed Controls ........... 143

Figure 6.2 Control Logic of Laser Glass Cutting Process .......................................... 143

Figure 6.3 Approach to Develop Process Model .......................................................... 144

Figure 6.4 Melting Depth vs. Cutting Time and Laser Power .................................... 147

Figure 6.5 Comparison Between Model and Experimental Results ........................... 149

Figure 6.6 Cutting Groove Depth vs. Cutting Time and Laser Power......................... 151

Figure 6.7 Temperature Measurement Unit with IR Sensor ..................................... 153

Figure 6.8 UC-1000 Laser Power Control Unit ..................................................... 155

Figure 6.9 Response of Synrad 100 W Laser Generator to Step Input ......................... 156

Figure 6.10 Decaying Response of Synrad 100 W Laser Generator ........................... 156

Figure 6.11 Velmex Motion Controller for Laser Beam Focus Position Control.......... 157

Figure 6.12 Motion Controller for Pulling Force Control........................................... 158

Figure 6.13 DT 9800 Data Acquisition Board ...................................................... 159

Figure 6.14 Schematic of Control System for Laser Glass Cutting ............................. 160

Figure 6.15 Physical Implementation of Control System for Laser Glass Cutting........ 161

Figure 6.16 Visual Front Panel of System Control Software....................................... 162

Figure 6.17 Block Diagram of System Control Software ........................................ 163 


\section{LIST OF TABLES}

Table 1.1 Tasks with Associated Approaches and Related Chapters 7

Table 2.1 Mechanical and Thermal Properties of Soda Lime Glass 14

Table 3.1 Parameters used in Model 44

Table 4.1 Expressions of Interior Nodes in Different Coordinate Systems 49

Table 4.2 Parameters for Single-Cycle Laser Glass Interaction Simulation $\quad 54$

Table 4.3 Parameters Common to Parametric Studies 62

Table 4.4 Melting Zone Computations $\quad 71$

Table 5.1 Geometrical Properties and Density of Sample Glassware 89

Table 5.2 Material Constituents of Clear Cylinder and Opaque Cylinder 89

Table 5.3 First Set of Laser Glass Cutting Experiments 102

Table 5.4 Second Set of Laser Glass Cutting Experiments 103

Table 5.5 Third Set of Laser Glass Cutting Experiments 104

Table 5.6 Geometrical Dimensions of Cutting Zone 116

Table 5.7 Distinct Sections and Features in the Cutting Edge 118

Table 5.8 Mass Losses in Laser Glass Cutting 119

$\begin{array}{ll}\text { Table 5.9 Laser Glass Cutting Process } & 120\end{array}$

Table 5.10 Effect of Laser Power on Cutting 123

Table 5.11 Laser Glass Cutting at Two Levels of Rotation Speed 126

Table 5.12 Cutting Groove Depth vs. Firing Time at Two Rotation Levels Speed 126

Table 5.13 Effect of Material Type on Cutting Process 131

Table 5.14 Effect of Focus Position on Cutting Process 134

Table 5.15 Cutting Process Results from Experiment with Purge 136

Table 6.1 Melting Depth Predicted by Simulation and by Process Model 146

Table 6.2 Melting Depths Predicted by Simulation and by Process Model with $\begin{array}{ll}\text { Geometrical Adjustment } & 148\end{array}$

Table 6.3 Groove Depth Obtained from Experiments and Predicted by Process Model 


\title{
NOMENCLATURE
}

\author{
a: $\quad$ Thermal diffusivity \\ $\mathrm{A}_{0}$ : $\quad$ Constant related to laser transmissibility \\ C: Thermal capacity \\ $\mathrm{C}_{\rho}$ : Thermal capacity (taking mass density into consideration) \\ $\mathrm{d}_{0}$ : $\quad$ Glassware thickness \\ D: Laser beam diameter \\ $\mathrm{D}_{0}$ : $\quad$ Glassware diameter \\ $\mathrm{D}_{\mathrm{g}}$ : Groove depth \\ $\mathrm{D}_{\mathrm{m}}$ : $\quad$ Melting depth \\ e: Natural exponential \\ E: $\quad$ Laser beam electrical field \\ $\mathrm{E}_{0}$ : Beam electrical field on axis of propagation \\ h: Convection coefficient \\ i: $\quad$ Index of simulation steps \\ I: $\quad$ Beam intensity \\ $\mathrm{I}_{0}$ : Beam intensity on axis of propagation \\ in: Inch \\ $\mathrm{k}$ : $\quad$ Thermal conductivity \\ 1: $\quad$ Length of rectangular-Gaussian beam \\ 1: $\quad$ Index of control volumes in finite difference method \\ $\mathrm{m}$ : Index of control volumes in finite difference method \\ $\mathrm{n}$ : Index of control volumes in finite difference method \\ $\mathrm{n}$ : Index of cycles of laser glass interaction \\ $\mathrm{N}$ : Number of cycles in laser glass interaction \\ $\mathrm{N}_{1}$ : Number of cycles of laser glass interaction to melt through glassware \\ P: $\quad$ Laser power \\ $\mathrm{P}_{0}$ : $\quad$ Laser power magnitude \\ Q: $\quad$ Heat flow \\ $\mathrm{Q}_{\mathrm{v}}$ : $\quad$ Heat flow in control volume \\ r: $\quad$ Radius to beam propagation axis in laser beam description \\ $r \quad$ Coordinate in cylindrical coordinate system \\ $\mathrm{r}_{1}$ : Glassware inner radius \\ $\mathrm{r}_{2}$ : $\quad$ Glassware outer radius \\ $\mathrm{R}$ : Radius of laser propagation wave front curvature in laser beam description \\ R: Thermal resistance \\ $\mathrm{s}_{2}$ : Distance of image to focal lens in laser beam description \\ $\mathrm{S}_{1}$ : $\quad$ First section in cutting edge \\ $\mathrm{S}_{2}$ : $\quad$ Second section in cutting edge
}




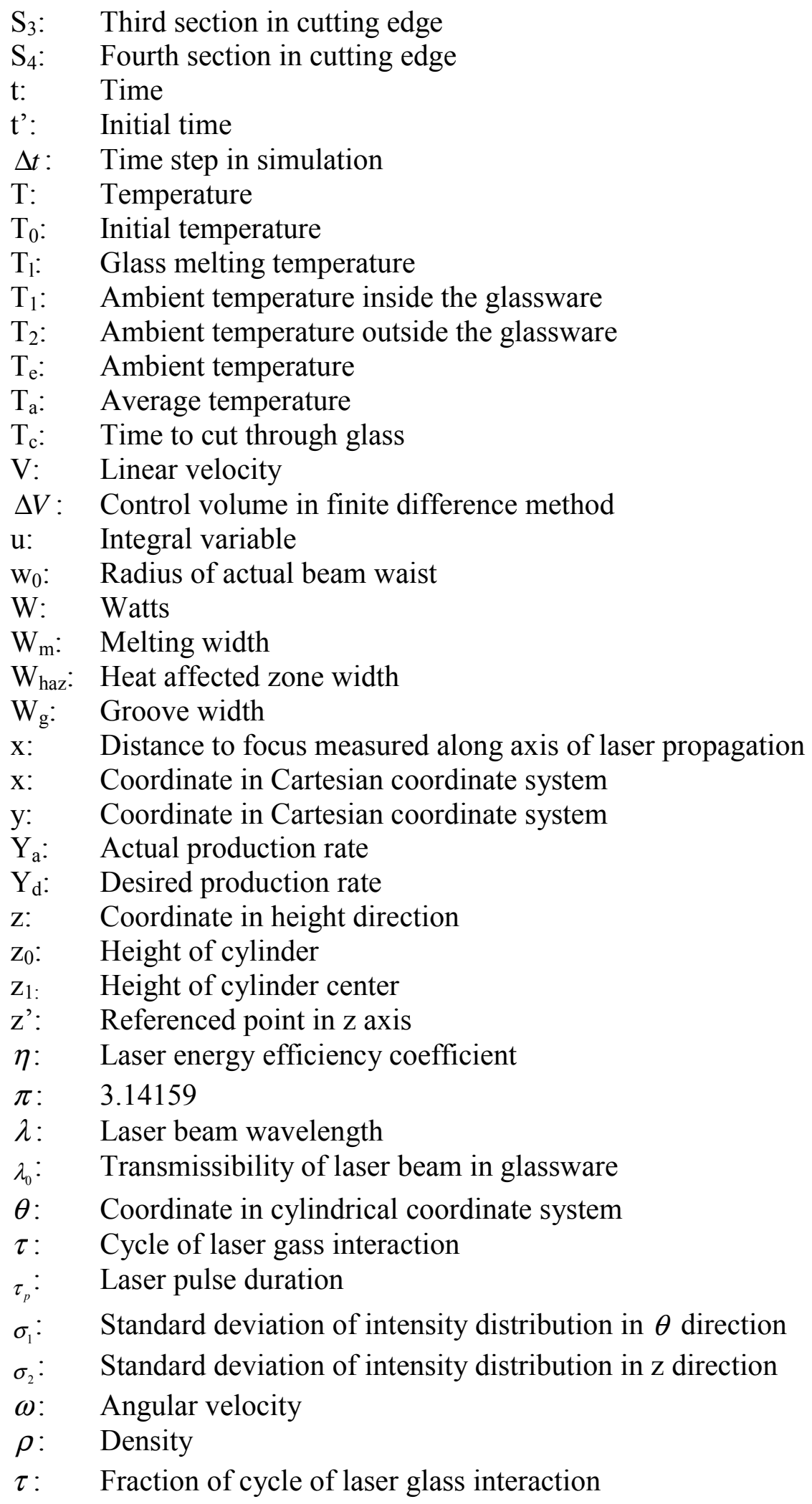




\section{INTRODUCTION}

\subsection{RESEARCH BACKGROUND}

Since the beginnings of the hand glass industry hundreds of years ago, some aspects have remained quite unchanged. Many of the current tools used in the forming process are almost the same tools that would have been found in ancient Italy around the $13^{\text {th }}$ and $14^{\text {th }}$ centuries. Much of the technology used in ancient hand glass industries was so basic that there really was not much need for improvement to a seemingly prosperous industry. From the blowpipes and the bellows of those days to blowpipes and refractory ovens of today, the procedure has remained much the same. Until recently, in the last ten to fifteen years, not too much advanced technology could be realistically applied to this industry, since the cost of implementing such technology would be have been too high for many small companies.

As in Italy of past centuries, so is the business of blowing glass today, a craft handed down from generation to generation in West Virginia. Many of the hand glass companies in West Virginia have developed their own particular low cost and ever-creative techniques for achieving productive processes. Companies such as Fenton Art Glass of Williamstown, WV and Pilgrim Glass Company of Ceredo, WV have shown special interests in changing this trend, among these company interests are ideas of using laser technology to benefit increased productivity with reduced waste. 
Until just recently, the use of laser for cutting glass was limited because of the enormous cost involved to implement a laser. The lasers necessary for cutting glass were too big, very expensive and required expertise for operation. Laser technology however has now become a viable option. Due to ever-increasing application of lasers in industries as a whole, the cost, size, and skilled expertise required have now been minimized to a suitable level to impact hand glass production.

A laser glass cutting machine can significantly improve the current methods for cutting hand glass. Figure 1.1 shows the approximate process flow for the conventional hand glass production process using the crack-off method for cutting glass in the cold shop. It was sketched by the author based on the plant observation in Davis Lynch Glass Company, WV. Figure 1.2 shows the expected process for the revised hand glass production process when laser glass cutting is introduced in the hot shop in place of the crack-off method.

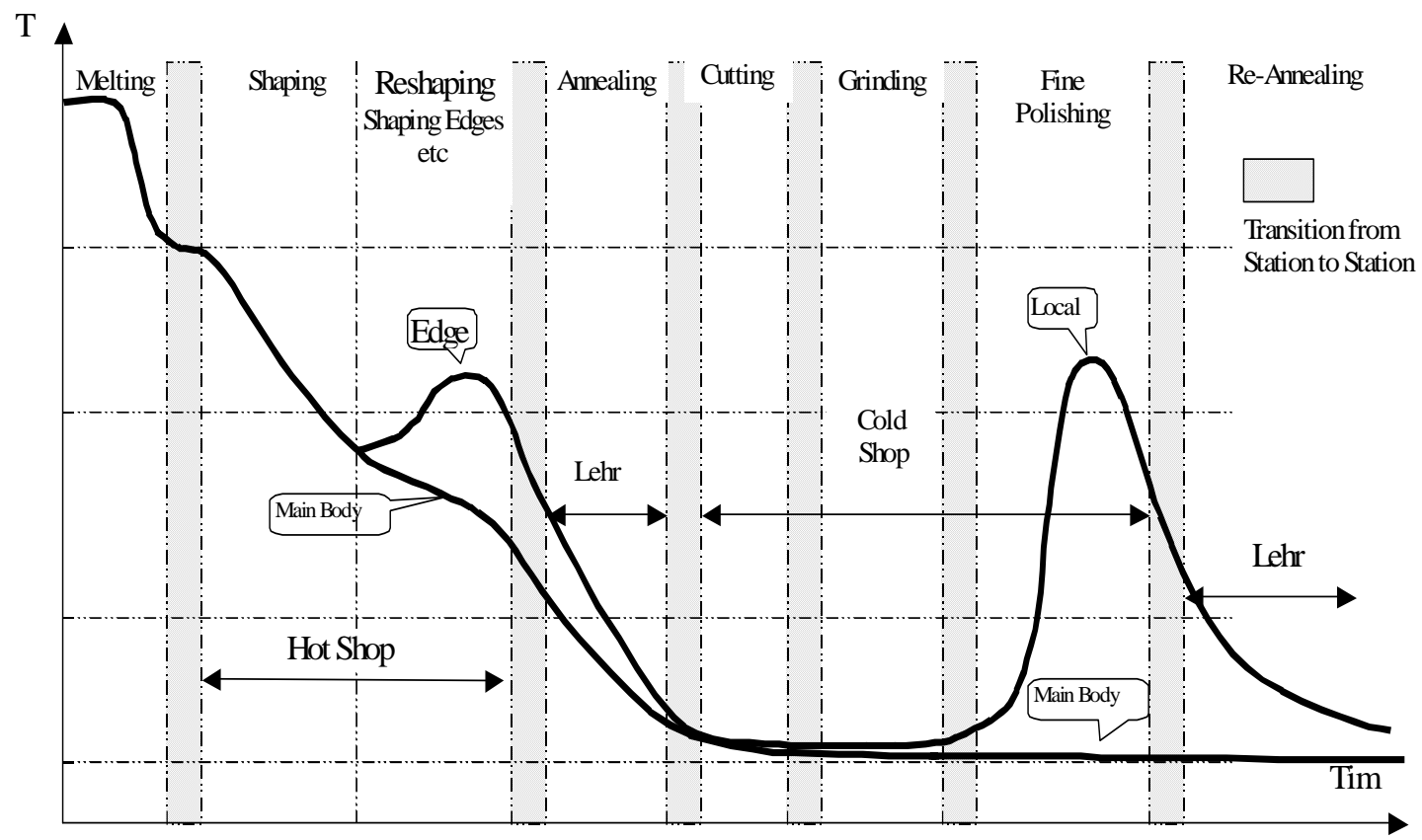

Figure 1.1 Hand Glass Production Process using Conventional Cutting in Cold Shop 


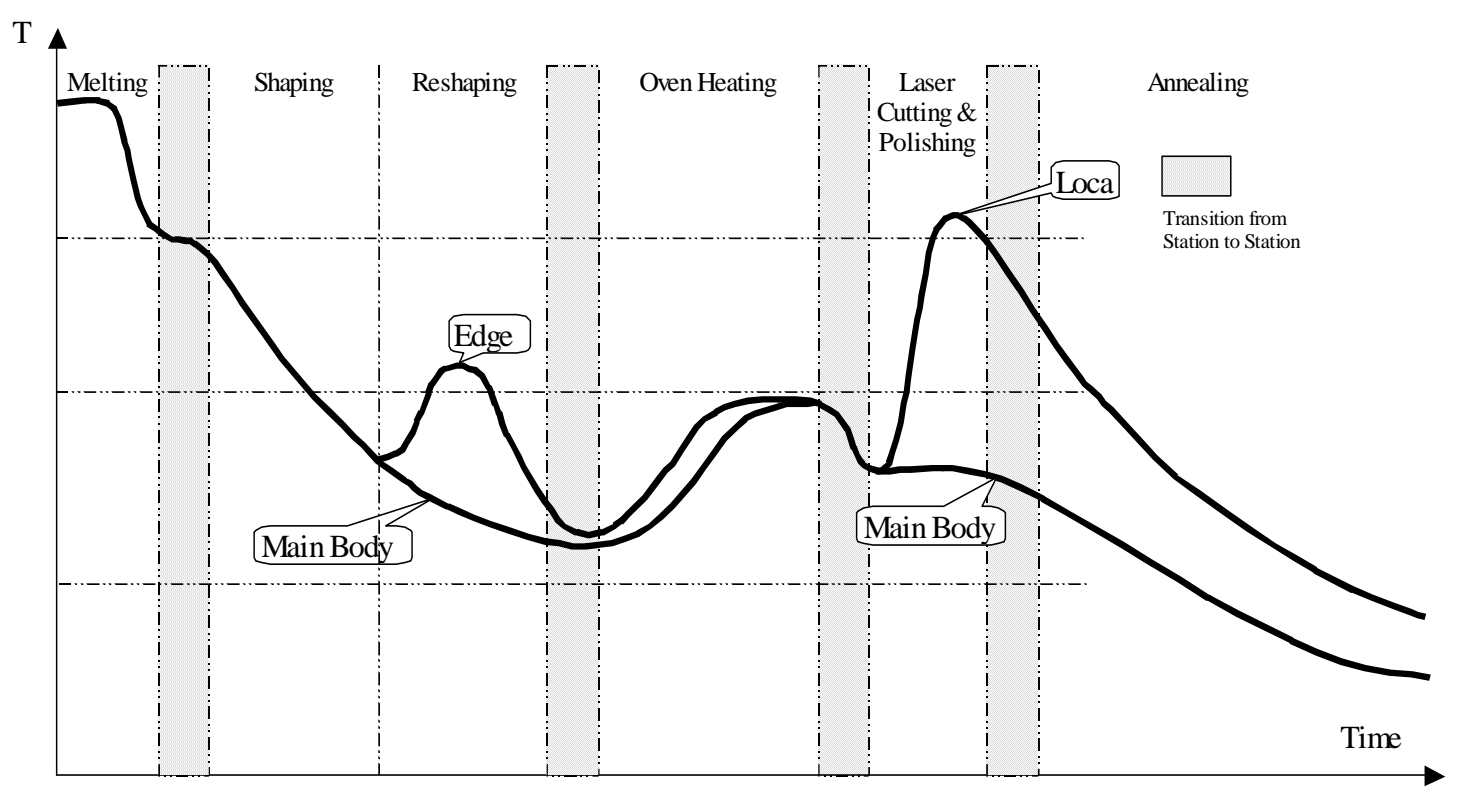

Figure 1.2 Expected Hand Glass Production Process using Laser Cutting in Hot Shop

In the conventional process, glassware leaving the hot shop will usually be moved to the lehr for annealing. Then the annealed glassware goes to the cold shop for cutting, grinding and fire polishing. Special equipment and certain person power are required in the cold shop to accomplish these operations. After these operations, glassware is moved to second lehr for reannealing since thermal stresses are created in the fire polishing operation. When implementing a laser, instead of going to the lehr, the glassware will be moved directly to an oven to maintain a certain temperature for laser glass cutting.

The proposed laser glass cutting method in this dissertation is to use laser as an energy source to melt and/or vaporize glass, then use the pulling mechanism to help the separation of glassware product from its moil. Due to the thermal characteristic of the laser glass interaction, both the cutting and polishing effects can be achieved at almost the same time when using the laser for cutting. 
Therefore, the most significant change when using a laser to cut glassware is that conventional cutting, grinding, and fire polishing in the cold shop can now be done by a laser in the hot shop. This means that the cost associated with both machine and personpower for those operations can now be saved. The time for production is also reduced significantly. Other benefits related to replacing the conventional crack-off method with the laser glass cutting technology include:

口 Improving overall process efficiency by eliminating extensive use of mechanical equipment such as polishing machines that require pressure and abrasives;

a Reducing energy costs by minimizing an extensive procedure to a single machine that will complete form and finish the glassware in less than a few minutes as opposed to the usual 24 hours that is required with the traditional method;

a Improving overall process efficiency in the cutting procedure by reducing product loss due to mechanical failure in the glassware;

- Improving finishing quality;

- Reducing setup time and improving process flexibility due to the machine's ability to be reconfigured quickly with sensors and controls.

\subsection{GOAL AND TASKS OF RESEARCH}

The idea of using technology to increase productivity, lower costs and increase efficiency is one of the driving principles behind the IOF Glass Industry Vision Statement and a method described in the IOF Glass Technology Roadmap [1]. 
The main goal of this research is to accomplish technological advance in the implementation of a $\mathrm{CO}_{2}$ laser glass cutting system for the hand glass industry. Four major tasks with sub-tasks were involved to achieve the goal are

1) Understanding the laser glass interaction, including

Glass heating under laser striking

a Glass melting under laser striking

- Glass vaporization under laser striking

2) Building a lab prototype machine for laser glass cutting, including

- Glass rotating mechanism

a Glass pulling mechanism

a Laser beam delivery subsystem

ـ Laser beam positioning subsystem

ـ Laser shielding device

ㄱeheating subsystem

๑ Vacuum subsystem

3) Perform experiments to investigate the effect of operation parameters on the laser glass cutting process, including

Effect of laser power

- Effect of preheating temperature

- Effect of glassware rotating speed 
ㄷffect of focal position

Effect of purge

4) Developing instrumentation and control for laser glass cutting process, including

a Laser control

\ Laser beam positioning control

․ Glass rotating control

a Pulling force control

- Temperature measurement

๑ Process monitoring

The term, process, is used to describe a system state or physical variable that changes with time. Examples are glassware manufacturing process, laser glass cutting process, heating process, melting process or vaporizing process. Heating, melting and vaporizing processes constitute the basic mechanism of the laser glass cutting. Laser glass cutting process is a part of the overall glass manufacturing process. This dissertation focuses on the heating, melting and vaporizing processes, and the resultant laser glass cutting process.

The term, machine, is used to describe a set of hardware integrated to achieve certain functionality. The laser glass cutting machine is one of the examples. The term, system, is more general than the term, machine. It can be used to describe hardware, software or both. In this dissertation, these two terms are used interchangeably, depending on the convenience for description of the subject. 
The first task, to theoretically explain the laser glass interaction, is mainly achieved by modeling and simulation. The work done and the results obtained will be described in Chapter 3 and Chapter 4 of this dissertation. Chapter 5 considers the first task from an experimental viewpoint. The second task, to build a lab prototype machine, is completely carried out in the lab, and the work done and the results obtained will be described in Section 5.2. The third task, to perform experiments to investigate the effect of operation parameters on the laser glass cutting process, was carried out by experiments. The work done and the results obtained will be described in Chapter 5. The fourth and last task, to develop instrumentation and control for laser glass cutting, was carried out experimentally, and will be described in Chapter 6. However, control model development was developed both theoretically and experimentally. The work related to this task will be described in Section 6.2.

As a summary, each of the four tasks with its associated approach and its Chapter in this dissertation are shown in the Table 1.1.

Table 1.1 Tasks with Associated Approaches and Related Chapters

\begin{tabular}{||c|l|l||}
\hline TASKS & APPROACHES & CHAPTERS \\
\hline Task 1 & Theoretical and Experimental & Chapters 3, 4 and 5 \\
\hline Task 2 & Experimental & Chapter 5 \\
\hline Task 3 & Experimental & Chapter 5 \\
\hline Task 4 & Theoretical and Experimental & Chapter 6 \\
\hline
\end{tabular}




\section{LITERATURE REVIEW}

\subsection{LASER AND ITS APPLICATION}

LASER, the acronym for Light Amplification by Stimulated Emission of Radiation, is a device that emits coherent and monochromatic, optical radiation. Commercially common lasers include $\mathrm{CO}_{2}$ laser, $\mathrm{ND}$ :YAG laser and Excimer laser.

LMP, or laser materials processing, is the art of altering the state of a target material either solely by the application of laser energy or in combination with other process where the laser is the principal source of energy.

When a laser strikes a material surface, a fraction of the energy will be absorbed by the material and turned into heat. Depending on the magnitude of heating, the state change of materials may be heating, melting or vaporizing. It results, correspondingly, in the development of industrial LMP applications, including surface treatment, welding and cutting [2]. Applications in surface treatment by heating, typically using low thermal input laser, can be

found in the work done by Dausinger [3], and work done by Bergmann [4]. Applications in material welding by melting, typically using medium thermal input laser, can be found in the work done by Behler, et al [5], and work done by Dausinger [6]. Applications in material cutting and drilling by vaporization, typically using high thermal input laser, can be found in work done by Beyer, et al [7]. 
Among these applications, laser cutting has grown steadily with great success in industry for the past 20 years, especially in the manufacturing industries like automobile, aircraft and other high-tech companies. It is also noticeable that in the last years the laser market has experienced a surprisingly large growth in the demand for low power lasers, ranging from 10 to 200 watts, like $\mathrm{CO}_{2}$ laser, specifically for cutting of non-metallic materials.

\subsubsection{Laser Cutting of Metals}

In metal cutting, the laser beam is focused at a very small spot diameter in the substratum causing raise in material temperature to the level at which a phase change from solid to liquid occurs [8]. If the optical power is high enough, vaporization of the molten pool takes place increasing the pressure locally, in turn, causing the ejection of the molten material out of the

pool. Once the whole depth of the material has been "drilled" through, the laser beam starts to move delivering its power continuously or pulsed. A cutting front is thus sustained, in which the solid is melted and the molten material is forced out. Most metals and metallic alloys have high melting and boiling points due to their strong metallic-type bonding. Once the metal has been melted, its viscosity and surface tension offer strong resistance to the motion of the liquid out of the cutting front. Cutting metal by vaporization usually requires high optical power in the amount of $1 \mathrm{~kW}$. For metals with high conductivity and reflectivity, such as copper and aluminum, the required power can be as high as $2 \mathrm{~kW}$.

Laser cutting of metals can be enhanced with the coaxial gas jet at high pressure that serves as a shear force impelling the melted material out of the cut [8]. This process, also called 
"melt shearing", leaves a good quality edge finish but with the presence of striations at different degrees. Typical coaxial gases used are oxygen and nitrogen.

\subsubsection{Laser Cutting of Non-metals}

For the majority of non-metallic materials such as polymers, wood, ceramics and organic substances, the absorption at the $\mathrm{CO}_{2}$ laser wavelength $(10.6 \mu \mathrm{m})$ is very high, reaching close to 90\% at room temperature. Therefore, the process involved in cutting these materials requires less energy density at an early stage than metal cutting.

Laser cutting of non-metals involves three mechanisms in which one of them became more dominant for a given non-metallic material. The three mechanisms are melt shearing, vaporization and chemical degradation. The dominant mechanism determines the cut edge quality possible in every case. A description of each process is given below [9]:

Melt shearing: most thermoplastics are cut quickly with a high quality edge that may be covered by microscopic ripples associated with the melt ejection from the cut zone. In this mechanism, the $\mathrm{CO}_{2}$ laser generates a small pool that is blown away by the gas jet acting coaxially with the beam. The material ejected during cutting has the same chemistry as the material being cut and thus the material experiences only phase change from solid to liquid [9][10].

Vaporization: polymethyl methacrylate (acrylic) and polyacetal are commonly laser cut by this mechanism. In the case of acrylic, it boils to give off a vapor of methyl methacrylate and the mechanism is mostly a physical phase change from solid to liquid to vapor with minimal 
breaking of chemical bonds. The cut edge is of extremely high quality and superior to flame polished or mechanically cut edges.

Chemical degradation: most thermoset polymers, wood based products, rubber products and epoxy resins are commonly laser cut by this mechanism. It involves the laser beam carrying out a large chemical reaction during cutting. The energy delivered by the laser serves to modify the integrity of the material by means of breaking the chemical bonds. When cutting cellulosic materials (wood, fiberboard, hardboard, paper etc.) the temperature in the cutting zone can reach over $2000^{\circ} \mathrm{C}$ depending on the density of the material. The oxidation of the carbon content is an exothermic process, which supplies the cut front with energy. The quality of the cut edge is superior to a mechanical one, being smooth and splinter free. This process tends to generate a carbon based smoke and residual carbon deposit on the cut edge.

In summary, a focused low-power $\mathrm{CO}_{2}$ laser beam will produce a temperature rise at the

focal spot. The thermal gradient will be enough to start a phase change, the breaking of the molecular bonds or both, thus inducing the melting, vaporization and chemical degradation of the material.

\subsection{Glass AND Glass CuTting}

Glass is an inorganic product of fusion, which has been cooled to a rigid condition without crystallizing. Glass is made by heating a mixture of dry ingredients, powdered or granular, to about $2800{ }^{\circ} \mathrm{F}$ in a refractory container until a viscous, homogenous liquid is formed. The batch consists of the following raw materials in the form of oxides or of compounds that yield such oxides [11]: always silica as the glass former, usually lime and soda for fluxing, and 
often potash, lead oxide, boron oxide, aluminum, magnesia, barium oxide or zinc oxide for modifying purposes.

Glass has unique mechanical and thermal properties. Its mechanical properties are described as follows [11]. Glass is non-ductile. Glass is a nearly ideal brittle material, exhibiting linear stress-strain behavior up to fracture stress in the magnitude of $10,000 \mathrm{psi}$. It has been found that the strength of glass depends strongly on the type of glass, specimen size and surface defects. The nature of the surface has a great effect on the tensile strength of glass. Not only are loading stresses considerably magnified in regions of surface imperfections, but also the stress concentrations cannot be relieved by yielding or cold flow since glass is non-ductile. Fracture of glass is a direct result of the tensile stress in the cross section, contrast to the fracture of a ductile material, and fracture starts in almost all cases from imperfections in the surface.

Glass suffers no permanent deformation when subjected to mechanical or thermal stress even at very low or high temperatures. For safe design practice, the tensile stress should be limited to 1000 psi maximum for annealed articles and to 2000 psi for tempered articles.

Most of the mechanical properties of glass are temperature dependent. If the temperature increases, the strength will decrease while ductility will increase. When the temperature is relatively low, below the annealing point, glass behaves as ideal brittle material. However, when the temperature is as high as the softening point, glass behaves as a plastic. Its stress-dependent deformation is referred to as slip. Deformation is an instantaneous process resulting from the slip that occurs along the boundaries between molecules that make up the solid.

Thermal properties of glass are described as follows [11]. Glass is a super-cooled liquid. It has no critical temperature. It has no freezing or melting point, and the viscosity changes continuously with the change of temperature. The "melting temperature" of glass is merely a 
high temperature at which the batch of materials will fuse together and give a homogenous, viscous liquid in a reasonable length of time. For practical control of shaping and annealing operations, certain useful reference temperatures have been defined. The softening, annealing, and strain points are the temperatures at which glass has more or less the viscosity of $4.5 \times 10^{7}$, $2.5 \times 10^{13}$, and $4.0 \times 10^{14}$ poises, respectively. At the annealing point, the upper end of the annealing temperature range, internal stresses are substantially relieved in $15 \mathrm{~min}$, whereas at the strain point temperature, the lower end of the annealing range, it takes $16 \mathrm{hr}$. In cooling through the strain point temperature, the properties have already begun to lag appreciably to about $4.0 \times 10^{14}$ poises, depending on the speed of cooling. It is for this reason that the maximum operating temperature for annealed ware, if undue thermal shock is avoided, may approach the strain point with no danger of introducing appreciable permanent strain. For tempered ware the maximum lehr temperature must be lower in order not to decrease the greater strength achieved by tempering.

Some typical mechanical and thermal properties of soda lime glass are listed in the Table $2.1[11][12]$.

Methods are needed in the hand glass industry to cut the glassware from its adjoining glass, called the moil, and to finish the cut edge of the resultant glassware. The existing methods have been in use for hundred of years. The methods include burn-off, scratch-off, burst-off, sawing and crack-off [12]. While effective, they are subject to the often unpredictable behavior of glass.

Burn-off in the hot-shop leaves bumps, marks and dimples. Scratch-off in the cold shop results in breakage when the thickness varies. Scratch-off in the hot shop, which is to score the cut line with a file and then drip cold water on the score, results in product breakage when the 
thickness varies or the score is uneven. Burst-off in the hot shop is to pull the product and moil apart in the intended separation line, knock or grind off the thin glass above the line, and polish to smooth the remaining heavier particles along the separation line. It results in chip and fine damage. Sawing in the cold shop causes considerable chip defect at the edges with cracking. Crack-off in the cold shop uses additional heat causing thermal fracture.

Table 2.1 Mechanical and Thermal Properties of Soda Lime Glass ([11][12])

\begin{tabular}{|c|c|}
\hline GLASS TYPE & SODA-LIME \\
\hline Density, $\mathrm{kg} / \mathrm{m}^{3}$ & 2400 \\
\hline Tensile Strength, $10^{3} \mathrm{psi}$ & $4 \sim 10$ \\
\hline Modulus of Elasticity, $10^{6} \mathrm{psi}$ & 9.8 \\
\hline Thermal Expansion Coefficient, $10^{-5} \mathrm{~cm} / \mathrm{cm} / \mathrm{C}$ & 0.92 \\
\hline Vaporization Point $[43],{ }^{\circ} \mathrm{C}\left({ }^{\circ} \mathrm{F}\right)$ & $1500(2732)$ \\
\hline Melting Point $[43],{ }^{\circ} \mathrm{C}\left({ }^{\circ} \mathrm{F}\right)$ & $1200(2192)$ \\
\hline Softening Point, ${ }^{\circ} \mathrm{C}\left({ }^{\circ} \mathrm{F}\right)$ & $693(1280)$ \\
\hline Annealing Point, ${ }^{\circ} \mathrm{C}\left({ }^{\circ} \mathrm{F}\right)$ & $510(950)$ \\
\hline Strain Point, ${ }^{\circ} \mathrm{C}\left({ }^{\circ} \mathrm{F}\right)$ & $477(890)$ \\
\hline Thermal Capacity at $300 \mathrm{~K}, \mathrm{~J} / \mathrm{kg} . \mathrm{K}$ & 840 \\
\hline Thermal Conductivity at $300 \mathrm{~K}, \mathrm{~W} / \mathrm{m} . \mathrm{K}$ & 0.88 \\
\hline
\end{tabular}


Problems with the existing glass cutting methods used in both the hot and cold shops result in considerable loss of glassware. In addition, these existing cutting methods often require subsequent finishing of the edges of the glassware by grinding, polishing and/or fire polishing which is labor intensive and can result in further glassware losses. Losses in these processes can be as high as 80 percent on some product lines requiring further finishing steps or as high as 40 percent total scrap.

\subsection{LASER Glass CUTting}

\subsubsection{Fracture Method}

Cutting glass by fracture, or crack-off, is a traditional method in the glass industry. When introducing a laser, the highly concentrated heat resulting from the laser striking the glass will create a high local glass temperature. Due to the low surrounding glass temperature, a high temperature gradient and thus thermal stress is developed. When the glass is at a temperature below its annealing point, this thermal stress cannot be released but causes micro-fractures due to the brittle nature of glass. When this micro-fracture and subsequent fracture propagation is well controlled, separation of the glassware product from the moil can be achieved.

There exist some examples of such application of laser glass cutting. Lumley succeeded in cutting a 0.039 in $(0.99 \mathrm{~mm})$ microscope slide with a $30 \mathrm{~W}$ laser at $60 \mathrm{in} / \mathrm{min}$ ([13]. Chui [14] made the effort to repeat Lumley's experiment. His repeatable results of cutting were $90 \mathrm{in} / \mathrm{min}$ at $75 \mathrm{~W}$ for $0.039 \mathrm{in}(0.99 \mathrm{~mm})$ microscope slides and $60 \mathrm{in} / \mathrm{min}$ at $200 \mathrm{~W}$ for $0.125 \mathrm{in}(3.0 \mathrm{~mm})$ glass. The length of most cuts was less than 5 in. Longer cuts were less successful. Attempts to 
increase the speed with higher power resulted in lost control of the crack propagation. One patent claims success in cutting $1 / 4$ in. glass at $100 \mathrm{in} / \mathrm{min}$ with a $100 \mathrm{~W}$ laser [15].

Finaucane and Black [16] investigated the application of laser cutting to stained glass. In their research, a $600 \mathrm{~W} \mathrm{CO}$ laser was coupled with a Ferranti MF400 CNC laser cutting machine to investigate the laser parameter settings governing successful cutting. It is found that the $250 \mathrm{~W}$ power setting in pulsing mode offered the best overall results. At this power level, a cutting speed of $350 \mathrm{~mm} / \mathrm{min}$ was possible. The cut product would require only minimal further processing. Both undercut and internal feature can be removed from the parent material after one cutting operation.

Yu V. Khlopkov [17] describes the successful application of laser cutting to mass production of protective color filters for fourth- and fifth-generation Vityaz color televisions. A basic requirement for color filter fabrication technology is to ensure high precision of dimension. The difference of a $500 \times 400 \mathrm{~mm}$ rectangle must not exceed $0.5 \mathrm{~mm}$. Traditional processing by grinding makes the process of filter fabrication laborious. After grinding, the end edges have dull surfaces that diffusely scatter light from the screen and form luminous bands. The output of fitting articles is low in this grinding process, being no greater than 30 to $40 \%$ of the initial surface area of the glass. Operation of the installation in industrial conditions at the Vitebsk Television Factory demonstrated inarguable advantage in comparison to the existing technology of mechanical procession of glass. Laser cutting of filters allowed the fixed dimensions to be precisely observed and obtained transparent ends that do not require additional processing. This made it possible to decrease the cost of the filters by 2 to 3 times while significantly improving their quality. 
Precision Technology Center (PTC) developed low debris glass cutting tools using a proprietary zero width cutting technology (OWCT) [18]. This technology can create a controlled separation in most brittle materials using internal stress generated by precisely controlled temporal and spatial laser power application. This unique process produces internal microcracks to any selectable depth including the entire thickness of the material. The PTC Laser Line Series Machines can provide glass separation on substrates of up to 1600 x 1300 x $25 \mathrm{~mm}$ with a cutting speed up to $1000 \mathrm{~mm} / \mathrm{second}$. It is shown that it produces enhanced product yield, produces radically reduced debris, and provides increased efficiency when compared to traditional scribe and break technologies.

However, there are problems in applying a laser to cut glass by fracture. These problems exist in the glass' intrinsic stress and fracture characteristics when it is subjected to intense concentrated energy radiation. Most glass will crack if heated non-uniformly. For the same reason, when a piece of cold glass is exposed to a powerful laser beam, the severe thermal stress that is generated can instantly crack the glass. Thus, the successful cutting of cold glass depends on control of the fracture so that a crack propagates only along the laser path. It is believed that the method by controlling fractures only works under certain well-defined laboratory conditions, and there are limits to the applicable power and the controllable cutting speed. For example, when the maximum temperature exceeds the melting point, the plasticity limit of the material is exceeded and the process will loose precise control of the cut. This also results in residual stresses developing after the glass product cools and an uncontrolled break develops. 


\subsubsection{Refined Fracture Method}

Veheyen, et al [19] claims in their patent a method to cut flat glass by radiating it with laser beam along a pre-scored line where it is to be cut. The cutting operation is insensitive, or at least less sensitive, to pre-existing mechanical stress in the sheet material. If the intended line of cutting crosses a fault in the material, the fault at most entails a local imperfection in the separated edges of the material. It doesn't cause fracturing stresses to be randomly propagated away from the intended line of cutting. Therefore, crack propagation is better controlled. The line along which the material is actually cut is strictly determined by the score line even if the path tracked by the laser beam departs slightly from such a score line.

\subsubsection{Vaporization/Melting Method}

The difficulties caused by the fracture characteristics of glass can be mainly resolved by cutting glass at a state where fracture cannot be sustained. This means that the temperature of the glass should be kept in its annealing range. In this range, cutting can be accomplished either by vaporizing enough glass to allow separation or by melting glass at the cutting path followed by the removal of the molten glass by other means, such as a gas jet.

Hafner [20] proposed the latter approach by preheating the sheet of glass, not intentionally to avoid the fracture but rather to save energy. He used several stationary laser beams that impinged the glass at acute angles to produce a beveled edge. Boddicker [21] proposed a method to cut a stationary tempered sheet of glass using a single moving laser beam 
that impinged the glass at right angles to produce a clean cut with minimum thermal shock. In this method, preheating means were employed to avoid fracture.

Chui [22] proposed a method in his patent to cut sheet glass by using a focused laser beam and preheating the glass to a temperature in the range from $1000^{\circ} \mathrm{F}$ to about $1250{ }^{\circ} \mathrm{F}$. The focal point of the laser beam is positioned at a location spaced from the surface of the glass sheet to form an optimal laser spot size. The beam spot size is such that at a normal glass cutting speed, the glass is vaporized faster than the feeding rate of glass into the space vacated by the glass vaporization. In his other patent [23], cutting a molten glass ribbon at a temperature in excess of $1000^{\circ} \mathrm{F}$ using a laser beam is described.

Chui also conducted a investigation on the cutting of hot glass by vaporization [15]. Three $\mathrm{CO}_{2}$ lasers, $400 \mathrm{~W}, 5 \mathrm{KW}$ and $15 \mathrm{KW}$ respectively, with continuous radiation at 10.6 microns were used. The lasers have been directed and focused to a spot about $0.010 \mathrm{in}$. (0.26 mm) diameter. The vapor and dust generated in each cut were removed by suction with a vacuum nozzle placed approximately $1 / 2$ in. from the laser spot. Removal of the vapor tended to reduce the scattering of the laser beam and helped avoid contamination of the glass surface. It is found that glass at temperatures between $1000{ }^{\circ} \mathrm{F}$ and $1250{ }^{\circ} \mathrm{F}$ can be cut by a $\mathrm{CO}_{2}$ laser and no cracks developed. To increase the speed of cutting, the power should be increased proportionally, but to cut thicker glass, the power must be increased with the square of the thickness, i.e.

$$
\mathrm{P} / \mathrm{V}=4.88 \mathrm{~h}^{2}
$$

The phenomena of cutting glass above its annealing point by vaporization involves the decomposition of glass, mainly into silica $\left(\mathrm{SiO}_{2}\right)$, sodium and calcium, the discharge removal of vaporized glass, and the flow of locally molten glass induced by decreased surface tension. 


\subsubsection{Cutting Rod-like Glass}

The applications or the investigations of laser cutting discussed so far are mostly restricted to the cutting of sheet glass. For the cutting of hollow glass cylinders, even few references can be found.

A patent to Meyer [24] describes the method to cut rod-like and relatively thick-walled hollow glass. Cutting is accomplished by repeatedly rotating the article while directing against the surface of the article a relatively sharply focused intense laser beam of wavelength such that the article will absorb a substantial amount of the radiant energy. The article being cut must rotate sufficiently rapid to prevent the laser from damaging or burning the surface by localized overheating. Cutting of the article is effected by cracking along the line repeatedly traced by the laser beam, the cracking being caused by the temperature differential between the glass along this line and glass in regions of close proximity. Categorically, this method is of the fracture type.

A patent to Minakawa [25] describes the method to cut hollow glass by maintaining the glass at a high temperature below the softening point and repeated radiation of the glass with a laser beam along the desired cutting line by rotating the glass. A tensile force is applied by gravity or by a mechanical device to the part to be cut off. Following the removal of the part, the edge of the glass is radiated again with the laser beam to affect fire polishing thereof, and thus improve the shape of that edge. During the first radiation by the laser beam, an auxiliary inert gas is blown into the glass article to prevent deposition of the vaporized glass. 


\subsection{Modeling/Simulation OF LASER Glass CuTting}

It is important to the success of process control that the performance, quality and thermal effect of the process be well understood.

Most mathematical models of the heat flow phenomena in laser cutting were based on the application of the classical heat conduction equation for stationary solid, using the concept of an instantaneous heat source for an infinite volume. Cases with and without phase change and a variety of radiation or source conditions have been studied. The problem of melting with complete removal of melt subjected to different types of boundary conditions has been studied by Soodak [26]. He considered constant heating of the surface and numerically evaluated the steady state melting rate. Landau [27] considered melting with complete removal of the melt from a one-dimensional slab with one end insulated. He obtained the time-dependent temperature distribution and the position of the melting front. Rogerson and Chayt [28] calculated the total melting time of a one-dimensional ablating slab subjected to constant heating with complete removal of melt.

Dabby and Paek [29] have analytically studied the problem of material removal from the surface by considering the laser penetration into the solid that is vaporizing on its free surface. They also assumed that gas created by vaporization is transparent to the incident laser beam. Von Allmen [30] considered a drilling process with material expulsion due to pressure gradients caused by vaporization. His theoretical results showed considerable agreement with experiments. 
Cline and Anthony [31] derived a model for laser heating and melting of material for Gaussian source moving at a constant velocity. They calculated the temperature distribution and depth of the melting zone as a function of laser beam diameter, velocity and power. A threedimensional heat transfer model was developed by Mazumder and Steen [32] for a laser beam striking the surface moving with uniform velocity. The model was solved by a finite difference method and the results were presented for temperature distribution and melt depth. The model also allowed for the formation of the groove by considering the grid points within the groove as part of the conducting network but operating at high temperature after vaporization. The model is capable of forecasting the temperature profile, the maximum processing speed and the heat affected zone.

Modest and Abakians [33] studied numerically the formation of a groove by vaporization on a moving semi-infinite solid. Results for groove depth and shape were presented for a variety of laser and solid parameters. Biyikli and Modeest [34] studied the effect of laser focusing parameters on the formation of the groove depth and shape using a numerical model.

Hsu, et. al. [35] investigated the effect of a continuous-wave laser on surface layer melting and subsequent solidification using a one-dimensional heat conduction model. Their model calculated interface velocities of melting and solidification in addition to calculation of the temperature profiles and rate of heat transfer.

Chan, et. al. [36] developed both one-dimensional transient and steady state models describing the process of material removal by vaporization and liquid expulsion. The problem of moving the solid-liquid interface and the vapor-liquid interface are modeled by boundary immobilization and a Motl-Smith type solution. 
Grigoropoulos, et al. [37] described detailed experimental observation of the associated phase change process and presented a computational conductive heat transfer model for laser melting and re-crystallization of thin semiconductor films. Minardi and Bishop [38] developed a two-dimensional transient computer model to determine the temperature distribution within a material subjected to radiation, the intensities required for laser drilling, and the effect of spatially varying laser intensities on the temperature distribution. The model accounts for both sensible heating and phase change (solid-to-liquid and liquid-to-vapor). Glass, et. al. [39] investigated the effect of various parameters in laser cutting of metallic glass ribbon that undergoes ductile-to-brittle phase transitions when heated above crystallization temperatures. They modeled the laser/material interaction using a quasi-steady, three-dimensional finite difference technique to predict the temperatures and cooling rates in the heat-affected zone and compared these with experiment results.

Kim, et. al. [40] formulated a two-dimensional model with triangular finite elements for the transient analysis of the material removed by vaporization with a high power laser. The model assumed a phase change from solid to vapor to occur in one step when the temperature at any node reached the vaporization temperature, the location of the vaporization front being established iteratively within each time step. Mesh is regenerated in the new domain without the evaporated nodes. It consumed much computing time.

There was an attempt by Yibas, et. al. [41] to perform steady-state analysis of the heattransfer mechanism during laser drilling. The one-dimensional model was able to predict the maximum temperature in the material, the explosion process and the drilling efficiency. The numerical results correlated well with experimental findings. 
$\mathrm{Yu}$ [42] performed the numerical studies of laser cutting by three-dimensional finite element modeling using ANSYS5.0/ED Parametric Design Language. In his study, all of the material, as well as the time- and response-dependent nonlinearities are included. In his study, the laser drilling and cutting of a $0.3 \mathrm{~mm}$ thick copper plate is considered for computer simulation. The laser beam has an intensity of $10 \mathrm{MW} / \mathrm{cm}^{2}$ and a focal spot radius of $0.1 \mathrm{~mm}$. Owing to the limitation of software in the number of elements and degree-of-freedom for the finite element model, only a domain with a size of $0.5 \times 0.5 \times 0.3 \mathrm{~mm}$ in the neighborhood of the cut is modeled.

Worthy of mention is the work done by P. A. Antanasov and S. I. Gendjov [43]. In their work, they developed a one-dimensional theoretical model for laser cutting of a glass cylinder by melting. The goal of this model was research to find the temperature of a point at the cutting ring. The solution consisted of solving the thermal conductivity equation. Unlike the 3-D heat conduction model that has to be solved numerically, this model can be solved to give an explicit expression to predict the temperature at a certain location and at a certain point of time during the laser glass interaction. Since it is a one-dimensional model, the said temperature at a certain location of cutting ring is the temperature averaged along the radial direction.

\subsection{CutTing Quality Characterization AND EXPERIMENT}

Of particular interest to glass manufacturers are the maximization of the production productivity and the subsequent quality of the laser-made products. There are a number of criteria available to assess laser glass cutting quality that includes geometrical properties such as 
arithmetic average roughness ( $\mathrm{Ra})$ and striation frequency, and non-dimensional properties such as dross, heat affected zone (HAZ) and blow holes. Both the productivity and the quality are governed by the selection of appropriate process parameters that are unique for each material. These parameters include laser power, laser mode, focal length, focal point position, and cuttingspeed, preheating temperature, assist gas pressure, and stand off height.

Reduction in focal length gives a smaller focal spot and therefore a higher energy density and reduced kerf width, which means that the cutting speed can be increased. However, smaller focal length has a lower depth of focus making the process more susceptible to surface irregularities. An increase in the laser power will significantly increase the productivity. It is found that a $50 \%$ increase of average laser power meant a nine times increase in cutting rate for 0.125 in. thick titantium [44]. The interaction time between the laser beam and material is another important parameter to consider when cutting soft materials such cloth, textile fabrics and woods. The optimum velocity of the beam relative to the surface (feed rate) controls the amount of energy delivered on the material. The amount of energy deposited must be sufficient to vaporize and chemically decompose the material, preventing a burning front to expand to the lateral sides of the cut.

High cutting quality is only possible when all process-related laser parameters remain constant. In particular, these are laser power, laser focus diameter and laser focus position. Laser power determines, with constant beam diameter, the power density at the focal point. Up to a certain upper limit, the higher the power density, the thicker the material that can be cut. Three influencing factors changing the characteristics of the laser beam are diameter of laser beam, time and laser power-dependent variations of the raw beam, and aging of optical elements in the laser generator and beam guiding system [45]. 
With movable processing optics, the beam diameter onto the focusing optics varies due to the divergence of the raw beam. For typical high power lasers with divergences of 2 millirad, this causes changes of up to $10 \mathrm{~mm}$ in the diameter of the raw beam onto the lens. Beyond the lens, this results in a shift in the focus position as well as variation in the focus radius onto the work piece. Depending upon the position of the optics within the working area, both lead to different processing results.

The time and laser power-dependent variation of the beam also influences beam quality. This results from the thermal time constant of the laser generator and laser optics. When firing the laser, the optical system, particularly the transmissible components, are thermally loaded through absorption of a fraction of the incidental radiation. Through heating up, the optical element expands, thereby changing the optical beam characteristics. These time and laser power-dependent effects particularly change the divergence and waist diameter of the beam and, in turn, the position and diameter of the focal point.

The third factor influencing the beam characteristics is the aging of the optics. The smallest particles of dust increase absorption so that the optical elements deform more than equivalent new components.

Experiments [46][47] were performed to determine the process efficiency and cutting quality by analyzing the laser beam and materials process. In these experiments, advanced sensing and measuring equipment, such as thermocouples, video imaging, and acoustic and plasma sensing devices especially designed for high temperature, are used. The findings of these experiments usually cannot be extrapolated for parts of different geometry and materials. Important data such as the time history of temperature distribution, phase change and cooling rate around the heat-affected zone are sometimes not available from experiments, but they are 
important for the evaluation of microstructure transformation during the cutting process. However, experiments do provide the basis for comparison with results obtained from numerical models. Numerical models depend on the simplification of the geometry and loading conditions. They also depend on the assumption of constant averaged values for temperature-dependent materials.

Kaebernick [48] performed experiments to investigate the correlation between striation frequency and the cutting quality, specifically, roughness. In his experiments, a $1.5 \mathrm{~kW} \mathrm{CO}$ PRC laser was coupled to a Lasag Vega cutting machine. Cutting was performed on two material thicknesses with three controlled parameters, namely, laser power, cutting speed, and assist gas pressure. A $9^{2}$ full factorial experiment was performed for each of the two materials.

\subsection{INSTRUMENTATION AND CONTROL}

Lisa T. Bird, et. al. [49] proposed a control system for the Integrated Machine-Tool System, which is an automated system that safely cuts a refractory material blank to a specified three-dimensional shape. The system includes a $50 \mathrm{~W}$ continuous-wave $\mathrm{CO}_{2}$ laser, associated optics, a 5-degree positioning and orienting subsystem, a system controller, a computer work station equipped with CAD/CAM software, and a machine-vision subsystem that locates and measures the workpiece. Using CAD/CAM, the computer workstation generates a threedimensional mathematical model, computes effective cutting paths, and exports the cutting path data to a positioning subsystem. In addition, the CAD/CAM software incorporates empirical equations that compute optimum values of laser power, airflow parameters, and positioning velocities to achieve the specified depth and quality of cut. 
Christopher [50] developed a CNC-controlled optical system, Behrens OPTICUT, to compensate thermal and distance related beam variations to ensure consistent cutting quality.

Considerations on adaptive control environments have been reported [51]. An adaptive control system for laser cutting has been developed by Kaebernick [48] with the aim to improve the productivity and the cut quality. The control strategy is based on a set of parameters that have an effect on the quality of the cut. As part of the overall strategy, striation in laser cutting is monitor and controlled. It was proven that the spectrum analysis technique is capable of measuring striation frequencies on-line, which provides the basic feedback for the improvement of surface roughness through pulse control. To acquire the cutting front geometrical information, a process monitoring system is utilized to detect light emissions directly at the cut front.

Temperature measurement [52] has been reported in various forms. Jorgenson [53] use the light emitted from the cut kerf and applies a Fast Fourier Transformation to establish a correlation to the frequency of striation formation. Tonshoff [54] developed a similar system to use an optical sensor integrated into the cutting head of a $\mathrm{CO}_{2}$ laser machine to monitor and control laser parameters on-line.

Chiang [55] built a prototype of laser cutting machine that uses a CNC system for controlling the motion of the workpiece and the position of the focal lens. The CNC system is connected to a PC in such way that it receives instructions from the PC via an RS 232 connection, and moves stepper motors to the desired positions. Therefore, an optimal and sophisticated cutting strategy can be developed on a PC, and the corresponding lower level ISO instructions can be downloaded to and executed by the CNC control system afterwards. 
Dworkowski [56] described a unique mechanical design and computer control of a precision, high-speed laser cutting system, developed at RD Corporation in Edmonton, Alberta, for cutting fabric. The system consists of an X-Y gantry type positioner laser, optical delivery subsystem, material transport subsystem, loading and unloading subsystem, and computer control system. The computer control system is comprised of two levels; namely, PC based high-level supervisory control and micro-controller based low-level motion control. The communication is through an RS 232 connection. 


\section{AnAlytical MODELING OF LASER GlaSs INTERACTION}

\subsection{INTRODUCTION}

In the laser glass cutting process, the melting and vaporizing of glass will occur due to the intensive thermal energy input and the limited heat conduction of the glass. The heat conduction can be modeled and simulated using the classical heat conduction model [12]. Modeling of the heat conduction in the glass is the major subject of this chapter. Simulation studies using this model are described in Chapter 4. The melting and vaporizing aspects of the laser glass cutting process have been investigated by experiments. The results of the experiments will be discussed in detail in Chapter 5. The melting and vaporizing phenomena were not considered in the modeling and simulation work covered in this dissertation, since modeling of these two phenomena is not possible with the heat conduction model.

In this chapter, three-dimensional classical heat conduction is first applied to model the laser glass interaction. Since a three-dimensional model can rarely be solved analytically, the model equations are usually solved numerically instead. The 3-D model described in this chapter forms the basis for the simulation that is presented in Chapter 4. One approximate model developed by some other researchers [43] is also described in this chapter. This is a onedimensional model and it can be solved analytically to yield an explicit expression to compute the temperature at a certain location in glassware and at a certain point of time. Although, the results from the approximate 1-D model are approximate, its analytical expression gives an 
alternative way to find the temperature behavior of laser glass cutting phenomena. It also provides valuable information to be compared to the results from the 3-D simulation.

\subsection{3-D Heat Conduction Model}

When optical radiation strikes a material surface, a fraction of the energy will be transmitted and absorbed into the material. The word "strike" is used due to the fact that a significant energy transfer from the radiation to the material usually will happen during their interaction, which is the case in laser glass cutting. This energy turns into heat or random thermal motion of the atomic constituents of the glass. Depending on the magnitude of the glass heating, the state change of the glass materials could be that of heating, melting or vaporizing.

In laser glass cutting, the fraction of the energy transmitted and absorbed into the glass is estimated to reach $90 \%$. This is mainly attributed to the fact that glass has high absorption of radiation at wavelength $10.6 \mu \mathrm{m}$ from the applied $\mathrm{CO}_{2}$ laser. In other words, glass is opaque to $\mathrm{CO}_{2}$ laser. The magnitude of glass heating, melting or vaporization is mainly determined by the laser, glassware and their interaction. Closely related laser features include laser power level, power spatial distribution and beam size. Closely related glassware features include glassware size (diameter and thickness) and material properties. Closely related laser glass interaction features include interaction time and laser glass spatial position.

In this section, two major components, laser beam and the cut glassware, in the laser glass cutting are first modeled, and then their interaction is modeled. 


\subsubsection{Laser Beam}

A Gaussian beam is the typical laser beam formed by a spherical lens. The Gaussian beam has a symmetric radial distribution whose electric field variation with respect to the radial distance is given by [57]

$$
E=E_{0} \exp \left(-r^{2} / w_{0}^{2}\right)
$$

where $E_{0}$ is the electrical field at the origin and $w_{0}$ is the radius of the actual beam waist as shown in Figure 3.2 [57].

It is assumed that the phase of the beam is uniform in $r$. The Gaussian source distribution remains Gaussian at every point along the beam's path of propagation through the optical system. The beam's size will change as it is focused by a lens or redirected by a mirror, but its intensity distribution remains Gaussian. The intensity of the beam is given by [57]

$$
I(r)=I_{0} \exp \left(-2 r^{2} / w_{0}^{2}\right)
$$

where $I_{0}$ is the beam intensity on the axis and is given by [57]

$$
I_{0}=\eta E_{0} E_{0}
$$

where $\eta$ is the energy efficiency coefficient. The Gaussian distribution has no obvious boundaries to give it a characteristic dimension, such as the diameter of the circular aperture. The radius of the Gaussian beam $w_{0}$ is defined as the distance from the axis at which the intensity has decreased to $1 / e^{2}$ or 0.135 of its value on the axis. Figure 3.1 shows the relative intensity distribution [57]. In this figure, the beam intensity on the axis is relative to $\mathrm{I}_{0}$ and the distance from the axis is normalized with respect to $w_{0}$. 


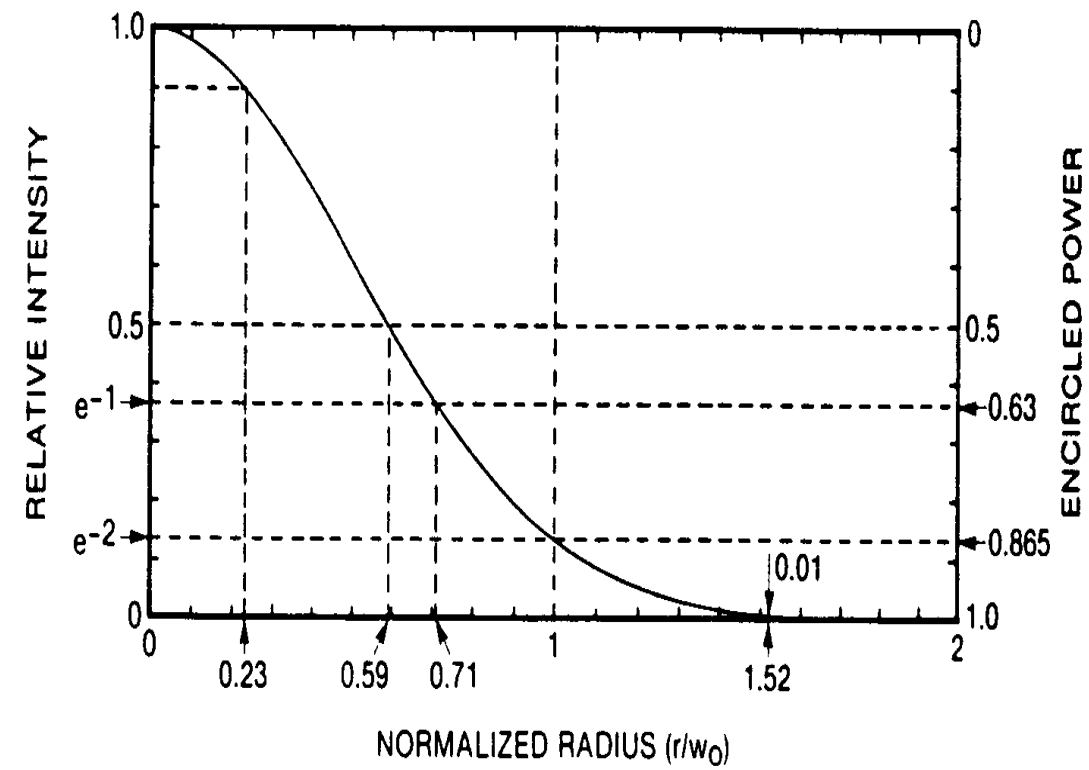

Figure 3.1 Gaussian Beam and its Relative Intensity Distribution

The power $P(r)$ contained within the beam at a radius $r$ is obtained by integrating the intensity distribution from 0 to $r$ to yield [57]

$$
P(r)=P(\infty)\left[1-\exp \left(-2 r^{2} / w_{0}^{2}\right)\right]
$$

where $P(\infty)$ is the total power in watts and is a quantity advertised by the laser manufacturers. It is related to the on-axis intensity $I_{0}$ in watts $/ \mathrm{m}^{2}$ by [57]

$$
P(\infty)=\left(\pi w_{0}^{2} / 2\right) I_{0}
$$

Nearly $100 \%$ of the power of the beam is contained within a radius $r=2 w_{0}$. One-half the power is contained within a radius $0.59 w_{0}$, and only $10 \%$ of the power is contained within a radius of $0.23 w_{0}$, the radius at which the intensity has only decreased by $10 \%$.

Propagation of a Gaussian beam in an optical system can be described without resorting to Fourier Transforms. Figure 3.2 shows a collimated Gaussian beam of diameter D (measured 
at $1 / e^{2}$ point) being brought to focus at the focal plane of an ideal lens [57]. The distance to the image $s_{2}$ is equal to the focal length $\mathrm{F}$ if the lens is ideal, or approximately equal to the $\mathrm{F}$ if the lens is not ideal.

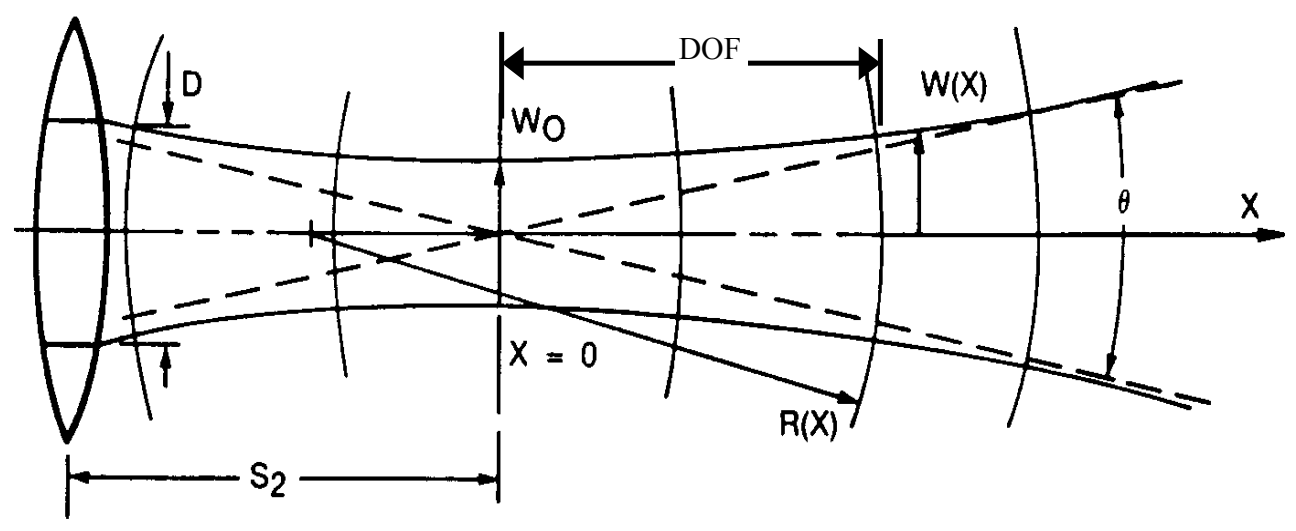

Figure 3.2 Collimated Gaussian Beam brought to a Focus

At the focus, the beam will have a Gaussian distribution with the smallest diameter (the beam waist) and a plane wave front. The beam waist diameter $2 w_{0}$ can be found in terms of the input beam parameters [57]

$$
2 w_{0}=(4 \lambda / \pi) \times\left(s_{2} / D\right)
$$

where $s_{2}$ is the distance to the image, $\lambda$ is the wavelength of the $\mathrm{CO}_{2}$ laser, and $\mathrm{D}$ is the diameter of the input beam. $\mathrm{D} / \mathrm{s}_{2}$ is called the $\mathrm{f}$-number of the beam focusing system. Therefore, the focal spot size of the Gaussian beam is about equal to the wavelength times the f-number of the system. The depth of focus (DOF), that is the distance between the values of $\mathrm{x}$ where the beam is $\sqrt{2}$ times larger than it is at the beam waist, is given by [57]

$$
D O F=(8 \lambda / \pi) \times\left(s_{2} / D\right)^{2}
$$


If the diameter of the beam is defined to be $2 w_{0}$ and the origin of the waist is at $x=0$, then the Fresnel integral could be used to solve the wave equation to determine how the beam propagates beyond $x=0$. The beam remains Gaussian and expands in a spherical wave with radius $w(x)$ and radius of curvature $R(x)$ given by [57]

$$
\begin{aligned}
& w^{2}(x)=w_{0}^{2}\left[1+\left(\lambda x / \pi w_{0}^{2}\right)^{2}\right] \\
& R(x)=x\left[1+\left(\pi w_{0}^{2} / \lambda x\right)^{2}\right]
\end{aligned}
$$

For $\mathrm{CO}_{2}$ laser, $\lambda$ is equal to $10.6 \mu \mathrm{m}$. If laser input diameter $\mathrm{D}=10 \mathrm{~mm}$, beam focal length $\mathrm{f}=127 \mathrm{~mm}$, beam waist radius $\mathrm{w}_{0}=0.1 \mathrm{~mm}$, the depth of focus can be calculated from Equation 3.7, which is $4.4 \mathrm{~mm}$. Let's assume that beam focus is $2 \mathrm{~mm}$ below the surface, and then the beam size can be calculated from Equation 3.8, which is about $20 \%$ larger than the beam waist size. This explains that if laser focus is $2 \mathrm{~mm}$ below the glassware surface, the effect on the laser glass cutting should not be neglected, and this larger beam size would produce wider but shallower groove and shallower melting zone as further described in Section 5.4.9.

\subsubsection{Cut Glassware}

Typical glassware for laser glass cutting is of a cylindrical shape, or at least the local cutting area of the glassware is a cylindrical shape. The local cutting area refers to the area where major thermodynamics and heat conduction take place. It includes what will be termed the cylindrical cutting ring and the area adjacent to the cutting ring. 
It is convenient to use a cylindrical coordinate system, $r, \theta, z$, to model the geometry of the glassware with cylindrical shape as shown in Figure 3.3. Boundary conditions are shown in Equations 3.10, 3.11 and 3.12,

$$
\begin{aligned}
& r_{1} \leq r \leq r_{2} \\
& 0 \leq \theta \leq 2 \pi \\
& 0 \leq z \leq z_{0}
\end{aligned}
$$

where $r_{1}$ and $r_{2}$ are the radii of inner and outer surfaces of the cylinder, and $z_{0}$ is the height of cylinder to be considered in the model.

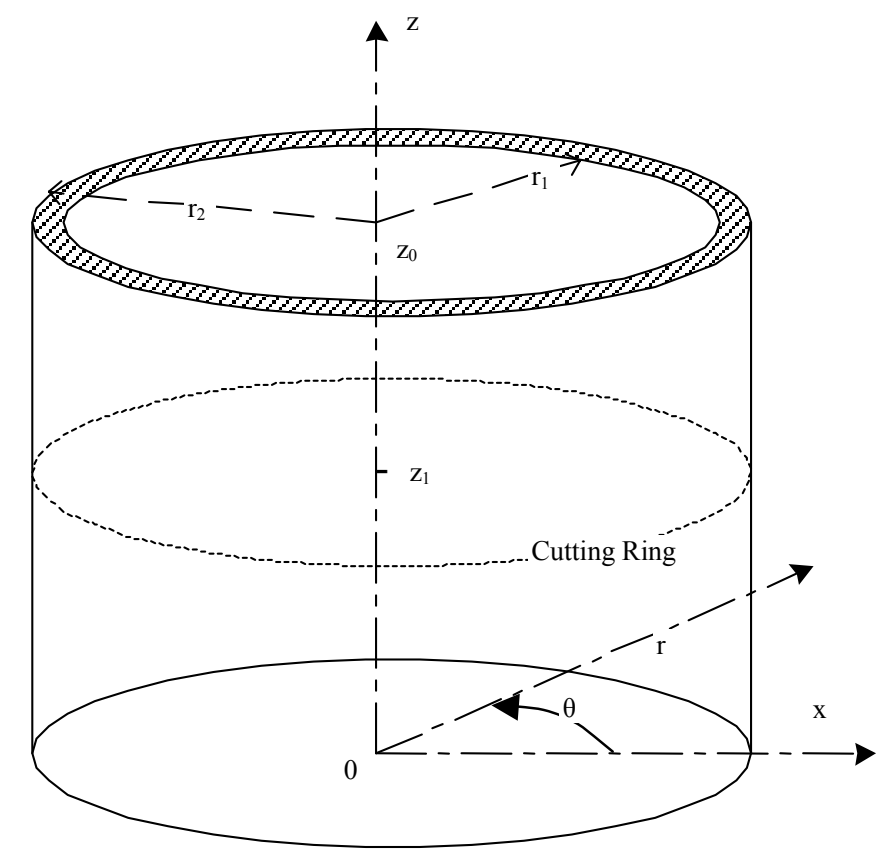

Figure 3.3 Geometry of Glassware in Cylindrical Coordinate System

In the case where the glass thickness is much smaller compared to the glass size, for which the following condition is met

$$
r_{2}-r_{1}<<r_{1}
$$


the geometry of the local glassware can be approximately modeled in a Cartesian coordinate system, $\mathrm{x}, \mathrm{y}, \mathrm{z}$, as shown in Figure 3.4. The boundary conditions for this coordinate system are shown in Equations 3.14, 3.15 and 3.16.

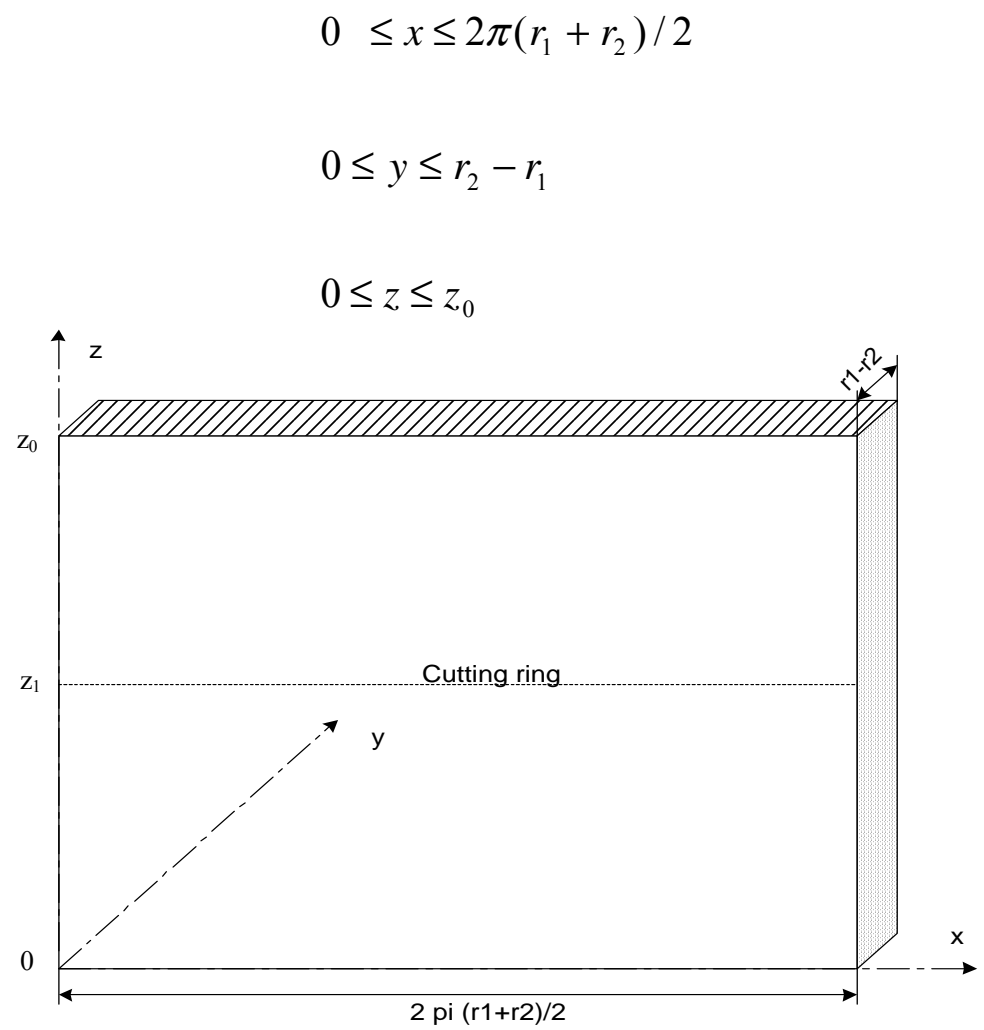

Figure 3.4 Approximate Geometry of Glassware in Cartesian Coordinate System

Besides the geometry modeling of glassware, glass material properties will be incorporated into the heat conduction model of laser glass interaction. These glass material properties include glass density, thermal conductivity, thermal capacity, and surface heat convection coefficient.

Glass properties will not be the same for different types of glass. They depend on the glass constitutes and they are usually temperature dependent. For soda lime glass, the density is $2400 \mathrm{~kg} / \mathrm{m}^{3}$ (see Table 2.1). Thermal conductivity at the temperature of $300 \mathrm{~K}$ is $0.88 \mathrm{~W} / \mathrm{m} . \mathrm{K}$, 
and the thermal capacity at the same temperature is $840 \mathrm{~J} / \mathrm{kg} . \mathrm{K}$. Both thermal conductivity and thermal capacity will increase when the temperature increases. The heat convection coefficient ranges from 3 to $20 \mathrm{~W} / \mathrm{m}^{2} . \mathrm{K}$.

\subsubsection{Laser Glass Interaction}

When the $\mathrm{CO}_{2}$ laser beam is intentionally focused by a focal lens to the surface of the glass, a majority of the energy (about 90\%), is transmitted into and absorbed by the glassware and is mainly absorbed at the surface of the glass.

Under laser striking, the temperature of the glass, especially the local instantaneous temperature, can be increased dramatically. However, the temperature change and temperature distribution in the glass is governed by the thermodynamics and heat conduction that occurs inside the glassware. This temperature behavior can be represented in the following Cartesian coordinate model [12]

$$
\frac{1}{a} \frac{\partial T}{\partial t}=\frac{\partial^{2} T}{\partial x^{2}}+\frac{\partial^{2} T}{\partial y^{2}}+\frac{\partial^{2} T}{\partial z^{2}}+\frac{\dot{Q}}{k}
$$

where $T$ is the temperature, which is a function of the three coordinates $x, y, z$, as well as time $t$, i.e., $T=T(x, y, z, t)$, and $\dot{Q}$ is the heat flow rate into the glass. The constant $a=k / c \rho$ is called the thermal diffusivity, where $k$ is the thermal conductivity, $c$ is the specific heat, and $\rho$ is the density of the glassware.

In a cylindrical coordinate system, the above model becomes [12] 


$$
\frac{1}{a} \frac{\partial T}{\partial t}=\frac{\partial^{2} T}{\partial r^{2}}+\frac{1}{r} \frac{\partial T}{\partial r}+\frac{1}{r^{2}} \frac{\partial^{2} T}{\partial \theta^{2}}+\frac{\partial^{2} T}{\partial z^{2}}+\frac{\dot{Q}}{k}
$$

An expression for $\dot{Q}$ in terms of rotation speed $\omega$, laser power $\mathrm{P}_{0}$ and location $(\mathrm{r}, \theta, \mathrm{z})$ in the glassware is derived in Equations 3.19 to 3.28. For a fixed and symmetrical Gaussian heat input, $\dot{Q}$ can be represented by a two-dimensional normal distribution model in Cartesian coordinates as

$$
\dot{Q}(x, y)=\frac{\eta P_{0}}{2 \pi \sigma^{2}} e^{-\frac{1}{2 \sigma^{2}}\left(x^{2}+y^{2}\right)}
$$

where $P_{0}$ is the laser power, $\eta$ is the laser energy efficiency and is estimated to be 0.9 to account for the reflection effect, $\sigma$ is the standard deviation of the distribution, and $\mathrm{x}$ and $\mathrm{y}$ are the Cartesian coordinates. If the energy distribution is not symmetric in these two dimensions, for example, the standard deviation in the $\mathrm{x}$ direction, $\sigma_{1}$, and the standard deviation in $\mathrm{y}$ direction, $\sigma_{2}$, are not equal, then

$$
\dot{Q}(x, y)=\frac{\eta P_{0}}{2 \pi \sigma_{1} \sigma_{2}} e^{-\frac{1}{2}\left[\left(\frac{x}{\sigma_{1}}\right)^{2}+\left(\frac{y}{\sigma_{2}}\right)^{2}\right]}
$$

When the laser beam is moving along the x direction, then $\dot{Q}$ can be represented as

$$
\dot{Q}(x, y, t)=\frac{\eta P_{0}}{2 \pi \sigma_{1} \sigma_{2}} e^{-\frac{1}{2}\left[\left(\frac{x-v_{0} t}{\sigma_{1}}\right)^{2}+\left(\frac{y}{\sigma_{2}}\right)^{2}\right]}
$$

where $\mathrm{v}_{0}$ is the beam moving velocity and $\mathrm{t}$ is the time. Let $\omega$ be the rotation speed in $\mathrm{rad} / \mathrm{second}$, and $\theta$ and $\mathrm{z}$ be two of the three coordinates in the cylindrical coordinate system. Substituting $\mathrm{x}=$ 
$\theta \times \mathrm{r}_{2}, \mathrm{v}_{0}=\omega \times \mathrm{r}_{2}$, and $\mathrm{y}=\mathrm{z}$ into Equation 3.21 yields the two-dimensional model in the cylindrical coordinate system

$$
\dot{Q}(\theta, z, t)=\frac{\eta P_{0}}{2 \pi \sigma_{1} \sigma_{2}} e^{-\frac{1}{2}\left[\left(\frac{\theta-\omega t}{\sigma_{1}} r_{2}\right)^{2}+\left(\frac{z}{\sigma_{2}}\right)^{2}\right]}
$$

If the transmission of laser power into the glassware, that is, transmission in the $r$ direction, is taken into consideration, then the model becomes three dimensional

$$
\dot{Q}(r, \theta, z, t)=\frac{\eta P_{0} A_{0}}{2 \pi \sigma_{1} \sigma_{2}} e^{-\frac{1}{2}\left[\left(\frac{\theta-\omega t}{\sigma_{1}} r_{2}\right)^{2}+\left(\frac{z}{\sigma_{2}}\right)^{2}\right]+\frac{r-r_{2}}{\lambda_{0}}}
$$

when $0 \leq|\theta-\omega t| \leq \pi$, or

$$
\dot{Q}(r, \theta, z, t)=\frac{\eta P_{0} A_{0}}{2 \pi \sigma_{1} \sigma_{2}} e^{-\frac{1}{2}\left[\left(\frac{2 \pi-|\theta-\omega t|}{\sigma_{1}} r_{2}\right)^{2}+\left(\frac{z}{\sigma_{2}}\right)^{2}\right]+\frac{r-r_{2}}{\lambda_{0}}}
$$

when $\pi<|\theta-\omega t| \leq 2 \pi$, where $\lambda_{0}$ is the transmissibility coefficient and $\mathrm{A}_{0}$ is introduced such that

$$
\int_{r_{1}}^{r_{2}} A_{0} e^{r-r_{2}} d r=1
$$

where $r_{1}$ and $r_{2}$ are the radii of the inner and outer surfaces of the glassware. Equation 3.25 implies that all the radiation transmitted into the glassware is absorbed by the glassware, in other words, no radiation could go through the glassware. Measurements in NETL indicate that $1 \mathrm{~mm}$ glass plate can totally block $100 \mathrm{~W} \mathrm{CO}$ laser. Solving this integral to find undetermined coefficient $\mathrm{A}_{0}$ yields

$$
A_{0}=\frac{1}{\lambda_{0}\left(1-e^{\frac{r_{1}-r_{2}}{\lambda_{0}}}\right)}
$$


The variation of $r_{1}$ and $r_{2}$ does not change $A_{0}$ very much only if $\lambda_{0}$ is considerably small compared to the glassware thickness, $r_{2}-r_{1}$. It is the case in the laser glass cutting where $\lambda_{0}$ is estimated to be about $0.1 \mathrm{~mm}$ while the typical glassware thickness is about 2 to $5 \mathrm{~mm}$. The estimation that $\lambda_{0}$ is $0.1 \mathrm{~mm}$ means that approximately $73 \%$ of the transmitted radiation is absorbed within $0.1 \mathrm{~mm}$ in the glassware thickness.

In multi-cycle laser glass interaction, energy input is cyclic and expressions of $\dot{Q}$ shown in Equations 3.23 and 3.24 are further modified as

$$
\dot{Q}(r, \theta, z, t)=\frac{\eta P_{0} A_{0}}{2 \pi \sigma_{1} \sigma_{2}} \exp \left(-\frac{1}{2}\left[\left(\frac{\theta-(\omega t-2 \pi n)}{\sigma_{1}} r_{2}\right)^{2}+\left(\frac{z}{\sigma_{2}}\right)^{2}\right]+\frac{r-r_{2}}{\lambda_{0}}\right)
$$

if $0 \leq|\theta-(\omega T-2 \pi n)| \leq \pi$, or

$$
\dot{Q}(r, \theta, z, t)=\frac{\eta P_{0} A_{0}}{2 \pi \sigma_{1} \sigma_{2}} \exp \left(-\frac{1}{2}\left[\left(\frac{2 \pi-|\theta-(\omega t-2 \pi n)|}{\sigma_{1}} r_{2}\right)^{2}+\left(\frac{z}{\sigma_{2}}\right)^{2}\right]+\frac{r-r_{2}}{\lambda_{0}}\right)
$$

if $\pi<|\theta-(\omega T-2 \pi n)| \leq 2 \pi$, where $n$ is the integer part of $\omega t / 2 \pi$;

For a symmetrical Gaussian beam, $\sigma_{1}$ and $\sigma_{2}$ can be related to the beam radius $w_{0}$ by $\sigma_{1}=\sigma_{2}=\frac{\sqrt{2}}{2} w_{0}$

Boundary conditions are two conditions represented as [12]

$$
\begin{aligned}
& \left.\left(h T+k \frac{\partial T}{\partial \hat{n}}\right)\right|_{r_{1}}=h T_{1} \\
& \left.\left(h T+k \frac{\partial T}{\partial \hat{n}}\right)\right|_{r_{2}}=h T_{2}
\end{aligned}
$$


where $\mathrm{h}$ and $\mathrm{k}$ are the surface convection coefficient and heat conductivity respectively, $T_{1}$ is the ambient temperatures inside the chamber of the glassware, $T_{2}$, is the ambient temperature surrounding the glassware, and $\frac{\partial T}{\partial \hat{n}}$ is the temperature derivative in the surface.

The initial condition is given by

$$
\left.T(r, \theta, z, t)\right|_{t=0}=T_{0}
$$

where $T_{0}$ is the initial glassware temperature, usually the preheating temperature.

Although simple steady state and transient heat conduction problems can sometimes be solved analytically, the problem discussed above is so complex that an analytical solution is impossible to obtain. Instead, it is the best to resort to numerical method, which will be discussed in detail in Chapter 4 .

\subsection{1-D MODEL AND ITS APPLICATION}

Another analytical model of the laser cutting of a glass cylinder by melting was developed by P. A. Antanasov and S. I. Gendjov [43], as is presented in Appendix A of this dissertation. The goal of their model was to find the temperature response of a point on the cutting ring to the multiple pulse inputs with finite length. Cutting ring refers to the narrow strip around the glassware along which the laser beam passes. The derivation of this model consists of solving the thermal conduction equation. Unlike the 3-D heat conduction model that has to be solved numerically, this model can be solved to give an explicit expression to predict the temperature at a certain location and at a certain point of time during the laser glass interaction as [43] 


$$
T(0, N, \xi)=T_{0}+T_{1} S(N, \xi)
$$

where

$$
\begin{gathered}
T_{1}=0.84 \frac{P \tau}{C_{\rho} \pi D_{0} w_{0} d_{0}} \times \frac{1}{\left[1+\left(w_{p} / w_{0}\right)^{2}\right]^{1 / 2}} \\
S(N, \xi)=\sum_{n=1}^{N} \frac{1}{\left[1+\left(n-1+\xi^{\prime}\right) / \delta^{2}\right]^{1 / 2}} \times \operatorname{erf}\left[\left(2+2 \delta^{2} /\left(n-1+\xi^{\prime}\right)\right]^{1 / 2}\right.
\end{gathered}
$$

where,

$$
\begin{aligned}
& \xi^{\prime}=\xi-\frac{\tau_{p}}{\tau} \\
& \delta=\frac{w_{0}}{(4 a \tau)^{1 / 2}}\left[1+\left(w_{p} / w_{0}\right)^{2}\right]^{1 / 2}
\end{aligned}
$$

where $T(0, N, \xi)$ is the temperature at location 0 (cutting ring start point), $\mathrm{N}$ is the number of revolutions and $\xi$ is the time phase, $P$ is the laser power, $\tau$ is the period of rotation, $\tau_{p}$ is the laser pulse duration length, $w_{0}$ is the radius of laser beam waist, $D_{0}$ is the outside diameter of the glassware, $d_{0}$ is the thickness of the glassware, $C_{\rho}$ is the thermal capacity, and $a$ is the thermal diffusivity.

Codes in MATLAB were written to analyze the laser glass interaction for the case with parameters listed in the Table 3.1. The temperature history of glassware under $100 \mathrm{~W}$ laser striking was predicted by this model and is shown in Figure 3.5. The temperature history under $1000 \mathrm{~W}$ of laser power as predicted by this model is shown in Figure 3.6. These results were compared to the results from the simulation (shown in Figure 4.9 in Chapter 4), and difference exists. 
The temperature predicted by the analytical model is lower than the temperature predicted by the numerical simulation. The major reason for this difference is that the temperature from the analytical model is the temperature averaged along the thickness direction, while the temperature in Figure 4.9 is the surface temperature.

There are three other limitations in the 1-D model. First, the temperature-dependent properties of glass in this model are averaged between temperature of $600{ }^{\circ} \mathrm{C}$ and $1500{ }^{\circ} \mathrm{C}$. Second, the heat loss due to the surface heat convection, although limited in the amount, is not taken into account in this model. Third, several approximations and restrictions were applied to this model to derive the solution, such as $D>>l>>w_{0} \sim d_{0}$ and $d_{0}<(4 a)^{1 / 2}$.

Because of these limitations and in order to predict the temperature profile along the glassware thickness direction, numerical simulations based on a 3-D model were performed as discussed in Chapter 4 to better evaluate the temperature behavior of the laser glass cutting.

Table 3.1 Parameters used in Model

\begin{tabular}{|c|c|c|c|}
\hline SIMULATION PARAMETER ITEMS & SYMBOL & UNIT & VALUE \\
\hline Diameter & $\mathrm{D}_{0}$ & $\mathrm{~mm}$ & 80 \\
\hline Wall thickness & $\mathrm{D}_{0}$ & $\mathrm{~mm}$ & 5 \\
\hline Pulse length & $\mathrm{L}$ & $\mathrm{mm}$ & 3 \\
\hline Density & $\rho$ & $\mathrm{kg} / \mathrm{m}^{3}$ & 2440 \\
\hline Average Thermal Conductivity & $\mathrm{K}$ & $\mathrm{W} / \mathrm{m} \cdot \mathrm{K}$ & 1.88 \\
\hline Average Thermal Capacity & $C_{\rho}$ & $\mathrm{J} / \mathrm{kg} \cdot \mathrm{K}$ & $3.36 \times 10^{6}$ \\
\hline Initial Temperature & $\mathrm{T}_{0}$ & ${ }^{\circ} \mathrm{C}$ & 600 \\
\hline Laser Power & $\mathrm{P}$ & Watts & 100,1000 \\
\hline Laser Radius & $w_{0}$ & $\mathrm{~mm}$ & 0.1 \\
\hline Rotation Period & $\tau$ & Second & 1 \\
\hline
\end{tabular}




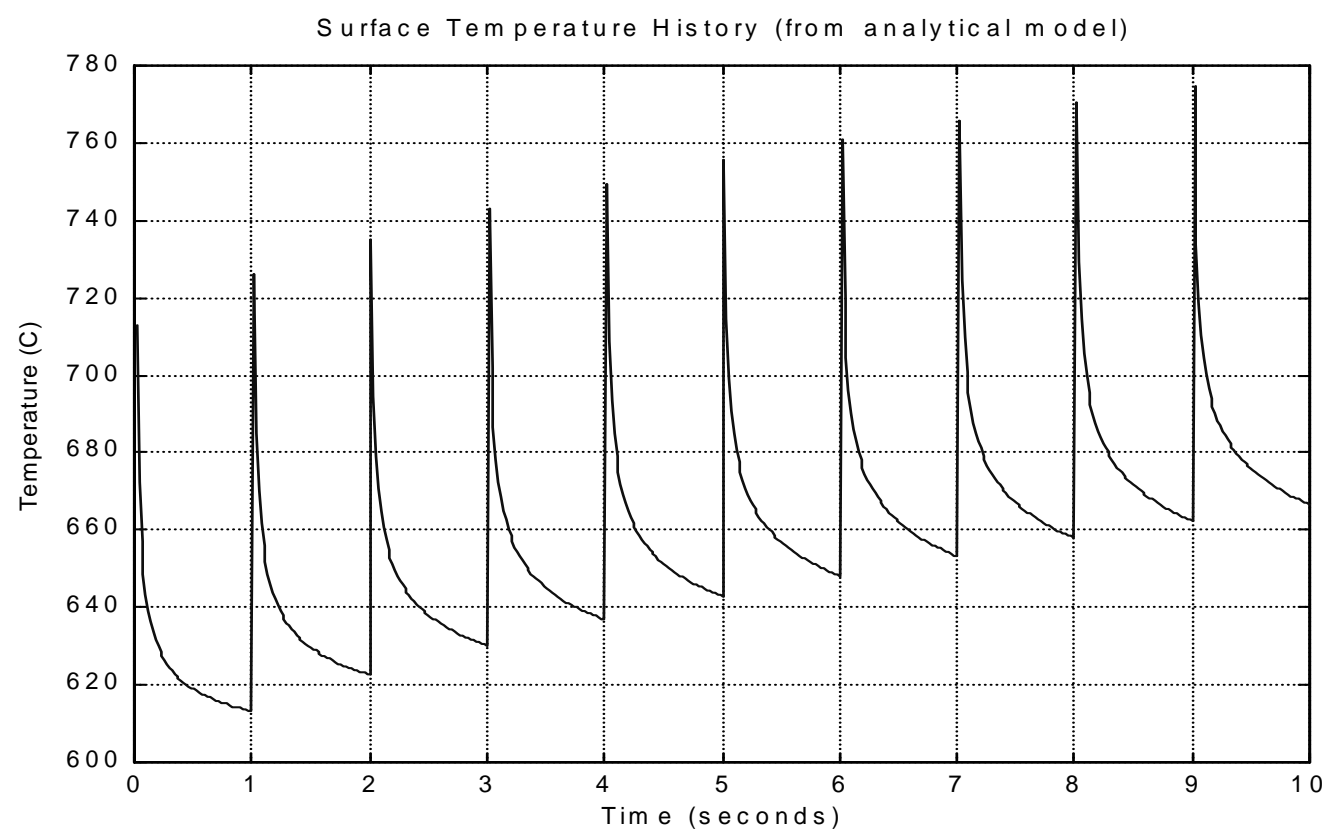

Figure 3.5 Temperature Response with Laser Power 100 W

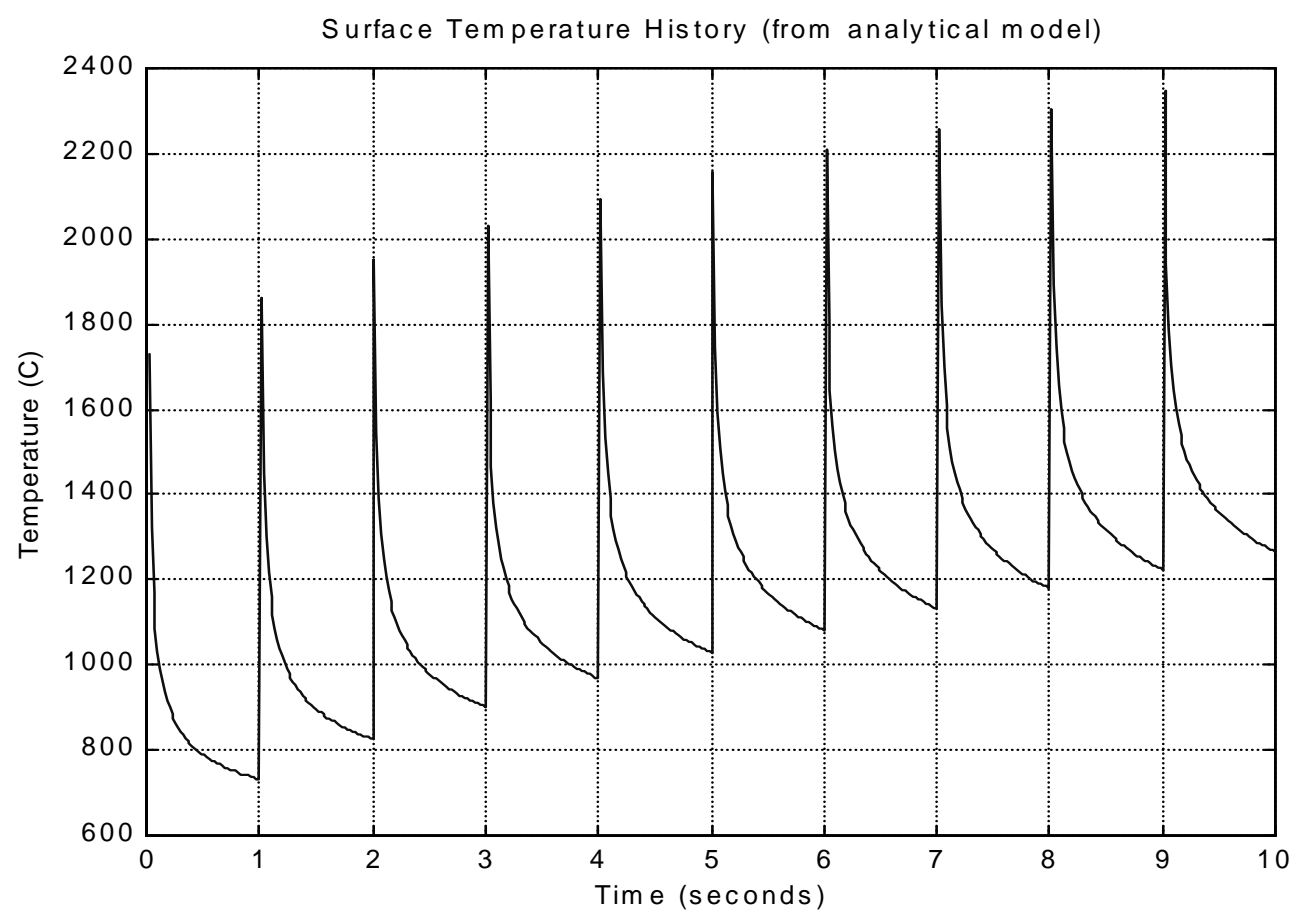

Figure 3.6 Temperature Response with Laser Power 1000 


\section{SIMULATION OF LASER GLASS INTERACTION}

\subsection{INTRODUCTION}

As presented in Chapter 3, 3-D heat conduction model was described to model the laser glass interaction. The 1-D analytical model developed by Antanasov and S. I. Gendjov [43] was presented in Appendix A. The solution to the 1-D model equations was used to compute the average temperatures along the radial axis of glassware during laser glass cutting as defined in Appendix A.

Although the solution to the 1-D approximate model can be used to predict the temperature in the laser glass interaction, the prediction is very limited due to the limitations associated with the model. These limitations were discussed in Section 3.2 of Chapter 3. The model also has the application limitation, since it is only able to predict the average temperature along the radial axis of the glassware wall instead of the temperature profile along this direction. In laser glass cutting, the temperature profile along the radial axis of glassware is of much interest, since temperature profiles at different points in time represent the progress of the heat. Therefore, an effort has been made to find the solution to the 3-D heat conduction model equations.

Although many simple steady state and transient heat-conduction problems can be solved analytically, a solution to a 3-D heat conduction problem is best obtained numerically. 
Numerical solution methods are particularly useful when the shape of the solid is irregular, when thermal properties are temperature-dependent or position-dependent, and when boundary conditions are non-homogenous. Numerical methods commonly used include the finitedifference methods, the finite-element methods, and the boundary-element method. The finitedifference method was the first numerical method to be used extensively for heat condition. It remains a popular method and was used in the simulation of laser glass cutting interaction in this dissertation, because it is easier to implement and is the most useful numerical solution method for the heat conduction problem.

\subsection{NuMERICAL MODEL}

The first step in a finite-difference solution procedure is to discretize the spatial coordinates to form a mesh of nodes. Next, finite-difference approximations are made to the derivatives appearing in the heat conduction equations to convert the differential equation to an algebraic difference equation. Alternatively, the difference equation can be constricted by applying the energy conservation principle directly to a volume element surrounding the node. In steady-state problems, a set of linear algebraic equations is obtained with as many unknowns as the number of nodes in the mesh. These equations can be solved by matrix inversion or by iteration. For transient conditions, temperatures at the current time step may be found directly using values at the preceding time step and the current heat input. In some formulations, iteration may be required, since values at the current time step are also involved.

A useful formulation for the finite-difference numerical method is the resistancecapacitance or R-C formulation. 
Figure 4.1 shows the volume element of interest with volume $\Delta V_{m}$ and with thermal capacitance $C_{m}=\rho_{m} C_{m} \Delta V_{m}$ [12]. The surrounding six volume elements are denoted by $\mathrm{n}=1$, $2, \ldots 6$, and conduction from one of the volume $\Delta V_{n}$ into $\Delta V_{m}$ is expressed in terms of a thermal resistance $R_{m n}$. An energy balance on volume $\Delta V_{m}$ over the time interval $\Delta t$ gives [12]

$$
C_{m} \frac{T_{m}^{i+1}-T_{m}^{i}}{\Delta t}=\sum_{n} \frac{T_{n}^{i}-T_{m}^{i}}{R_{m n}}+\dot{Q}_{v} \Delta V_{m}
$$

where the superscript refers to the time step and the subscript refers the node number. When the properties are temperature-dependent, the capacitance $C_{m}$, resistance $R_{m n}$, and source $Q_{v}$ must be evaluated at each step. Solving for $T_{m}^{i+1}$ gives [12]

$$
T_{m}^{i+1}=\left(1-\frac{\Delta t}{C_{m}} \sum_{n} \frac{1}{R_{m n}}\right) T_{m}^{i}+\left(\dot{Q_{v}} \Delta V_{m}+\sum_{n} \frac{T_{n}^{i}}{R_{m n}}\right) \frac{\Delta t}{C_{m}}
$$

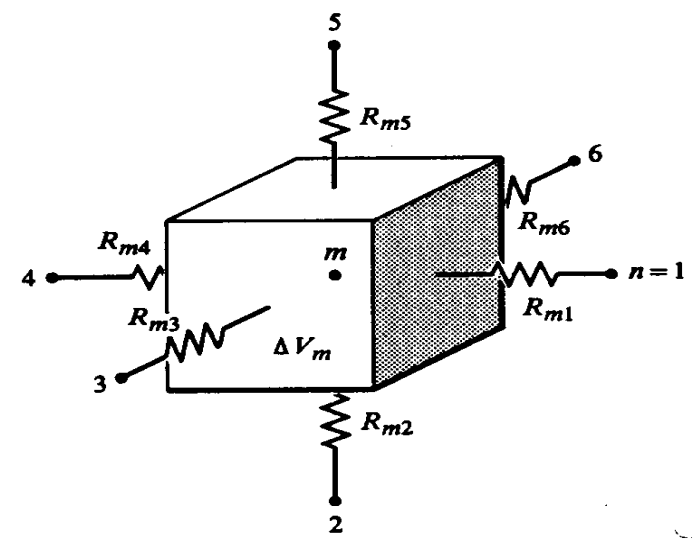

Figure 4.1 Resistance-Capacitance Formulations for Finite Difference Method

A satisfactory condition for stability [12] is that the coefficient of $T_{m}^{i}$ should not be negative:

$$
1-\frac{\Delta t}{C_{m}} \sum_{n} \frac{1}{R_{m n}} \geq 0
$$


The resistance-capacitance representation is usually applied to problems that have complicated boundary conditions, that requires a variation in the size and shape of volume $\Delta V_{m}$, or that have temperature-dependent thermal properties. Thus, the stability criterion must be evaluated for each node, and a time step chosen such that [12]

$$
\Delta t \leq\left(\frac{C_{m}}{\sum_{n} 1 / R_{m n}}\right)_{\min }
$$

This is the most restrictive equation that controls the allowable step.

Depending on what coordinate system is chosen in the model, expressions for both the volume element and resistance could be in various forms. Table 4.1 gives the volumes $\Delta V_{m}$ and resistance $R_{m n}$ for interior nodes in the Cartesian, cylindrical, and spherical coordinate systems [12]. These three coordinate systems are shown in the Figure 4.2 [12]. The Cartesian coordinate system was used for the approximate numerical modeling of the glassware due to the equivalence when the glassware diameter is much greater than the glassware thickness. The results were still presented in cylindrical coordinate system.

Table 4.1 Expressions of Interior Nodes in Different Coordinate Systems ([12])

\begin{tabular}{||c|c|c|c||}
\hline \multirow{2}{*}{ PARAMETERS } & \multicolumn{3}{|c||}{ COORDINATE SYSTEMS } \\
\cline { 2 - 4 } & Cartesian & Cylindrical & Spherical \\
\hline \hline Coordinates & $x, y, z$ & $r, \theta, z$ & $r, \phi, \theta$ \\
\hline Indices & $m, n, l$ & $m, n, l$ & $m, n, l$ \\
\hline Volume Element & $\Delta x \Delta y \Delta z$ & $r_{m} \Delta r \Delta \theta \Delta z$ & $r_{m}^{2} \Delta r \Delta \phi \Delta \theta$ \\
\hline
\end{tabular}




\begin{tabular}{||c|c|c|c||}
\hline$R_{m^{+}}$ & $\frac{\Delta x}{\Delta y \Delta z k}$ & $\frac{\Delta r}{\left(r_{m}+\Delta r / 2\right) \Delta \theta \Delta z k}$ & $\frac{\Delta r}{\left(r_{m}+\Delta r / 2\right)^{2} \sin \theta \Delta \phi \Delta \theta k}$ \\
\hline$R_{m^{-}}$ & $\frac{\Delta x}{\Delta y \Delta z k}$ & $\frac{\Delta r}{\left(r_{m}-\Delta r / 2\right) \Delta \theta \Delta z k}$ & $\frac{\Delta r}{\left(r_{m}-\Delta r / 2\right)^{2} \sin \theta \Delta \phi \Delta \theta k}$ \\
\hline$R_{n^{+}}$ & $\frac{\Delta y}{\Delta x \Delta z k}$ & $\frac{r_{m} \Delta \theta}{\Delta r \Delta z k}$ & $\frac{\Delta \phi \sin \theta}{\Delta r \Delta \theta k}$ \\
\hline$R_{n^{-}}$ & $\frac{\Delta y}{\Delta x \Delta z k}$ & $\frac{r_{m} \Delta \theta}{\Delta r \Delta z k}$ & $\frac{\Delta \phi \sin \theta}{\Delta r \Delta \theta k}$ \\
\hline$R_{l^{+}}$ & $\frac{\Delta z}{\Delta x \Delta y k}$ & $\frac{\Delta z}{r_{m} \Delta \phi \Delta r k}$ & $\frac{\Delta \theta}{\sin (\theta+\Delta \theta / 2) \Delta r \Delta \phi k}$ \\
\hline$R_{l^{-}}$ & $\frac{\Delta z}{\Delta x \Delta y k}$ & $\frac{\Delta z}{r_{m} \Delta \phi \Delta r k}$ & $\frac{\Delta \theta}{\sin (\theta-\Delta \theta / 2) \Delta r \Delta \phi k}$ \\
\hline
\end{tabular}

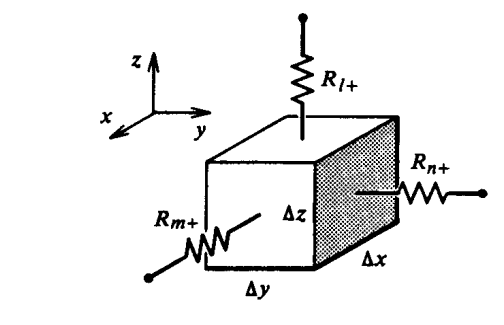

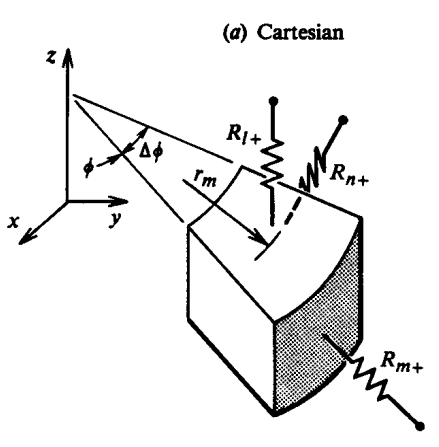

(b) Cylindrical

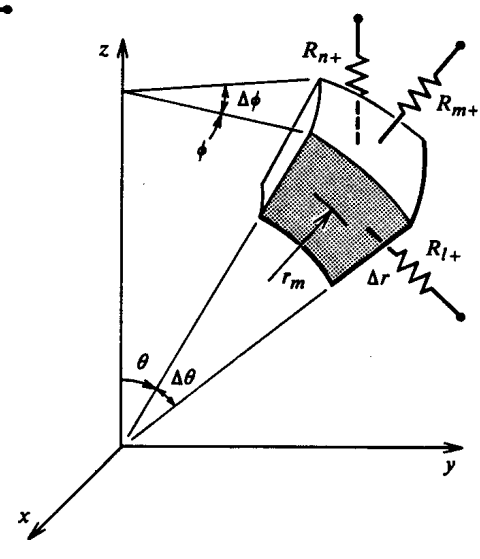

(c) Spherical

Figure 4.2 Control Volumes and Resistance in Different Coordinates for R-C Representation 


\subsection{Simulation}

A special software program named Laser Glass Cutting Simulation (LGCSim) has been developed in Visual $\mathrm{C}++6.0$ for the numerical model discussed in Section 4.1. The glassware is represented by a three-dimensional mesh in a Cartesian coordinate system. The heat input to a volume element depends on the location of that cell relative to the Guassian laser beam and varies with the time as described in Equations 3.27 and 3.28, since the laser beam with Gaussian distribution is moving along the cylinder.

Parameters that were implemented in the LGCSim program include:

- Geometrical properties including mesh size in three dimensions and mesh resolution in three dimensions;

- Material properties including density, thermal conductivity, specific heat and convection coefficient;

- Initial conditions including initial temperature of glassware;

- Boundary conditions including internal and external interface convection coefficients, and ambient temperature;

- Laser properties including laser power, laser speed, laser beam radius and laser beam transmissibility;

- Simulation properties including simulation duration and time step.

In the simulation, thermal conductivity $k$ and specific heat $C$ are considered temperature dependent in the laser glass cutting. The dependency of $k$ and $C$ on temperature at low end of 
the temperature range $(T \leq 1500 C)$ is described respectively in Equation 4.5 and Equation 4.6. These two equations were derived from the data given by reference [58]. These dependencies are also shown graphically in the Figure 4.3 and Figure 4.4. At higher end of the temperature range, both $k$ value and $C$ value were truncated as a constant value.

$$
\begin{array}{cc}
k=3.752 \times 10^{-8} T^{3}-5.467 \times 10^{-5} T^{2}+2.681 \times 10^{-2} T-3.2 & T \leq 1500 C \\
C=6.181 \times 10^{-7} T^{3}-2.243 \times 10^{-3} T^{2}+2.813 T+143.9 & T \leq 1500 C
\end{array}
$$

To understand the process, the initial effort was made to investigate the thermal behavior of the glassware during single-cycle laser glass interaction. Further effort was then made to investigate the temperature behavior of the glassware during multi-cycle laser glass interactions. Effort was also made to investigate the effect of certain parameters on the temperature behavior of the glassware in laser cutting. Four parameters of interest were laser power, relative glassware rotation speed, glassware diameter and glassware wall thickness.

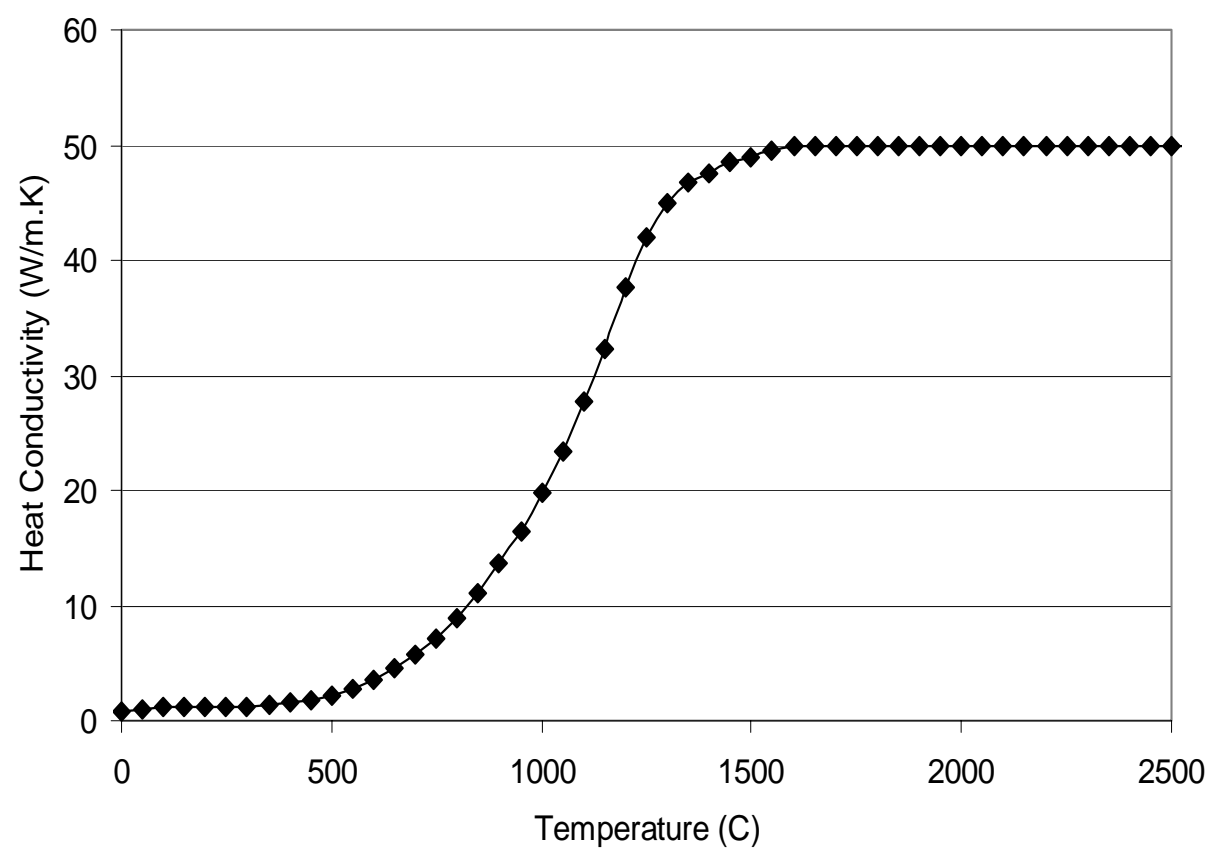

Figure 4.3 Heat Conductivity as a Function of Temperature 


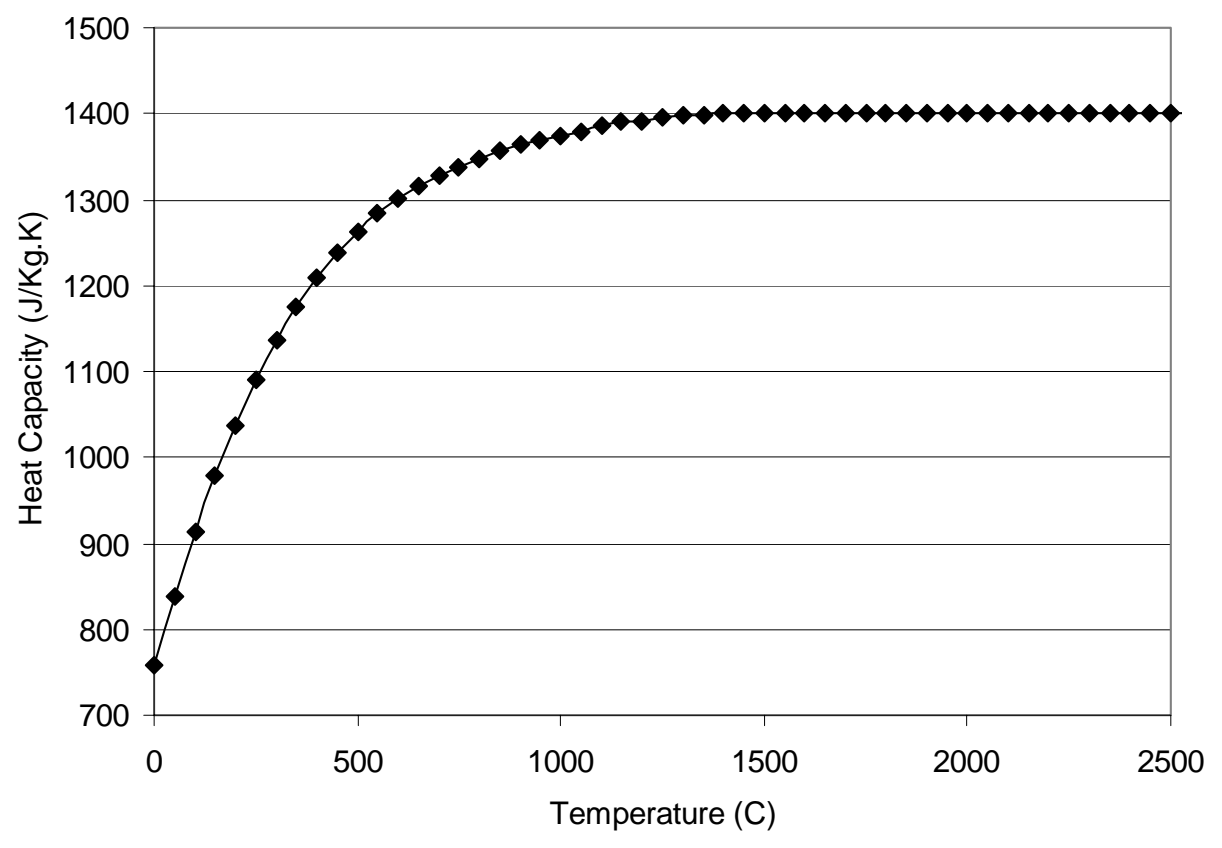

Figure 4.4 Specific Heat as a Function of Temperature

\subsection{ReSUlts}

\subsubsection{Single-Cycle Laser Glass Interaction}

Since the laser beam has a Gaussian distribution, the energy input to an infinitely small volume of the glass in a certain location within the glass behaves like a pulse and follows the Gaussian distribution when the laser beam moves around the glassware and only pass this volume once. Of particular interest is the response of this small volume of glass to this pulse Gaussian laser energy input. The peak temperature, temperature-decay rate, time constant, and residual temperature can be determined from this response. Residual temperature refers to the temperature of the glass right before the laser re-strikes the volume. It is main purpose of the simulation when limited to the single-cycle laser glass interaction, i.e. simulation duration no 
more than one rotation cycle, to explore the temperature response to a pulse Gaussian energy input.

The parameters for the single-cycle laser glass interaction simulation are listed in Table 4.2. The laser power is specified as $100 \mathrm{~W}$, equal to the power of the Synrad $\mathrm{CO}_{2}$ laser in the laboratory prototype machine. The rotational speed of laser beam relative to glassware is one revolution per second, and the simulation duration is one second to ensure single-cycle laser glass interaction. The diameter and thickness of glassware are $\mathrm{D}_{0}$ at $95 \mathrm{~mm}$ and $\mathrm{d}_{0}$ at $5 \mathrm{~mm}$, which is equivalent to inner radius $r_{1}$ at $42.5 \mathrm{~mm}$ and outer radius $r_{2}$ at $47.5 \mathrm{~mm}$. The height of glassware taken into consideration, noted as $\mathrm{z}_{0}$ in Figures 3.3 and 3.4 , is $10 \mathrm{~mm}$. Initial temperature is $650{ }^{\circ} \mathrm{C}$ and ambient temperature is $50{ }^{\circ} \mathrm{C}$. Heat convection coefficient is specified as $10 \mathrm{~W} / \mathrm{m}^{2} \cdot \mathrm{k}[12]$.

Table 4.2 Parameters for Single-Cycle Laser Glass Interaction Simulation

\begin{tabular}{|c|c|c|c|c|}
\hline \multicolumn{2}{|c|}{$\begin{array}{l}\text { SIMULATION PARAMETER } \\
\end{array}$} & SYMBOL & UNIT & VALUE \\
\hline \multirow{2}{*}{$\begin{array}{l}\text { Glassware } \\
\text { Geometry }\end{array}$} & Diameter & $\overline{\mathrm{D}_{0}}$ & $\mathrm{~mm}$ & 95 \\
\hline & Wall Thickness & $\mathrm{d}_{0}$ & $\mathrm{~mm}$ & 5 \\
\hline Glassware & Density & $\rho$ & $\mathrm{Kg} / \mathrm{m}^{3}$ & 2440 \\
\hline \multirow{3}{*}{$\begin{array}{c}\text { Material } \\
\text { Properties }\end{array}$} & Thermal Conductivity at $300 \mathrm{~K}$ & $\mathrm{~K}$ & $\mathrm{~W} / \mathrm{m} \cdot \mathrm{K}$ & 0.88 \\
\hline & Specific Heat at $300 \mathrm{~K}$ & $C$ & J/kg.K & 840 \\
\hline & Convection Coefficient & $\mathrm{H}$ & $\mathrm{W} / \mathrm{m}^{2} \cdot \mathrm{k}$ & 10 \\
\hline \multirow{2}{*}{$\begin{array}{l}\text { Boundary } \\
\text { and Initial }\end{array}$} & Initial Temperature & $\mathrm{T}_{0}$ & ${ }^{\circ} \mathrm{C}$ & 650 \\
\hline & Ambient Temperature & $\mathrm{T}_{\mathrm{e}}$ & ${ }^{\circ} \mathrm{C}$ & 50 \\
\hline \multirow{4}{*}{$\begin{array}{c}\text { Laser } \\
\text { Parameters }\end{array}$} & Laser Power & $\bar{P}$ & $\mathrm{~W}$ & 100 \\
\hline & Laser Radius & $w_{0}$ & $\mathrm{~mm}$ & 0.1 \\
\hline & Laser Lamda & $\lambda_{0}$ & $\mathrm{~mm}$ & 0.1 \\
\hline & Rotation Cycle & $\tau$ & second & 1 \\
\hline
\end{tabular}


The temperature response of a volume element on the surface $\left(r=r_{2}\right)$ and in the cutting $\operatorname{ring}\left(\mathrm{z}_{=} \mathrm{z}_{1}\right)$ is computed as shown in the Figure 4.5. All the volume elements in the glassware have the similar response. The difference between volume elements is that heat input to one volume could differ from the heat input to another volume at a certain point in time. Temperature profiles were computed along the cutting ring ( $\theta$ direction), radial direction ( $\mathrm{r}$ axis) and height direction ( $\mathrm{z}$ axis), and also at several points in time within the cycle. In detail, Figure 4.6 shows the surface temperature profile along the cutting ring direction at $t=1 / 4$ second. Figure 4.7 shows the surface temperature profiles along the height direction at $t=1 / 4$ and 1 second. Figure 4.8 shows the temperature profiles along the radial direction at $t=1 / 4$ and 1 second.

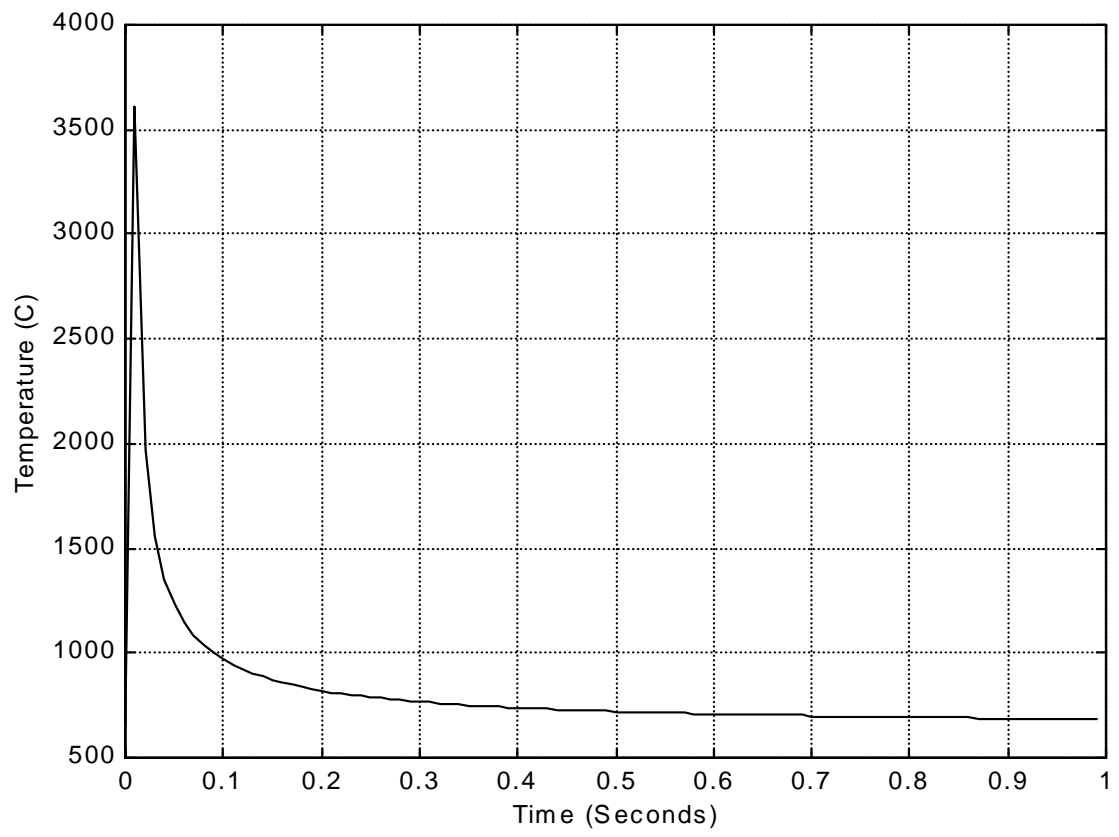

Figure 4.5 Temperature Response to Single-Cycle Energy Input $\left(\theta=0, r=r_{2}, z=z_{1}\right)$ 


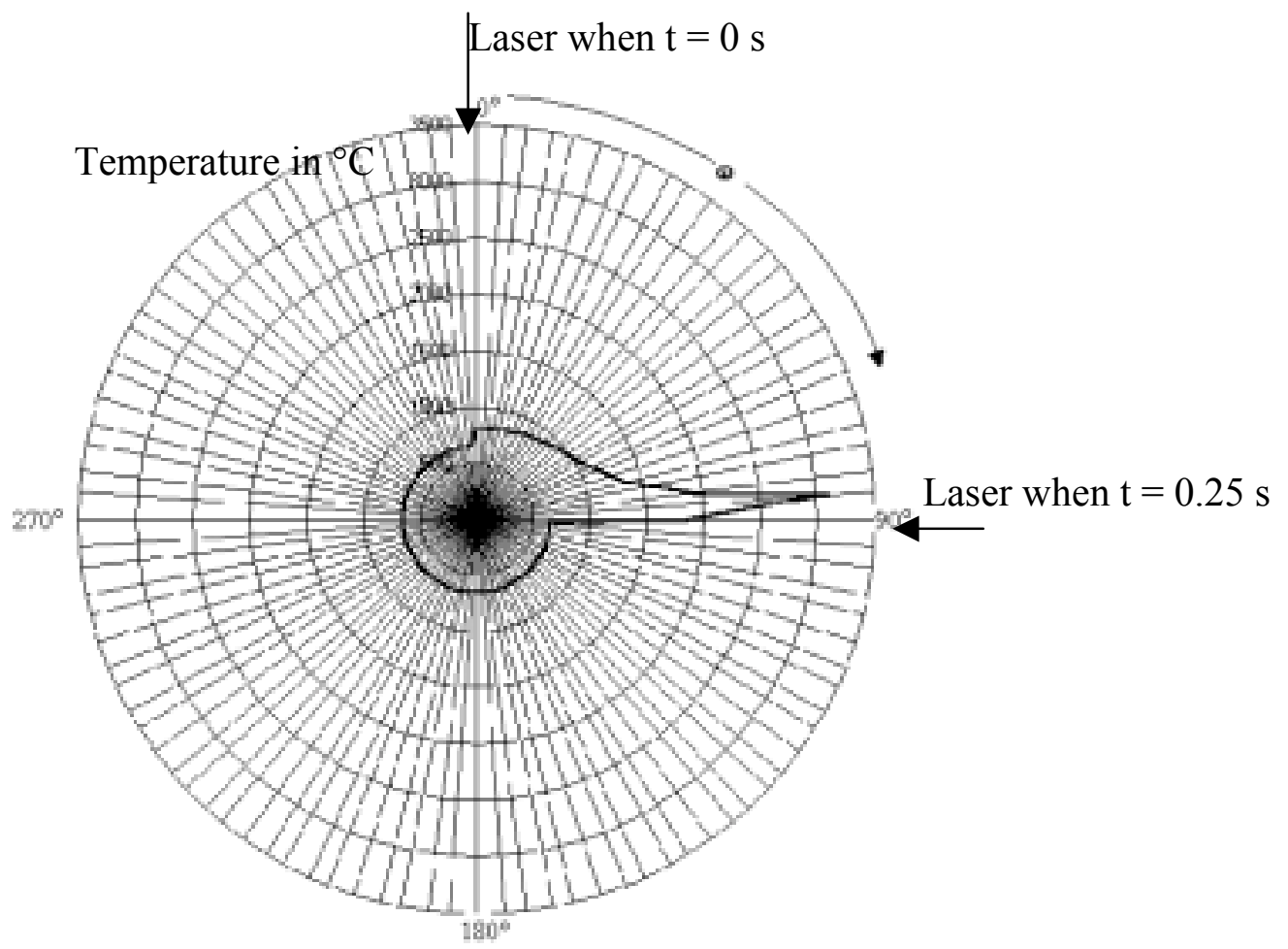

Figure 4.6 Temperature Profile along $\theta$ Direction at $t=0.25 \operatorname{second}\left(r=r_{2}, z=z_{1}\right)$

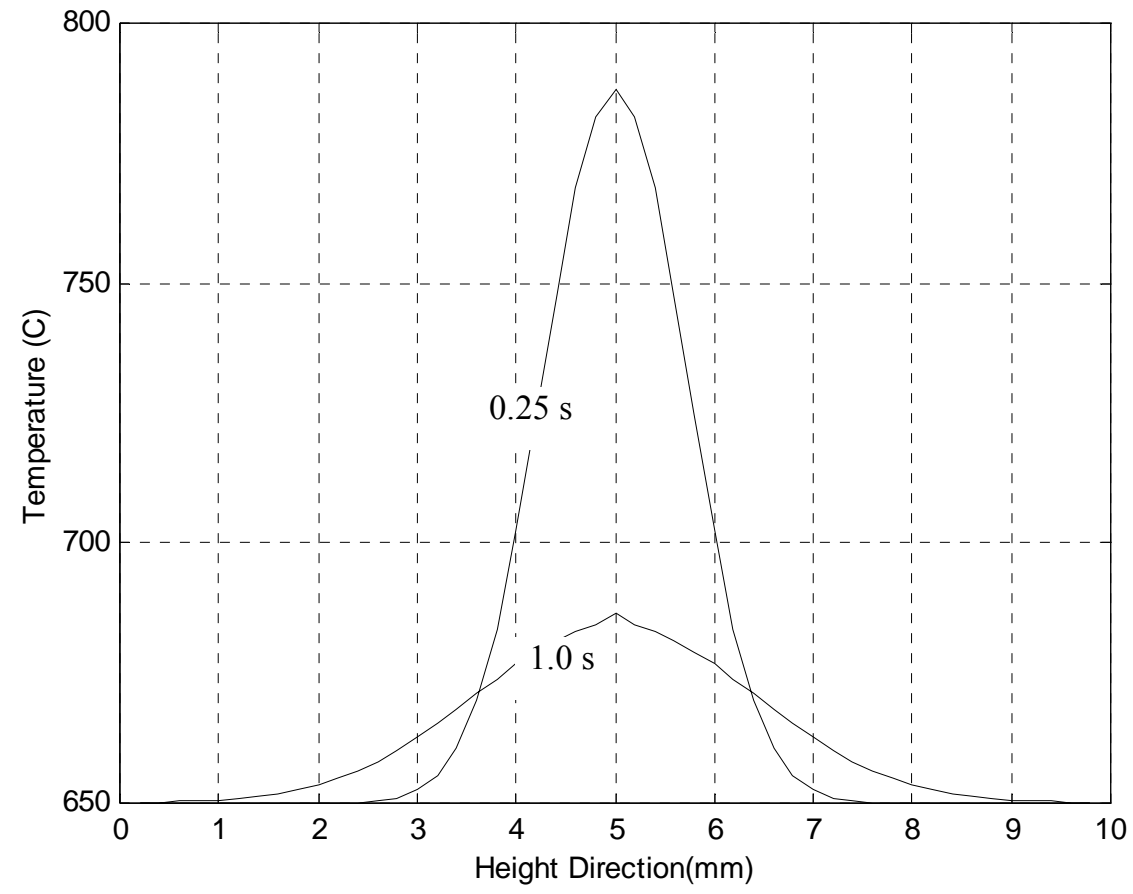

Figure 4.7 Temperature Profiles along $z$ Axis at $t=0.25 \operatorname{second}$ and $1.0 \operatorname{second}\left(\theta=0, r=r_{2}\right)$ 


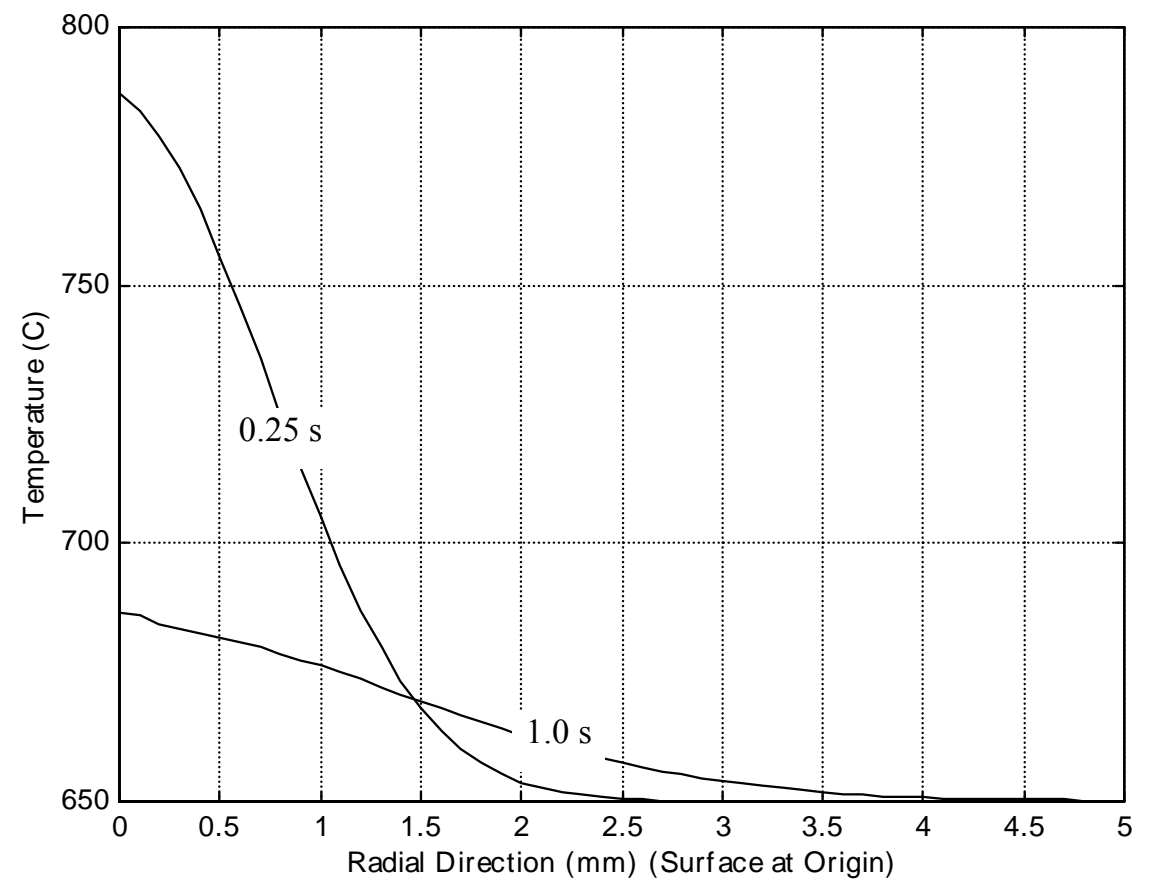

Figure 4.8 Temperature Profiles along $r$ Axis at $t=0.25 \operatorname{second}$ and $1.0 \operatorname{second}\left(\theta=0, z=z_{1}\right)$

From the temperature responses, it was found that the peak temperature of glassware is as high as $3500{ }^{\circ} \mathrm{C}$. It is believed that glass starts to melt at the temperature around $1200{ }^{\circ} \mathrm{C}$ and start to vaporize at the temperature around $1500{ }^{\circ} \mathrm{C}$ [43]. This temperature is sufficiently high to cause the melting and even vaporization of the glass. Hence, it indicated that the proposed method of laser glass cutting using melting and/or vaporizing is feasible. When the laser strikes, the temperature of the glass increases very fast. However, it also decays fast after the laser beam leaves the area. The time constant related to this decaying response is approximately 0.02 seconds. Although the peak temperature can reach $3500{ }^{\circ} \mathrm{C}$, the residual glass temperature is only slightly higher than the initial glass temperature. These results and some of the results presented in the following sections can also be found in the paper by the author [59].

The temperature adjacent to the laser-striking center is far lower than that at the laserstriking center, indicating that temperature gradient and the corresponding thermal stress is very 
high. If the glassware is not preheated to its annealing temperature, the glassware will break because the thermal stress will be inevitably too severe.

The heat penetration to the glassware is very limited, although the surface temperature is very high. There are three main reasons for this: 1) the glassware has a very low transmissibility to $\mathrm{CO}_{2}$ laser, 2) the glassware has a very low thermal conductivity, and 3) the energy absorbed is concentrated but limited in amount.

\subsubsection{Multi-Cycle Laser Glass Interaction}

In the real application, the laser will strike the glassware a number of cycles before the cutting is accomplished. In multi-cycle laser glass interaction simulation, the parameters are the same as those listed in Table 4.2 except that the initial temperature is $600{ }^{\circ} \mathrm{C}$ instead of $650{ }^{\circ} \mathrm{C}$ and the simulation duration is specified as 10 seconds to achieve ten cycles of laser glass interaction. The temperature response of a volume element at the center of the cutting ring and at glassware surface to this multi-cycle Gaussian laser energy input is shown in Figure 4.9.

It is noted that the temperature oscillates at the same cycle at which the glassware rotates, while the low-end temperature increases slightly from one cycle to the next. This means, the faster the glassware rotates, the more frequent the oscillation of the glass temperature. This result agrees with that from the 1-D model as discussed in Sections 3.2. It should be noted that the peak temperature was not shown in Figure 4.9, since the simulation software LGCSim does not output data at every step of the simulation; it outputs data every one hundred steps instead. 


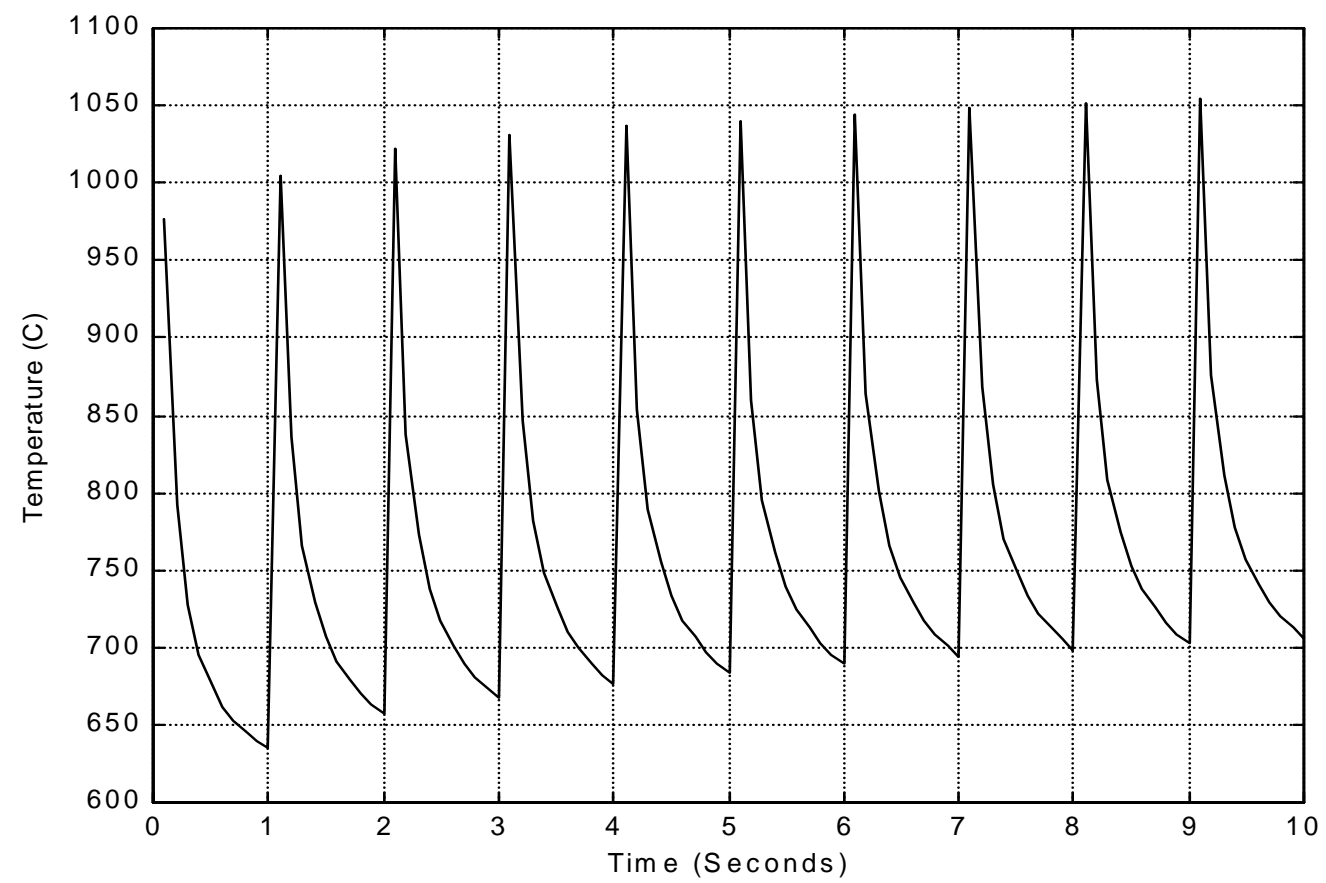

Figure 4.9 Temperature Response to Multi-Cycle Energy Input $\left(\theta=0, r=r_{2}, z=z_{1}\right)$

They are two types of average temperatures mentioned in this dissertation. The first type of average temperature is the temperature averaged along the radial direction ( $\mathrm{r}$ axis), and was introduced as part of the 1-D analytical model presented in Section 3.2 and Appendix A. In this section, a second type of average temperature is introduced. This average temperature is the temperature averaged along the circumference direction ( $\theta$ axis). This average temperature can be computed from the 3-D model, and is computed by assuming that the laser power is uniformly distributed along the $\theta$ direction, or in other words, by assuming that the relative rotation speed between the glassware and the laser beam is infinite. Although the 3-D model is able to predict the three-dimensional temperature distribution at a certain point in time, the average temperature along the $\theta$ direction is widely used when investigating the effects of the laser power, and the glassware size on the laser glass cutting. There are three points that need to be made. First, the average heat propagation and average melting-front propagation toward the glassware inner side 
wall is of the most interest in laser glass cutting by melting and pulling. The average temperature and its profile in the rz plane can be used to indicate this heat propagation and melting front propagation. Second, it makes more sense to use this average temperature in the rz plane to indicate the heat propagation and melting front propagation instead of using the temperature profile in rz plane, since the temperature profile in rz plane is not uniform, it still varies along the circumference direction ( $\theta$ direction). Third, although averaging the temperature profile along the $\theta$ direction gives the average temperature along the $\theta$ direction, its magnitude will depend on the rotation speed. It is not a good measure for investigating the effect of laser power or glassware size on the heating and melting.

Figure 4.10 shows the average temperature response at the glassware surface. Results from $200 \mathrm{~W}$ laser glass interaction simulations are also shown in the Figure 4.10. The temperature response is smooth; no oscillation occurred as the case in multi-path temperature history. The average temperature increases when laser glass interaction is progressing. However, the temperature increase slows as each cycle occurs. As an example, for a laser with a power of $100 \mathrm{~W}$, the temperature increases more than $200{ }^{\circ} \mathrm{C}$ in the initial cycle, while in the rest of the nine cycles, it increases less than $100^{\circ} \mathrm{C}$. 


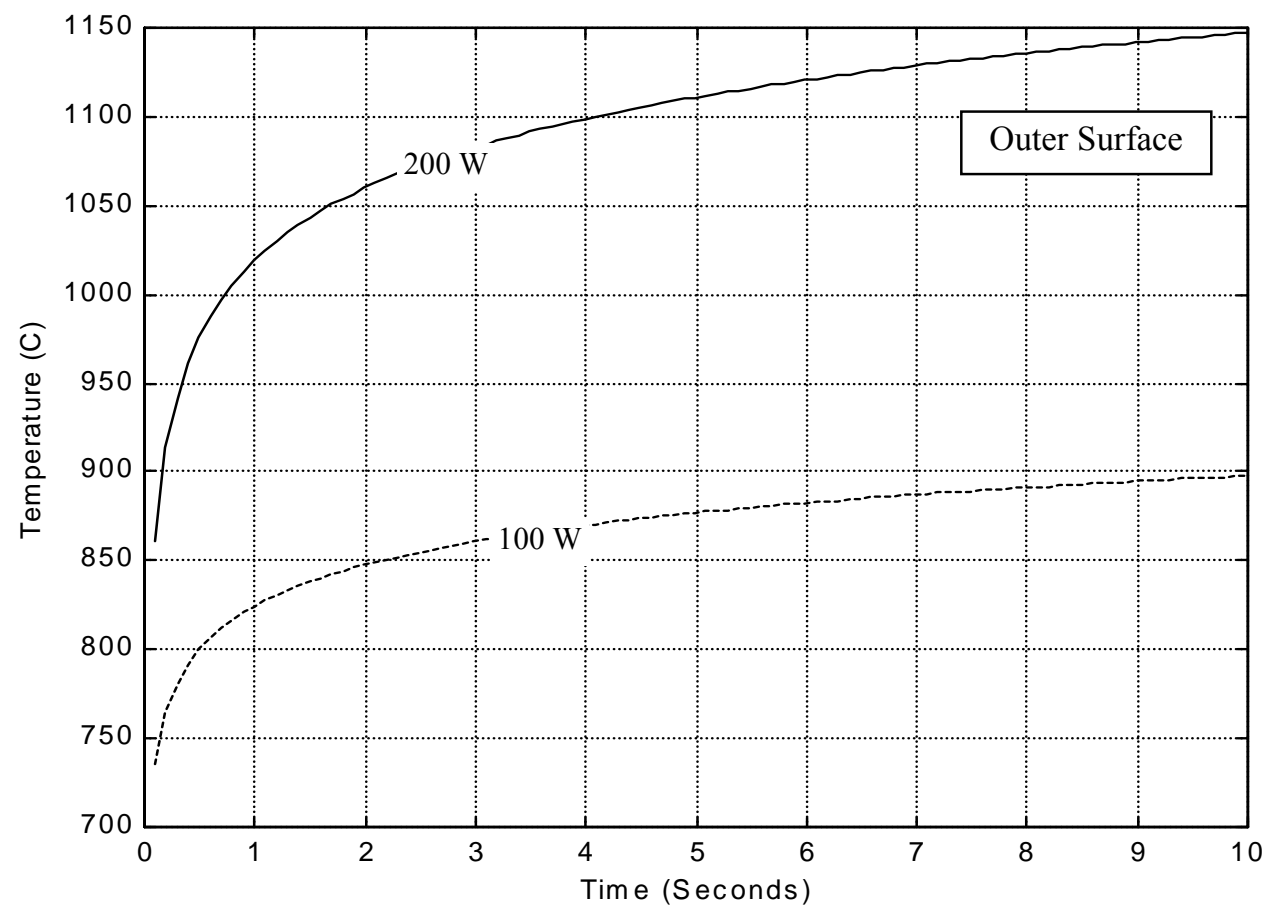

Figure 4.10 Average Temperature Response to Multi-Cycle Energy Input $\left(r=r_{2}, z=z_{1}\right)$

\subsubsection{Parametric Studies}

Additional results were provided by a parametric study. The four parameters of glassware rotation speed, laser power, glassware diameter and glassware wall thickness were investigated using this simulation tool.

The parameters common to all four parametric studies are listed in the Table 4.3. The results of these parametric studies are presented in Sections 4.3.3.1 to 4.3.3.4. 
Table 4.3 Parameters Common to Parametric Studies

\begin{tabular}{|c|c|c|c|c|}
\hline \multicolumn{2}{|c|}{ SIMULATION PARAMETER } & SYMBOL & UNIT & VALUE \\
\hline \multirow{2}{*}{$\begin{array}{c}\text { Glassware } \\
\text { Material }\end{array}$} & Density & 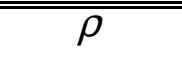 & $\overline{\mathrm{kg} / \mathrm{m}^{3}}$ & 2440 \\
\hline & Thermal Conductivity at $300 \mathrm{~K}$ & $\bar{K}$ & $\mathrm{~W} / \mathrm{m} \cdot \mathrm{K}$ & 0.88 \\
\hline \multirow[t]{2}{*}{ Properties } & Specific Heat at $300 \mathrm{~K}$ & $C$ & $\mathrm{~J} / \mathrm{kg} \cdot \mathrm{K}$ & 840 \\
\hline & Convection Coefficient & $\mathrm{h}$ & $\mathrm{W} / \mathrm{m}^{2} \cdot \mathrm{k}$ & 10 \\
\hline $\begin{array}{l}\text { Boundary } \\
\text { and Initial }\end{array}$ & Initial Temperature & $\mathrm{T}_{0}$ & ${ }^{\circ} \mathrm{C}$ & 600 \\
\hline $\begin{array}{l}\text { and Initial } \\
\text { Conditions }\end{array}$ & Ambient Temperature & $\mathrm{T}_{\mathrm{e}}$ & ${ }^{\circ} \mathrm{C}$ & 50 \\
\hline \multirow{2}{*}{$\begin{array}{c}\text { Laser } \\
\text { Parameters }\end{array}$} & Laser Radius & $w_{0}$ & $\mathrm{~mm}$ & 0.1 \\
\hline & Laser Lameda & $\lambda_{0}$ & $\mathrm{~mm}$ & 0.1 \\
\hline
\end{tabular}

\subsubsection{Effect of Glassware Rotation Speed}

The laser glass interaction under a glassware rotation speed of four revolutions per second was simulated. In addition to the parameters listed in Table 4.3, the laser power was 100 $\mathrm{W}$, the glassware diameter was $95 \mathrm{~mm}$, the glassware wall thickness was $5 \mathrm{~mm}$, and the simulation duration was 10 seconds. The temperature response for a volume element in the center of the cutting ring at the glassware surface was computed as shown by the solid curve in Figure 4.11. The dotted curve in Figure 4.11 represents the temperature response of laser glass interaction under a glassware rotation speed of one revolution per second, which is the same result shown previously in Figure 4.9. These two responses are comparable since all the parameters are the same except the glassware rotation speed. 
It was noted that the frequency of the glassware temperature oscillation is proportional to the glassware rotation speed. However, the magnitude of this oscillation will decrease when the laser moves faster, meaning a lower temperature gradient. For laser cutting by glass melting that is aided by a pulling mechanism, a uniform and high temperature in the cutting ring is always preferred. Therefore, increasing the rotational speed of the laser will be beneficial to the laser cutting. Again, the peak temperature for both cases was not shown in Figure 4.11.

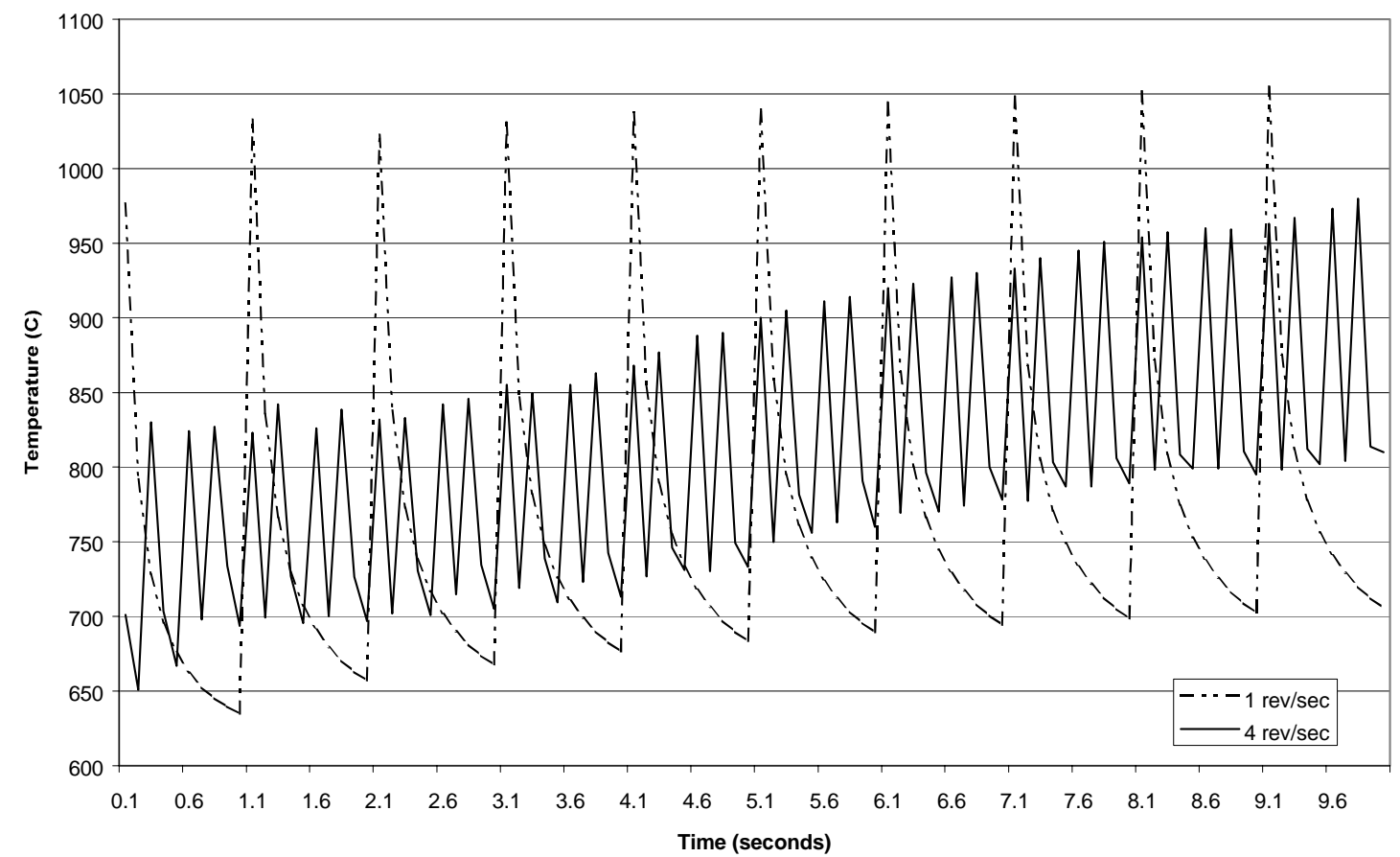

Figure 4.11 Effect of Glassware Rotation Speed on Temperature Response $\left(\theta=0, r=r_{2}, z=z_{1}\right)$

\subsubsection{Effect of Laser Power}

Besides the laser glass interaction for a $100 \mathrm{~W}$ laser power that was simulated and presented in the Section 4.3.2, laser glass interactions for $600 \mathrm{~W}, 800 \mathrm{~W}$ and $1000 \mathrm{~W}$ laser power were simulated and the results were presented to investigate the effect of laser power on the laser 
glass cutting. In addition to the parameters listed in the Table 4.3, the glassware rotation speed was one revolution per second, the glassware diameter was $95 \mathrm{~mm}$, the wall thickness was $5 \mathrm{~mm}$, and the simulation duration was 20 seconds.

The average temperature in the cutting ring ( $\theta$ direction) is of most interest in laser glass cutting using melting and/or vaporizing. Therefore, the average temperature responses of a volume element in the cutting ring $\left(\mathrm{z}=\mathrm{z}_{1}\right)$ at several locations in radial direction ( $\mathrm{r}$ axis) were computed. Three locations in the $r$ axis were considered including $\mathrm{r}=\mathrm{r}_{2}$ (outer side surface), $\mathrm{r}=$ $\left(r_{1}+r 2\right) / 2$ (midpoint of the wall) and $r=r_{1}$ (inner side wall). Results are shown in Figures 4.12,

\subsection{3 and 4.14 .}

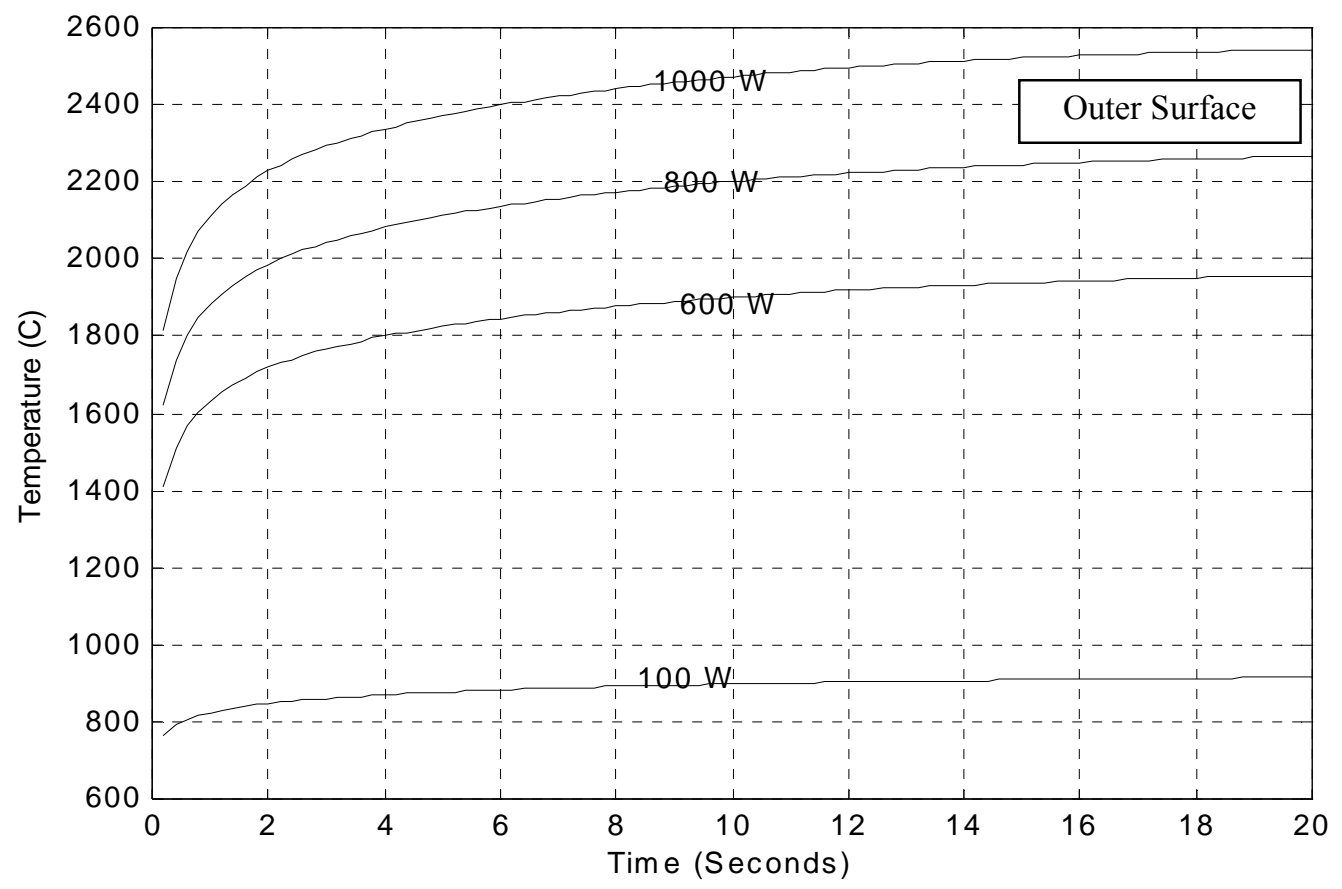

Figure 4.12 Effect of Laser Power on Average Temperature Response $\left(r=r_{2}, z=z_{1}\right)$ 


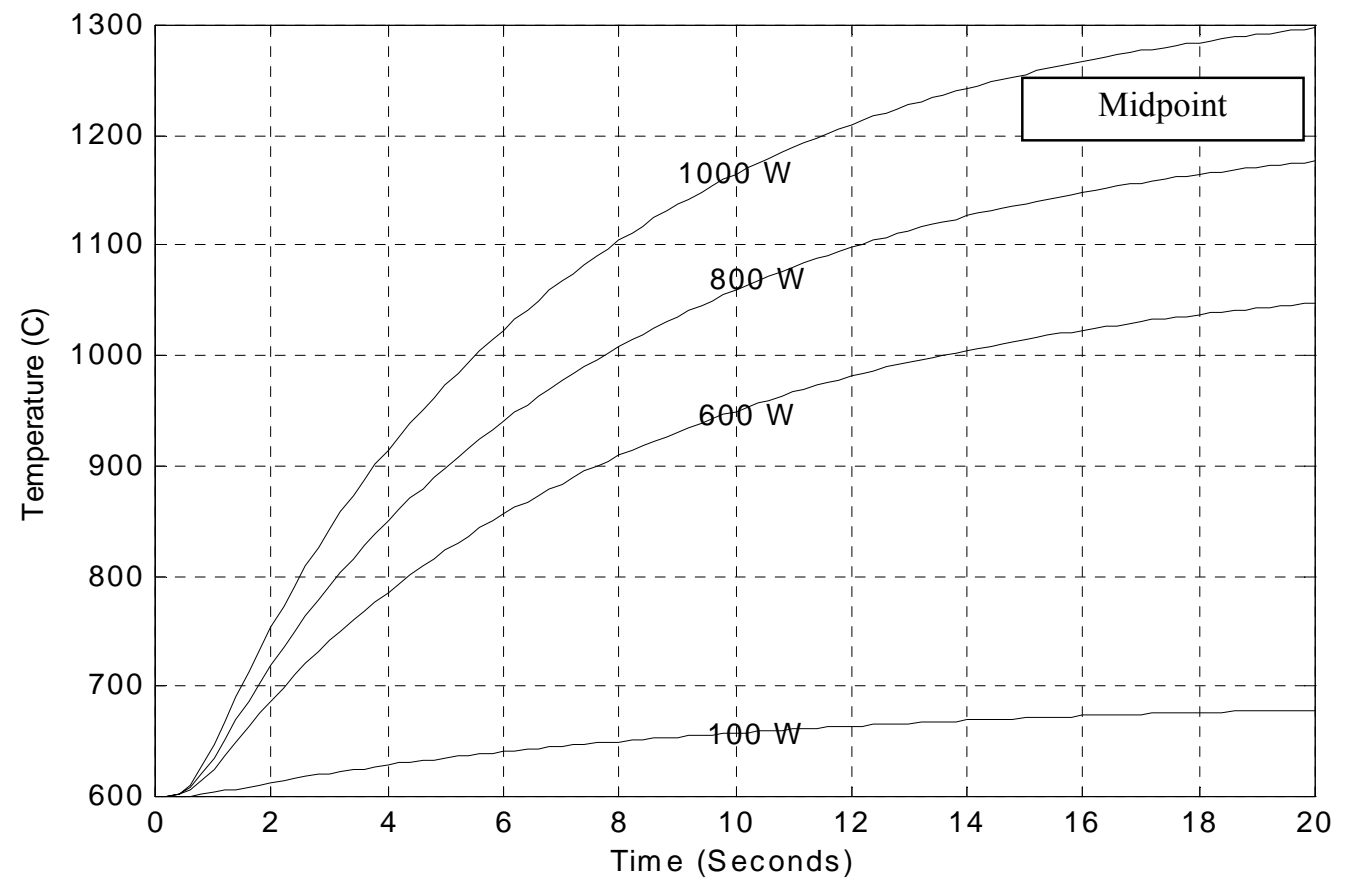

Figure 4.13 Effect of Laser Power on Average Temperature Response $\left(r=1 / 2\left(r_{1}+r_{2}\right), z=z_{1}\right)$

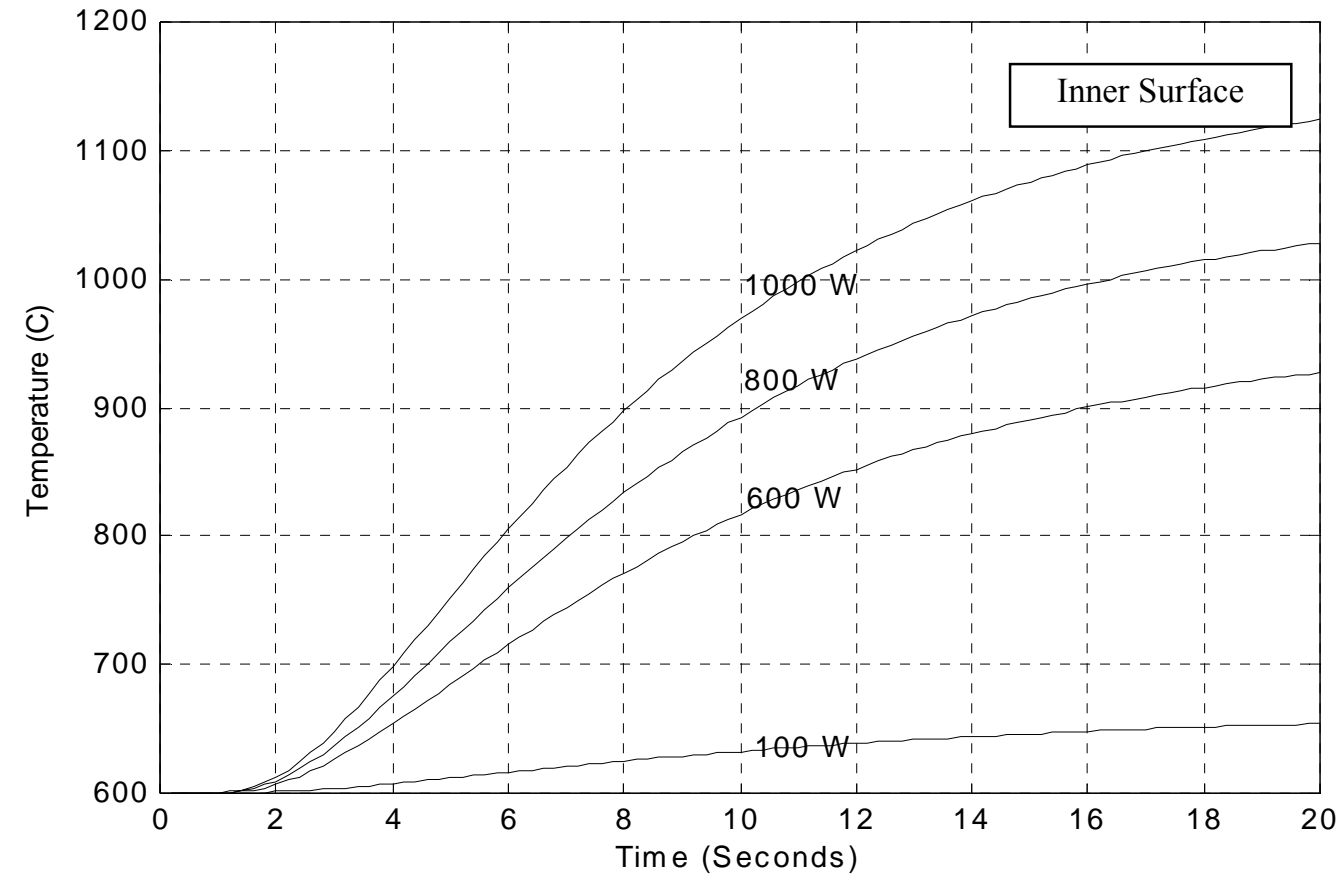

Figure 4.14 Effect of Laser Power on Average Temperature Response $\left(r=r_{1} \quad z=z_{1}\right)$ 
It was found that increasing the laser power has a significant effect on the temperature behavior. The higher the laser power, the higher the temperature of the glassware, and the deeper the heat can penetrate. It was concluded that increasing the laser power is definitely beneficial to laser cutting. The increase of temperature in the glassware surface is much more significant than the temperature increase inside the glassware at the early stage of laser glass interaction. The reason for this is that the interaction that happens in the surface and the temperature increase in the surface are dominantly due to the laser energy input, while the temperature increase inside the glass is mainly due to the heat conduction. Although, inside the glassware, there is energy input directly from the laser due to laser energy transmission, the amount is very limited. Another reason is that glass has a low thermal conductivity when its temperature is low, thus, there is no much heat conduction from the surface.

Two-dimensional temperature image and the temperature profile in the rz plane were computed using the Matlab toolbox and using the data from the simulation. These images and profiles visually show the heat propagation and melting front propagation toward the glassware inner side wall. The melting front is defined by the $1200{ }^{\circ} \mathrm{C}$ temperature profile. The temperature profile in the rz plane is critical information to describe the process of laser glass cutting in terms of heating, melting and vaporizing. The temperature images and profiles at two points in laser glass interaction time, 5 seconds and 15 seconds, are shown in Figure 4.15 to 4.22. Two levels of laser power, $600 \mathrm{~W}$ and $1000 \mathrm{~W}$, were considered in the simulation. It was found that increasing laser power helps the heat propagation and melting front propagation. For example, at time 15 seconds, melting front is $1.4 \mathrm{~mm}$ in depth for $600 \mathrm{~W}$ laser power and $3 \mathrm{~mm}$ in depth for $1000 \mathrm{~W}$ laser power. 


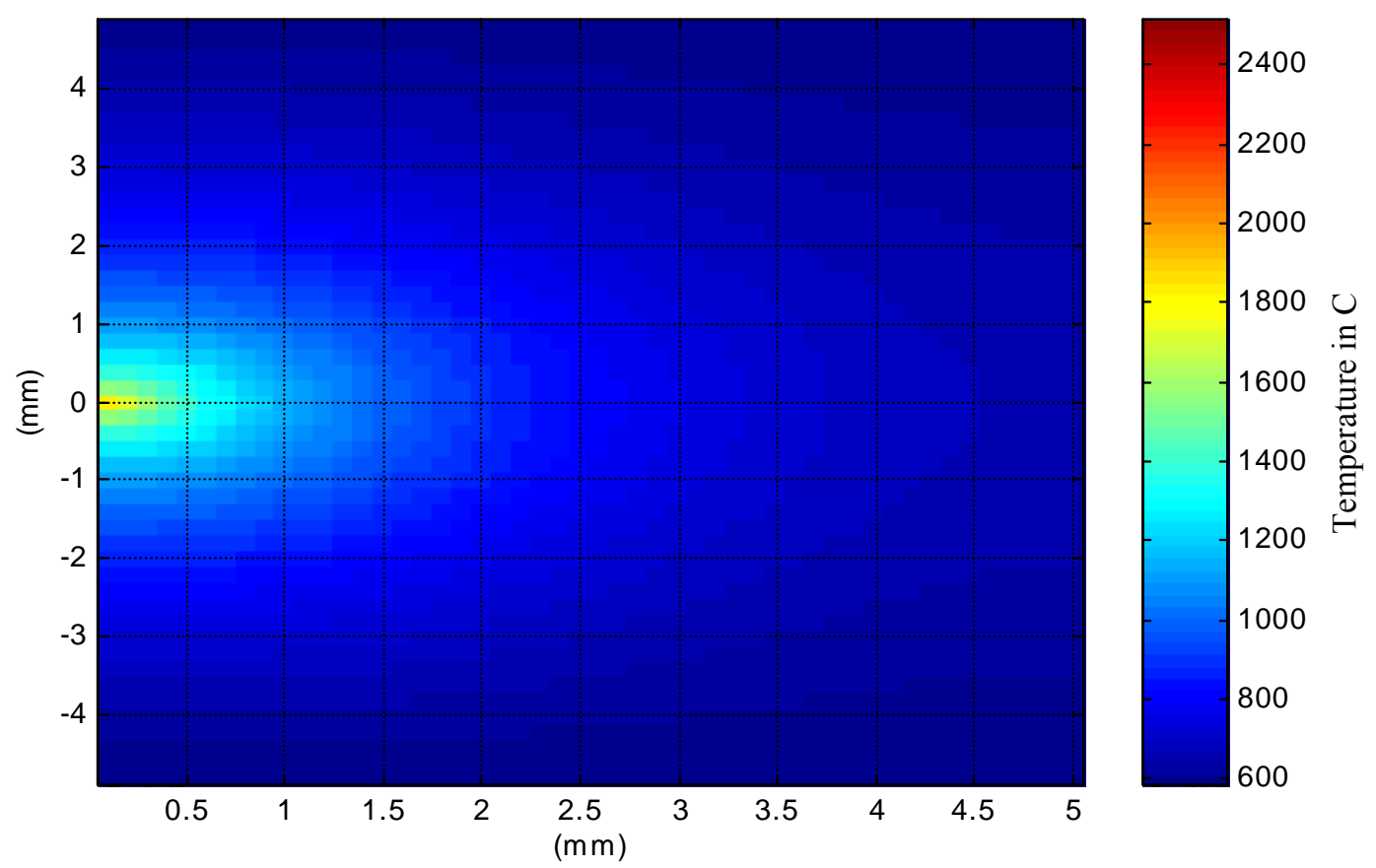

Figure 4.15 Temperature Image at 5 seconds $\left(P=600 \mathrm{~W}, D_{0}=95 \mathrm{~mm}, d_{0}=5 \mathrm{~mm}\right)$

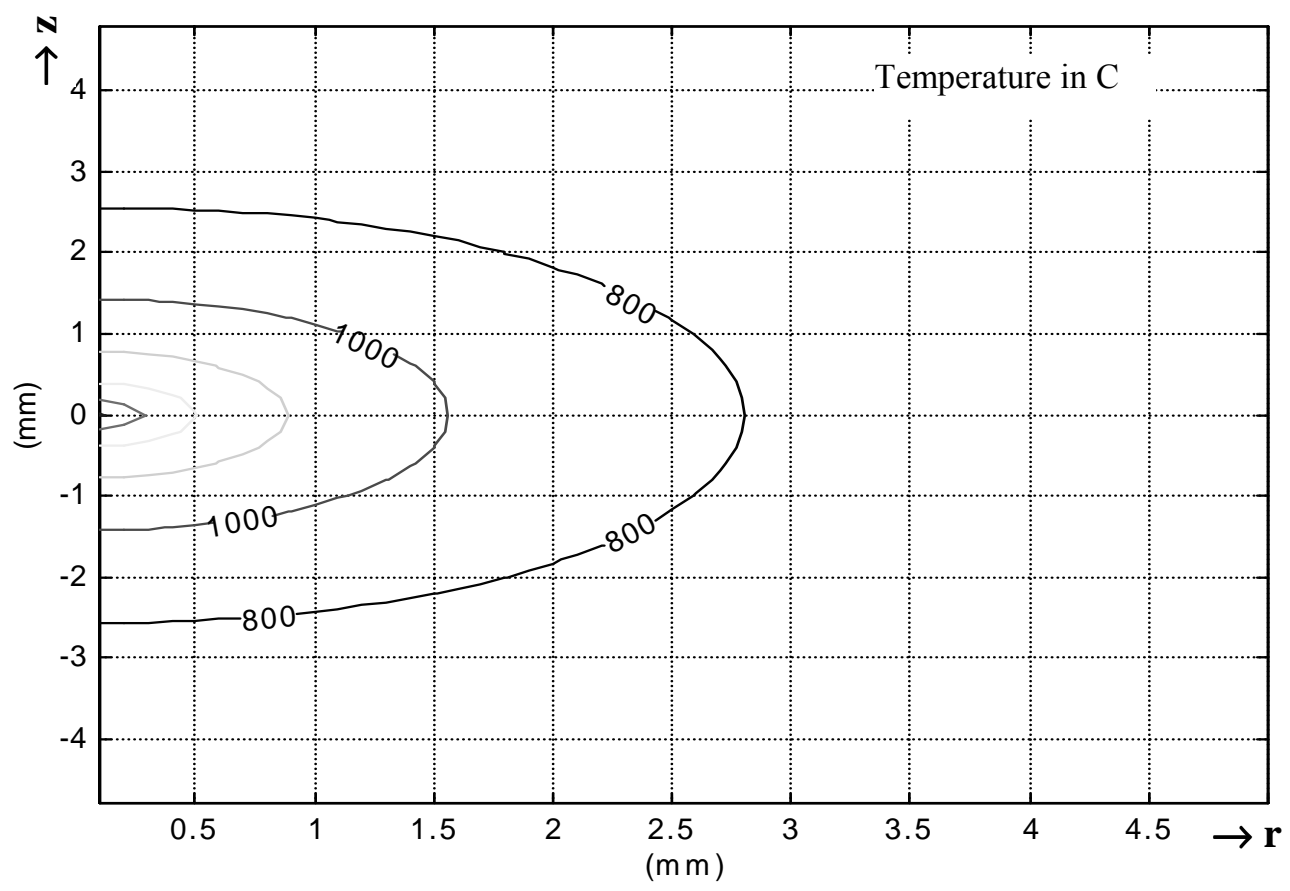

Figure 4.16 Temperature Profile at 5 seconds $\left(P=600 \mathrm{~W}, D_{0}=95 \mathrm{~mm}, d_{0}=5 \mathrm{~mm}\right)$ 


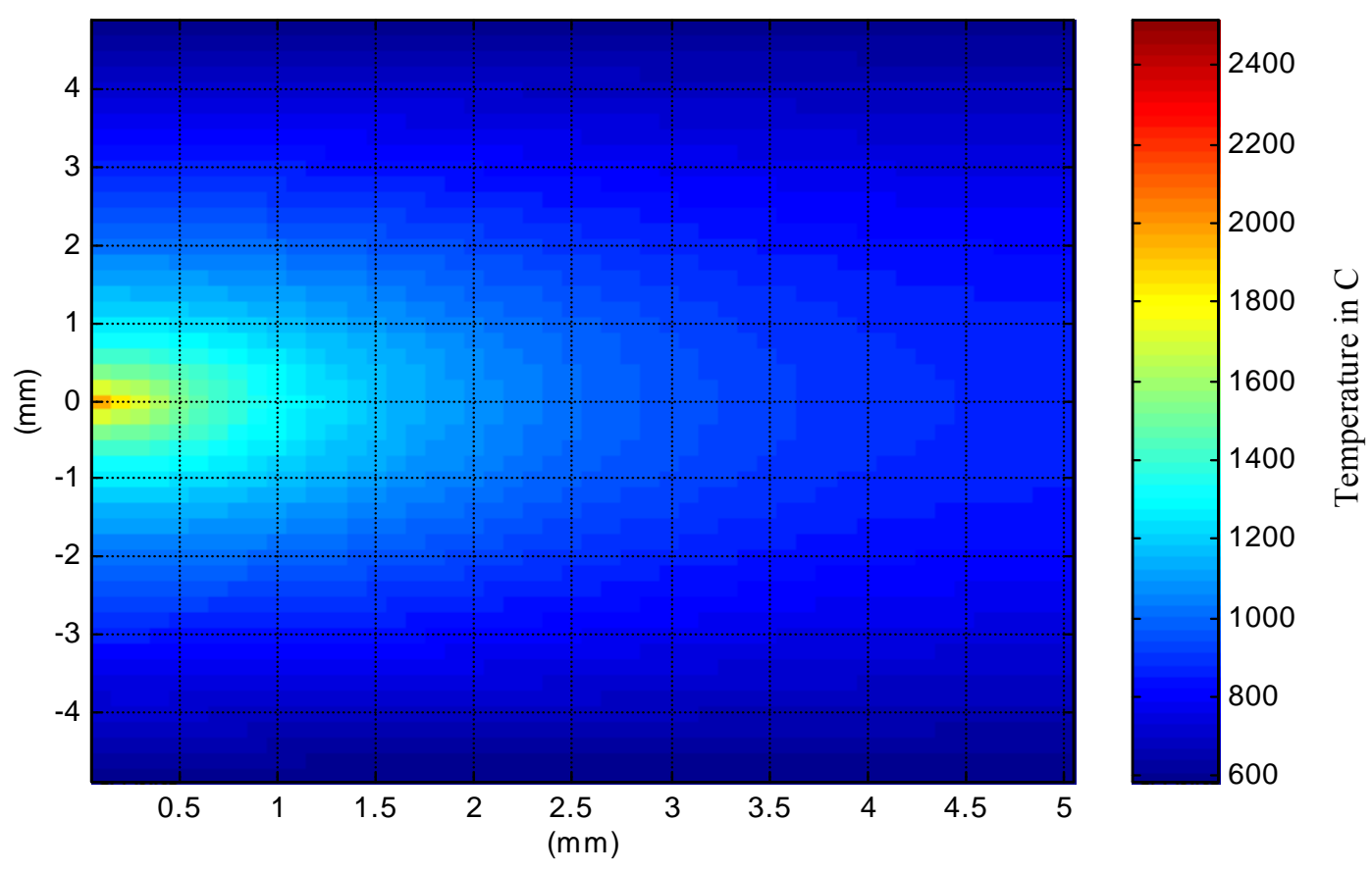

Figure 4.17 Temperature Image at 15 seconds $\left(P=600 \mathrm{~W}, D_{0}=95 \mathrm{~mm}, d_{0}=5 \mathrm{~mm}\right)$

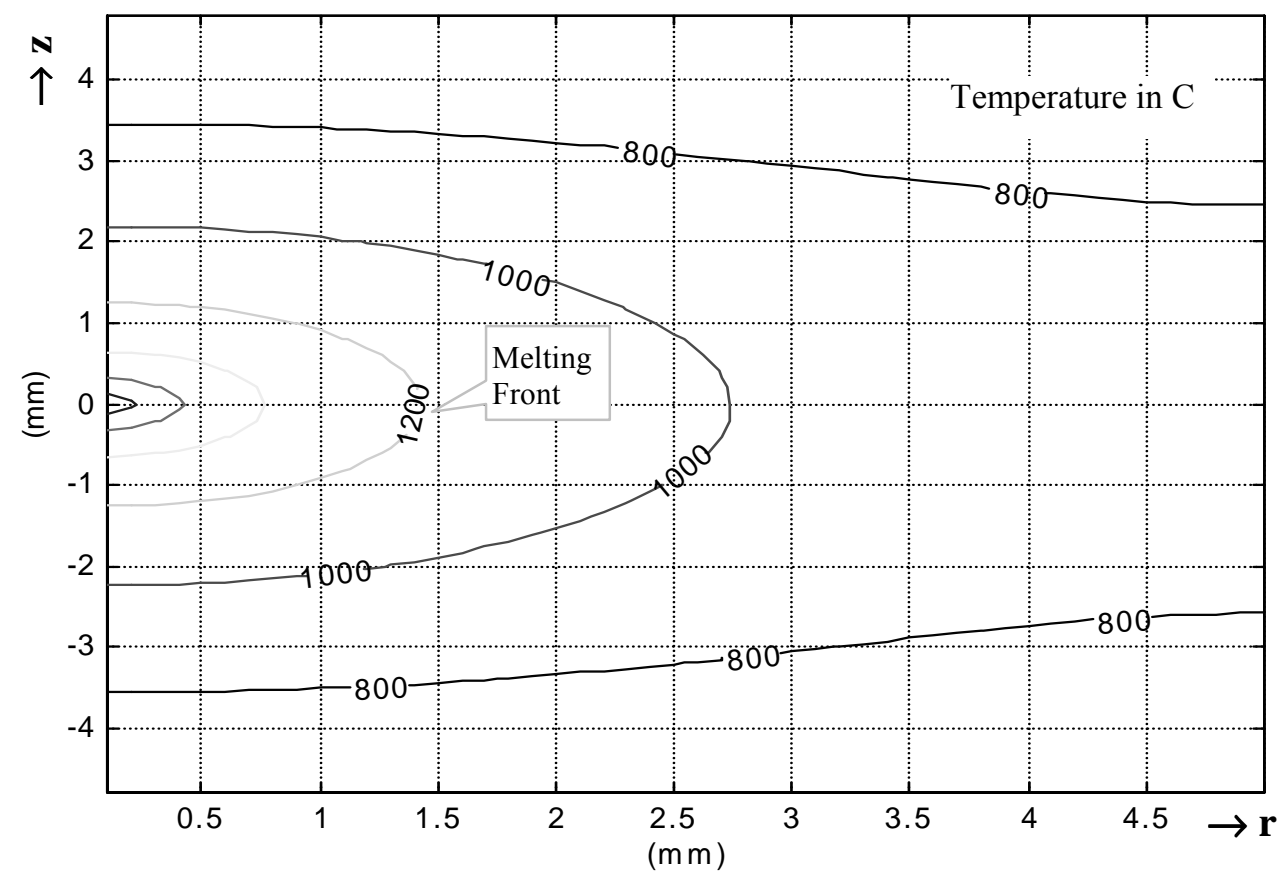

Figure 4.18 Temperature Profile at 15 seconds $\left(P=600 \mathrm{~W}, D_{0}=95 \mathrm{~mm}, d_{0}=5 \mathrm{~mm}\right)$ 


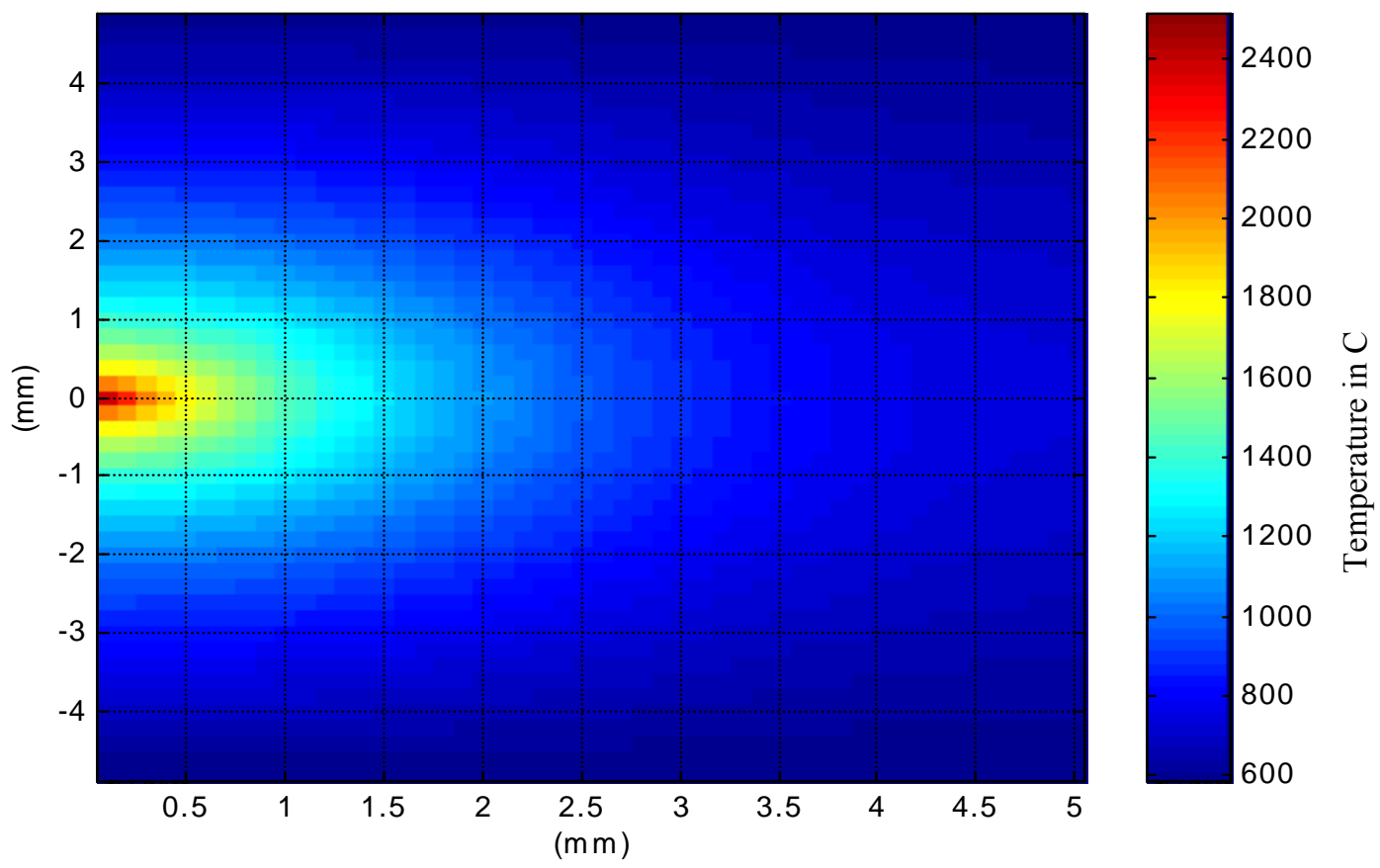

Figure 4.19 Temperature Image at 5 seconds $\left(P=1000 \mathrm{~W}, D_{0}=95 \mathrm{~mm}, d_{0}=5 \mathrm{~mm}\right)$

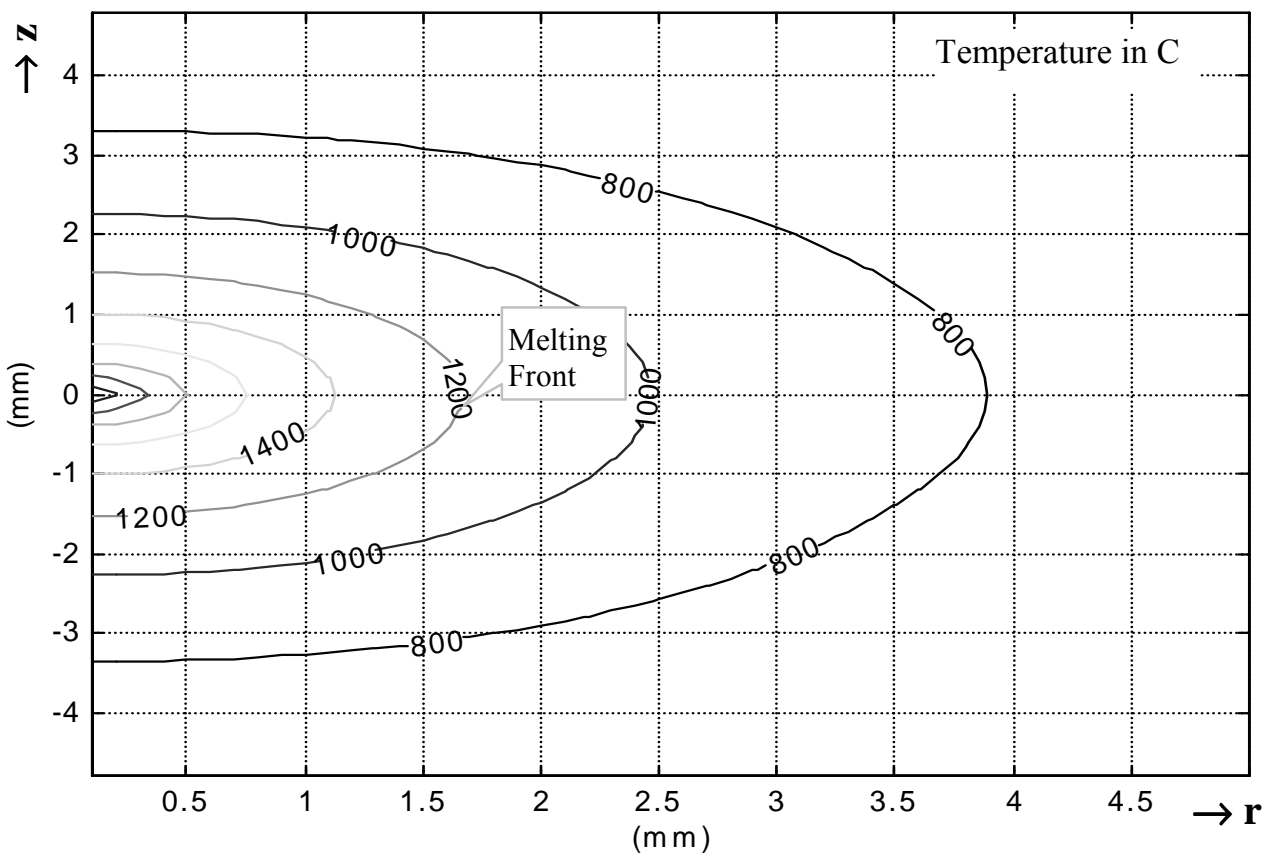

Figure 4.20 Temperature Profile at 5 seconds $\left(P=1000 \mathrm{~W}, D_{0}=95 \mathrm{~mm}, d_{0}=5 \mathrm{~mm}\right)$ 


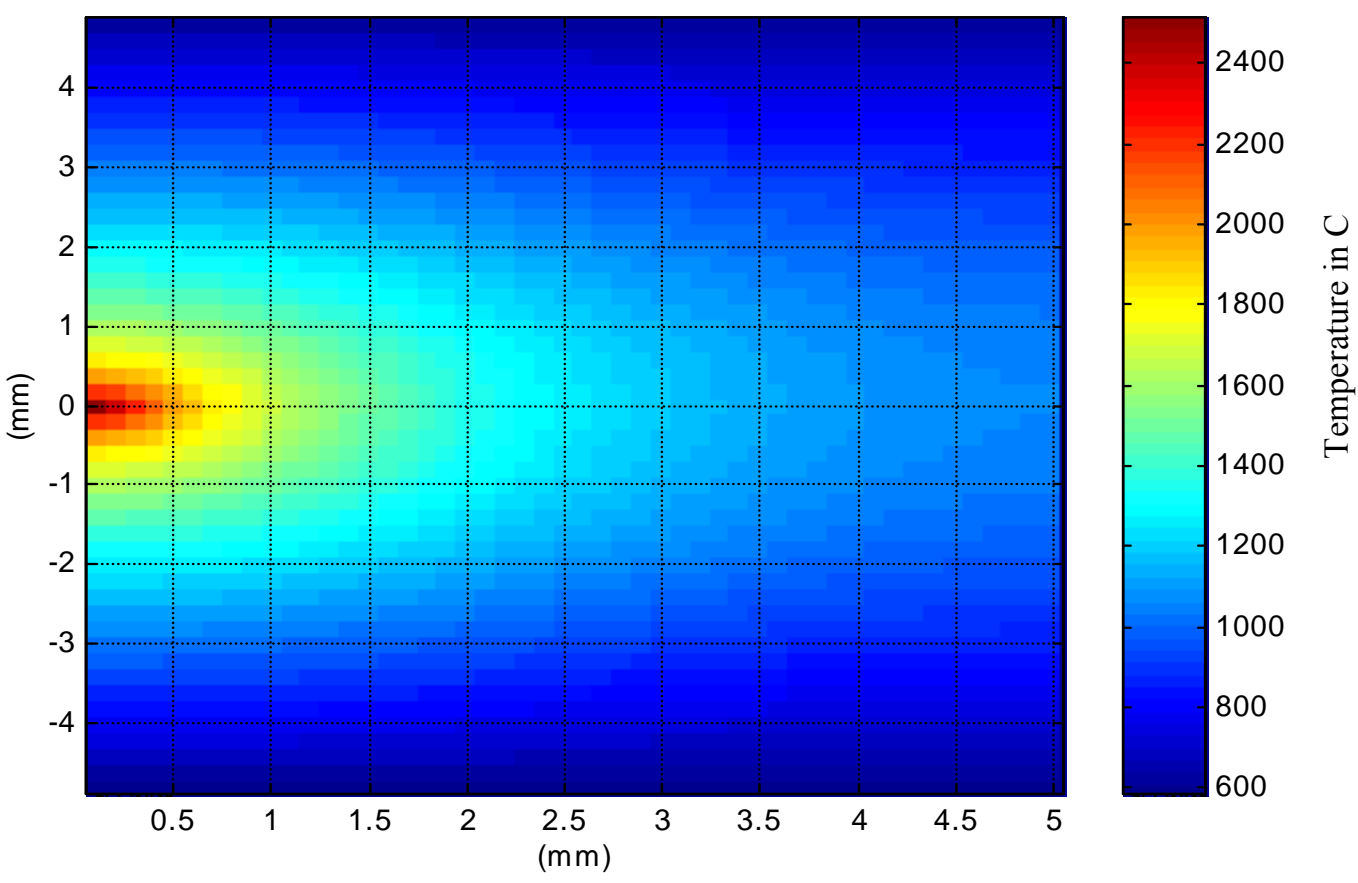

Figure 4.21 Temperature Image at $15 \operatorname{seconds}\left(P=1000 \mathrm{~W}, D_{0}=95 \mathrm{~mm}, d_{0}=5 \mathrm{~mm}\right)$

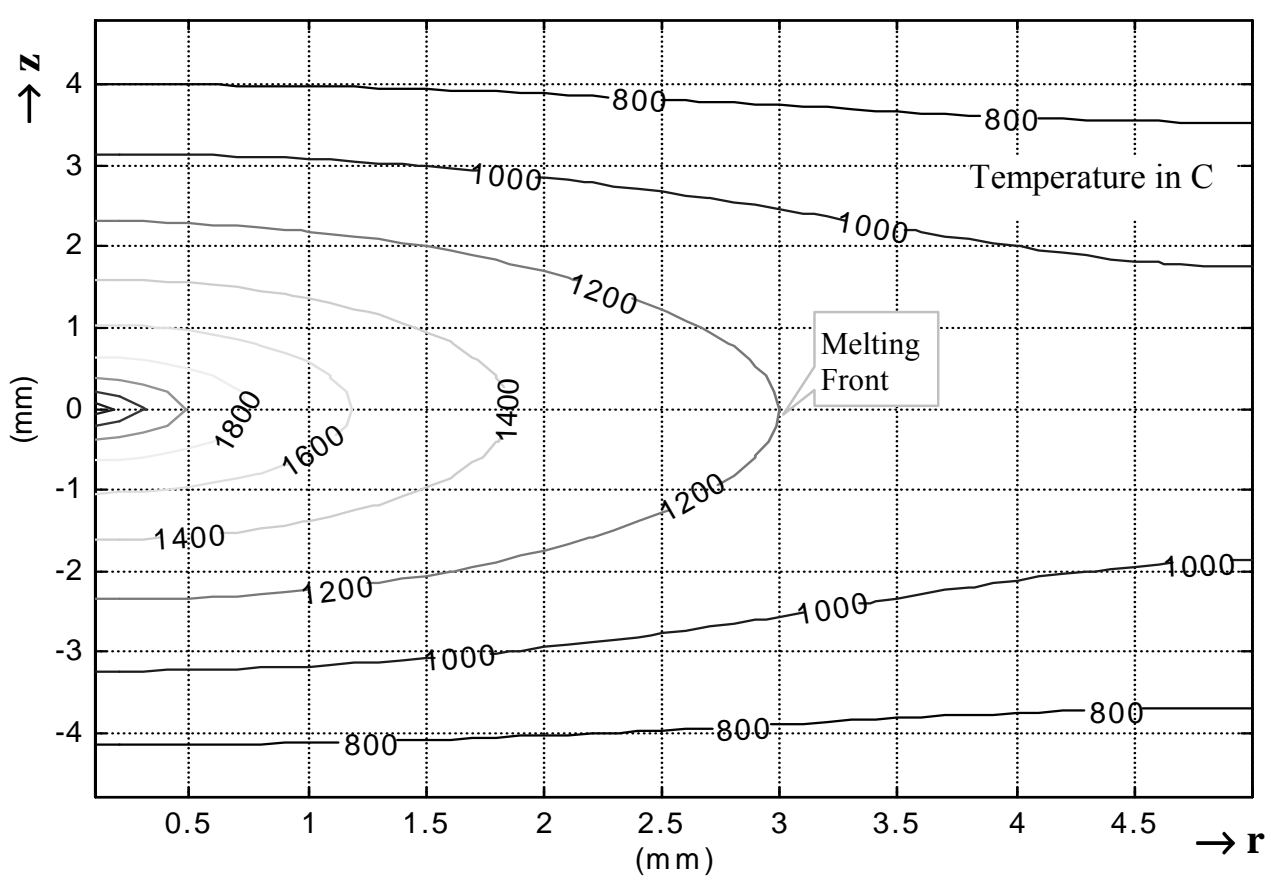

Figure 4.22 Temperature Profile at 15 seconds $\left(P=1000 \mathrm{~W}, D_{0}=95 \mathrm{~mm}, d_{0}=5 \mathrm{~mm}\right)$ 


\subsubsection{Effect of Glassware Size}

The effect of glassware size was also investigated. In addition to the parameters listed in the Table 4.3, the laser power was $1000 \mathrm{~W}$, the glassware rotation speed was one revolution per second, and the wall thickness was $5 \mathrm{~mm}$. The glassware diameter was $80 \mathrm{~mm}$ instead of 95 $\mathrm{mm}$. The simulation duration was 20 seconds.

Temperature images and profiles at two points of interaction time, 5 seconds and 15 seconds, are shown in the Figures 4.23 to 4.26 . These results were compared to the results shown in Figures 4.19 to 4.22, which came from the simulation under the same conditions as that for the simulation discussed in this section except that the glassware diameter was smaller.

It is noted that the glassware diameter has an effect on the heat penetration, and thus the laser glass cutting. If the isothermal curve with a temperature of $1200{ }^{\circ} \mathrm{C}$ were used to represent the melting zone frontier, the melting zone depth $\mathrm{D}_{\mathrm{m}}$ in the $\mathrm{r}$ axis direction and melting zone width $\mathrm{W}_{\mathrm{m}}$ in the $\mathrm{z}$ axis direction can be computed, as shown in Table 4.4.

Table 4.4 Melting Zone Computations

\begin{tabular}{||c|c|c|c|c|c||}
\hline GLASSWARE DIA & MEASURAND & $5 \mathrm{~s}$ & $10 \mathrm{~s}$ & $15 \mathrm{~s}$ & $20 \mathrm{~s}$ \\
\hline \multirow{2}{*}{$80 \mathrm{~mm}$} & $\mathrm{~W}_{\mathrm{m}}(\mathrm{mm})$ & 3.6 & 4.8 & 5.2 & 5.4 \\
\cline { 2 - 6 } & $\mathrm{D}_{\mathrm{m}}(\mathrm{mm})$ & 2.0 & 3.0 & 4.0 & $>5.0$ \\
\hline \multirow{2}{*}{$95 \mathrm{~mm}$} & $\mathrm{~W}_{\mathrm{m}}(\mathrm{mm})$ & 3.0 & 4.1 & 4.6 & 4.9 \\
\cline { 2 - 6 } & $\mathrm{D}_{\mathrm{m}}(\mathrm{mm})$ & 1.7 & 2.4 & 3.0 & 3.4 \\
\hline
\end{tabular}




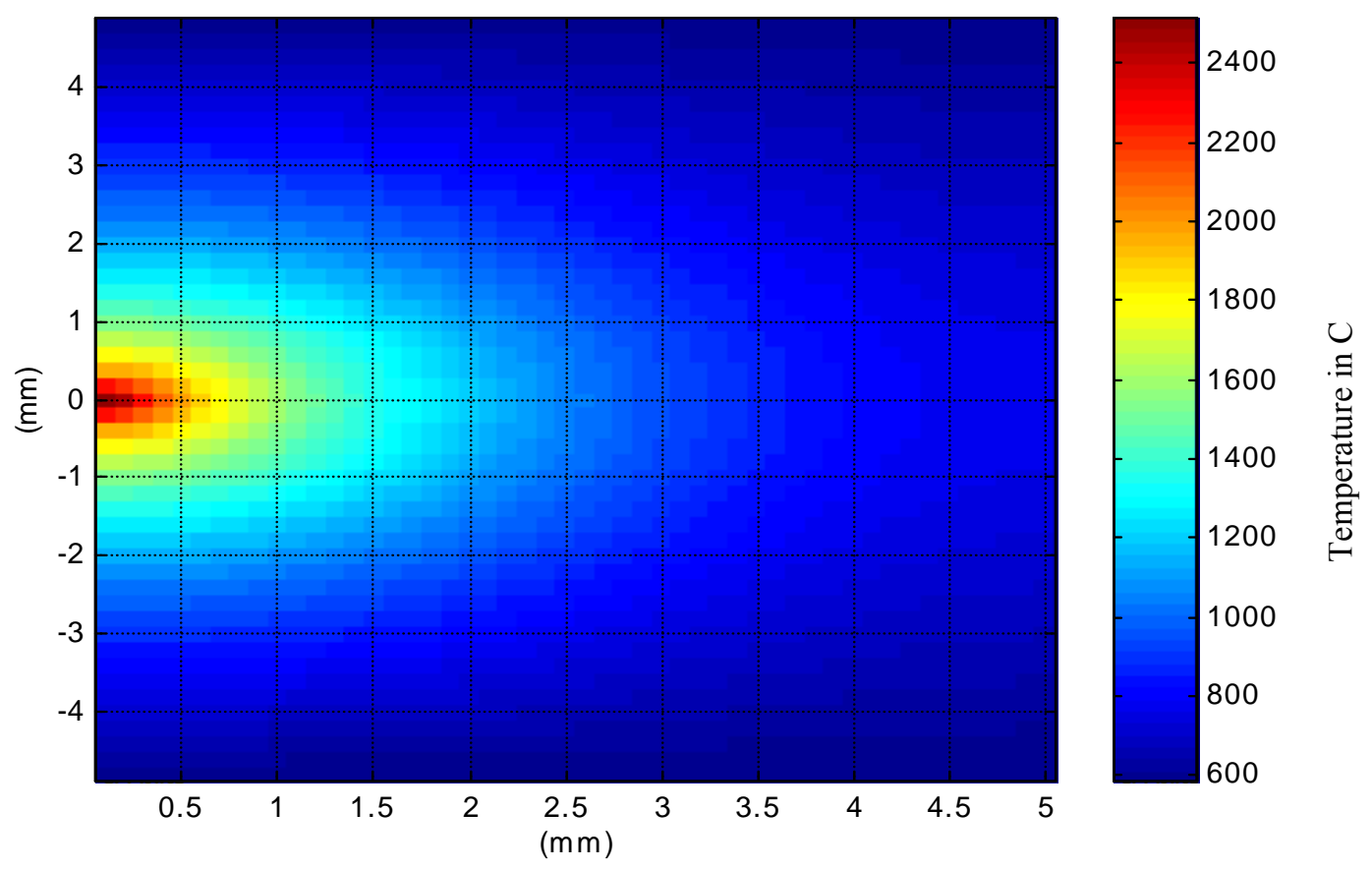

Figure 4.23 Temperature Image at 5 Seconds $\left(P=1000 \mathrm{~W}, D_{0}=80 \mathrm{~mm}, d_{0}=5 \mathrm{~mm}\right)$

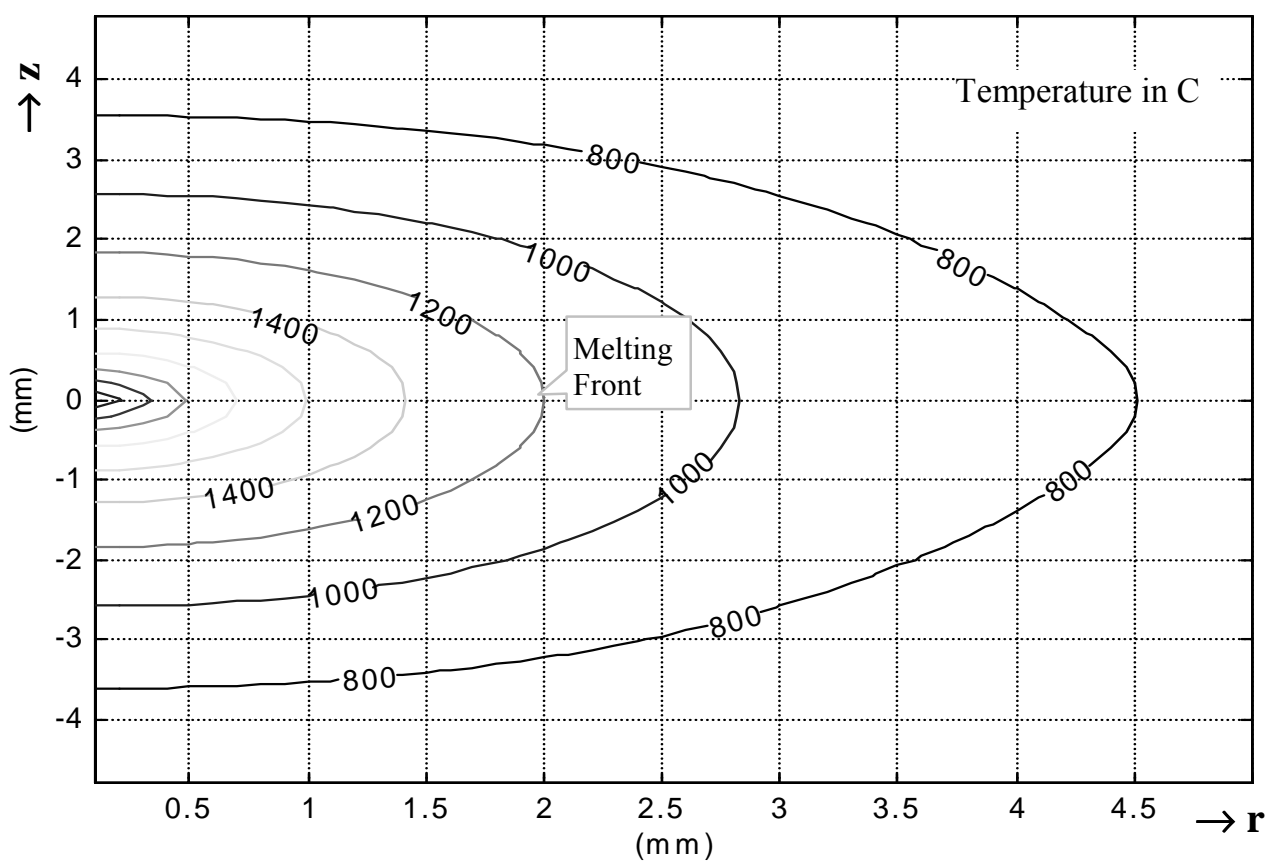

Figure 4.24 Temperature Profile at 5 Seconds $\left(P=1000 \mathrm{~W}, D_{0}=80 \mathrm{~mm}, d_{0}=5 \mathrm{~mm}\right)$ 


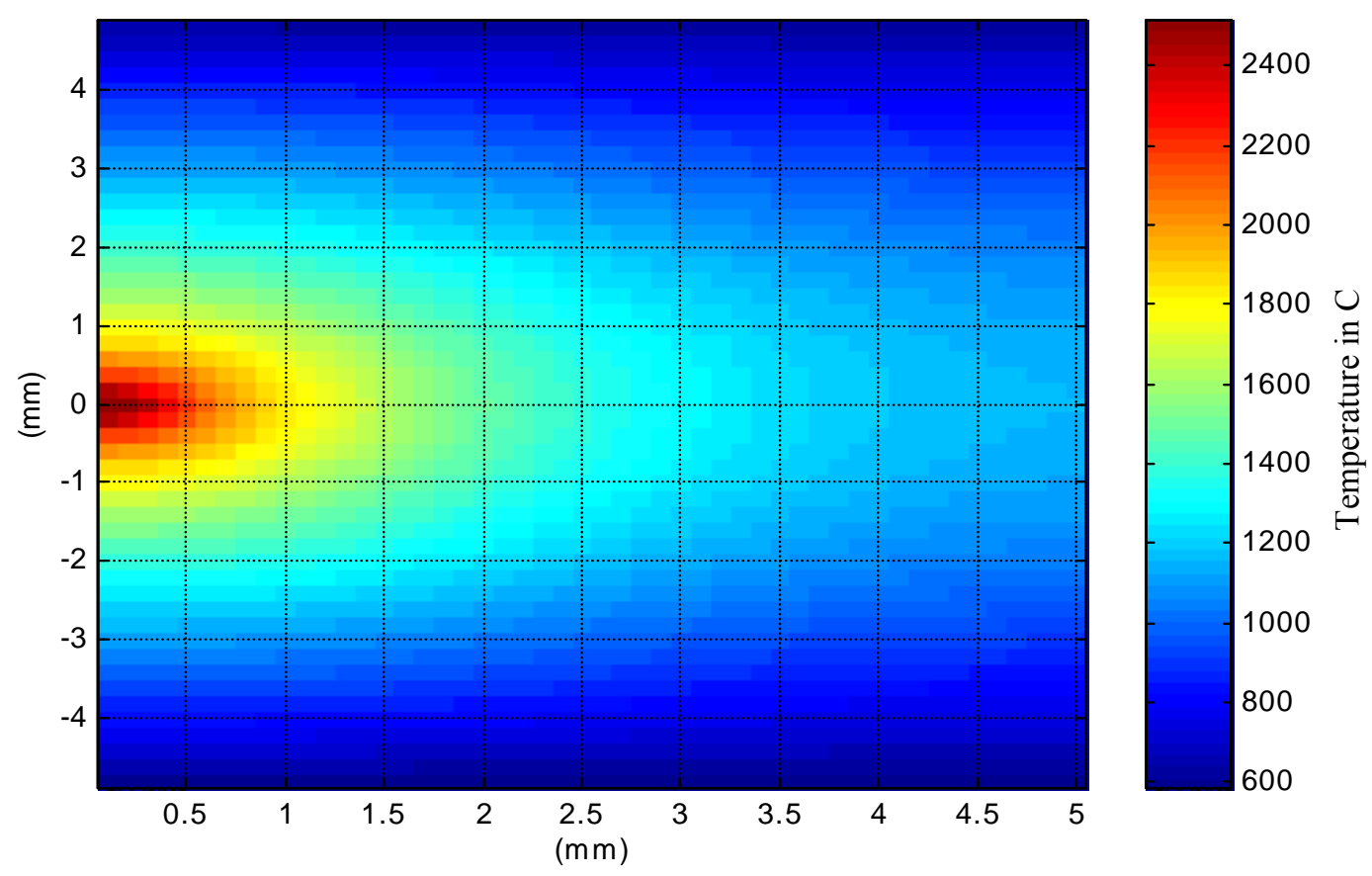

Figure 4.25 Temperature Image at 15 Seconds $\left(P=1000 \mathrm{~W}, D_{0}=80 \mathrm{~mm}, d_{0}=5 \mathrm{~mm}\right)$

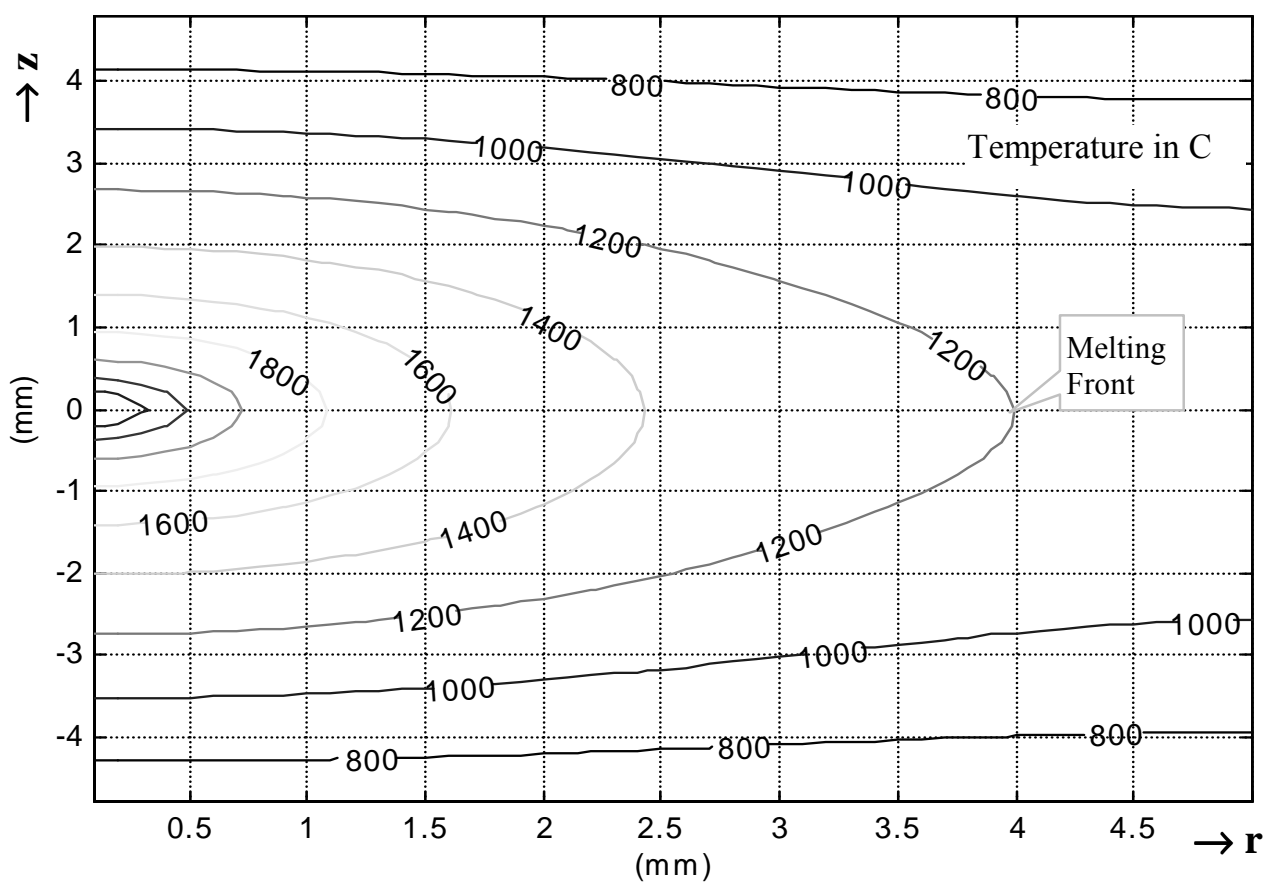

Figure 4.26 Temperature Profile at $15 \operatorname{Seconds}\left(P=1000 \mathrm{~W}, D_{0}=80 \mathrm{~mm}, d_{0}=5 \mathrm{~mm}\right)$ 


\subsubsection{Effect of Glassware Wall Thickness}

The effect of the glassware wall thickness was also investigated. In addition to the parameters listed in the Table 4.3, the laser power was $1000 \mathrm{~W}$, the glassware rotation speed was one revolution per second, and the glassware diameter was $80 \mathrm{~mm}$. The glassware wall thickness was $3 \mathrm{~mm}$ instead of $5 \mathrm{~mm}$. The simulation duration was 20 seconds.

Temperature images and temperature profiles in rz plane were created using a Matlab toolbox and using the data from the simulation. Temperature images and profiles at two points in interaction time, 5 seconds and 15 seconds, are shown in the Figures 4.27 to 4.30 . These results were compared to the results shown in Figures 4.23 to 4.26 , which came from the simulation under the same conditions as the simulation discussed in Section 4.3.3.3 except the glassware wall was thinner.

It is noted that the glassware thickness has an effect on the heat penetration, and thus the laser glass cutting. At 5 seconds, the melting zone depth is about $2.2 \mathrm{~mm}$ when the glassware thickness is $3 \mathrm{~mm}$, while it is about $2.0 \mathrm{~mm}$ when the glassware thickness is $5 \mathrm{~mm}$. At a time of 10 seconds, the melting zone depth is beyond $3 \mathrm{~mm}$ when the glassware wall thickness is $3 \mathrm{~mm}$, meaning that the melting frontier has already reached the inner surface of the wall, while it has barely reached to $3 \mathrm{~mm}$ when the glassware is $5 \mathrm{~mm}$ in thickness.

It was determined that for a typical glassware with a diameter of $80 \mathrm{~mm}$ and a thickness of $3 \mathrm{~mm}$, it will take about 8 seconds to melting through the glass with a $1000 \mathrm{~W}$ laser. This result is to be verified by experiment, and the verification is discussed in Section 6.1.1 in Chapter 6. 


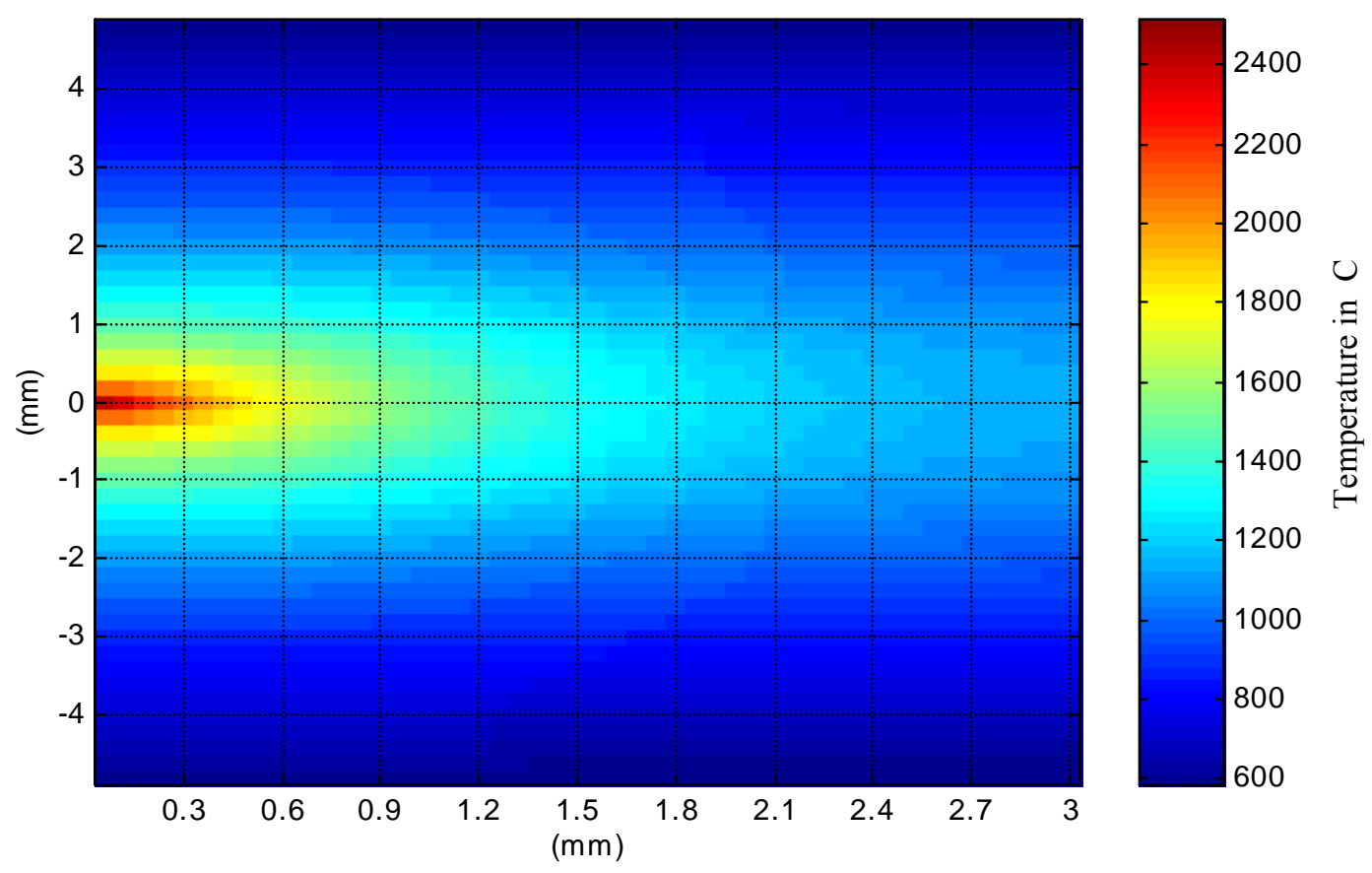

Figure 4.27 Temperature Image at 5 Seconds $\left(P=1000 \mathrm{~W}, D_{0}=80 \mathrm{~mm}, d_{0}=3 \mathrm{~mm}\right)$

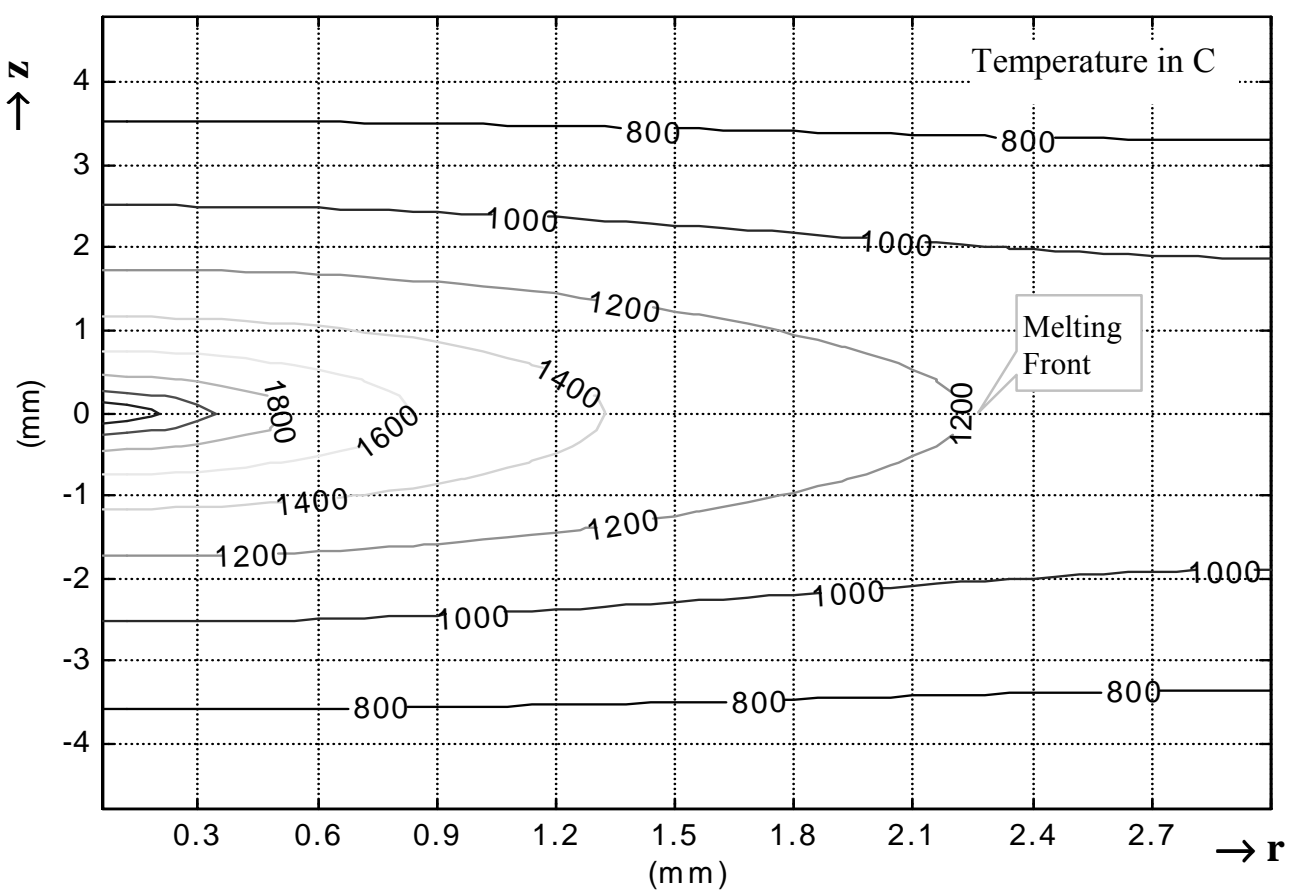

Figure 4.28 Temperature Profile at 5 Seconds $\left(P=1000 \mathrm{~W}, D_{0}=80 \mathrm{~mm}, d_{0}=3 \mathrm{~mm}\right)$ 


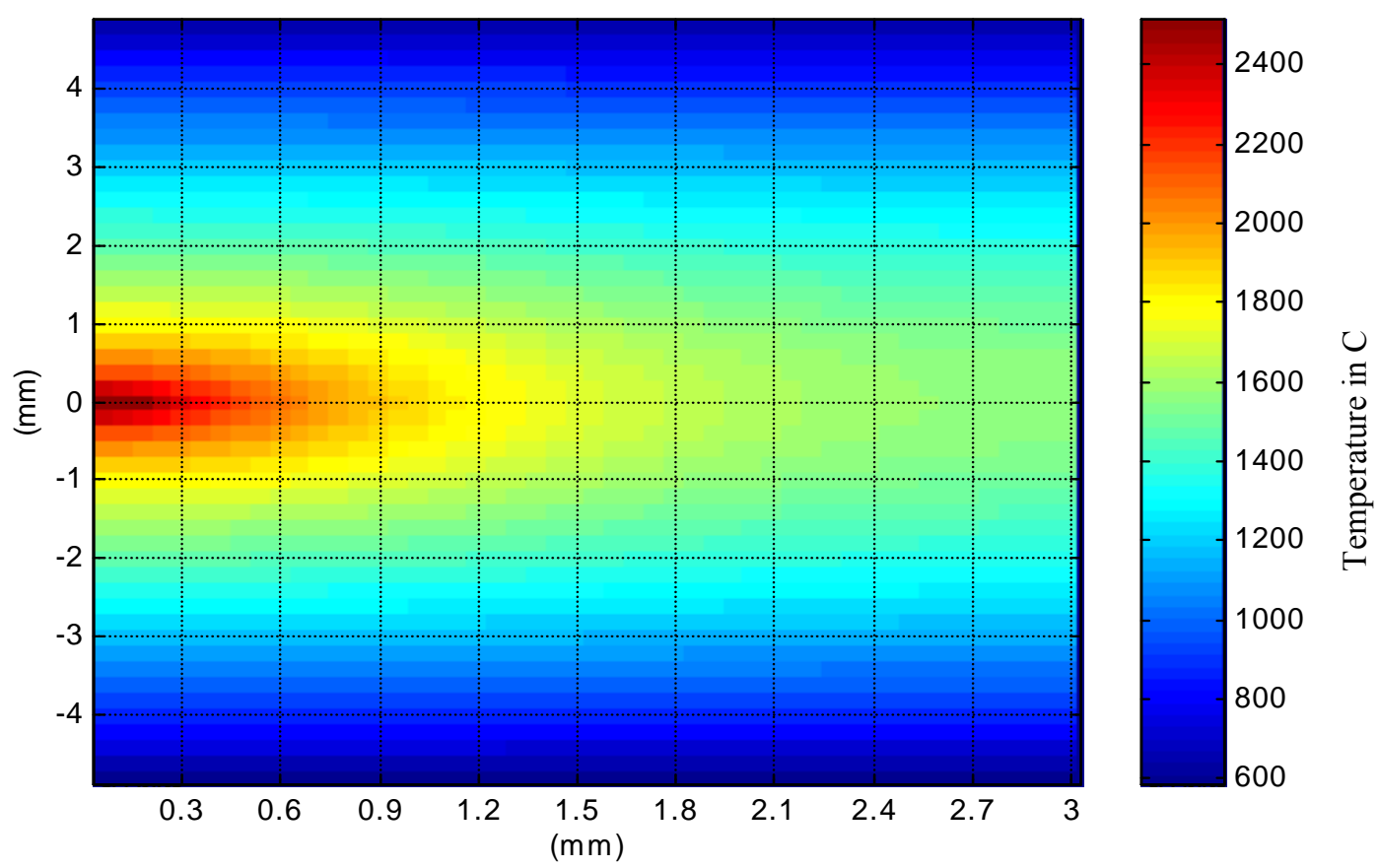

Figure 4.29 Temperature Image at 15 Seconds $\left(P=1000 \mathrm{~W}, D_{0}=80 \mathrm{~mm}, d_{0}=3 \mathrm{~mm}\right)$

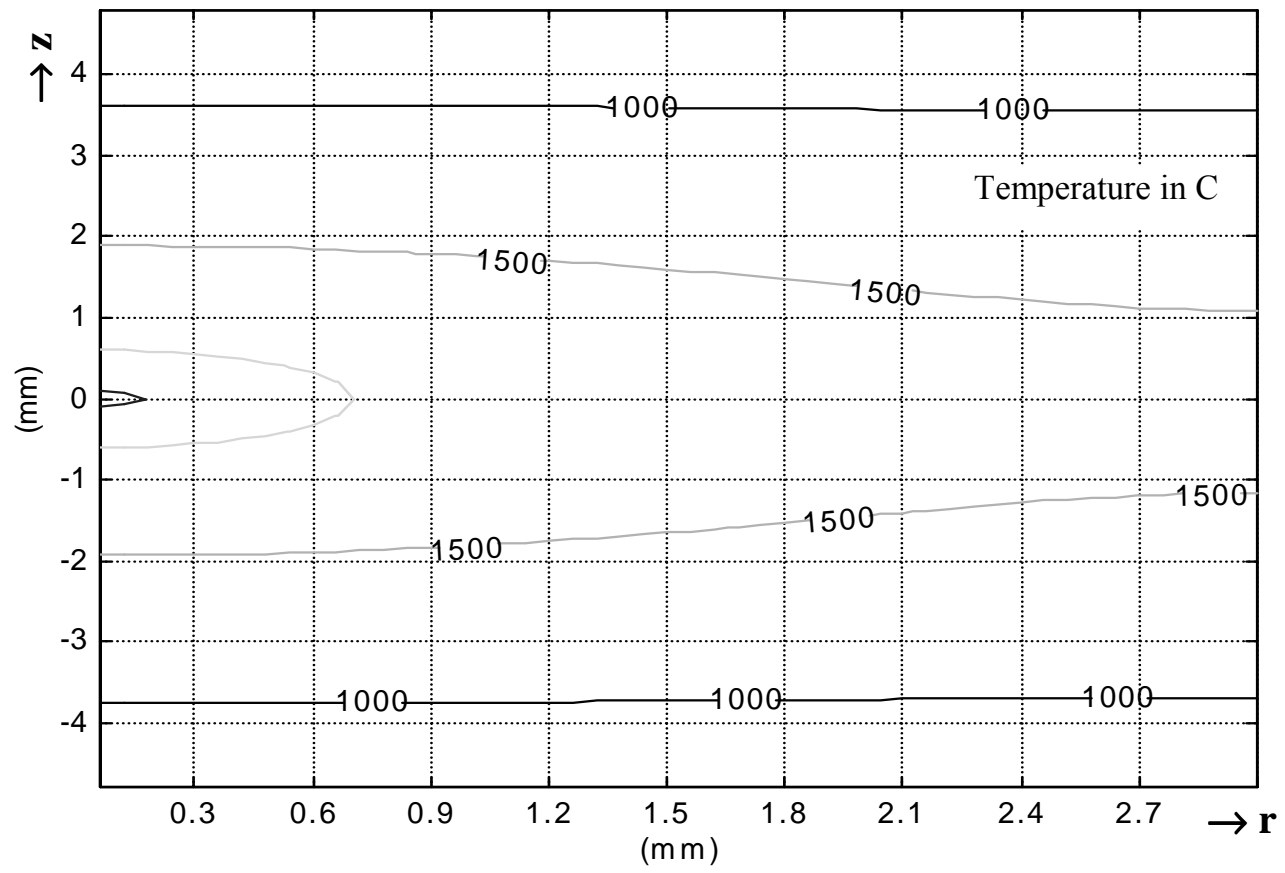

Figure 4.30 Temperature Profile at 15 Seconds $\left(P=1000 \mathrm{~W}, D_{0}=80 \mathrm{~mm}, d_{0}=3 \mathrm{~mm}\right)$ 


\subsubsection{Discussion}

There are two types of energy loss that are not considered in the simulation. The first type of energy loss is that due to vaporization. The second type of energy loss is due to radiation.

In the 3-D model, the vaporization phenomenon of glass could not be incorporated. It is known that vaporization will consume energy from the laser input. However, the phenomenon associated with this energy loss is not very known. There is almost no information about such specifics as the vaporization temperature or vaporization energy in the literature and are not easy to be found by experiment. Also, there is no critical vaporization point for glass since it is always a liquid. The vaporization of glass actually refers to the decomposition of the glass into its constituents. This makes an estimation of energy due to vaporization extremely difficult. One literature source estimated that glass starts vaporization (decomposition) at the temperature of $1500{ }^{\circ} \mathrm{C}$. It was thus decided that at this time there was no appropriate way to determine energy loss associated with vaporization or to determine the vaporization front from the temperature profile obtained in the simulation.

In the modeling and simulation of laser glass cutting, heat convection between the ambient air and the glass surface is considered by specifying that the convection coefficient is 10 $\mathrm{W} / \mathrm{m}^{2} . \mathrm{k}$, since the range of convection coefficients between glass and air is $5 \sim 20 \mathrm{~W} / \mathrm{m}^{2} . \mathrm{k}$ [12]. The energy loss due to the heat convection does not exceed $6 \%$ of the absorbed laser power [43]. More detail about the heat convection and its effect in laser glass interaction simulation was presented in Appendix C. 
The energy loss due to radiation from glassware is also assumed to not exceed $6 \%$ of the absorbed laser power. The estimation of the radiation energy loss and its effect on the laser glass interaction simulation was presented in Appendix D.

The inability to consider the energy loss due to vaporization will introduce some error in the simulation results, but only in the limited glass area where vaporization occurs. The error associated with not including energy loss due to radiation is considered insignificant. 


\section{EXPERIMENTS ON LASER GLASS CUTTING}

\subsection{INTRODUCTION}

Experiments are an effective method that will be used in this research to 1) confirm the capability and functionality of the lab prototype machine, 2) gain knowledge of the laser glass interaction, 3) validate the heat conduction simulation model, and 4) develop the models for process control.

First, the capability and functionality of the lab prototype machine need to be confirmed. The lab prototype machine is expected to have the capability to cut glassware using the proposed laser cutting method. The proposed cutting method is to cut glassware using melting and vaporizing mechanism. This melting and/or vaporizing are caused by the radiation of the highly concentrated $\mathrm{CO}_{2}$ laser. A pulling force is expected in this method to get the eventual separation of the glassware. In achieving this capability, each machine component should function properly. For example, the laser generator should be able to output the laser beam in the required mode and at the required power level; In addition, the beam guiding subsystem should be able to deliver the laser to the right place on the glassware to be cut, and the lathe should be able to rotate the glassware at the required speed. The initial laser glass cutting experiments were conducted at the National Energy Technology Laboratory (NETL) in Morgantown, WV, with the lab prototype machine incorporated with a $100 \mathrm{~W} \mathrm{CO}_{2}$ laser. Laser glass cutting 
experiments with the lab prototype machine incorporated with a 400 to $4000 \mathrm{~W}$ power laser were conducted at the Laser Processing Company (LPC) near Morgantown, WV.

Second, knowledge about laser glass cutting needs to be gained. Although there is plenty of literature and knowledge of laser cutting, the knowledge about laser glass cutting is very limited, especially the knowledge about the laser cutting that uses glass melting and/or vaporization. The knowledge about such phenomena as the temperature behavior, glass melting, vaporization, and the mass transfer are important to both the understanding and implementation of the laser glass cutting.

Third, experiments are needed to validate the heat conduction model embedded in the simulation of laser glass interaction that was discussed in detail in Chapter 3 and Chapter 4 . The results produced by the simulation can be given confidence and can be used to analyze the process only after the model is validated.

Fourth, experiments are needed to validate the process control model. It is impossible to find the process control model of laser glass cutting model by the analytical method due to the complexity of the laser glass cutting process. Therefore, a simulation method was used to define one of the process control models, model that is used to predict the required laser power and the melting depth as a function of time (see Section 6.1.1 of Chapter 6). The validity of this model was verified by experiments.

In this chapter, most of the aspects of the experiments will be discussed. It includes the experiment setup, experiment procedure, experiment results, and data analysis. 


\subsection{EXPERIMENT SETUP}

\subsubsection{Machine Requirements}

Successful application of laser glass cutting is largely a result of the ability of the laser glass cutting machine. To satisfy the requirements of the laser cutting, the laser glass cutting machine should include the following components or subsystems:

a $\mathrm{CO}_{2}$ laser generator. The $\mathrm{CO}_{2}$ laser must be powerful enough to support process productivity and product finishing goals. The power of the laser must be adjustable to meet the variable power requirement;

a Laser delivery subsystem. The laser delivery subsystem must be shielded to avoid the contamination of mirror and irradiation of laser beam;

a Mechanical motion subsystem. The mechanical motion subsystem must be sufficiently rigid at glassware processing speed to meet the finishing and part repeatability requirements;

- Workpiece fixturing. The fixture must be specifically designed to hold the glassware in position during processing and to avoid stress concentration to potentially cause cracking of the glassware;

a Preheating subsystem. The preheating subsystem must be sufficient to preheat the glassware to the annealing temperature to avoid stress-induced cracking of the glassware in the lab environment. Preheating may not be necessary in the plant hot shop; 
a Pulling mechanism. The pulling mechanism must have the capability to produce a sufficient and controllable force to separate the glassware product from the moil;

a Vacuum subsystem. The vacuum subsystem must be able to pull away the powder or particles that are produced by laser cutting, especially by vaporization;

a Instrumentation and controls. These include temperature measurement, position control of laser beam, motion control of glassware, laser control and pulling force control;

- Safety equipment. It must protect the laser irradiation at a normal situation, degrade the laser operation status at an unexpected situation, and shut down the laser at an emergency situation.

\subsubsection{Machine Setup}

A lab prototype laser glass cutting machine was constructed jointly by NETL and WVU at NETL in Morgantown, WV.

A major component of this machine is the Synrad 57-1 $\mathrm{CO}_{2}$ laser capable of $100 \mathrm{~W}$ continuous or $160 \mathrm{~W}$ pulsed. The laser power is controlled by the pulse width modulation (PWM) signal from the UC-1000 control unit. Two mirrors, a spherical focal lens, two motion platforms and two stepper motors are incorporated in the machine to deliver, move and focus the laser beam. The laser and the beam delivery subsystem are shown in Figure 5.1.

Another major component of the machine is the Litton Glass Lathe. The lathe was used to hold and rotate the glassware about the vertical axis. This lathe is driven by a DC motor and able to rotate up to 4 revolutions per second. The lathe is shown in Figure 5.2. 


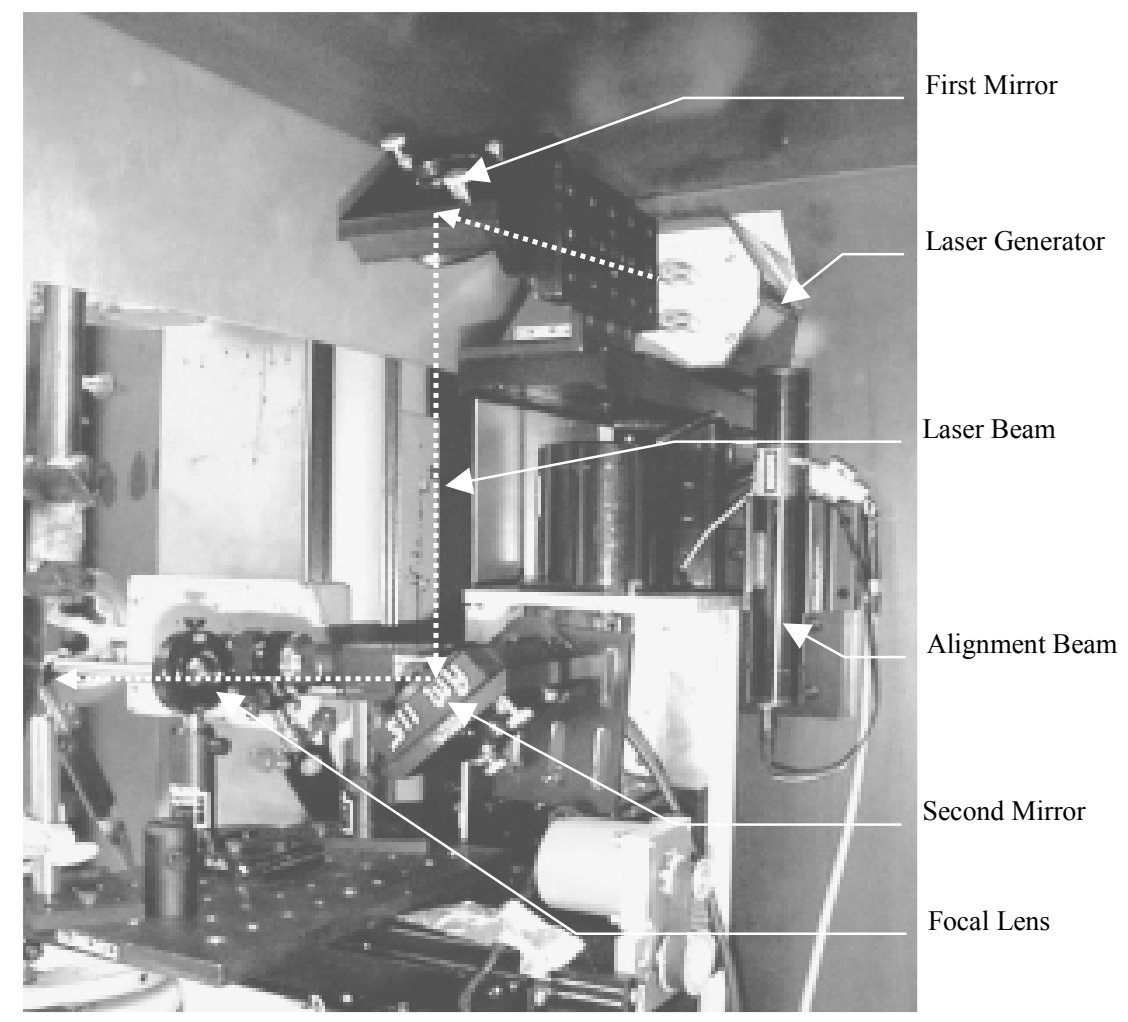

Figure 5.1 Laser and Beam Delivery Subsystem

Besides these two major components, there is a Model OS 554-V1-6 infrared temperature sensor made by Omega Company to measure the preheating temperature of the glassware, a charge-coupled device (CCD) camera connected to a monitor to monitor the laser glass cutting, two natural gas torches used to preheat the glassware, and a vacuum device used to pull the vapor away. An annealing oven is also available for the possible preheating and annealing purpose before and after the laser glass cutting. Details of the instrumentation and control of the laser glass cutting will be covered in Chapter 6 .

Figure 5.3 shows the pulling mechanism designed and built by the author. This pulling mechanism is designed for laser cutting of the schoolhouse globes produced by Davis Lynch 
Glass Company in Morgantown, WV. It is to be attached to the tailstock of the current lathe. It rotates together with the glassware in the laser cutting. The upper three-point gripper is able to hold the glassware by applying an adjustable holding force. The lower gripper can be pulled downward by the pre-compressed spring and by a motor during laser cutting, thus producing the pulling force to the moil of the glassware.

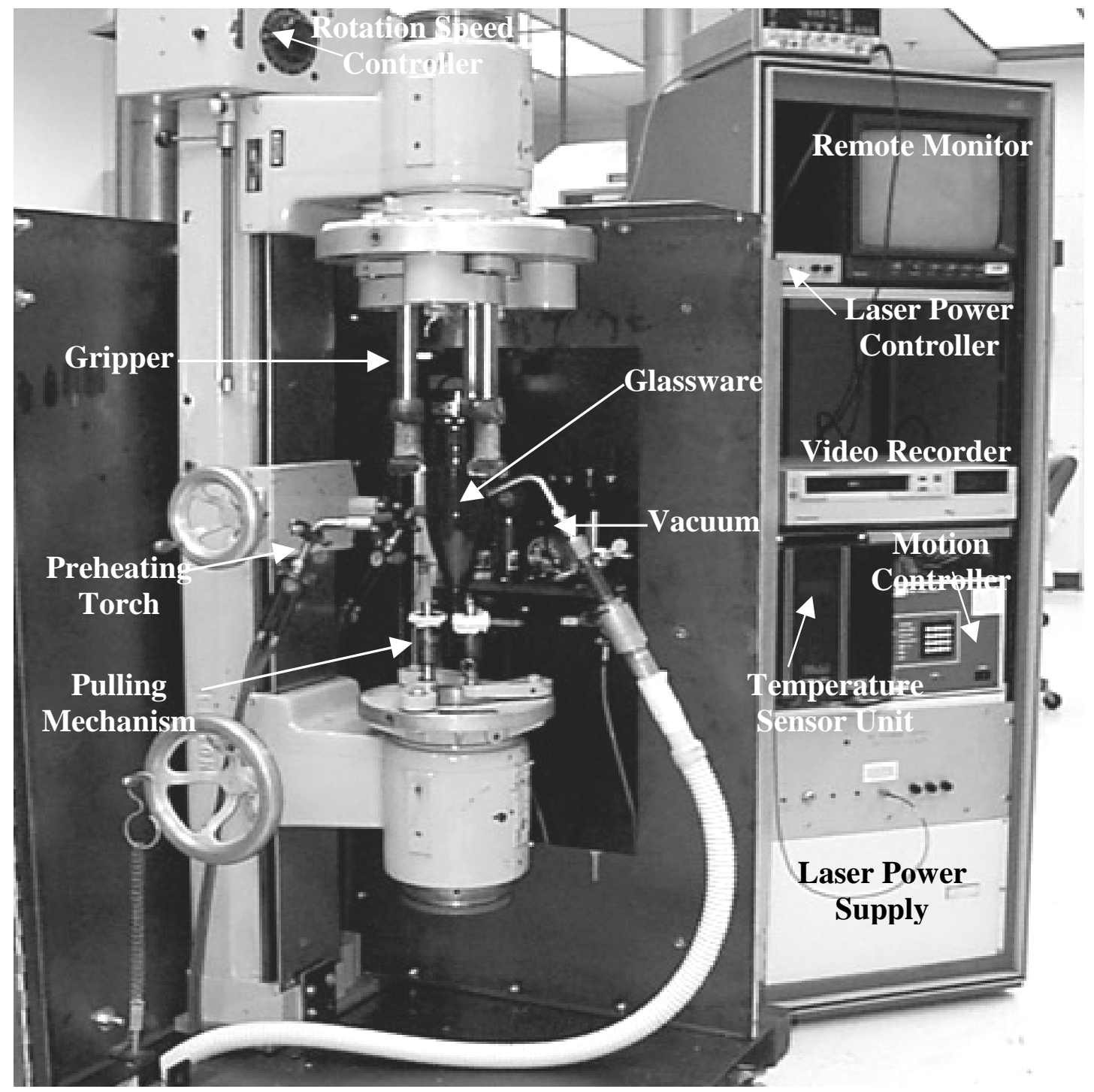

Figure 5.2 Lab Prototype Laser Glass Cutting Machine 


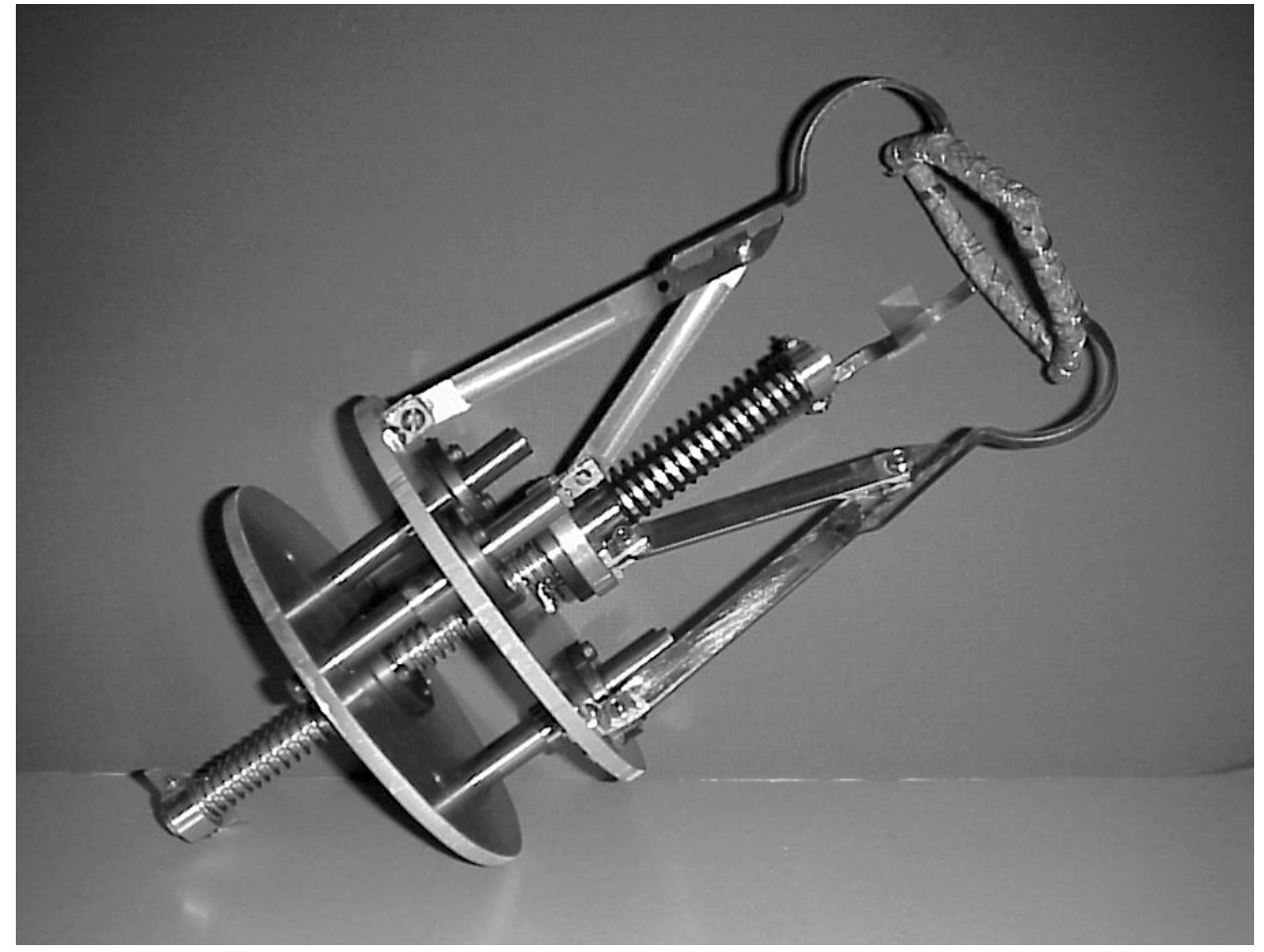

Figure 5.3 Pulling Mechanism

A Trumpf $4 \mathrm{~kW} \mathrm{CO} 2$ Laser System at the Laser Processing Company near Morgantown, WV was also used in the experiments. This laser has an adjustable power ranging from $400 \mathrm{~W}$ to $4000 \mathrm{~W}$. It can work in continuous or pulsed mode. When in pulse mode, the pulse frequency can vary from $100 \mathrm{~Hz}$ to $20 \mathrm{kHz}$. The diameter of the input beam is about $30 \mathrm{~mm}$. Beam diameter at focal position is about $1.3 \mathrm{~mm}$. The laser beam is delivered to the workpiece by a scanning head that is controlled by an X-Y gantry type positioner. The laser system also has a purge subsystem, where air and nitrogen gas are available for purging. Figure 5.4 shows this Trumpf $4 \mathrm{~kW} \mathrm{CO}$ laser that was incorporated into the lab prototype machine for laser glass cutting experiments. 


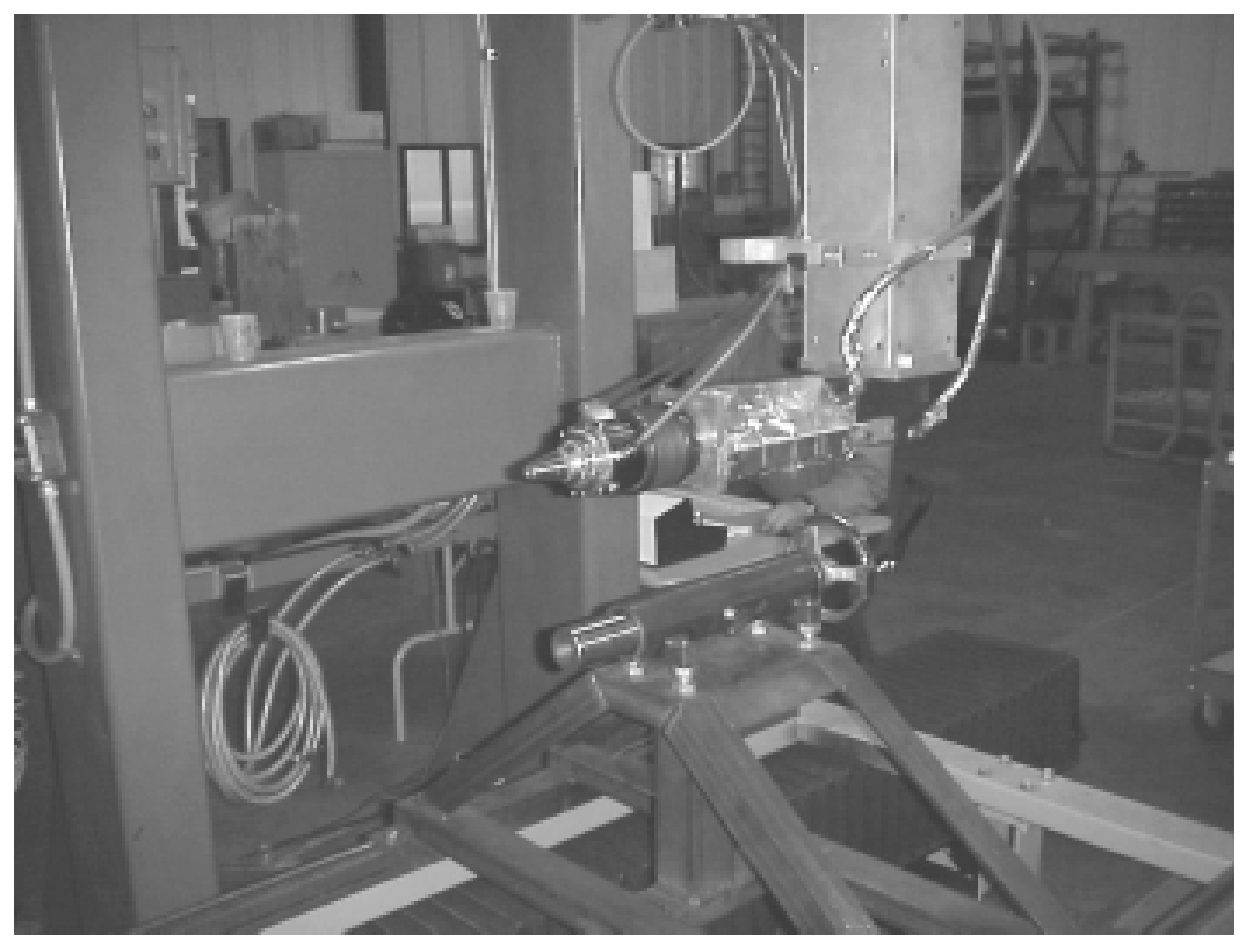

Figure 5.4 $4000 \mathrm{WCO}_{2}$ Laser in LPC

\subsubsection{Performance Measures}

Performance measures include time $t_{C}$ to cut through the glassware (separate), the groove geometry such as groove width $\mathrm{W}_{\mathrm{g}}$, groove depth $\mathrm{D}_{\mathrm{g}}$, melting zone depth $\mathrm{D}_{\mathrm{m}}$, and heating affected zone width $\mathrm{W}_{\text {haz. }}$ The illustrations in Figures 5.20, 5.21 and 5.22 show these groove geometry measures.

In the experiments, the laser cutting process was videotaped. In the complete-cut experiments, the cutting time $t_{C}$ was measured and used for the overall machine capability and economic analysis. The overall capability and economic analysis of this laser glass cutting technology was covered in References [60] and [61] and was not the objective of this 
dissertation. In the partial-cut experiments, glassware samples were collected after laser cutting was performed, from which groove geometry was measured. These measurements and the analysis of these measurements form the major part of the results presented in this dissertation.

\subsubsection{Experiment Parameters}

Important parameters in the laser glass cutting process come from three sources:

a Parameters associated with the laser: power level, mode (continuous or pulsed), beam focal lens shape (spherical or cylinder), beam diameter, focal length and focal depth.

a Parameters associated with the glassware: material type, glassware diameter and glassware wall thickness.

a Parameters associated with the operation: rotation speed, preheating temperature, purge gas (on/off, mass flow rate and hot/cold), pulling force and focal position.

However, not all of these parameters can be investigated in these experiments, because physical limitations existed in the lab prototype machine and because some of these parameters were determined to be not as important as other parameters.

Based on the knowledge of laser glass cutting process and the limitation in the current laser glass cutting machine, 1) laser power, 2) glassware rotation speed, 3) beam focal position, only on surface, 4) gas purge, and 5) glassware material were chosen to be investigated in the laser glass cutting experiments for this dissertation. For laser power, a range from $100 \mathrm{~W}$ to $4000 \mathrm{~W}$ was considered. For glassware rotation speed, a range from $1 / 2 \mathrm{rev} / \mathrm{sec}$ to $4 \mathrm{rev} / \mathrm{sc}$ was 
considered. For beam focal position, two positions including beam focus on surface and beam focus $2 \mathrm{~mm}$ below surface were considered. For gas purge, conditions of purge on or off and purge hot or cold were considered. For glassware material, four types of glassware including clear cylinder, opaque cylinder, wine bottle and champagne bottle were considered.

\subsubsection{Glassware Samples}

Four types of glassware samples were chosen for the experiments due to their availability and their standard geometrical dimensions. They are wine bottles and champagne bottles available locally, and clear cylinders and opaque cylinders donated by the Davis Lynch Glass Company in Star City, WV. The geometrical dimensions of these four types of glassware samples are listed in Table 5.1. The material constituents of the clear cylinder and opaque cylinder are listed in Table 5.2. The Clear cylinder is a common type of soda-lime glass. The densities of these four samples were measured as shown in Table 5.1. Although slightly different, their densities are all close to the density of soda lime, which is $2440 \mathrm{~kg} / \mathrm{m}^{3}$. Although the thermal properties of the typical soda lime glass are known as shown in Table 2.1, the exact thermal properties of these four types of samples are not available. To measure the thermal properties of the glass other than soda lime is beyond the scope of this dissertation. 
Table 5.1 Geometrical Properties and Density of Sample Glassware

\begin{tabular}{||c|c|c|c||}
\hline SAMPLE TYPE & $\begin{array}{c}\text { OUTER DIAMETER } \\
(\mathrm{mm})\end{array}$ & $\begin{array}{c}\text { THICKNESS } \\
(\mathrm{mm})\end{array}$ & $\begin{array}{c}\text { DENSITY } \\
\left(\mathrm{kg} / \mathrm{m}^{3}\right)\end{array}$ \\
\hline Wine Bottle & 80 & $2.0 \sim 2.2$ & 2485 \\
\hline Champagne Bottle & 83 & $4.0 \sim 4.2$ & 2498 \\
\hline Clear Cylinder & 80 & 3.0 & 2495 \\
\hline Opaque Cylinder & 80 & 3.0 & \\
\hline
\end{tabular}

Table 5.2 Material Constituents of Clear Cylinder and Opaque Cylinder (D-L Glass Co.)

\begin{tabular}{||c|c||c|c||}
\hline \multicolumn{2}{||c||}{ CLEAR CYLINDER } & \multicolumn{2}{c||}{ OPAQUE CYLINDER } \\
\hline Material & Weight Ratio (\%) & Material & Weight Ration (\%) \\
\hline \hline Sand & 32.5 & Zinc & 49.4 \\
\hline Lime & 6.9 & Cryolite & 8.4 \\
\hline Soda Ash & 24.7 & Soda Ash & 2.9 \\
\hline Aragonite & 11.9 & Nitrate & 2.6 \\
\hline Feldspar & 7.5 & Feldspar & 14.4 \\
\hline Borax & 6.5 & Fluorspar & 6.9 \\
\hline Nitrate & 6.6 & Borax & 10.3 \\
\hline Others & 3.4 & Others & 0.6 \\
\hline
\end{tabular}


Figure 5.5 shows the clear cylinder sample and Figure 5.6 shows the opaque cylinder sample. Figure 5.7 shows the bottoms of a champagne bottle and a wine bottle that resulted from laser glass cutting.

Some other glassware samples from companies including Fenton Art Glass Company, Pilgrim Glass Company, and Davis Lynch Glass Company were also used in the experiments. However, they were basically used in the complete-cut experiments to collect the cutting time for the purpose of capability and economic analysis. This is mainly covered in References [60] and [61], which focuses on the economic and application aspects of the laser glass cutting machine.

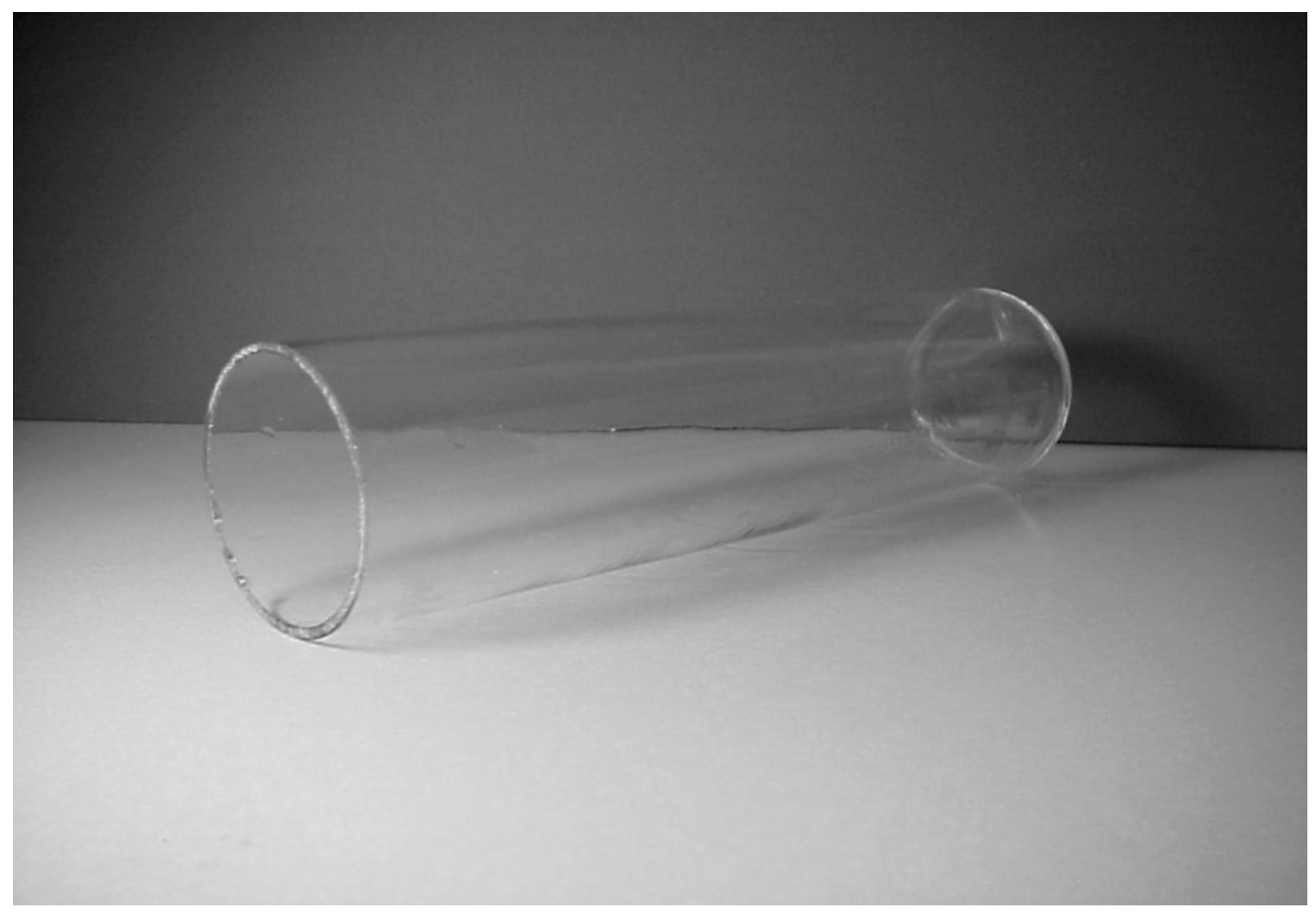

Figure 5.5 Cut Sample (Clear Cylinder) from Davis Lynch Glass Company 


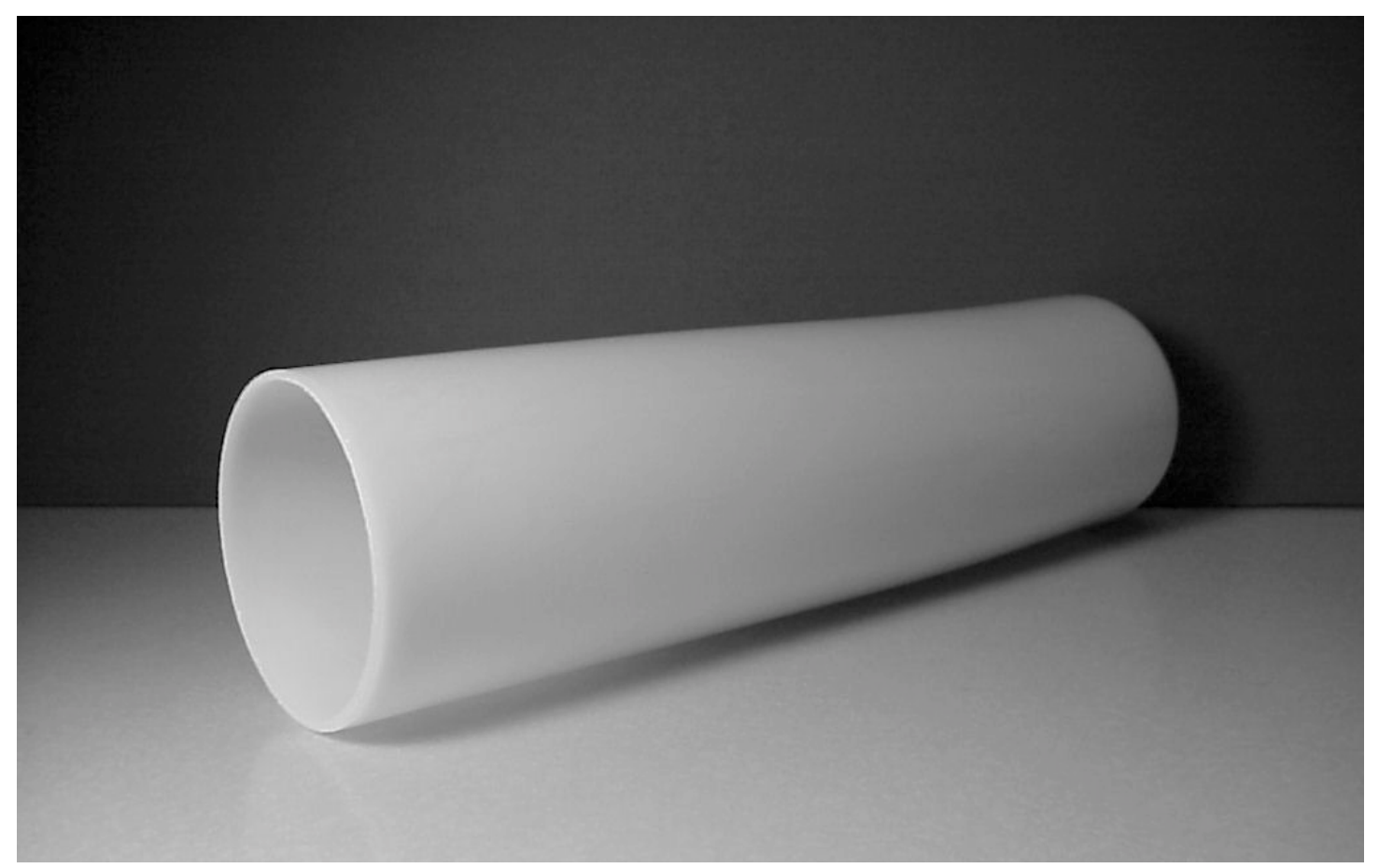

Figure 5.6 Cut Sample (Opaque Cylinder) from Davis Lynch Glass Company

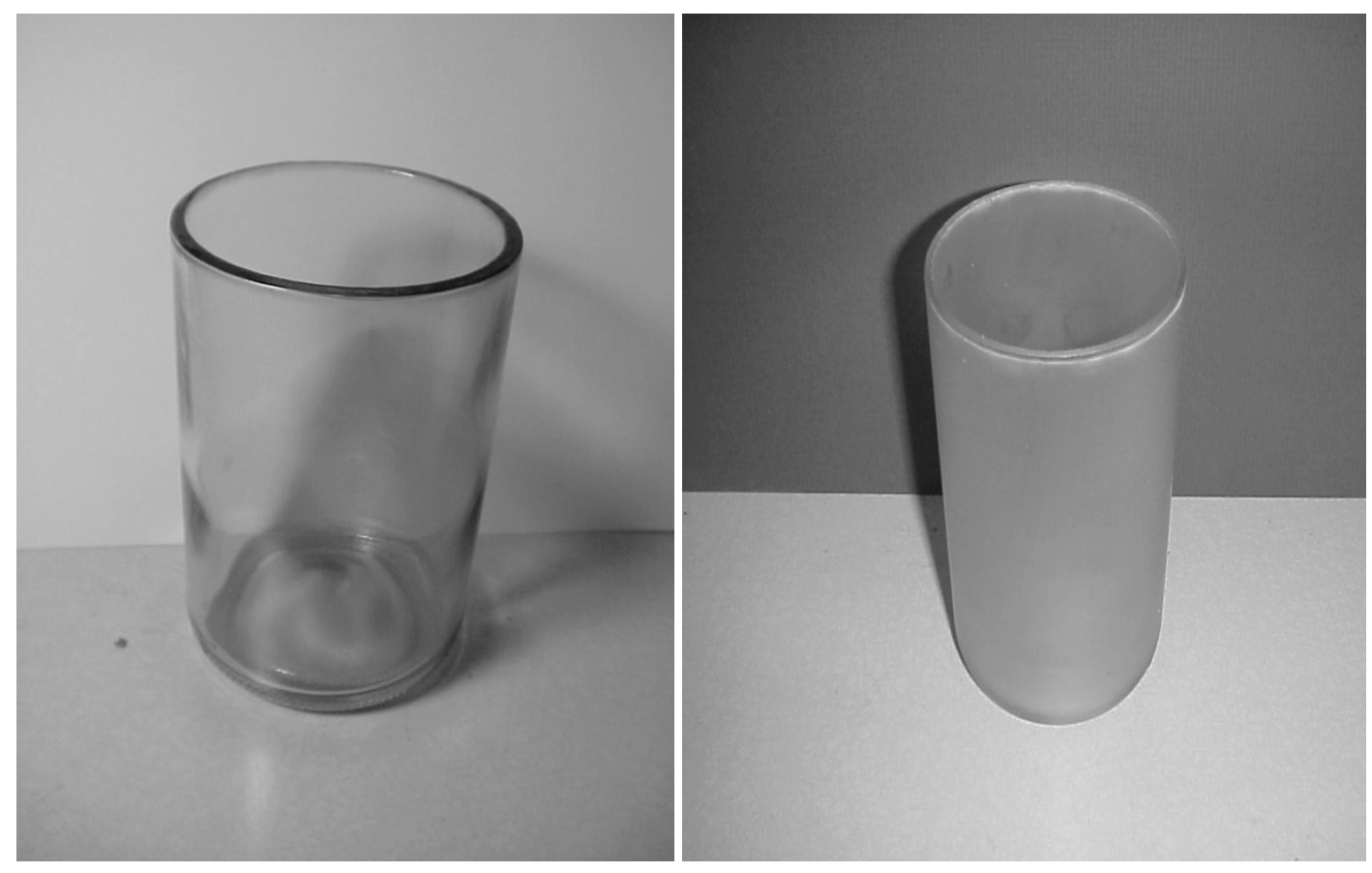

Figure 5.7 Cut Samples (Left: Bottom of Champagne Bottle, and Right: Bottom of Wine Bottle) 


\subsection{EXPERIMENT Procedure}

口 Load the glassware

Before laser glass cutting, the glassware is loaded into the laser glass cutting machine. This is done manually since no automatic machine is available to pick up the glassware.

\section{口 Align the glassware}

To align the sample centrically, grippers in both headstock and tailstock were used to hold the upper end and lower end of the glassware. Adjustment of the grippers is possible to accommodate a variety of glassware shapes. After the glassware is held by the grippers, the laser head is moved close to the glass surface, the glassware rotated manually, and a gauge is used to check the space between the glassware and the laser head. It was experimentally deemed acceptable that the space varies less than $1 \mathrm{~mm}$ when rotating the glassware for a complete revolution; otherwise further adjustment of the glassware in the griper was performed. The laser head was moved back only after the glassware was gripped in a good position. The pulling force may be applied using the lower end gripper, depending on the requirement in experiment design. Figure 5.8 shows the glassware to be cut when loaded in the laser glass cutting machine.

- Rotate and preheat the glassware

After the glassware has been loaded and aligned, it starts to rotate. Preheating is then applied to the glassware using a natural gas torch. One or two torches may be needed depending on the glassware size. The temperature of glassware is measured and observed. The expected application of this machine is in the hot shop where the glassware is still hot and preheating 
should become unnecessary. Figure 5.9 shows how the glassware to be cut is preheated using a natural gas torch.

\section{口 Set desired experimental conditions}

When the preheating temperature of the glass approaches to the desired preheating temperature of $600{ }^{\circ} \mathrm{C}$, for example, other experimental conditions need to be set as specified by the experiment design. These conditions include the laser focus position, laser power level, laser firing time, glassware rotation speed, purge and vacuum condition, etc.

a Fire the laser

Laser is fired after the desired experimental conditions have been set and when the glassware is at a temperature above its annealing point and below its softening point. Fracture will not happen when the glassware is above its annealing temperature. Melting and vaporizing happen due to the intense heat input from the laser. This makes the proposed method, cutting glassware by utilizing melting and/or vaporization mechanism, unique. The traditional crack-off method utilizes the fracture mechanism, so do other existing laser glass cutting machines, although they use a laser as a heating source. Figure 5.10 shows the laser being fired to start cutting a glassware sample.

After laser firing for a while, the local glass heating/melting/vaporizing causes the cutting ring to become liquidized enough to start separation of glassware under the pulling force. Figure 5.11 shows how separation of glassware can begin.

In complete-cut experiments, laser and pulling will eventually cause separation of the glassware from the moil with process progressing. The moil is a part of raw glassware form blowing station, which has to be removed to make the product. Then the laser will continue to 
fire in the cutting edge to produce a polishing effect. Figure 5.12 shows when separation of the glassware has been completed. Figure 5.13 shows the final glassware product produced by this laser glass cutting machine.

In the many partial-cut experiments that were performed, the glass sample often stayed in the machine for cutting the multiple partial cuts. When another cut was performed in the same sample, the experimental conditions were reset according to the experiment design, and the laser head moved up or down by $10 \mathrm{~mm}$ so that the new cut would not interfere with the previous cuts.

After finishing the partial-cut experiments on a glassware sample, the sample was collected, labeled, and further prepared for micrograph measurement.

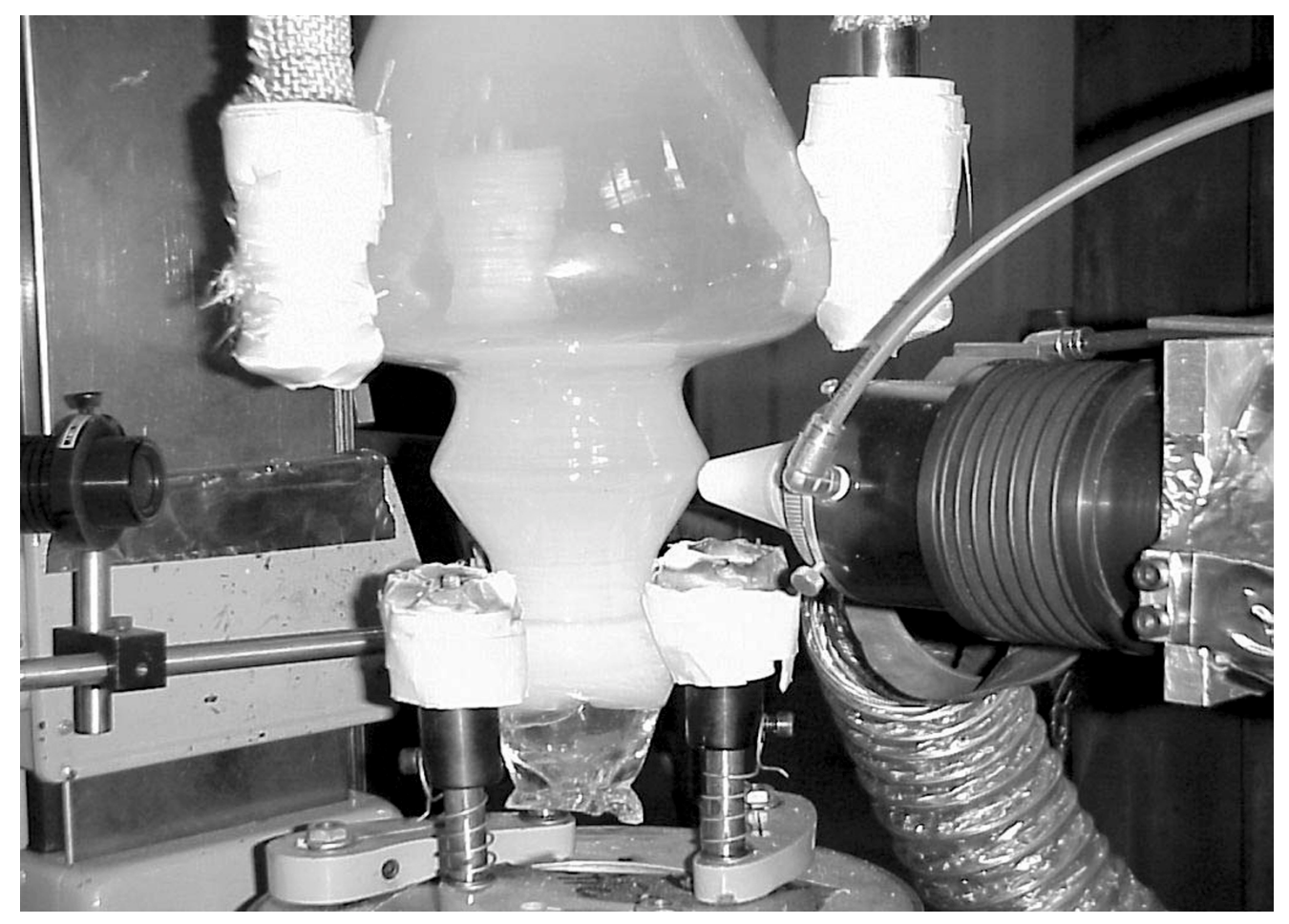

Figure 5.8 Glassware Held in Lathe 


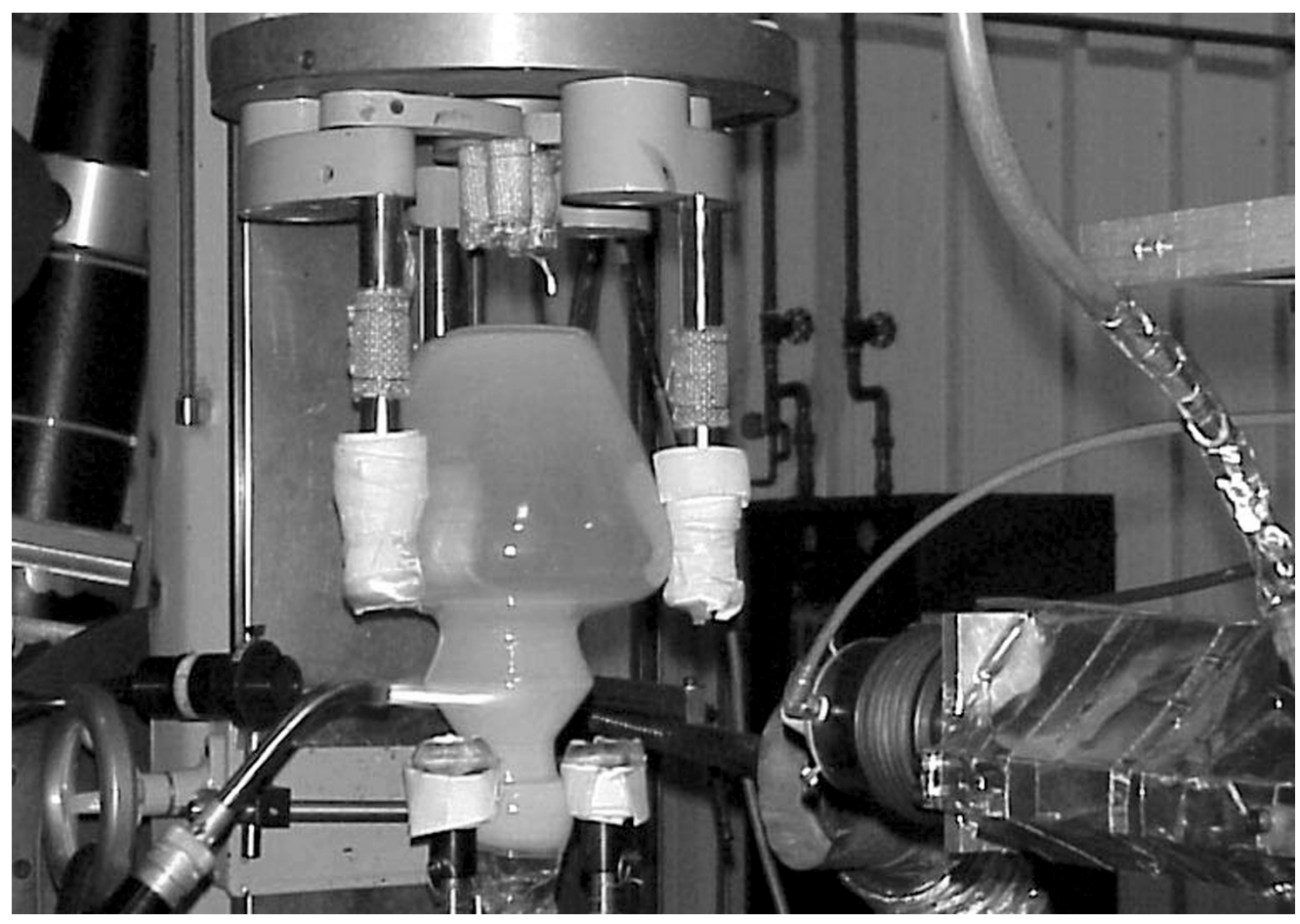

Figure 5.9 Glassware being Preheated

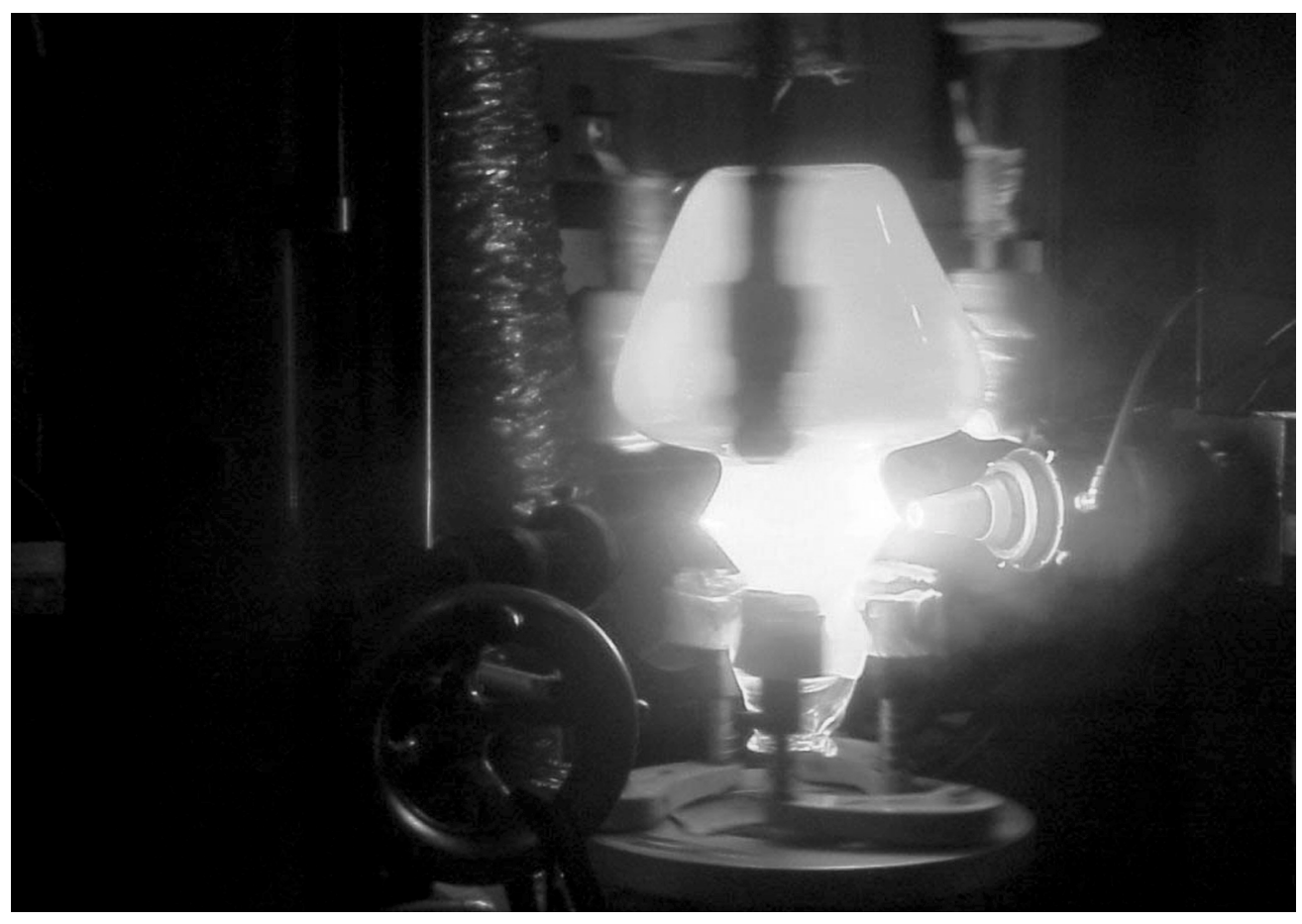

Figure 5.10 Glassware being Cut by Laser 


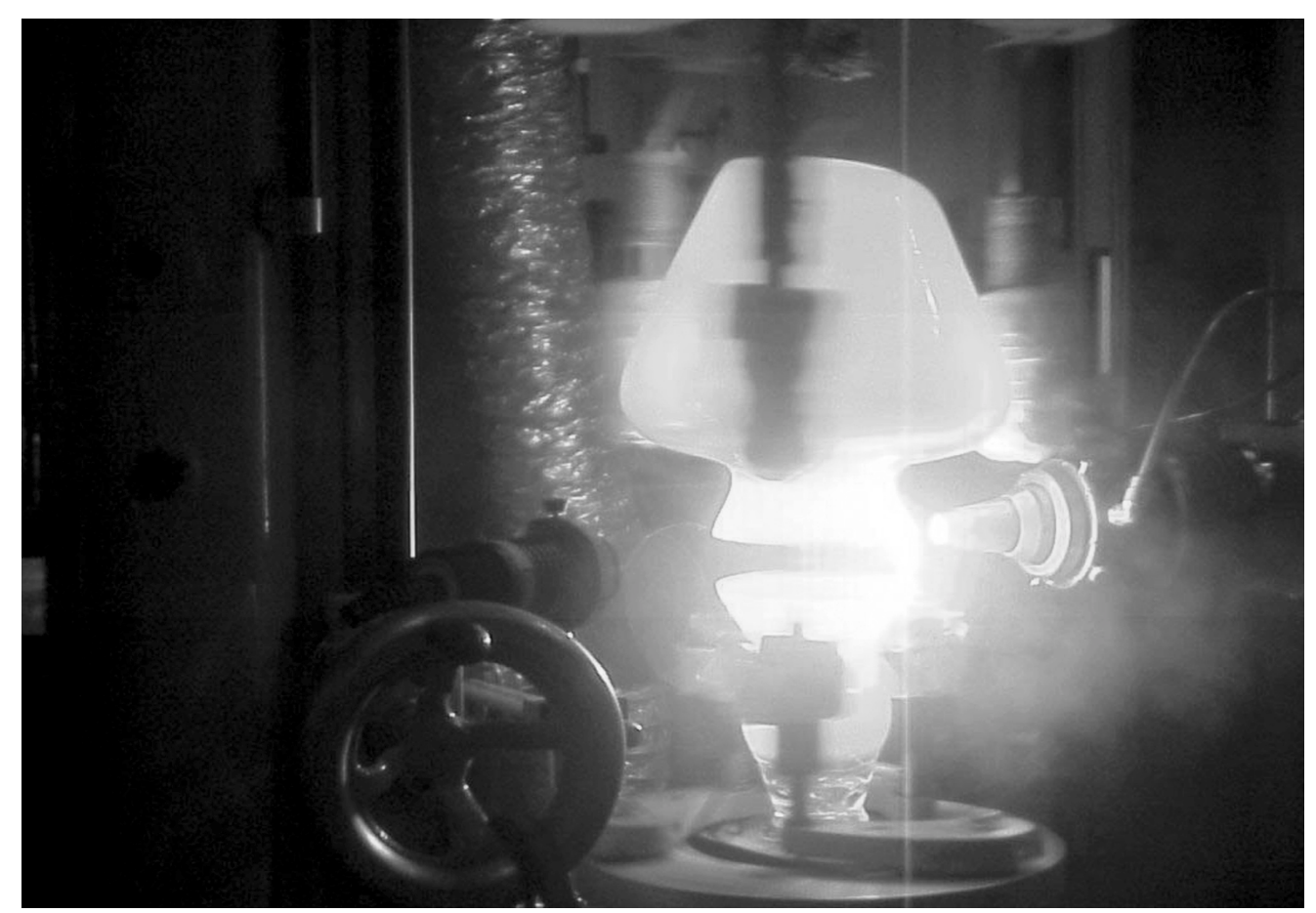

Figure 5.11 Separation of Lower Section of Glassware (Moil) Begins

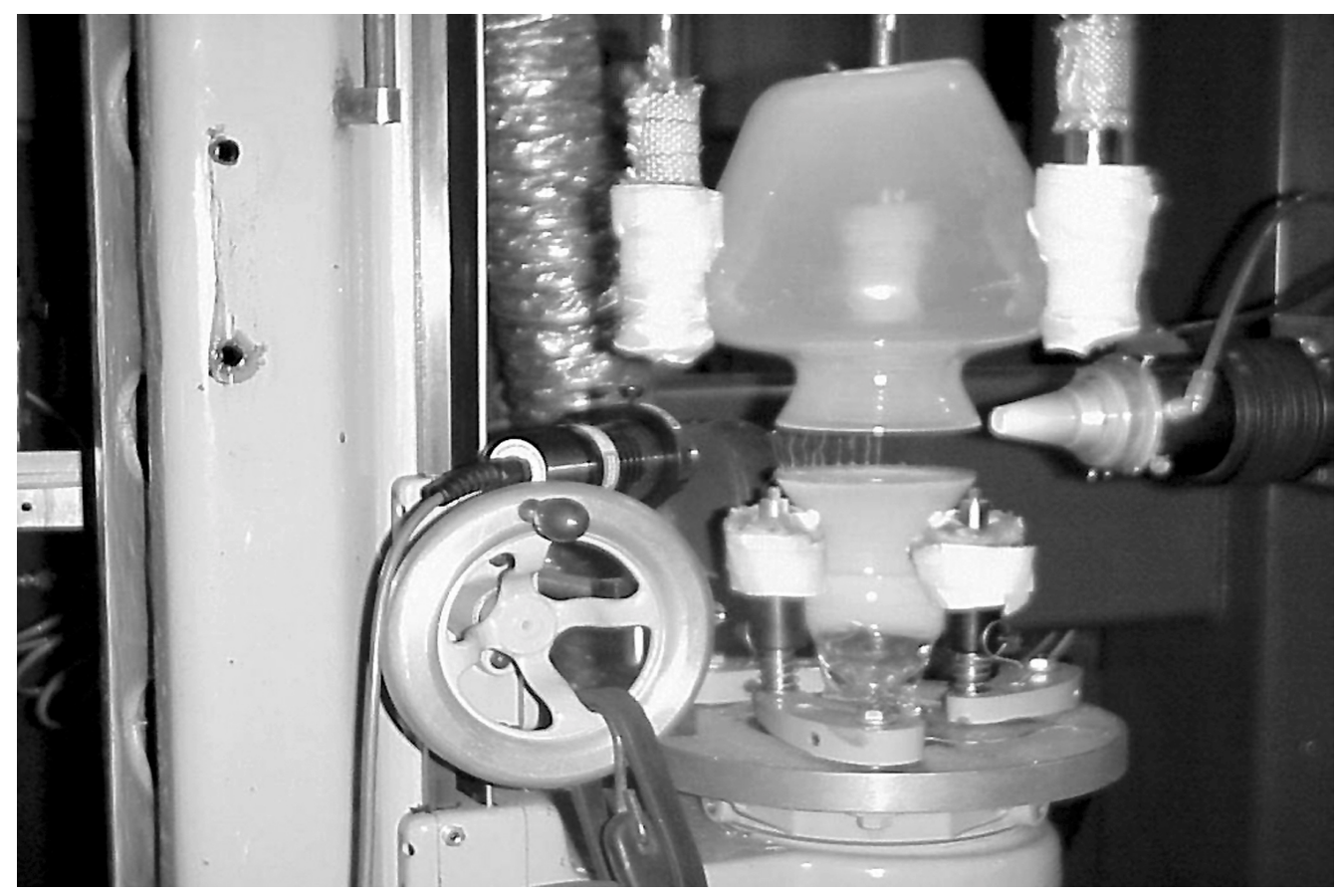

Figure 5.12 Separation of Lower Section of Glassware (Moil) Completed 


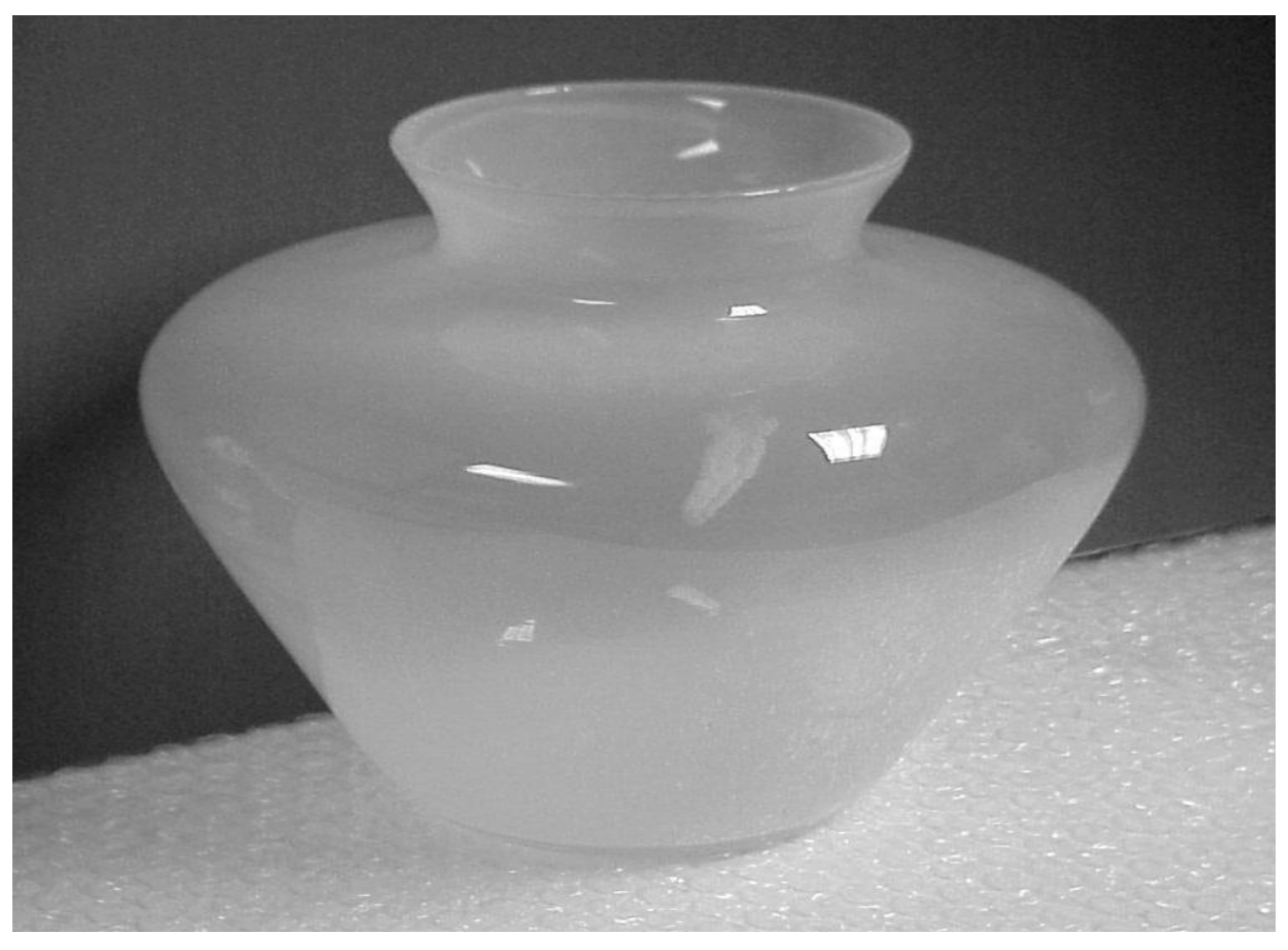

Figure 5.13 Glassware Product Produced

\section{- Prepare specimen}

Two steps are taken to prepare a specimen for the micrograph measurement. The first step is to saw the glassware sample into small pieces that contain the grooves. The tool for sawing was a diamond saw. The sawing edge should be either parallel or perpendicular to the groove for the convenience and accuracy of measurement. The second step is to polish the sawed edges using a mechanical polishing machine in the Micrograph Laboratory. After these two steps, a specimen is ready for the micrograph measurement.

\section{Micrograph Measurement}

Graphs of the cutting groove will be taken using the Hi-Scope equipment, and the quantitative data will be extracted from the graphs for the analysis purpose. The optical 
equipment, Hi-Scope from HiRox Co. and the related software, Vision Gauge 4.98, from VISIONx Inc., were made available by Dr. Keh-Minn Chang of the Metalorgraph and Instrument Lab in the Department of Mechanical Engineering and Aerospace Engineering in College of Engineering and Mineral Resources at WVU. Figure 5.14 shows this Hi-Scope optical equipment for the measurement of the cut samples.

For each specimen, pictures from three different views were taken. The first view is from the height direction, and the picture from this view provides the information of melting depth. The second view is from the radial direction, and the picture from this view provides the information of groove width and heat affected zone width. The third view is from the circumference direction, and the picture from this view provides the information of groove depth and melting depth.

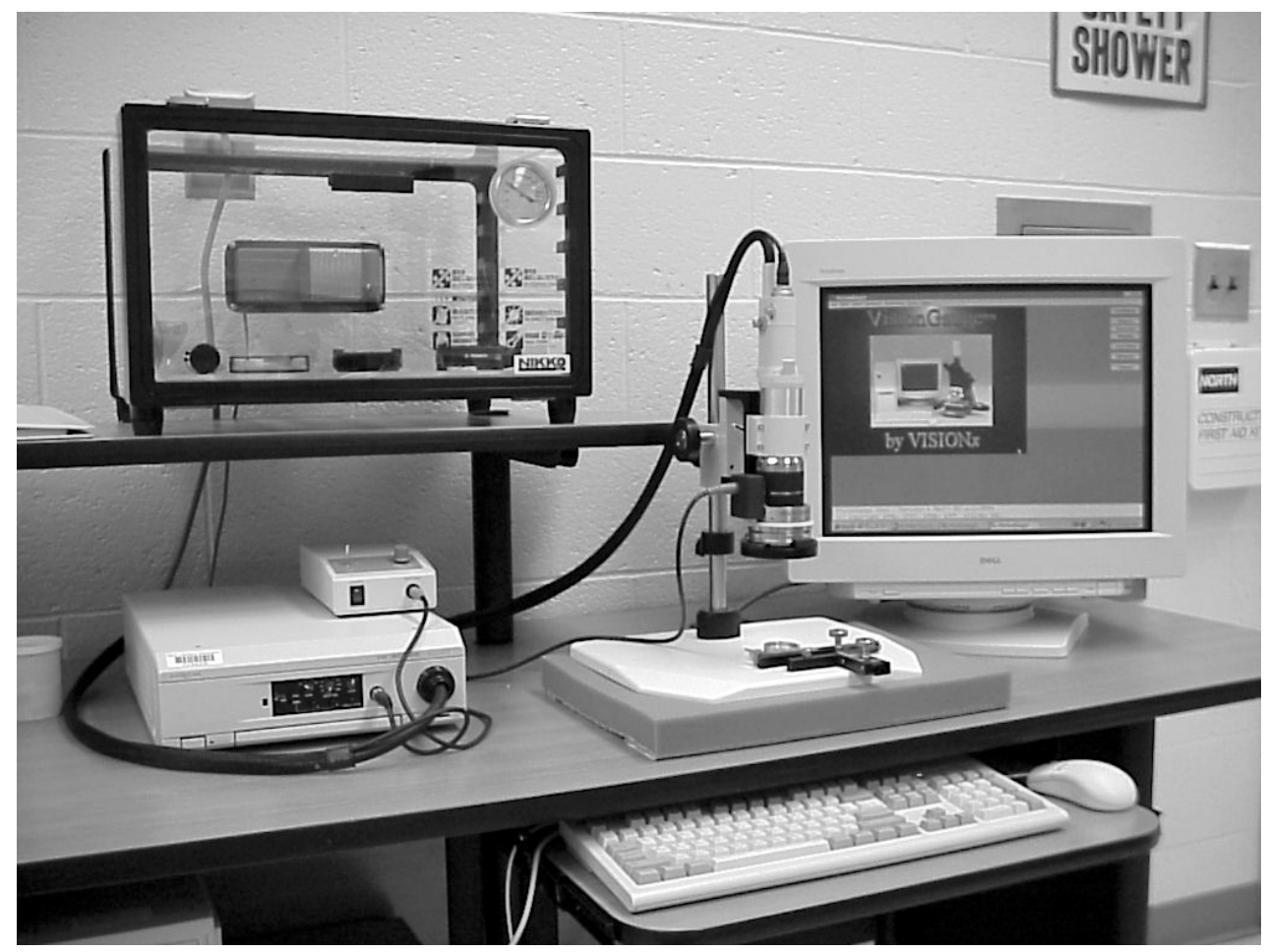

Figure 5.14 Optical Equipment for Measurement of Cut Samples 


\subsection{EXPERIMENT ARRANGEMENT}

To investigate the success of this laser glass cutting, a total of 56 glass samples were used and a total of 97 laser glass cuts, partial or complete, were performed. Some glass samples such as the clear cylinders and opaque cylinders were used multiple times and thus may have had multiple cut grooves in one sample. Lists of the experiments that were performed and were contributive to the results presented in this dissertation are shown in the Table 5.3, Table 5.4 and Table 5.5. The samples and associated experiments in the each table constitute a set of experiments. It is to be noted that in the different sets of experiment samples may have the same ID number.

Experiments listed in these tables focused on three areas. The first area includes trial experiments to test the machine's functionality and to narrow down the range of experimental conditions. A total of 24 glassware samples ( 13 wine bottles, 3 champagne bottles and 6 Fenton glass wares) were used and 24 complete-cut were performed. Results from these experiments are basically descriptive and described in the results of Section 5.4.1. The second area includes investigative experiments of the cutting process, i.e. melting and vaporization as a function of cutting time. A total of 4 glassware samples ( 1 champagne bottle, 2 clear cylinders and 1 opaque cylinder) were used and 25 partial-cuts were performed. The champagne bottle cracked in the experiment. The third area includes investigative experiments of the parameters including mass transfer, laser power, rotation speed, focal position and gas purge. A total of 15 glassware samples ( 8 wine bottles, 1 champagne bottle, 6 clear cylinders and 1 opaque cylinder) were used 
and a total of 34 partial-cuts were performed. Details of the usage of each glassware sample, factor levels and other operational conditions are described in the following three paragraph.

In Table 5.3, Samples ID 1 to 11 were used for trial experiments to test the machine's functionality and to narrow down the range of experimental conditions. Samples ID 12 to 19 were used for mass transfer investigation. Two levels of laser power (600 W and $1000 \mathrm{~W})$ and two levels of rotation speed ( $1 \mathrm{rev} / \mathrm{s}$ and $4 \mathrm{rev} / \mathrm{s}$ ) were considered. Sample ID 20 was used to investigate the effect of glassware rotation speed on the single-cycle laser cutting of a wine bottle. Three levels of speed ( $4 \mathrm{rev} / \mathrm{s}, 2 \mathrm{rev} / \mathrm{s}$ and $1 \mathrm{rev} / \mathrm{s})$ were considered. Samples ID 21 and ID 22 were used to investigate the air purge and laser mode. Samples ID 23 and ID 24 were used for trial experiments.

In Table 5.4, Samples ID 1 to 3 were used to investigate the effect of laser power and glassware rotation speed on a complete cut of the champagne bottle. Two levels of laser power $(1000 \mathrm{~W}$ and $1500 \mathrm{~W})$ and two levels of rotation speed ( $1 \mathrm{rev} / \mathrm{s}$ and $2 \mathrm{rev} / \mathrm{s})$ were considered. Sample ID 4 was used to investigate the effect of glassware rotation speed on single-cycle laser cutting of the champagne bottle. Two levels of rotation speed (1 rev/s and $2 \mathrm{rev} / \mathrm{s})$ were considered. Sample ID 5 was used to investigate the cutting process as a function of time, using the champagne bottle. Five laser firing times $(1 \mathrm{~s}, 2 \mathrm{~s}, 4 \mathrm{~s}, 8 \mathrm{~s}$ and $10 \mathrm{~s})$ were considered. Samples from ID 6 to 11 were hand glassware from the Fenton Art Glass Company for experiments in cutting hand glass.

In Table 5.5, Sample ID 1, which is a clear cylinder, was used to investigate the process as a function of time. Eight laser firing times $(1 \mathrm{~s}, 2 \mathrm{~s}, 4 \mathrm{~s}, 6 \mathrm{~s}, 8 \mathrm{~s} 10 \mathrm{~s}, 12 \mathrm{~s}$ and $14 \mathrm{~s})$ were considered. Sample ID 2, which is an opaque cylinder, was used to investigate the glassware rotation speed on the laser cutting process on an opaque cylinder. Two levels of rotation speed 
( $1 \mathrm{rev} / \mathrm{s}$ and $4 \mathrm{rev} / \mathrm{s})$ and four laser firing times $(1 \mathrm{~s}, 4 \mathrm{~s}, 8 \mathrm{~s}$ and $12 \mathrm{~s})$ were considered. Sample ID 3, which is a clear cylinder, was used to investigate the effect of laser power on cutting. Five levels of laser power $(400 \mathrm{~W}, 800 \mathrm{~W}, 1000 \mathrm{~W}, 1500 \mathrm{~W}$ and $2000 \mathrm{~W})$ were considered. A laser firing time of $5 \mathrm{~s}$ was used. Two more cuts were performed for $400 \mathrm{~W}$ and $1500 \mathrm{~W}$ power level, respectively, with a laser firing time of $10 \mathrm{~s}$. Sample ID 1 together with sample ID 7 was used to find the effect of glassware rotation speed on the laser cutting process on a clear cylinder. The rotation speed was $1 \mathrm{rev} / \mathrm{s}$ for Sample ID 1 and $2 \mathrm{rev} / \mathrm{s}$ for Sample ID 7. Sample ID 4, which is a clear cylinder, was used to investigate the effect of laser focal position. Two position levels ( 2 $\mathrm{mm}$ below the surface and on the surface) were considered. Samples ID 5, 6 and 8, which are clear cylinders, were used to investigate the effect of purge on laser glass cutting. Three levels of purge (purge off, purge on and purge maximum) were considered. The purge was hot when cutting Sample ID 5 and cold when cutting Sample ID 8. Sample ID 9 was used to investigate the effect of laser power and glassware rotation speed. Samples from ID 10 to 13 were used for trial experiments. 
Table 5.3 First Set of Laser Glass Cutting Experiments

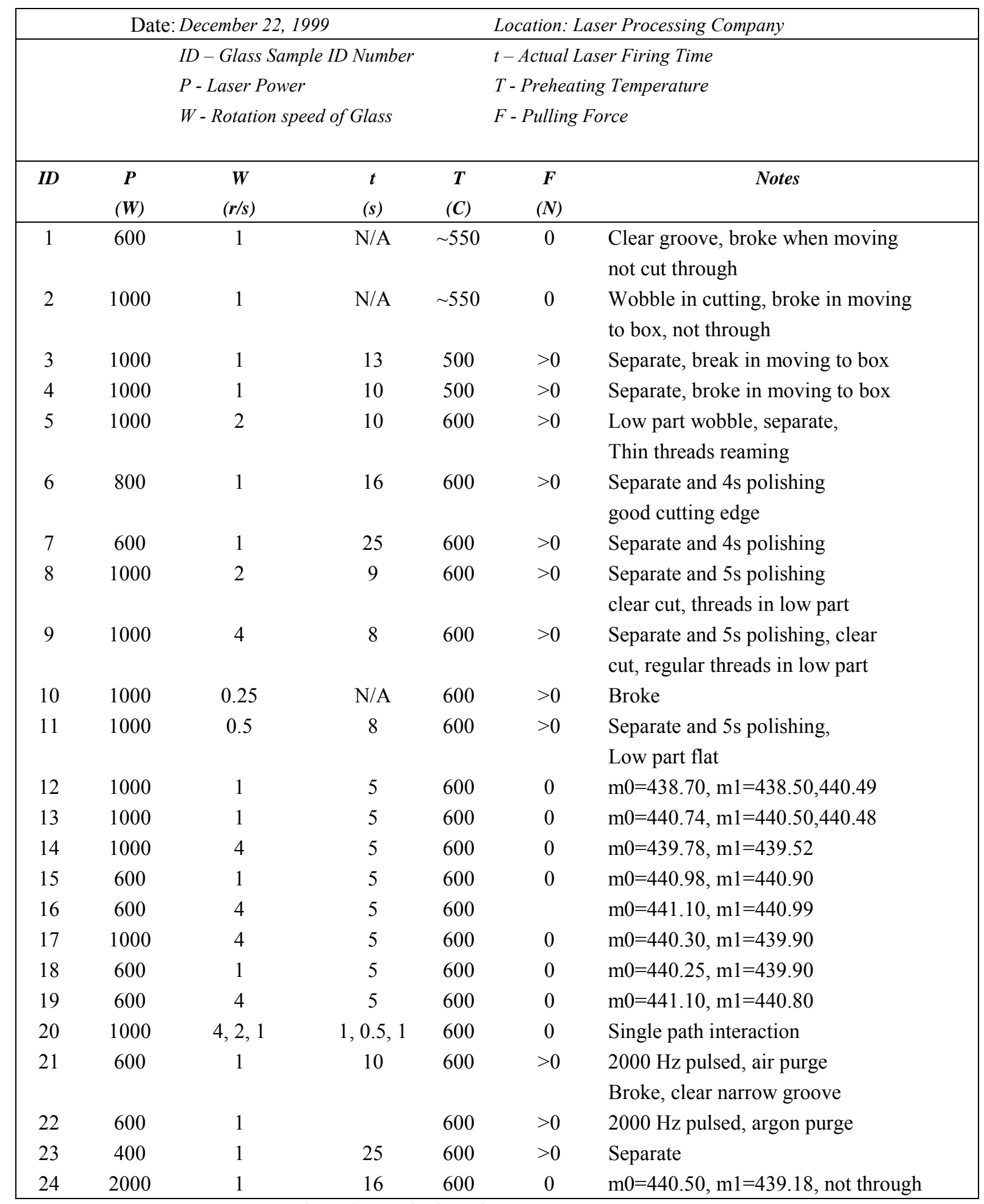

Note: "separate" means cutting through the glassware

$\mathrm{m} 0$ and $\mathrm{m} 1$ in the table are the mass weighted in gram before and after laser glass cutting 
Table 5.4 Second Set of Laser Glass Cutting Experiments

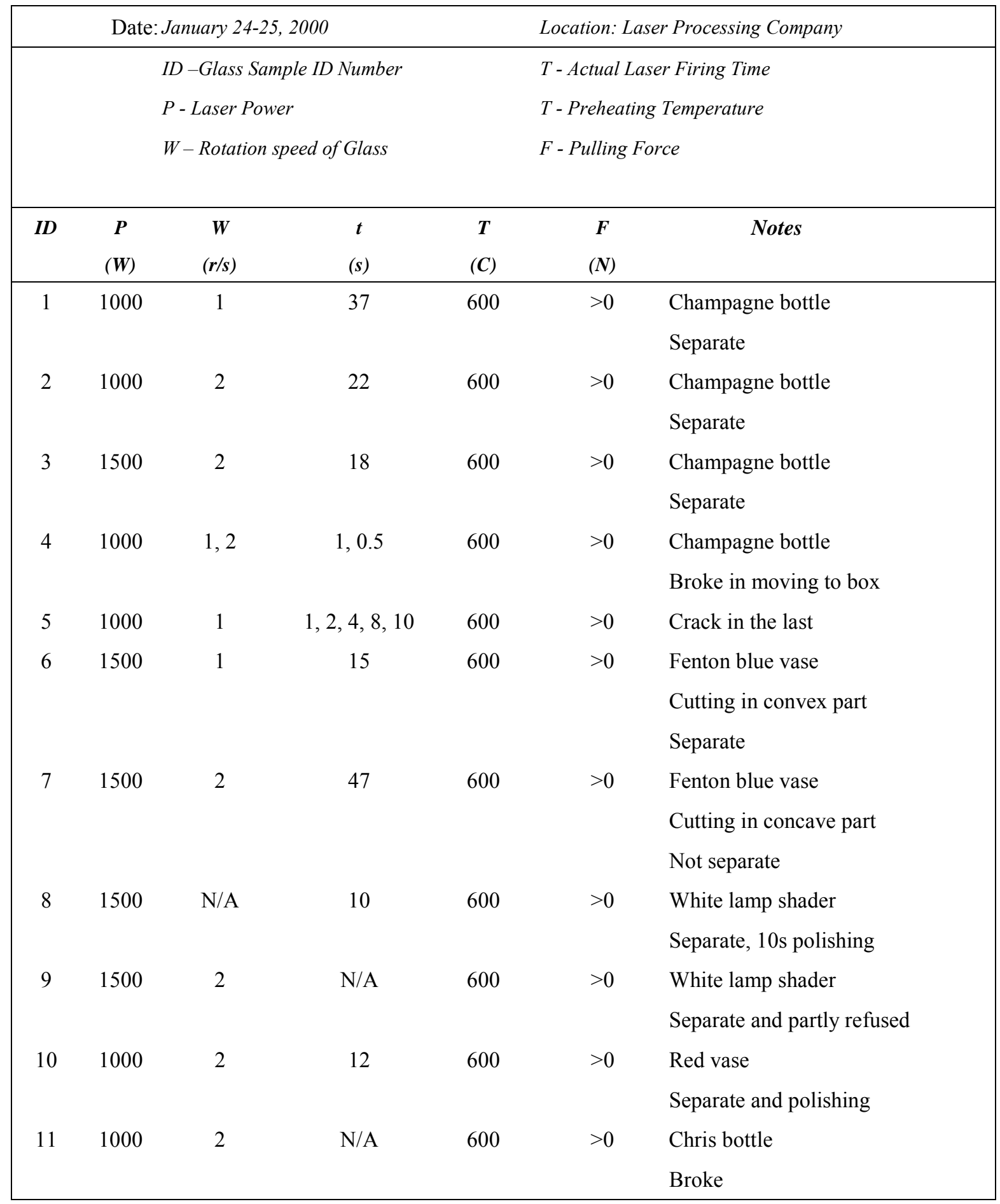


Table 5.5 Third Set of Laser Glass Cutting Experiments

\begin{tabular}{|c|c|c|c|c|c|c|c|c|}
\hline \multicolumn{5}{|c|}{ Date: February 25-28, 2000} & \multicolumn{4}{|c|}{ Location: Laser Processing Company } \\
\hline & & \multicolumn{3}{|c|}{ ID - Glass Sample ID Number } & \multicolumn{4}{|c|}{$t$-Actual Laser Firing Time } \\
\hline & & \multicolumn{3}{|c|}{$P$-Laser Power } & \multicolumn{4}{|c|}{$T$-Preheating Temperature } \\
\hline & & \multicolumn{3}{|c|}{$W$ - Rotation speed of Glass } & \multicolumn{4}{|c|}{ F-Pulling Force } \\
\hline \multirow[t]{2}{*}{$I D$} & $P$ & $\boldsymbol{W}$ & $t$ & $T$ & $\boldsymbol{F}$ & Purge & Focus & Sample Type \\
\hline & $(W)$ & $(r / s)$ & $(s)$ & $(C)$ & $(N)$ & & & \\
\hline \multirow[t]{2}{*}{1} & 1000 & 1 & $1,2,4,6$ & 600 & 0 & Off & On & Clear cylinder \\
\hline & 1000 & 1 & $8,10,12,14$ & 600 & 0 & Off & On & \\
\hline \multirow[t]{2}{*}{2} & 1000 & 1 & $1,4,8,12$ & 600 & 0 & Off & On & Opaque cylinder \\
\hline & 1000 & 4 & $12,8,4,1$ & 600 & 0 & Off & On & \\
\hline \multirow[t]{3}{*}{3} & $400,800,1000$ & 1 & 5 & 600 & 0 & Off & On & Clear cylinder \\
\hline & 1500,2000 & & & & & & & \\
\hline & 400,1500 & 1 & 10 & 600 & 0 & Off & On & \\
\hline \multirow[t]{2}{*}{4} & 500 & 1 & 5 & 600 & 0 & Off & On, below & Clear cylinder \\
\hline & 1000 & 1 & 5 & 600 & 0 & Off & Below, on & \\
\hline \multirow[t]{3}{*}{5} & 400 & 1 & 10 & 600 & 0 & Off & On & Clear cylinder \\
\hline & 400 & 1 & 5 & 600 & 0 & Off, hot & On & \\
\hline & 1000 & 1 & 5 & 600 & 0 & Off, hot & On & \\
\hline 6 & 1000 & 1 & 8 & 600 & 0 & Cold & On & Clear cylinder \\
\hline 7 & 1000 & 2 & $12,8,4,1$ & 600 & 0 & Off & On & Clear cylinder \\
\hline 8 & 1000 & 1 & 5 & 600 & 0 & Off, on & On & Clear cylinder \\
\hline & & & & & & Max & & \\
\hline \multirow[t]{3}{*}{9} & 1000 & 1,4 & 8 & 600 & 0 & Off & On & Opaque cylinder \\
\hline & 2000 & 1 & 5 & 600 & 0 & Off & On & \\
\hline & 400 & 1 & 5 & 600 & 0 & Off & On & \\
\hline 10 & 3200 & 2 & N/A & 600 & 0 & Off & On & Clear bubble cylinder (6") \\
\hline 11 & 2000 & 2 & N/A & 600 & 0 & Off & On & Clear bubble cylinder (6") \\
\hline 12 & 1000 & 2 & N/A & 600 & 0 & On at $5 \mathrm{~s}$ & On & Clear bubble cylinder (6") \\
\hline 13 & 1000 & $1,1 / 2$ & 5 & 600 & 0 & Off & On & Opaque cylinder \\
\hline
\end{tabular}




\subsection{EXPERIMENTAL RESULTS AND ANALYSIS}

\subsubsection{General Results}

In the lab experimental environment when the glassware to be cut is at a cool temperature, preheating of glassware is required for the laser glass cutting to avoid cracking the glassware. The preheat temperature has to be above the glassware's annealing point, typically, ranging from $500{ }^{\circ} \mathrm{C}$ to $600{ }^{\circ} \mathrm{C}$ depends on the type of glassware. It was found that the required preheating temperature for clear glassware is $500{ }^{\circ} \mathrm{C}$, which is lower than $600{ }^{\circ} \mathrm{C}$ that required

for opaque glassware. This is consistent with measurements that were made in the Davis Lynch Glass Company where the working temperature for clear cylinder was about $100{ }^{\circ} \mathrm{C}$ lower than that for opaque glassware, indicating that the annealing point for the clear cylinder is lower than the opaque glassware. However, no evidence shows that the preheating temperature has significant effect on the process of laser glass cutting.

It was found that, in the laser glass cutting using the melting/vaporizing mechanism, a pulling mechanism is necessary to achieve quick and stable separation of moil from the glassware, especially in cutting glassware with a big diameter and thick wall. Vaporization alone is not able to separate the glassware from the moil under normal condition (medium power and typical size glassware), although it definitely helps the laser to penetrate into the glassware. At the same time, without an external pulling force to separate the glassware and the moil, melting alone is also not able to separate the glassware due to the tension in the liquid glass. Applying a pulling force to the glassware product and the moil is an effective means to separate the liquid 
glass. Gravity of the moil can act as a pulling force in cutting glassware with thin walls and small diameters. In this case, only a small amount of pulling force is required and not much wobbling will occur. Wobbling refers to eccentric rotation and was noted in the laser glass cutting of bigger (diameter $>150 \mathrm{~mm}$ ) or thicker (thickness $>5 \mathrm{~mm}$ ) glassware without the pulling. In cutting typical glassware with a relatively bigger size, the gravity of the moil alone cannot function as the pulling force. First, the gravity of moil for the same type glass varies and thus is not predictable and may not be sufficient. Second, wobbling will occur in cutting when glassware is rotating and separation does not occur simultaneously in all sections of the cutting ring. There are two reasons for this non-simultaneous separation. First, non-uniform wall thickness in the cutting ring will cause non-uniform melting/vaporizing, thus causing nonsimultaneous separation. Second, eccentricity of the glassware will cause the distribution of laser input energy to be non-uniform in the cutting ring when the glassware is rotating. This also causes non-uniform melting/vaporizing and causes non-simultaneous separation.

It was found that, using the pulling mechanism, the separation and the quality of the cutting edge are greatly sensitive to the amount of pulling force as well as the thickness of the glassware. When the thickness of glassware is irregular, the prediction of the required pulling force becomes difficult, and the quality in the cutting edge will vary from one section to another section according to its thickness. How much pulling force is required, when it is to be applied and how it is to be applied needs further investigation.

A cold air purge was used in experiments with Sample ID 21 and ID 22 in Table 5.3 and Sample ID 8 in Table 5.5. They all broke as a result. The reason is that the cold air introduced significant thermal stress that caused the glassware to crack. However, the grooves that were formed was clear, narrow and deep, leading one to think about a new method to assist laser glass 
cutting - the use of a hot gas jet as an alternative way to accomplish the separation in laser glass cutting.

It was found that the laser power plays a very important role in laser glass cutting. The required power of laser is largely determined by the size of glassware, thickness of the glassware wall, and the time expected to cut the glassware. It was shown that a $100 \mathrm{~W} \mathrm{CO}_{2}$ laser could cut glassware with a thin wall (less than $2 \mathrm{~mm}$ ) and a small diameter (less than $60 \mathrm{~mm}$ ). However, in order to cut the typical glassware produced by West Virginia hand glass manufacturers, a $\mathrm{CO}_{2}$ laser with power ranging from 500 to $1500 \mathrm{~W}$ is appropriate.

The "typical glassware" mentioned in this dissertation usually has a diameter ranging from $60 \mathrm{~mm}$ to $150 \mathrm{~mm}$, and a thickness ranging from $2 \mathrm{~mm}$ to $5 \mathrm{~mm}$.

More detailed results from the actual experiments and the micrograph analysis performed thereafter are discussed in Sections 5.4.2 to 5.4.10.

\subsubsection{Cutting Mechanism}

The modeling and simulation work described in Chapter 3 and Chapter 4 found that in laser glass cutting, a laser even with a power of $100 \mathrm{~W}$ can produce a sufficiently high local instantaneous temperature to let the melting and vaporizing in the glass happen. This combined effect constitutes the basic mechanism of the proposed laser glass cutting method, cutting by melting and/or vaporizing, described in this dissertation.

The vaporization of glass discussed here refers to the decomposition of glass basically into silicate, soda and calcium. The decomposition takes place almost instantly when the laser strikes the glassware. While the vaporization takes a portion of laser input energy, the amount of 
glass vaporized is limited as discussed in Section 5.4.4. It is partially because of the high special energy for vaporization and partially because of the deposit of vapor back to the glassware. Melting of the glass also occurs, and it takes less energy from the laser input. However, the process is slower than the vaporization process.

Figure 5.15 and Figure 5.16 show the two thermal phenomena in the glassware when using the laser glass cutting mechanism. The two distinct zones can be seen, i.e. the vaporization zone near the surface and melting zone right below the vaporization zone. The vaporization zone is resulted from the vaporization and forms a clear groove. The melting zone is resulted from the melting process. Melting zone is much deeper than the vaporization zone. Micrograph measurement can not tell the heating affected zone, another measure of the laser glass cutting process.

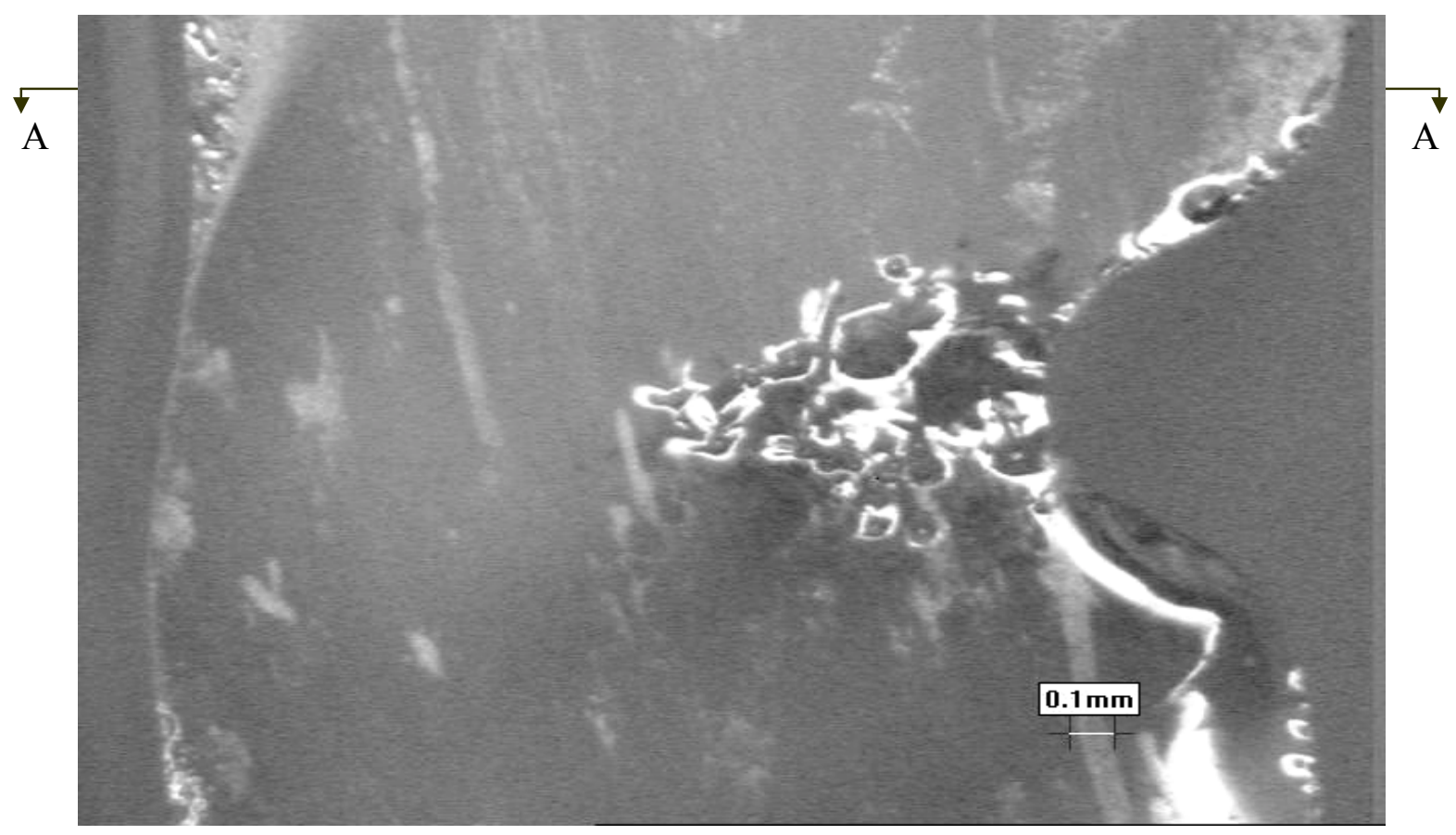

Figure 5.15 Melting and Vaporizing Phenomena in Laser Glass Cutting 

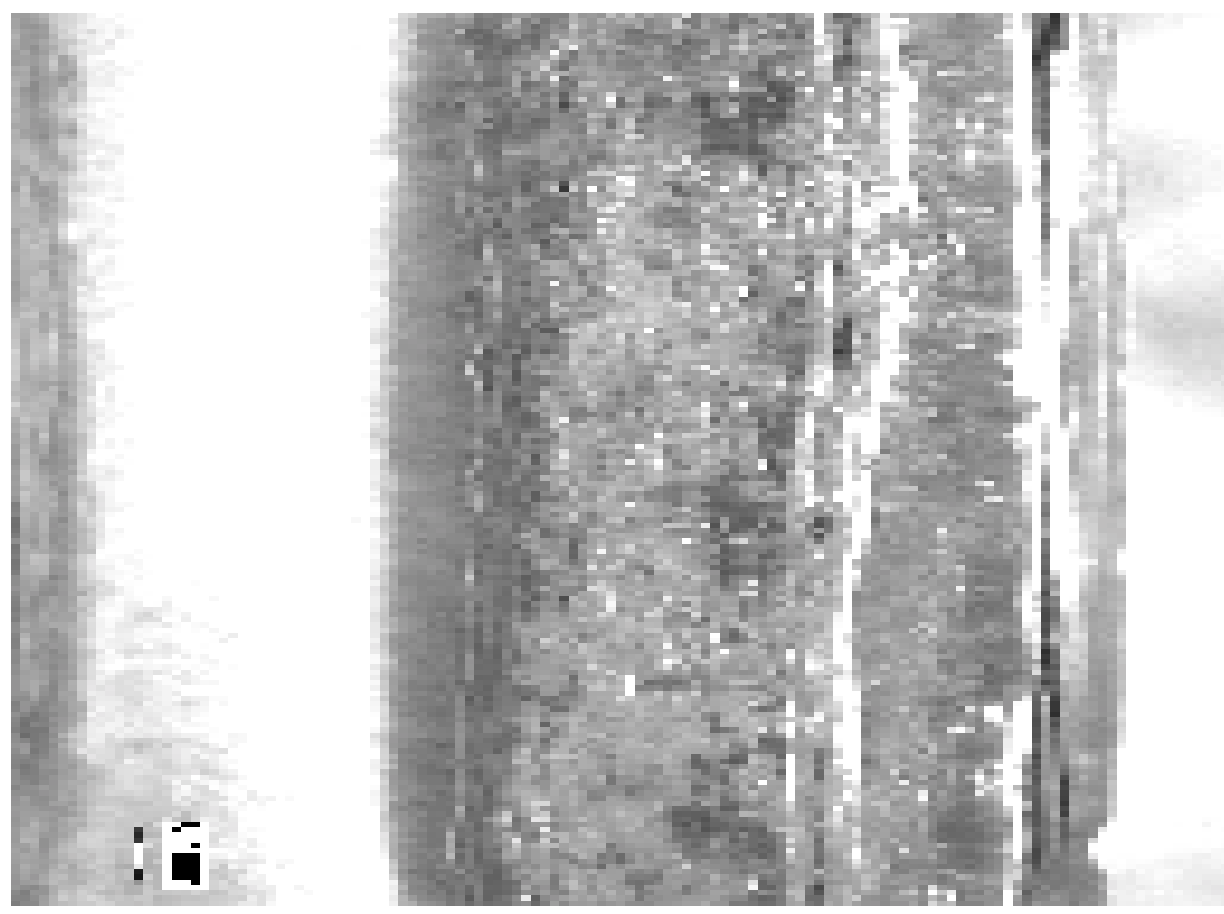

Figure 5.16 Melting and Vaporizing Phenomena in Laser Cutting (A-A View)

Vaporization occurs in the very local area where the laser is striking the glass and is expected to produce a narrow and straight groove. However, melting also occurs at the same time resulting in the flow of liquid glass and distortion of groove formed by the vaporization. The biggest benefit that vaporization provides is that it causes the laser energy to penetrate into the glassware, thus enhancing the melting process. However, melting of the glass will interfere with the vaporization and, therefore, the two processes are not mutually beneficial. It is proposed that when the glass is liquid, vaporization will become less efficient due to the rapidlly increasing thermal conductivity.

Glass will possess a plastic-like behavior and lose its brittle nature when the temperature is beyond its softening point. The glass tends to slip when it is softening and is subjected to tension. This tension could be caused by gravity pulling on the moil or an intentionally applied pulling force. Continuation of the slip initiates the separation of the glassware product from the 
moil and facilitates penetration of the laser into the glassware at the same time. This, in turn, facilitates cutting process. However, on the other hand, this kind of gradual slip has an effect on the shape formation of the cutting edge. It tends to stretch the glass to form a half "V" shaped edge instead of a flat rectangular edge with round corner "U" shape. Continuing to fire the laser can eliminate this undesired cutting edge shape by melting the edge surface if the slip occurs at an appropriate rate, that is, not faster than the laser can melt and vaporize it. This slipping rate can possibly be controlled by controlling the pulling force applied to the glassware. Further investigation is needed to explore the relation between the pulling force and the formation of cutting edge. After the glassware is separated, the laser will continue to fire for a few seconds to 10 seconds for an edge polishing effect.

An observed phenomenon in the laser glass cutting is the resealing of the groove. The process of resealing is complicated. In general, a groove is formed first by the vaporization. Then the glass in the surface of the groove starts to melt and flow. At a certain location and a certain point of time, the liquid glass from both sides of groove joins due to tension. This glass fusion is solidified when the glass cools. Resealing of the groove in the glass blocks penetration of the laser into the glass during the following rotations of the glassware, which complicates the cutting.

Three groove geometries could be formed when resealing is present as shown in Figure 5.17. First, the groove is deep without resealing. Second, resealing happens sometime after the groove is formed. In this case, resealing at a location between groove bottom and surface occurs, forming a cavity. Third, resealing occurs at the groove bottom. In this case, the groove is very wide and shallow, while the melting zone is deep. Figure 5.18 and Figure 5.19 show physical grooves that are partially resealed. 


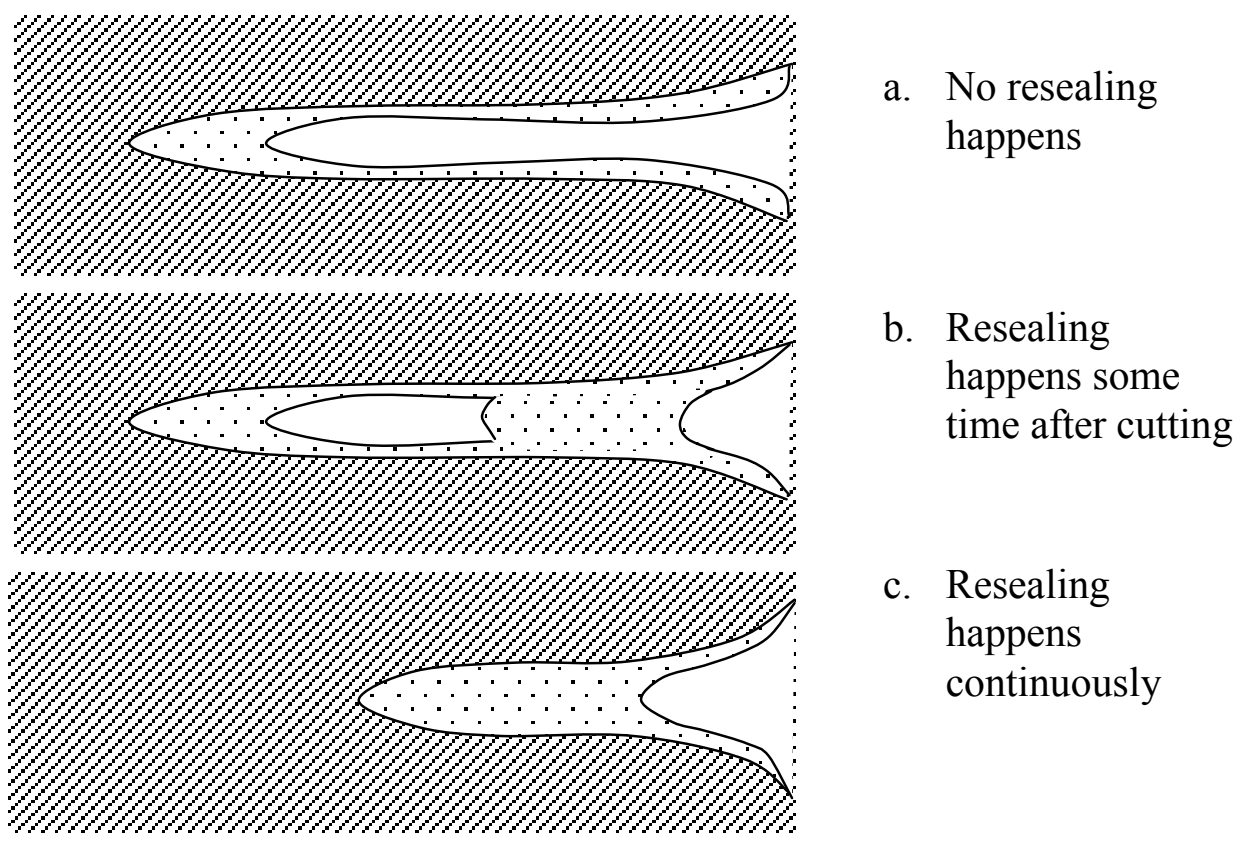

Figure 5.17 Three Types of Possible Groove Geometry

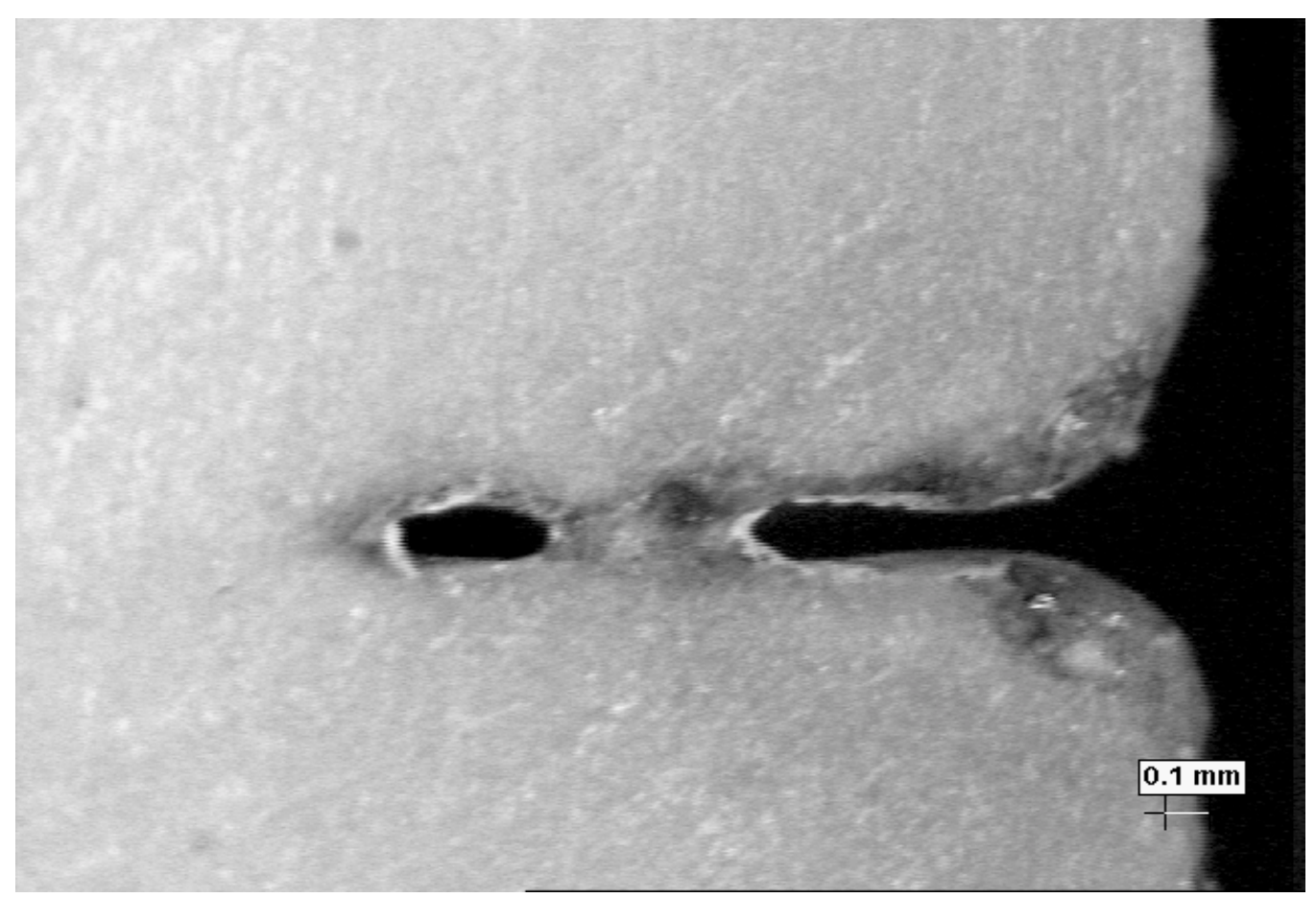

Figure 5.18 Resealing in Laser Glass Cutting (case one) 


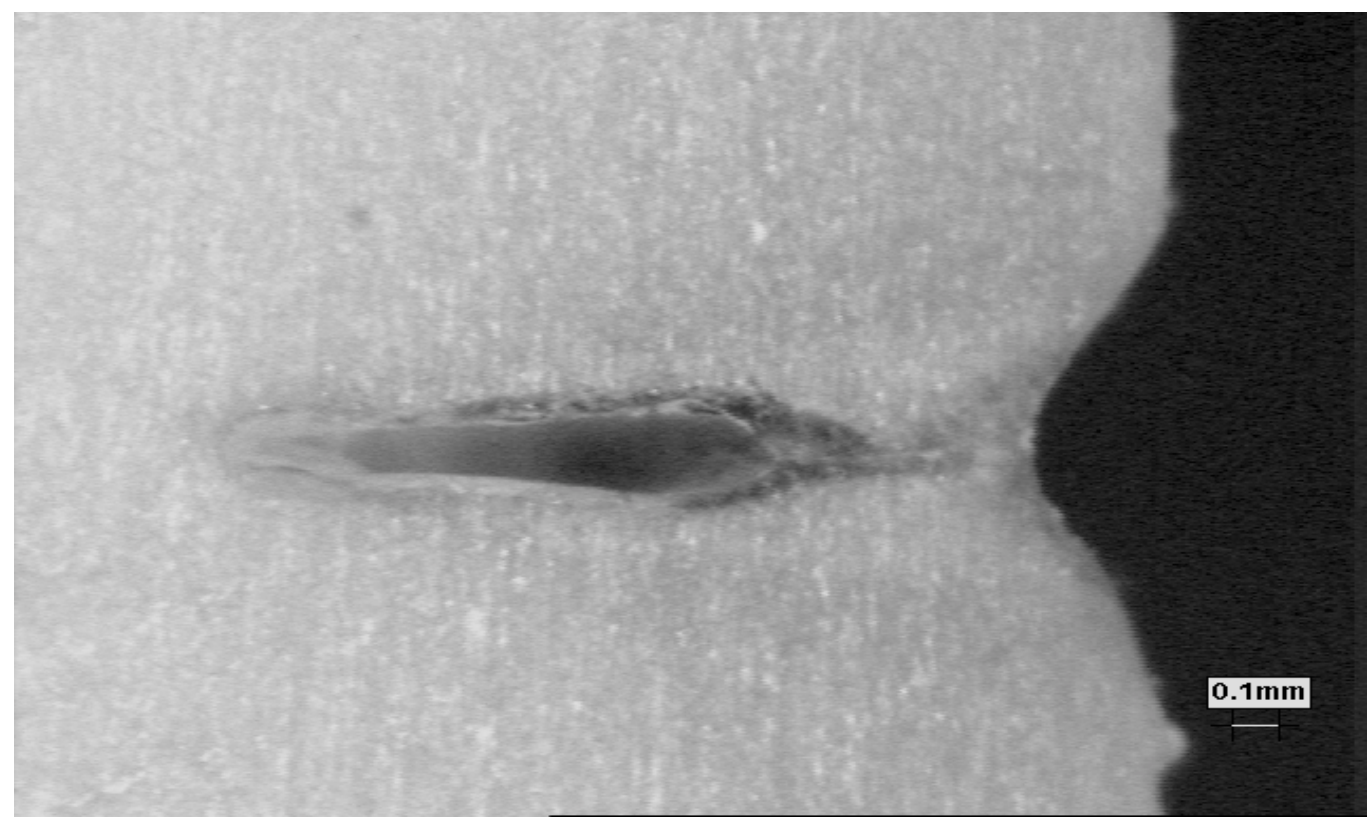

Figure 5.19 Resealing in Laser Glass Cutting (case two)

Since groove resealing makes the subsequent groove shallower, which subsequently partially blocks the laser penetration, the laser glass cutting process is diminished. Experiments show that increasing the glassware rotation speed can reduce the resealing problem, especially when the laser power is also increased. Increasing the glassware rotation speed enables heat from the laser to be more uniformly distributed along the cutting ring instead of being overly focused in one local area of the cutting ring at a certain time. Therefore, the local melting effect can thus be limited to some extent. Chui [14] also describe a resealing problem in his investigation to use the laser to cut flat glass. However, he suggests decreasing the speed and increasing the laser power according to the formula

$$
\mathrm{P} / \mathrm{V}=4.88 \mathrm{~d}^{2}
$$

where $\mathrm{P}$ is laser power, $\mathrm{V}$ is the speed and $\mathrm{d}$ is the thickness. This equation makes sense for laser cutting of flat glass, since it is a single-cycle cut, and limiting the speed to allow enough 
vaporization to take place seems to be the best way to avoid resealing and to get separation of flat glass.

\subsubsection{Cutting Characteristics}

\section{Cutting Zone Geometry}

There are four important dimensions to measure the cutting zone geometry, namely, melting zone depth $\mathrm{D}_{\mathrm{m}}$, groove width $\mathrm{W}_{\mathrm{g}}$, groove depth $\mathrm{D}_{\mathrm{g}}$ and heat affected zone width $\mathrm{W}_{\text {haz }}$. Measurements of the groove width $\mathrm{W}_{\mathrm{g}}$ and the groove depth $\mathrm{D}_{\mathrm{g}}$ are represented in Figure 5.20. Since the groove width when measured in the surface is very sensitive to the location of measurement, it is measured at the location $0.5 \mathrm{~mm}$ under the surface. Measurement of the melting zone depth is represented in the Figure 5.21. Due to the fuzzy boundary, determination of the melting zone is somewhat approximate, as is the melting zone depth. A straight line is drawn in the fuzzy melting front, and the melting zone depth is measured as the distance from the surface of the glassware to this straight line. Measurement of the heat affected zone is represented in Figure 5.22. Like the melting zone, the boundary of the heat affected zone is also fuzzy. Similarly, two straight lines are first drawn in the heating fronts indicated by the two white fuzzy strips, and the heat affected zone width is measured as the distance between these two straight lines. 


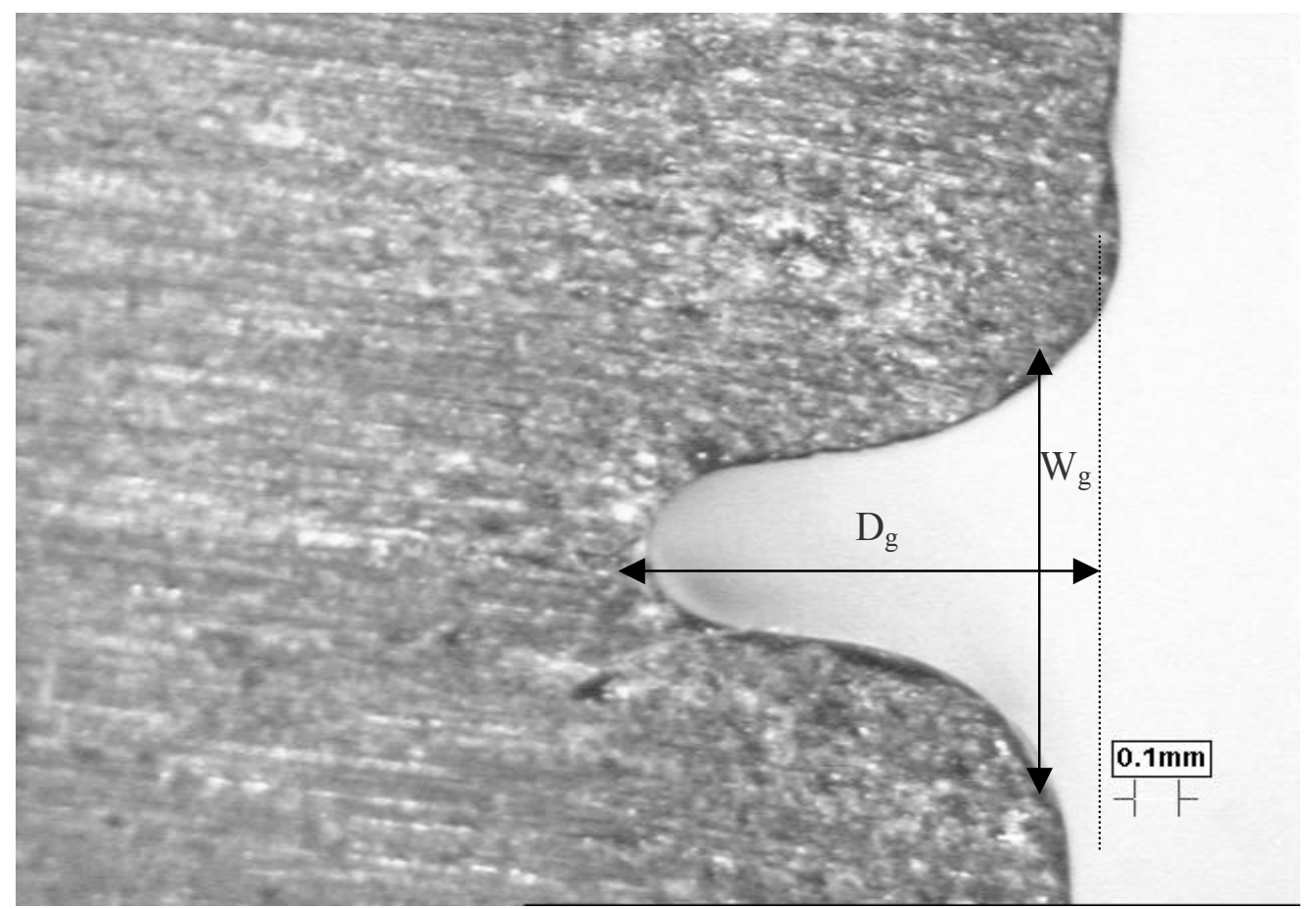

Figure 5.20 Groove Depth and Width
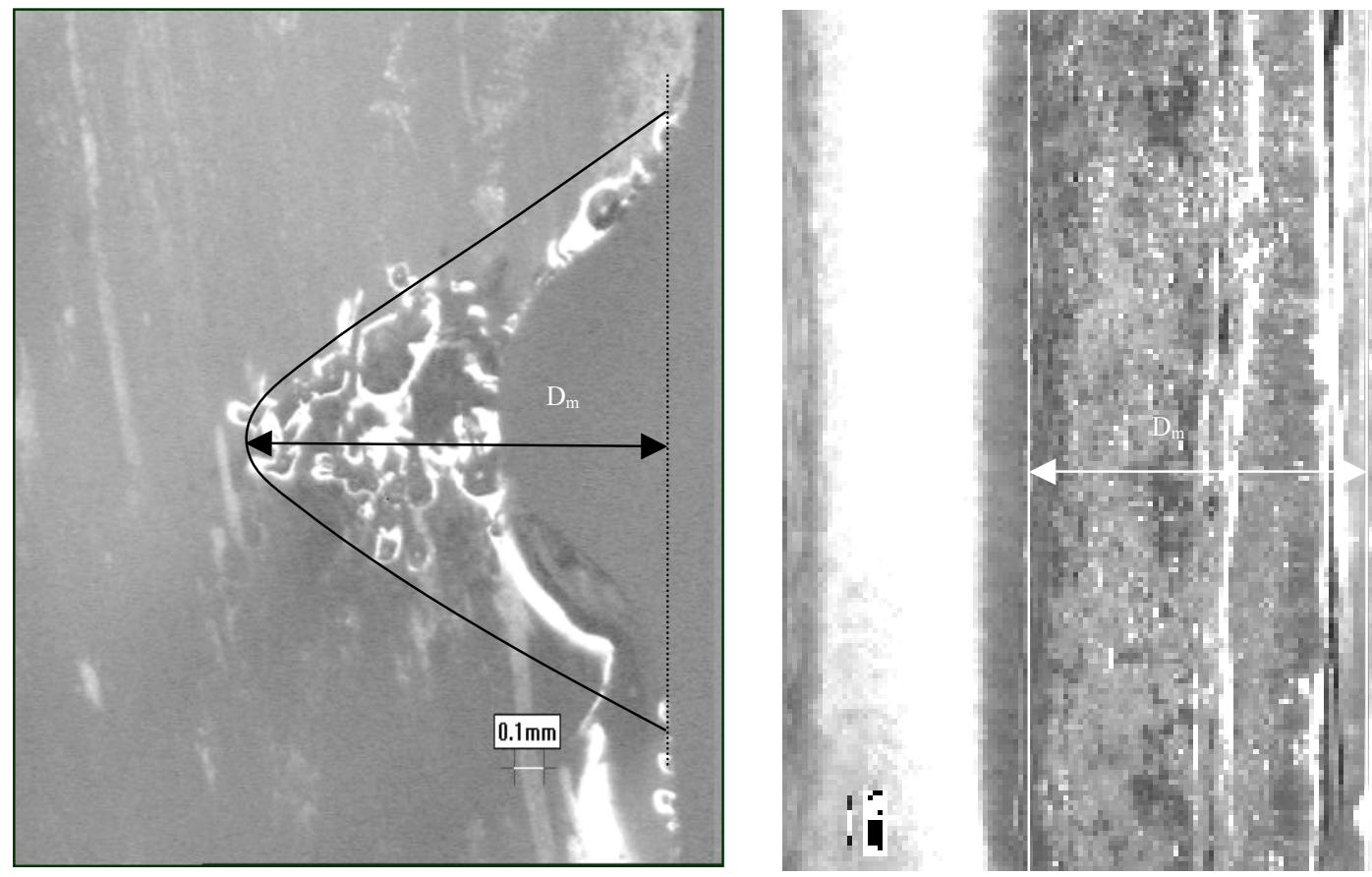

Figure 5.21 Melting Zone Depth 


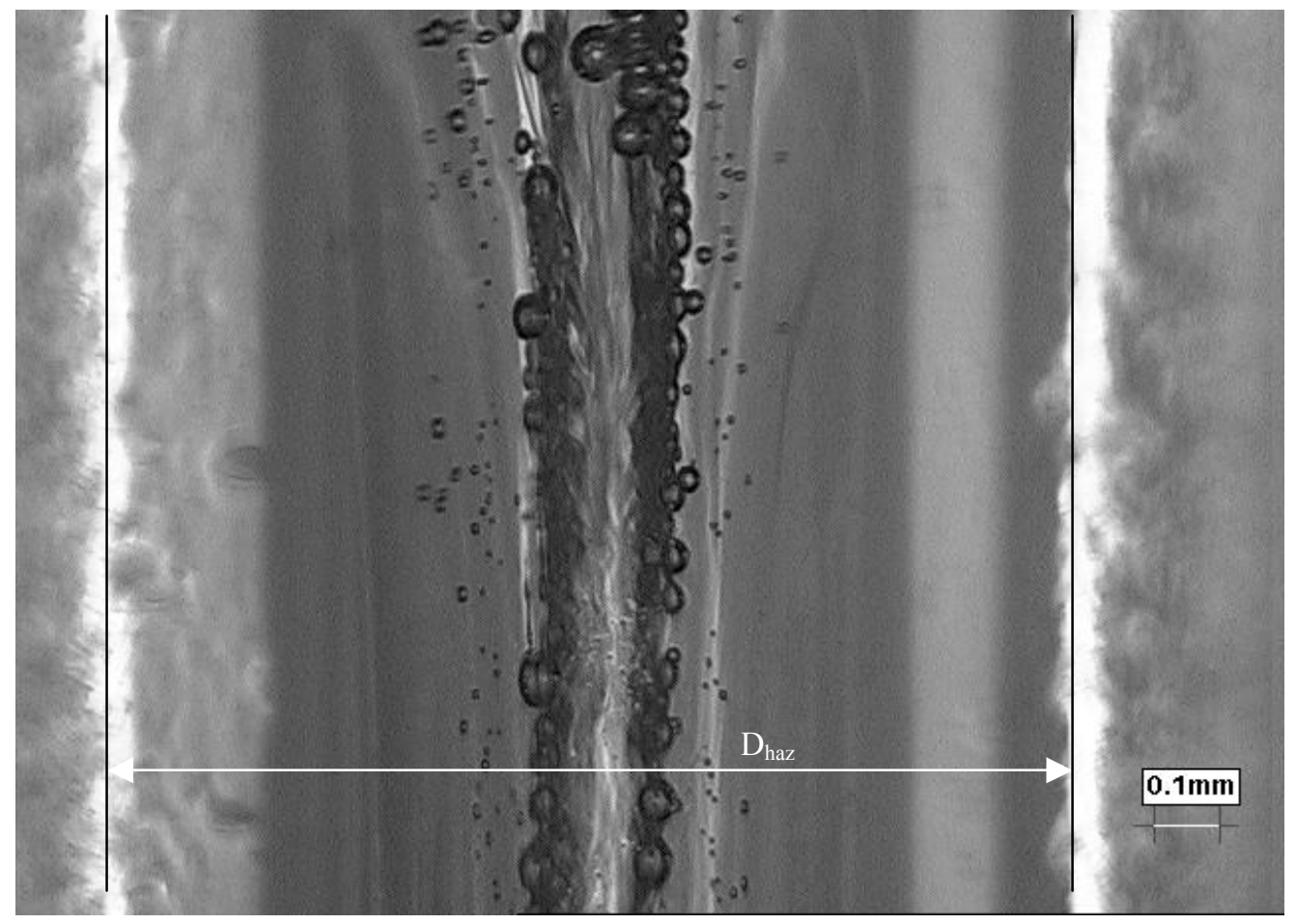

Figure 5.22 Heat Affected Zone Width

Such geometrical dimensions were obtained through optical measurement and analysis for every glassware sample after laser glass cutting. Table 5.6 lists those data acquired from experiments on one champagne bottle (ID 5 in Table 5.4) and four wine bottles. The ratio of groove depth to groove width is computed to indicate the groove shape. For the champagne bottles, although the groove depth or width varies from one sample to the other due to the different laser firing time, the ratio of depth to width was approximately a constant value of about 1.0. For the wine bottles, this ratio was about 0.30 , which is significantly smaller than that for the champagne bottles. It is thus concluded that the ratio of depth to width is not time dependent, and is only affected by the operation parameters and the glass material type. It was also found that melting zone in the wine bottle is much deeper than the groove depth. This fact indicates that a wider and shallower groove is normally associated with a deeper melting zone. 
One experiment showed that when an air purge is used, this depth/width ratio in wine bottles can reach 2.5 , however the melting zone depth was also reduced. The air purge keeps the groove narrow and straight. More results about the air purge are discussed in Section 5.3.10.

Table 5.6 Geometrical Dimensions of Cutting Zone

\begin{tabular}{|c|c|c|c|c|c|}
\hline GLASSWARE TYPE & $\begin{array}{c}\text { LASER } \\
\text { FIRING TIME } \\
\text { (SECONDS) } t_{C}\end{array}$ & $\begin{array}{l}\text { GROOVE WIDTH } \\
(\mathrm{mm}) \\
\mathrm{W}_{\mathrm{g}}\end{array}$ & $\begin{array}{c}\text { GROOVE DEPTH } \\
(\mathrm{mm}) \\
\mathrm{D}_{\mathrm{g}}\end{array}$ & $\begin{array}{c}\text { MELTING } \\
(\mathrm{mm}) \\
\mathrm{D}_{\mathrm{m}}\end{array}$ & $\begin{array}{c}\text { GROOVE DEPTH } \\
\text { / GROOVE WIDTH } \\
\mathrm{D}_{\mathrm{g}} / \mathrm{W}_{\mathrm{g}}\end{array}$ \\
\hline Wine Bottle & $>5$ & 1.22 & 0.63 & 1.55 & 0.51 \\
\hline Wine Bottle & 5 & 0.86 & 0.29 & 1.64 & 0.33 \\
\hline Wine Bottle & 5 & 0.80 & 0.21 & 1.64 & 0.27 \\
\hline Wine Bottle & 10 & 0.35 & 0.88 & $\sim 0.88$ & $2.51 *$ \\
\hline Champagne Bottle & 10 & 1.04 & 0.99 & $\sim 0.99$ & 0.95 \\
\hline Champagne Bottle & 8 & 0.63 & 0.66 & $\sim 0.66$ & 1.04 \\
\hline Champagne Bottle & 4 & 0.57 & 0.50 & $\sim 0.50$ & 0.88 \\
\hline Champagne Bottle & 2 & 0.38 & 0.31 & $\sim 0.31$ & 0.84 \\
\hline Champagne Bottle & 1 & 0.32 & 0.32 & $\sim 0.32$ & 1.00 \\
\hline
\end{tabular}

Note: * - with purge gas

\section{Cutting Edge}

Typically, four sections, $\mathrm{S}_{1}, \mathrm{~S}_{2}, \mathrm{~S}_{3}$ and $\mathrm{S}_{4}$, in the cutting edge can be distinguished from the outer surface to the inner surface as shown in Figure 5.23. The features of these four sections 
and their causes are listed in Table 5.7. $S_{1}$ is smooth while $S_{3}$ is always very rough. The quality of $S_{2}$ with much bubbling is in between $S_{1}$ and $S_{3}$. The quality varies from one experiment to another. $\mathrm{S}_{4}$ is smooth and narrow. It is formed due to the glassware thinning effect in laser cutting.

The thickness of the glassware affects this distribution of sections. Figure 5.24 shows the cutting edge from the same sample glassware as that in Figure 5.23, but it is $0.5 \mathrm{~mm}$ thinner. It was found that $\mathrm{S}_{2}$ in the thinner wall portion is smoother and merges with $\mathrm{S}_{1}$, and $\mathrm{S}_{3}$ is narrower and shifts to the outer surface. Also, $\mathrm{S}_{4}$ in the thinner wall portion is wider. The reason for this is that more melting happens in the thinner wall portion before the pulling force takes place. The thicker the wall, the less the melting can penetrate. $\mathrm{S}_{1}$ and $\mathrm{S}_{4}$ will thus become narrower, while $\mathrm{S}_{1}$ and $\mathrm{S}_{3}$ will become wider.

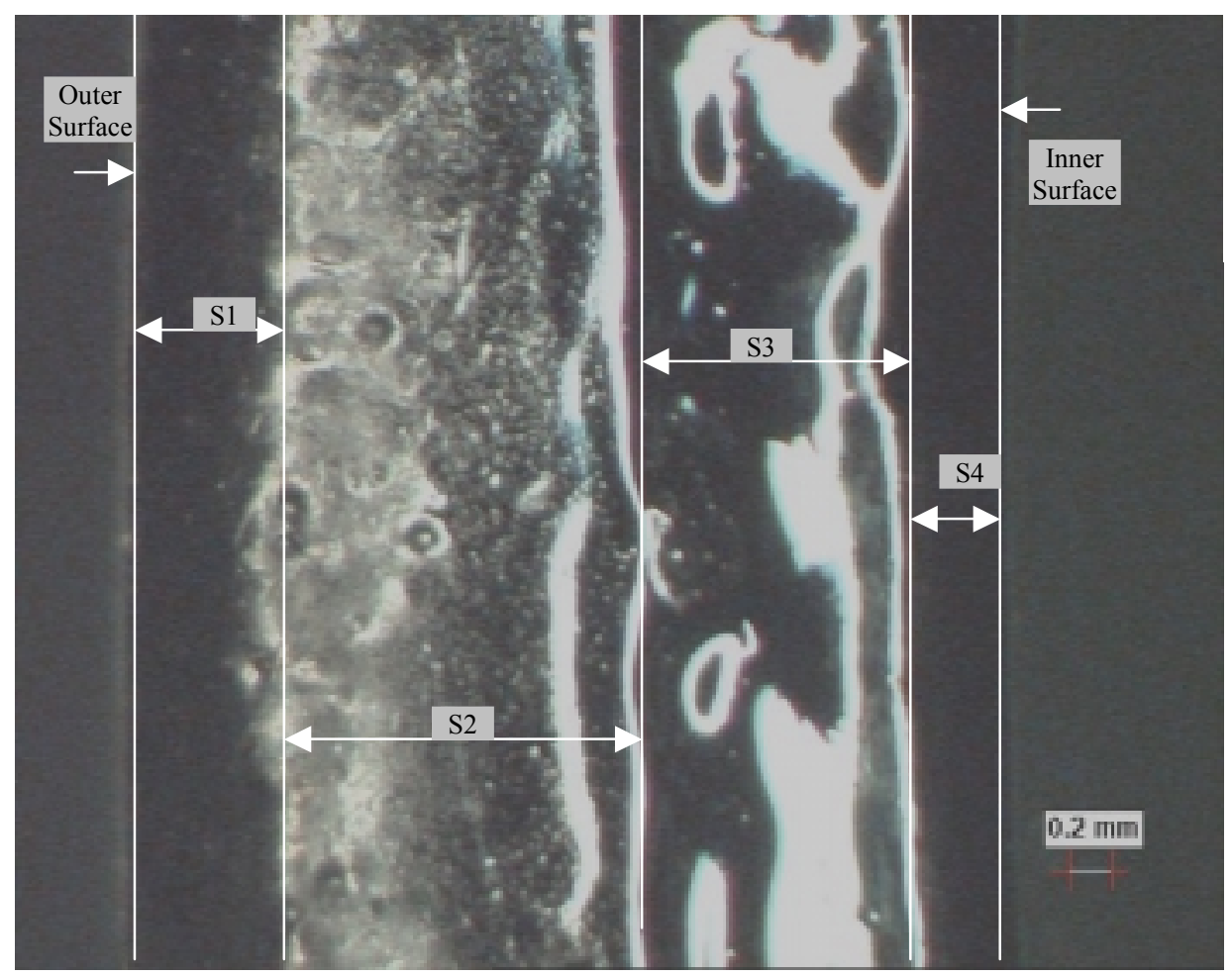

Figure 5.23 Cutting Edge Features $\left(P=1000 \mathrm{~W}, \omega=1 \mathrm{r} / \mathrm{s}, d_{0}=4.3 \mathrm{~mm}\right)$ 


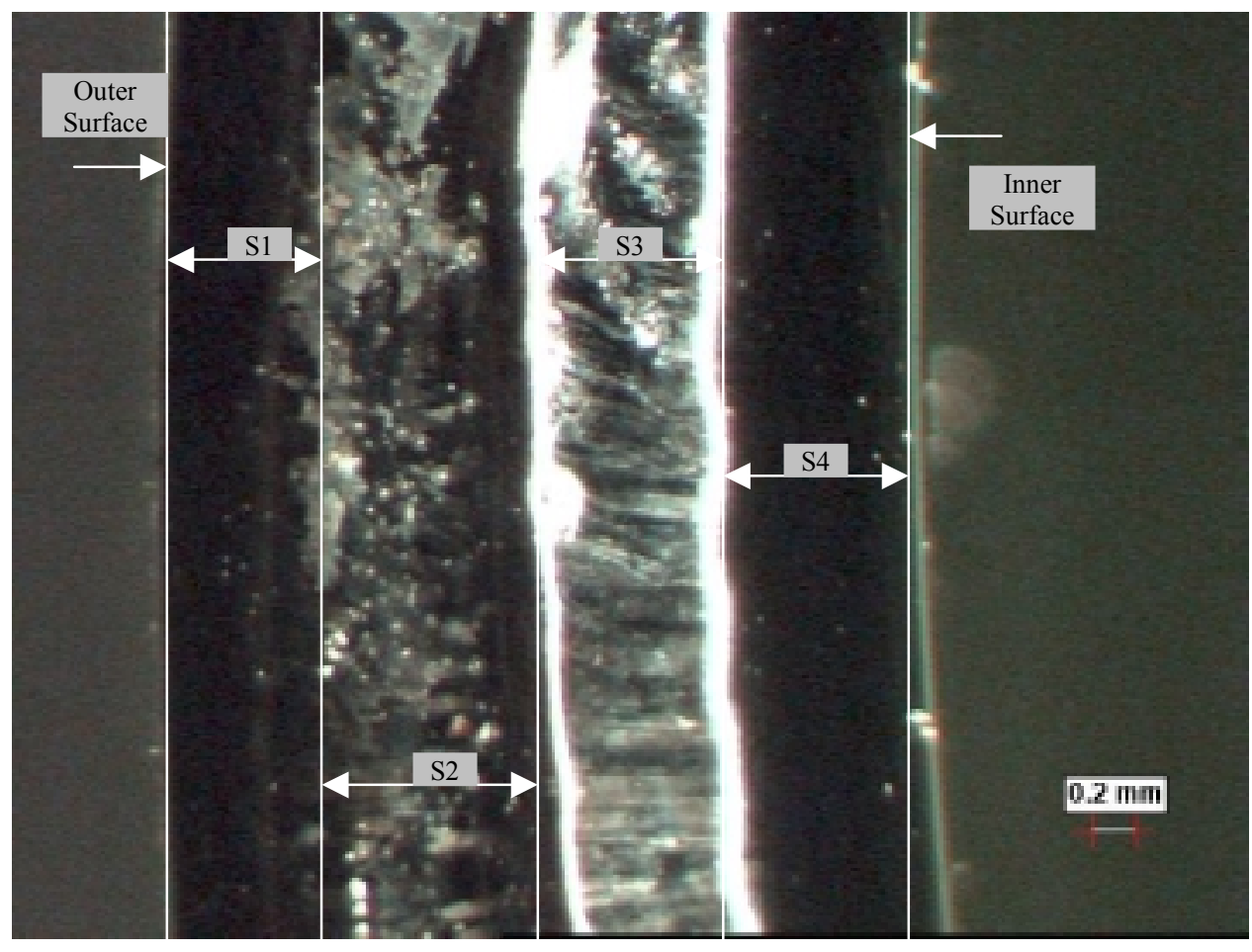

Figure 5.24 Cutting Edge Features $\left(P=1000 \mathrm{~W}, \omega=1 \mathrm{r} / \mathrm{s} d_{0}=3.8 \mathrm{~mm}\right)$

Table 5.7 Distinct Sections and Features in the Cutting Edge

\begin{tabular}{||c|c|c|c|c||}
\hline \multirow{2}{*}{} & \multicolumn{4}{|c||}{ SECTION } \\
\cline { 2 - 5 } & $\mathrm{S}_{1}$ & $\mathrm{~S}_{2}$ & $\mathrm{~S}_{3}$ & $\mathrm{~S}_{4}$ \\
\hline Causes & melting and polishing & melting & melting and pulling & thinning \\
\hline Features & smooth, some bubble & rough & very rough & smooth \\
& & bubble & bubble & few bubble \\
\hline
\end{tabular}

\subsubsection{Mass Transfer}

Mass transfer in laser glass cutting was investigated using wine bottles (ID 12 to 19 in Table 5.3). Two levels of power $(600 \mathrm{~W}$ and $1000 \mathrm{~W})$, and two levels of rotation speed $(1 \mathrm{r} / \mathrm{s}$ and $4 \mathrm{r} / \mathrm{s}$ ), are specified. The preheating temperature is controlled at $600{ }^{\circ} \mathrm{C}$, and laser-firing time is controlled at 5 seconds. 
The weight of each wine bottle was measured before and after the experiment. The mass loss due to vaporization in each case is listed in Table 5.8. No evidence was found that the laser power level or glassware rotation speed has a significant effect on the mass loss. It can be concluded that the mass loss in each case is very limited.

Table 5.8 Mass Losses in Laser Glass Cutting

\begin{tabular}{||c|c|c|c||}
\hline \multirow{2}{*}{ Case } & \multirow{2}{*}{ Laser Power $(\mathrm{W})$} & \multicolumn{2}{|c||}{ Rotation Speed (rev/sec) } \\
\cline { 3 - 4 } & & & 4 \\
\hline \hline $\mathrm{A}$ & 1000 & $0.21 \mathrm{~g}$ & $0.26 \mathrm{~g}$ \\
\hline $\mathrm{B}$ & 1000 & $0.24 \mathrm{~g}$ & $0.40 \mathrm{~g}$ \\
\hline $\mathrm{C}$ & 600 & $0.08 \mathrm{~g}$ & $0.11 \mathrm{~g}$ \\
\hline $\mathrm{D}$ & 600 & $0.35 \mathrm{~g}$ & $0.30 \mathrm{~g}$ \\
\hline
\end{tabular}

The volume of the groove for case A and case B were measured as $38.6 \mathrm{~mm}^{3}$ and 41.8 $\mathrm{mm}^{3}$, respectively. The mass losses were $0.21 \mathrm{~g}$ and $0.24 \mathrm{~g}$, respectively. The estimated mass density is $5440 \mathrm{~kg} / \mathrm{m}^{3}$ and $5740 \mathrm{~kg} / \mathrm{m}^{3}$, respectively. They are considerably larger than the density of soda lime glass, which is $2440 \mathrm{~kg} / \mathrm{m}^{3}$.

The energy of vaporization of glass is defined as the required energy (in W) to vaporize a unit volume of glass (in $\mathrm{cm}^{3}$ ). Chui [14] published a number for this energy of vaporization, which is $1.86 \times 10^{5} \mathrm{~J} / \mathrm{cm}^{3}$. According to Chui's number, a laser power of $1000 \mathrm{~W}$ and groove volumes of $38.6 \mathrm{~mm}^{3}$ and $41.8 \mathrm{~mm}^{3}$, the cutting times were expected to be 7.2 seconds and 7.8 seconds for case A and case B, while the actual cutting time was 5.0 seconds. On the other hand, the energy of vaporization can be estimated using the actual cutting time, laser power and groove volume. It was computed as about $1.25 \times 10^{5} \mathrm{~J} / \mathrm{cm}^{3}$. 


\subsubsection{Cutting Process}

Temporal behavior of melting and vaporizing will now be described. The sample glassware used in this experiment was a clear cylinder (ID 1 in Table 5.5). Operation parameters such as preheating temperature, rotation speed, focal position and purge status, are kept constant except for the laser firing time. The laser firing time varied between experiments. The cut sample was then prepared manually for the purpose of micrograph measurement and analysis.

Data of groove width $\mathrm{W}_{\mathrm{g}}$, groove depth $\mathrm{D}_{\mathrm{g}}$, melting zone depth $\mathrm{W}_{\mathrm{m}}$, and heat affected zone width $\mathrm{W}_{\text {haz }}$ measured on each experiment are listed in Table 5.9. Figure 5.25 shows the temporal behavior of these heating, melting and vaporizing. Figure 5.26 shows the raw data as well as the fitted curves. It can be found that with laser firing, both the melting and vaporizing progress, and so does heating.

Table 5.9 Laser Glass Cutting Process

\begin{tabular}{|c|c|c|c|c||}
\hline $\begin{array}{c}\text { LASER FIRING TIME } \\
(\text { Seconds })\end{array}$ & $\begin{array}{c}\text { GROOVE WIDTH } \\
(\mathrm{mm})\end{array}$ & $\begin{array}{c}\text { GROOVE DEPTH } \\
(\mathrm{mm})\end{array}$ & $\begin{array}{c}\text { MELTING ZONE DEPTH } \\
(\mathrm{mm})\end{array}$ & $\begin{array}{c}\text { HEAT AFFECTED } \\
\text { ZONE WIDTH (mm) }\end{array}$ \\
\hline 1 & 0.70 & 0.26 & 0.71 & 0.86 \\
\hline 2 & 0.46 & 0.20 & 0.57 & 1.07 \\
\hline 4 & 0.80 & 0.40 & 0.63 & 1.29 \\
\hline 6 & 1.36 & 0.50 & 1.00 & 1.84 \\
\hline 8 & 1.30 & 0.32 & 1.14 & 2.57 \\
\hline 10 & 1.52 & 0.54 & 1.14 & 3.2 \\
\hline 12 & 1.70 & 0.46 & 1.57 & 4.00 \\
\hline 14 & 1.40 & 0.64 & 1.86 & \\
\hline
\end{tabular}




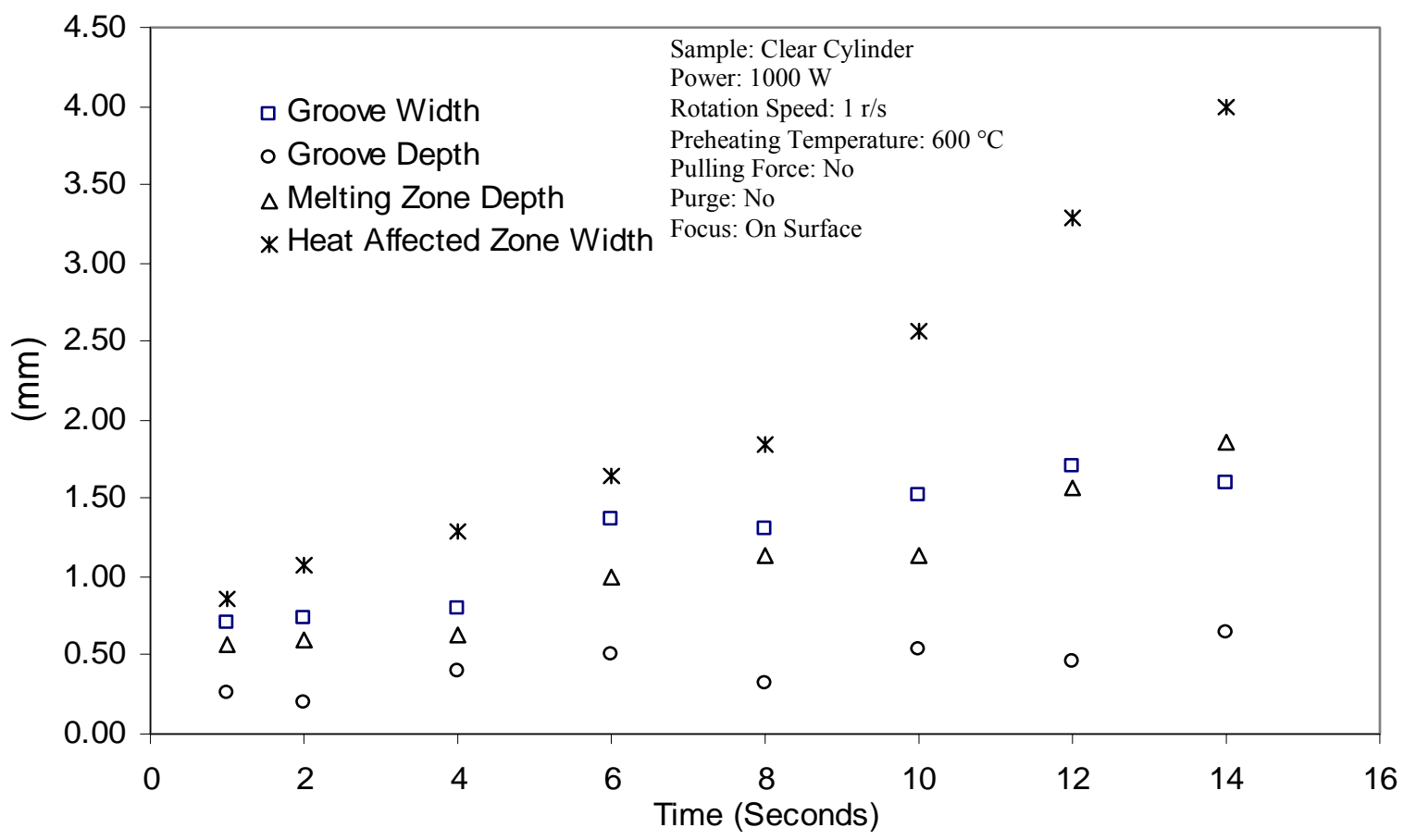

Figure 5.25 Laser Glass Cutting Process

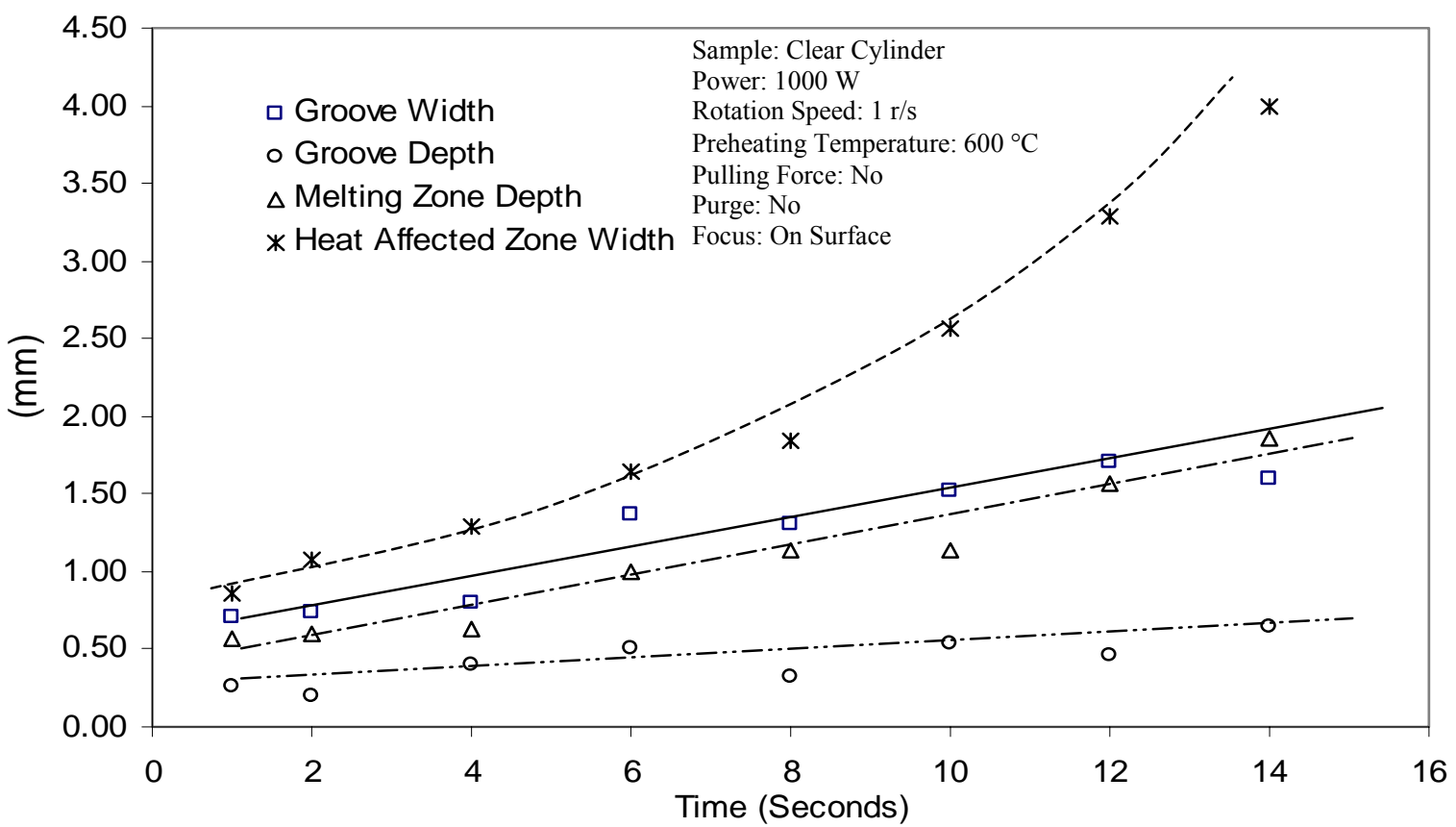

Figure 5.26 Laser Glass Cutting Process with Fitted Curves 


\subsubsection{Effect of Laser Power}

The effect of the level of laser power on laser glass cutting was obtained from experiments using opaque cylinders (ID 3 in Table 5.5). Operation parameters for the laser glass

cutting machine were kept constant except for the laser power. The constant operation parameters include rotation speed at $1 \mathrm{r} / \mathrm{s}$, preheating temperature at $600{ }^{\circ} \mathrm{C}$, no pulling force, no purge, laser focused on glassware surface, and a laser firing time of 5 seconds. Table 5.10 lists the process data from the experiments and Figure 5.27 graphically summarizes the effect of the level of laser power on cutting glassware.

It was found that the level of laser power has a significant effect on laser cutting. When the laser power was increased, the melting zone depth increased significantly. Increasing the power also increased the cutting groove width. However, this effect decreased as the power was further increased.

It was found from the experiments that increasing the laser power decreases the groove depth. When the laser power is increased, more melting will take place. It causes two things to happen. First, the vaporization of glass decreases when the glass becomes liquid. Second, liquid glass can flow back into the groove and make the groove become shallower. The groove becoming shallower is supported by the results from experiments with a laser firing time of 5 seconds. The results were shown in Table 5.10. Experiments of glass laser cutting with a laser firing time of 10 seconds were also performed on the same samples, and at two power levels (400 $\mathrm{W}$ and $1000 \mathrm{~W})$. These results were included in Table 5.10 to give the evidence that a higher laser power produces a shallower groove. 
Table 5.10 Effect of Laser Power on Cutting

\begin{tabular}{||c|c|c|c|c||}
\hline $\begin{array}{c}\text { LASER FIRING } \\
\text { TIME (seconds) }\end{array}$ & $\begin{array}{c}\text { LASER POWER } \\
(\mathrm{W})\end{array}$ & $\begin{array}{c}\text { GROOVE WIDTH } \\
(\mathrm{mm})\end{array}$ & $\begin{array}{c}\text { GROOVE } \\
\text { DEPTH (mm) }\end{array}$ & $\begin{array}{c}\text { MELTING ZONE } \\
\text { DEPTH (mm) }\end{array}$ \\
\hline \hline 5 & 400 & 0.56 & 0.44 & 0.79 \\
\hline 5 & 800 & 0.83 & 0.36 & 1.14 \\
\hline 5 & 1000 & 0.97 & 0.30 & 1.59 \\
\hline 5 & 1500 & 1.24 & 0.29 & 2.37 \\
\hline 5 & 2000 & 1.03 & 0.26 & 2.40 \\
\hline 10 & 400 & 0.86 & 0.60 & 3.09 \\
\hline
\end{tabular}

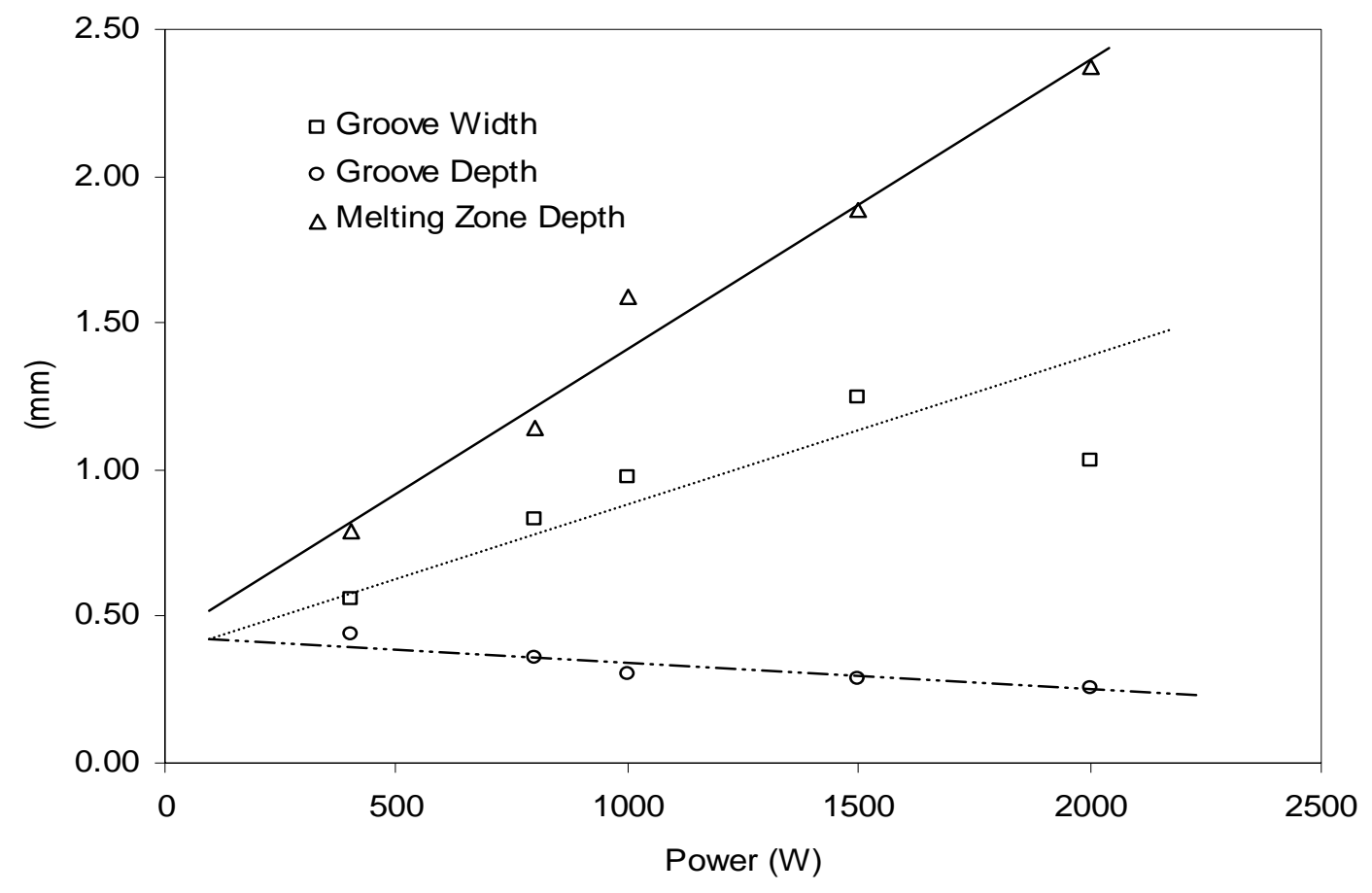

Figure 5.27 Effect of Laser Power on Cutting 


\subsubsection{Effect of Rotation Speed}

The effect of rotation speed on a single-path cut was obtained from experiments using wine bottles and champagne bottles (ID 20 in Table 5. 3 and ID 4 in Table 5.4). All operation parameters were kept constant except for the glassware rotation speed and the laser firing time. The rotation speed was specified as $1 \mathrm{r} / \mathrm{s}$ and $2 \mathrm{r} / \mathrm{s}$, respectively. The laser firing time was specified correspondingly as 1 second and 0.5 second to form a single-path cut. Constant operation parameters were laser power at $1000 \mathrm{~W}$ and preheat temperature at $600{ }^{\circ} \mathrm{C}$. There were no purge and no pulling force, and the laser focus was on the surface of the glassware. As examples, grooves from experiments on wine bottles are shown in Figure 5.28 and Figure 5.29.
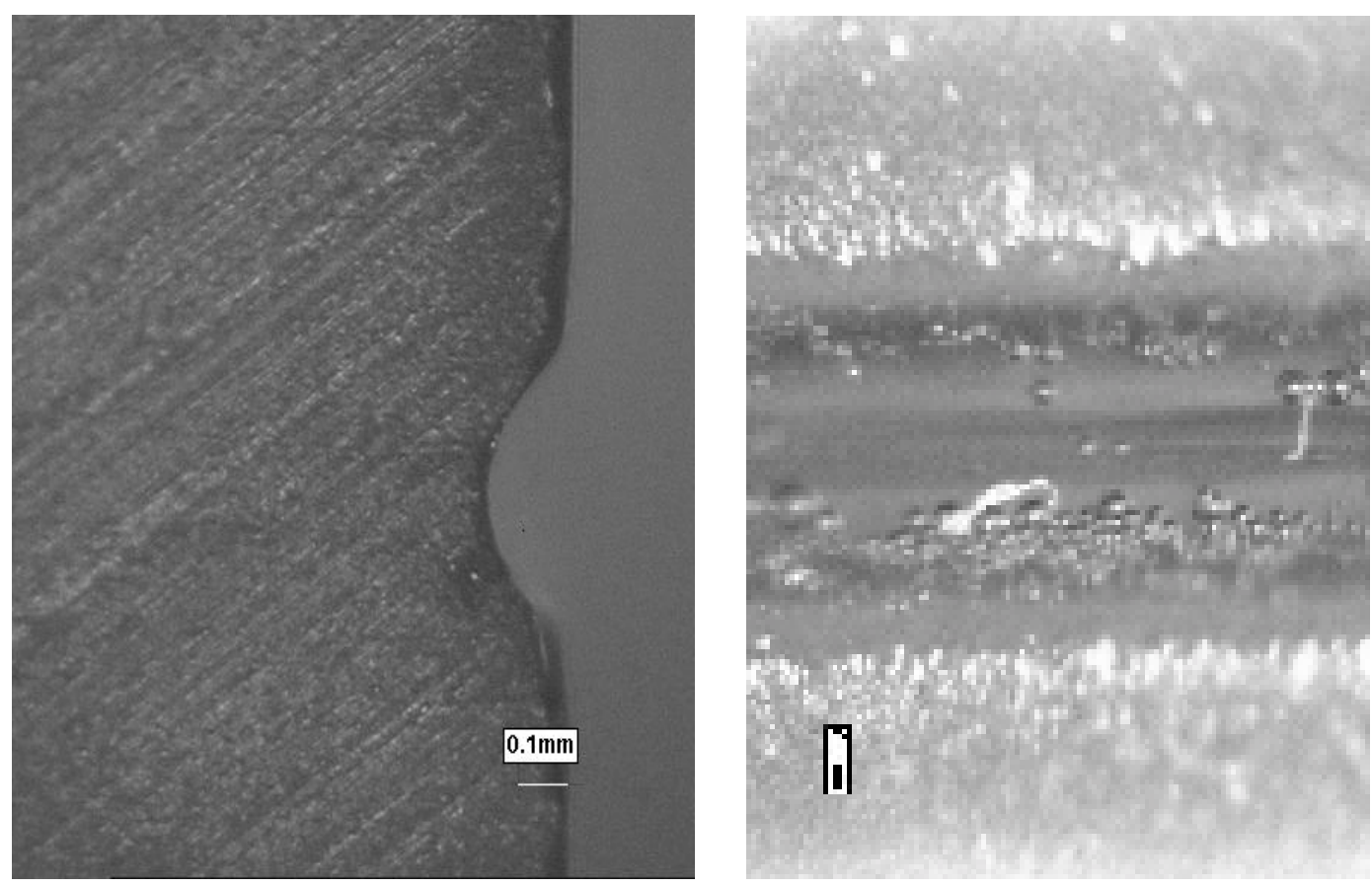

Figure 5.28 Single-path Groove Geometry $(\omega=1 \mathrm{r} / \mathrm{s}$, wine bottle) 

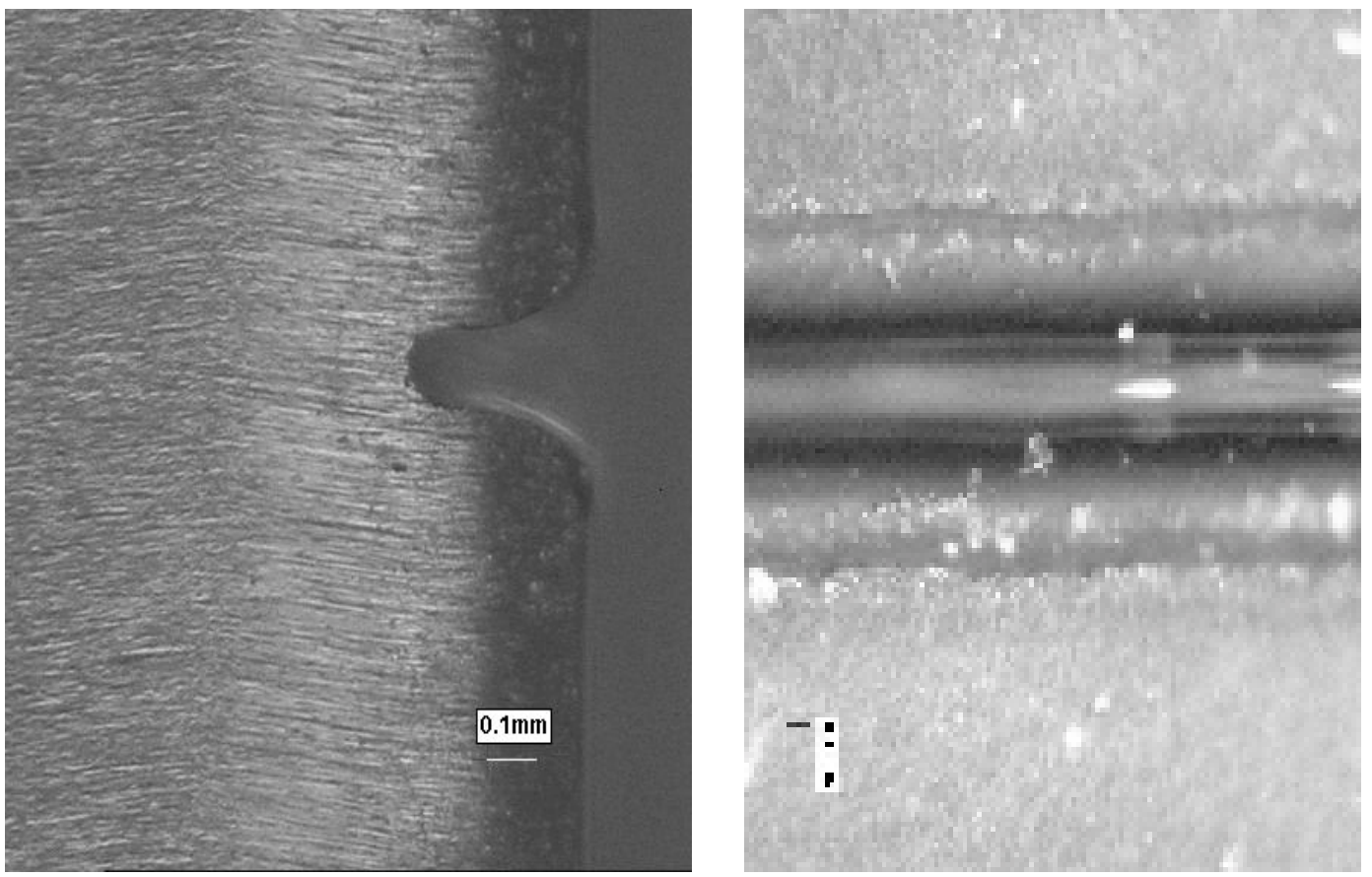

Figure 5.29 Single-path Groove Geometry $(\omega=2 \mathrm{r} / \mathrm{s}$, wine bottle)

Evidences from experiments in both samples show that, in single-path laser cutting, the rotation speed has an effect on both the cutting process and the cutting quality. The faster the glassware is rotating, the shorter the laser glass interaction, producing a narrower and cleaner groove with less bubbling. On the other hand, the slower the glassware rotates; the longer the laser glass interaction, producing a wider groove and more bubbling.

Multi-path results were obtained from experiments using clear cylinders and opaque cylinders (ID 1, 2, 7 in Table 5.4). Constant operational parameters include laser power at 1000 $\mathrm{W}$ and preheating temperature at $600{ }^{\circ} \mathrm{C}$. There was no pulling force, no purge, and the focus was on the surface. Table 5.11 and

Table 5.12 list the process data from the experiments on clear cylinder and opaque cylinder. 
Table 5.11 Laser Glass Cutting at Two Levels of Rotation Speed (Clear Cylinder)

\begin{tabular}{||c|c|c|c|c|c||}
\hline $\begin{array}{c}\text { SPEED } \\
(\text { REV/SEC) }\end{array}$ & $\begin{array}{c}\text { LASER FIRING TIME } \\
(\text { Seconds })\end{array}$ & $\begin{array}{c}\text { GROOVE WIDTH } \\
(\mathrm{mm})\end{array}$ & $\begin{array}{c}\text { GROOVE DEPTH } \\
(\mathrm{mm})\end{array}$ & $\begin{array}{c}\text { MELTING DEPTH } \\
(\mathrm{mm})\end{array}$ & $\begin{array}{c}\text { HEAT AFFECTED } \\
\text { ZONE DEPTH (mm) }\end{array}$ \\
\hline \multirow{3}{*}{1} & 1 & 0.70 & 0.26 & 0.57 & 0.86 \\
\cline { 2 - 6 } & 4 & 0.80 & 0.40 & 0.63 & 1.29 \\
\cline { 2 - 6 } & 12 & 1.30 & 0.32 & 1.14 & 1.84 \\
\hline \multirow{3}{*}{2} & 1 & 1.70 & 0.46 & 1.57 & 0.69 \\
\cline { 2 - 7 } & 4 & 0.40 & 0.20 & 0.87 & 0.86 \\
\cline { 2 - 7 } & 12 & 1.06 & 0.30 & 2.43 & 1.43 \\
\cline { 2 - 6 } & 12 & 1.14 & 0.62 & 2.86 & 1.86 \\
\hline
\end{tabular}

Table 5.12 Laser Glass Cutting at Two Levels of Rotation Speed (Opaque Cylinder)

\begin{tabular}{||c|c|c|c|c|c||}
\hline $\begin{array}{c}\text { SPEED } \\
(\mathrm{rev} / \mathrm{sec})\end{array}$ & $\begin{array}{c}\text { LASER FIRING TIME } \\
(\text { Seconds })\end{array}$ & $\begin{array}{c}\text { GROOVE WIDTH } \\
(\mathrm{mm})\end{array}$ & $\begin{array}{c}\text { GROOVE DEPTH } \\
(\mathrm{mm})\end{array}$ & $\begin{array}{c}\text { MELTING DPETH } \\
(\mathrm{mm})\end{array}$ & $\begin{array}{c}\text { HEAT AFFECTED } \\
\text { ZONE DEPTH (mm) }\end{array}$ \\
\hline \multirow{3}{*}{1} & 1 & 0.16 & 0.13 & 1.06 & 0.54 \\
\cline { 2 - 6 } & 4 & 0.50 & 0.21 & 1.19 & 1.21 \\
\cline { 2 - 6 } & 8 & 0.84 & 0.30 & 1.57 & 1.43 \\
\hline \multirow{3}{*}{4} & 12 & 0.90 & 1.00 & 1.83 & 1.86 \\
\cline { 2 - 7 } & 4 & $\mathrm{~N} / \mathrm{A}$ & 0.60 & $\mathrm{~N} / \mathrm{A}$ & 1.00 \\
\cline { 2 - 7 } & 12 & 0.31 & 1.29 & 1.29 & 1.40 \\
\cline { 2 - 7 } & 12 & 0.77 & 2.09 & 2.09 & 1.93 \\
\hline
\end{tabular}


Figure 5.30 shows the melting depth as a function of time at two levels of rotation speed. Figure 5.31 shows the groove width as a function of time at two levels of rotation speed. Figure 5.32 shows the heat affected zone width as a function of time at two levels of rotation speed. Figure 5.33 shows the groove depth as a function of time at two levels of rotation speed.

Again, it was found that the rotation speed has an effect on laser glass cutting. The faster the glassware rotates, the deeper the groove depth, the deeper the melting depth, and the narrower the groove width. This is because the average temperature in the cutting ring is higher when the glassware is rotated faster, allowing the heat to penetrate deeper. Meanwhile, temperature at the point where laser strikes is lower when glassware rotates faster, and it limits the surface melting.

The glassware cannot rotate too fast due to the mechanical limitations of the lathe. Furthermore, the glassware itself cannot sustain the tensile stresses produced by the inertial force in fast rotating glassware. It is suggested that, for glassware with small and moderate diameter $(<150 \mathrm{~mm})$, two revolutions per second is appropriate. For glassware with a big diameter $(>150$ $\mathrm{mm})$, a speed of one revolution per second is appropriate.

It is also concluded that increasing the rotation speed will reduce groove resealing. The reason is that faster rotation of glassware will increase the average temperature but limit the local instantaneous temperature, therefore limiting the melting effect. This finding is contradictory to what is said in the literature by Chui [14]. In his publication, it is believed that the rotation speed should be kept lower to let more vaporization take place to avoid the resealing issue. 


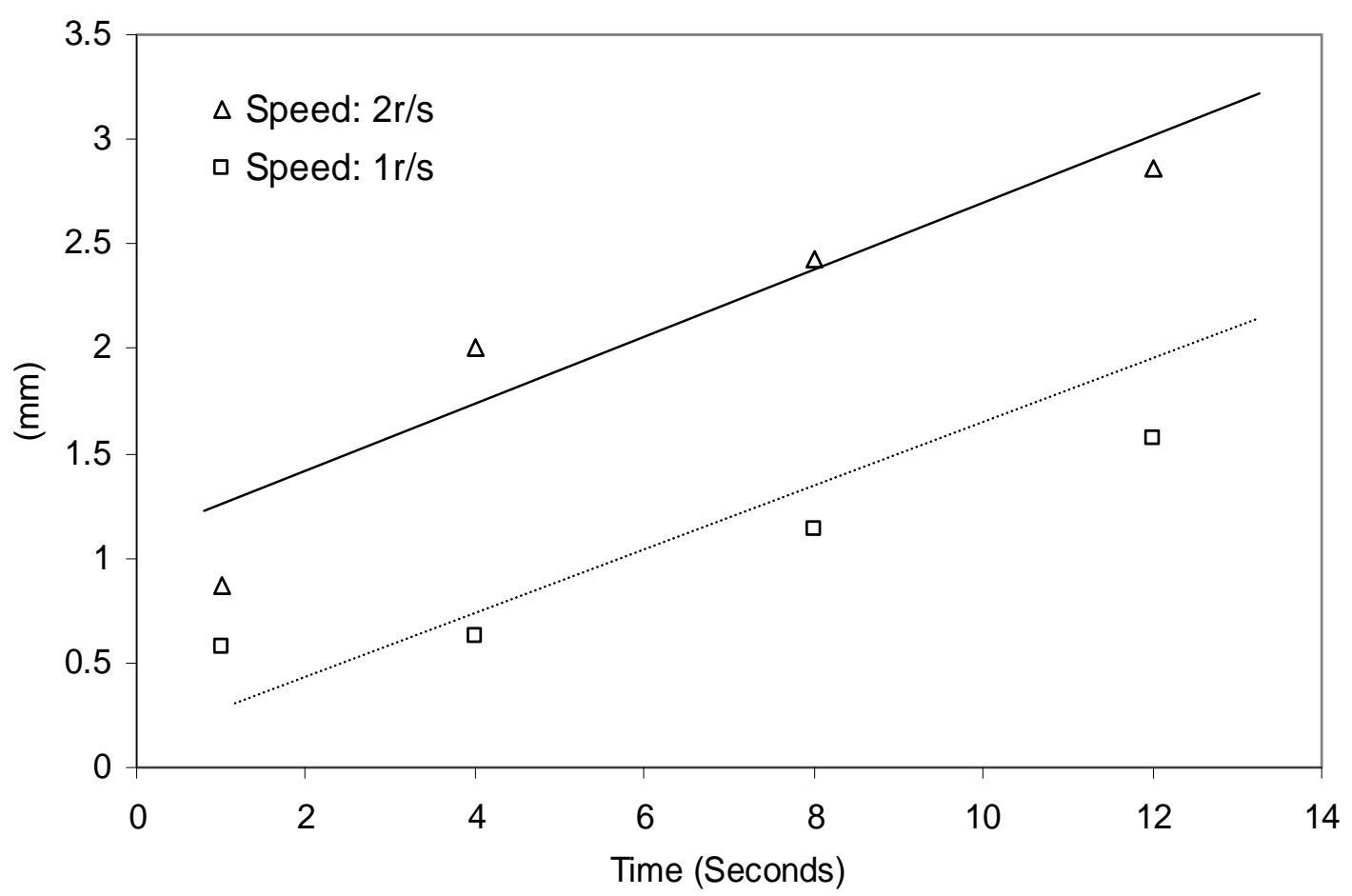

Figure 5.30 Melting Depth vs. Time at Two Levels of Rotation Speed

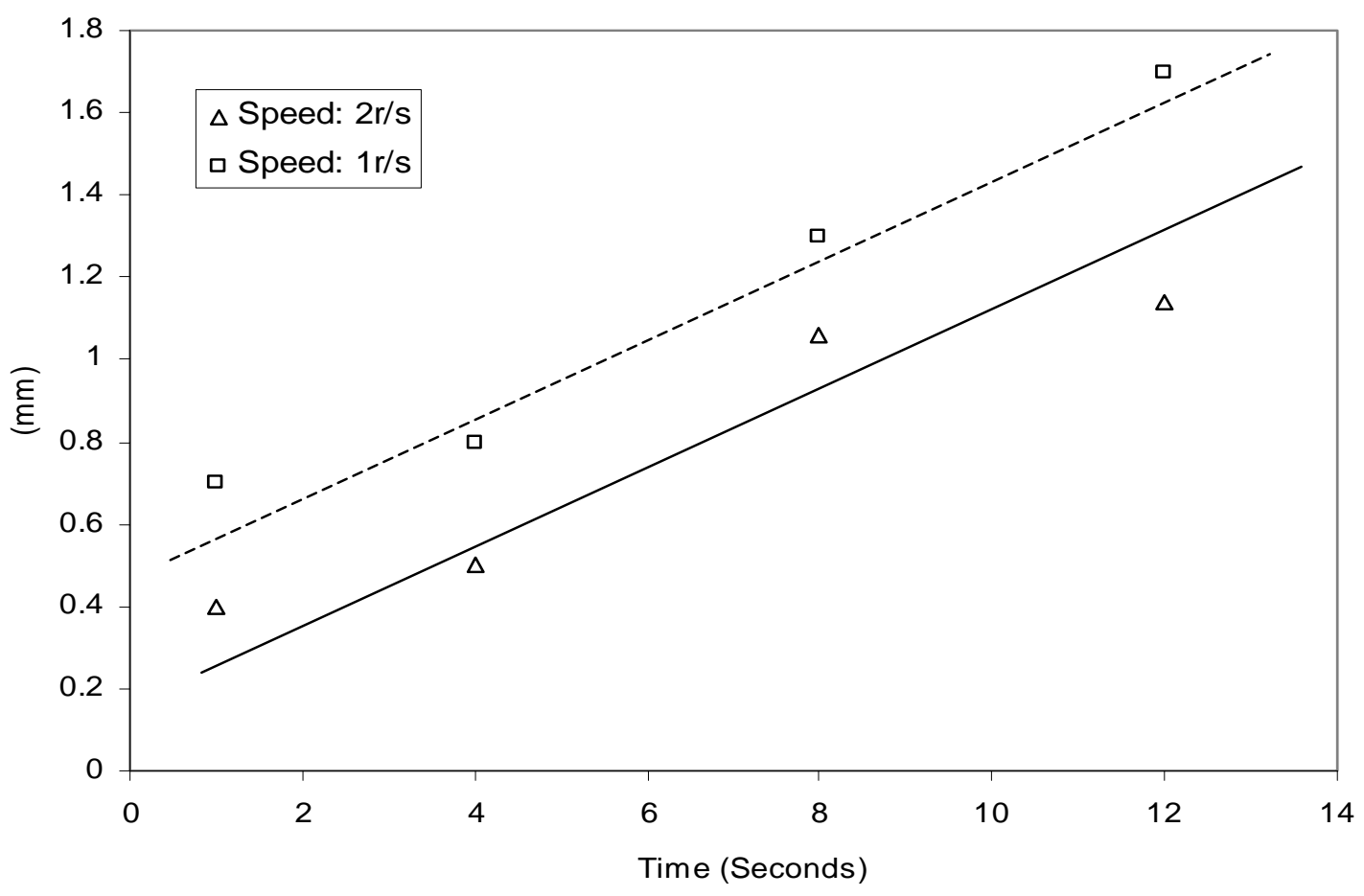

Figure 5.31 Groove Width vs. Time at Two Levels of Rotation Speed 


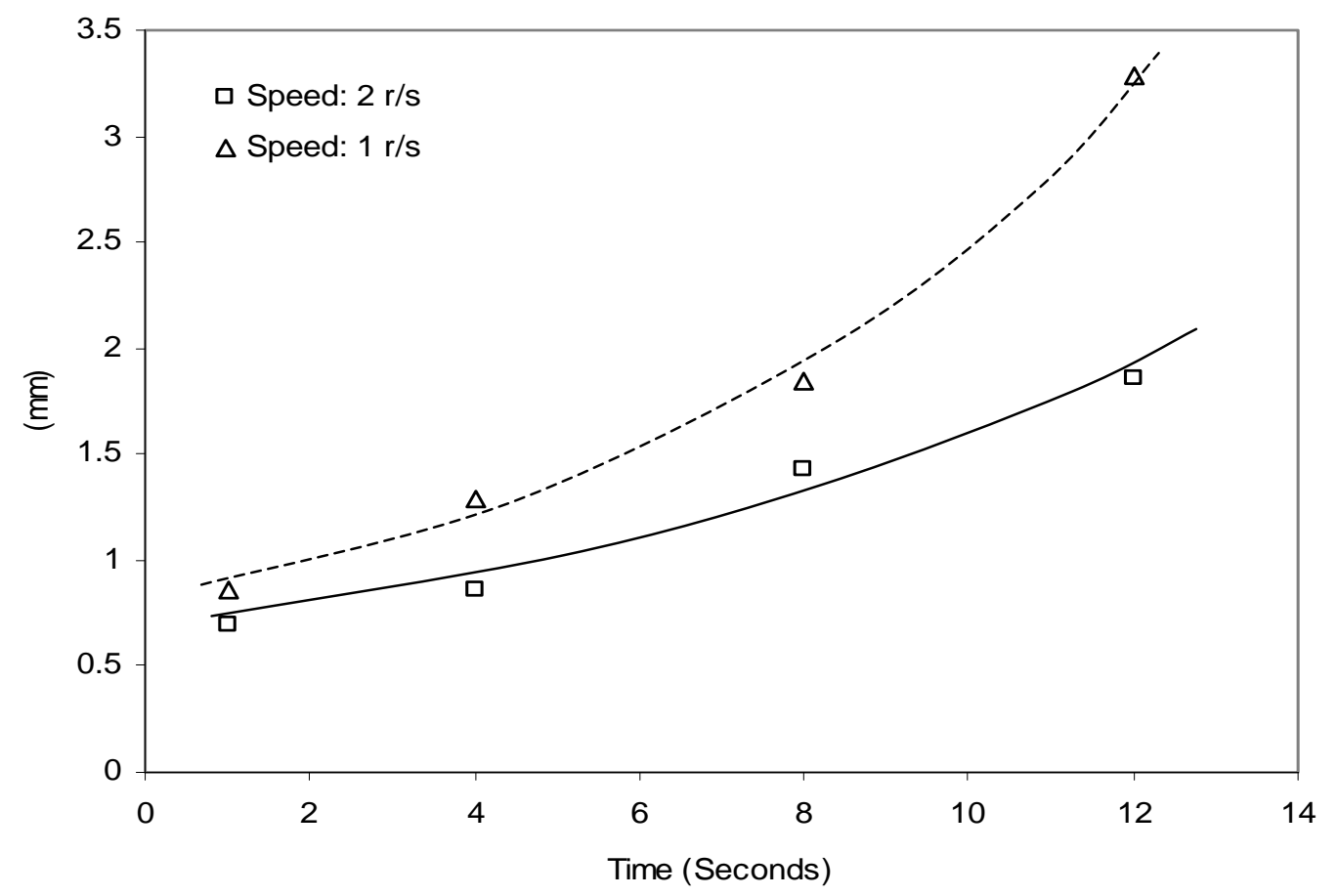

Figure 5.32 Heat Affected Zone Widths vs. Time at Two Levels of Rotation Speed

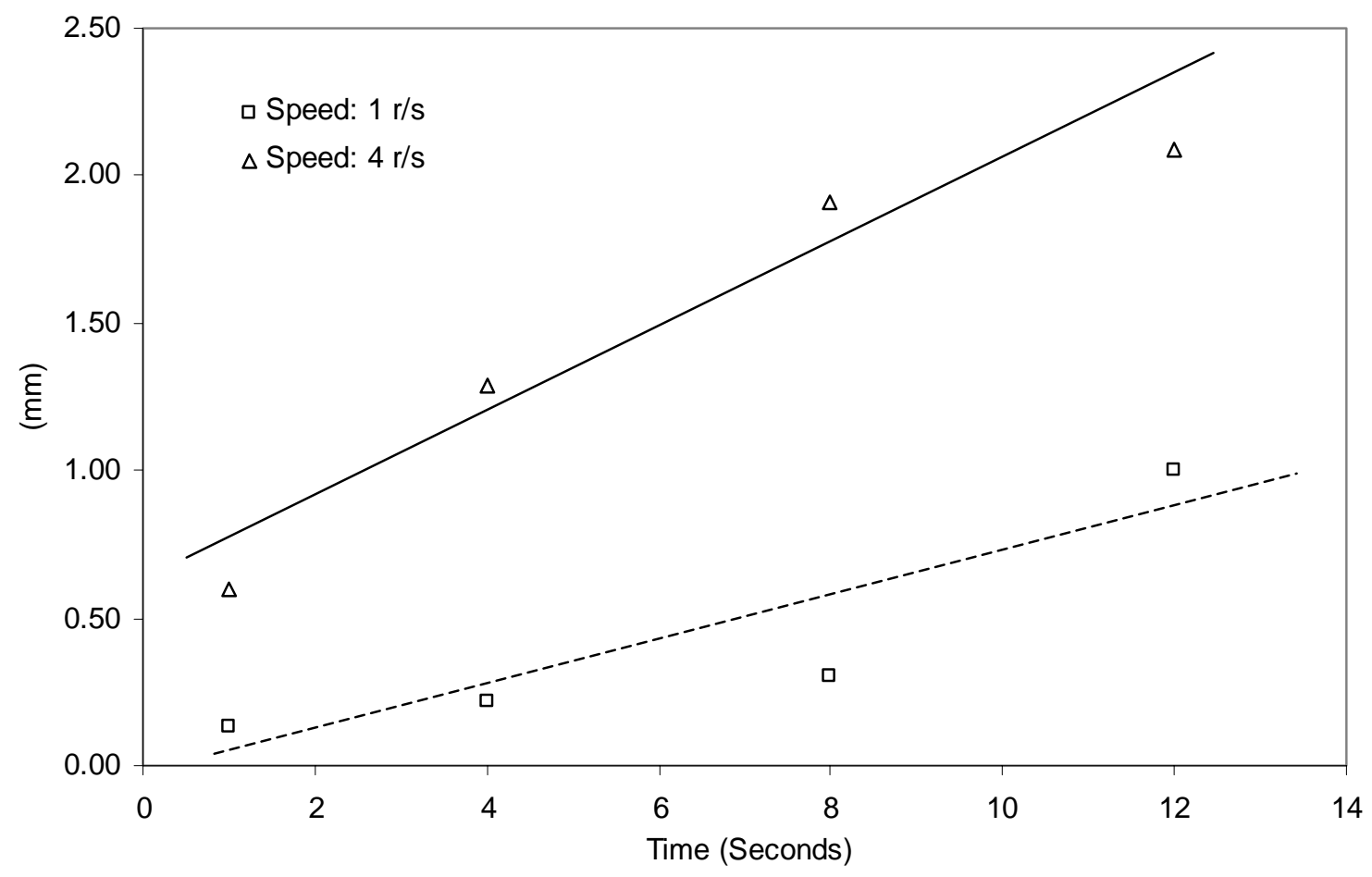

Figure 5.33 Groove Depths vs. Time at Two Levels of Rotation Speed 


\subsubsection{Effect of Material}

Three types of glassware were involved to investigate the effect of the material on the laser glass cutting. These are clear cylinder (ID 1 in Table 5.5), opaque cylinder (ID 2 in Table 5.5) and Champagne bottle (ID 5 in Table 5.4). The material constituents in ratio were listed in the Table 5.2. There is no significant difference in the density between these two types of material.

The operation parameters were rotation speed at 1 rev per second and the laser power at $1000 \mathrm{~W}$. There was no purge and no pulling force, and the focus was on the surface of the glassware.

The temporal behavior within the time scale of 15 seconds for each type of glassware under laser glass cutting was achieved by performing experiments. The results were listed in the Table 5.13 and are graphically shown in Figure 5.34, Figure 5.35 and Figure 5.36. The results from laser cutting of champagne bottles were also listed in the Table 5.13, but were not shown in the figures. It was found that there is a difference in the temporal behaviors of these two types of material. Laser cutting of the clear cylinder resulted in a wider groove and a wider heat affected zone compared to the opaque cylinder. There are possible two reasons to explain this. One possible reason is that the clear cylinder has either lower thermal capacity or high thermal conductivity than the opaque cylinder. Another possible reason is that the clear cylinder has more transmission or refraction than opaque cylinder. Although the position of focus will effect on these two measures, it is not the problem in this study since the size of these two glassware samples are identical and laser beam was kept focused on the surface of glassware. For the 
groove depth, laser cutting of clear cylinder also resulted in a deeper groove than the opaque cylinder at the early stage of the cutting. However, in the late stage of cutting, the groove in the clear cylinder turned out to be shallower than that in the opaque cylinder. It was due to the resealing which is likely to happen in the clear cylinder since it is easy to melt.

Table 5.13 Effect of Material Type on Cutting Process

\begin{tabular}{|c|c|c|c|c|c|}
\hline Material & $\begin{array}{c}\text { Time } \\
\text { (seconds) }\end{array}$ & $\begin{array}{c}\text { Groove Width } \\
\text { (mm) }\end{array}$ & $\begin{array}{l}\text { Groove Depth } \\
\qquad(\mathrm{mm})\end{array}$ & $\begin{array}{l}\text { Melting Depth } \\
\qquad(\mathrm{mm})\end{array}$ & $\begin{array}{c}\text { Heat Affected } \\
\text { Zone Width (mm) }\end{array}$ \\
\hline \multirow{4}{*}{ 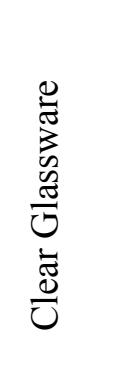 } & 1 & 0.70 & 0.26 & 0.57 & 0.86 \\
\hline & 4 & 0.80 & 0.40 & 0.63 & 1.29 \\
\hline & 8 & 1.30 & 0.32 & 1.14 & 1.84 \\
\hline & 12 & 1.70 & 0.46 & 1.57 & 3.29 \\
\hline \multirow{4}{*}{ 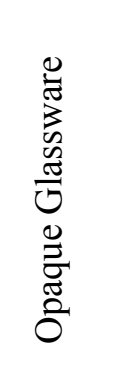 } & 1 & 0.16 & 0.13 & 1.06 & 0.54 \\
\hline & 4 & 0.50 & 0.21 & 1.19 & 1.21 \\
\hline & 8 & 0.84 & 0.30 & 2.00 & 1.43 \\
\hline & 12 & 0.60 & 1.00 & 1.83 & 1.86 \\
\hline \multirow{5}{*}{ 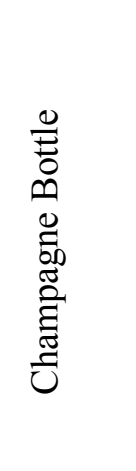 } & 1 & 0.32 & 0.32 & 0.32 & 0.56 \\
\hline & 2 & 0.38 & 0.31 & 0.31 & 0.62 \\
\hline & 4 & 0.57 & 0.50 & 0.50 & 0.87 \\
\hline & 8 & 0.63 & 0.66 & 0.66 & 1.32 \\
\hline & 10 & 1.04 & 0.99 & 0.99 & 1.48 \\
\hline
\end{tabular}




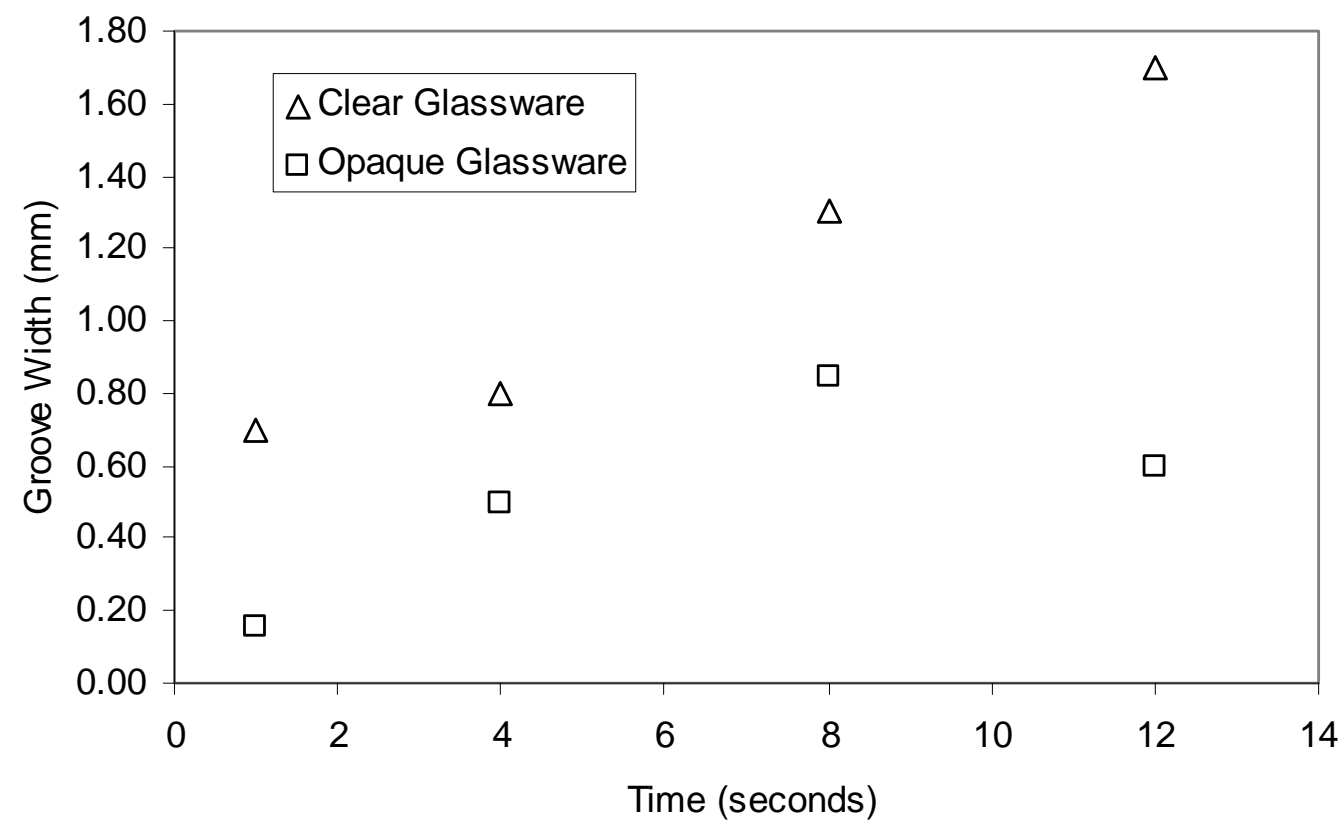

Figure 5.34 Groove Widths vs. Time

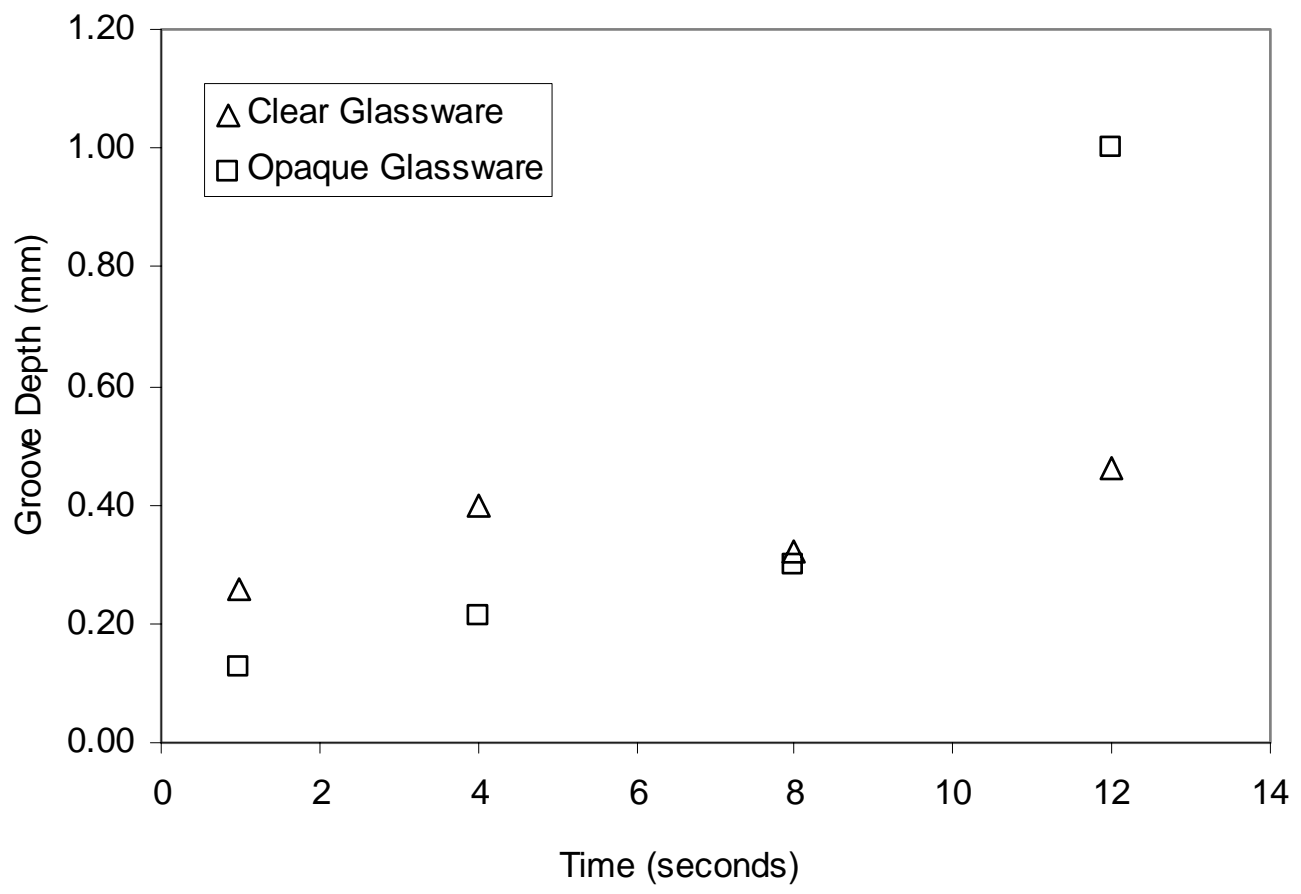

Figure 5.35 Groove Depths vs. Time 


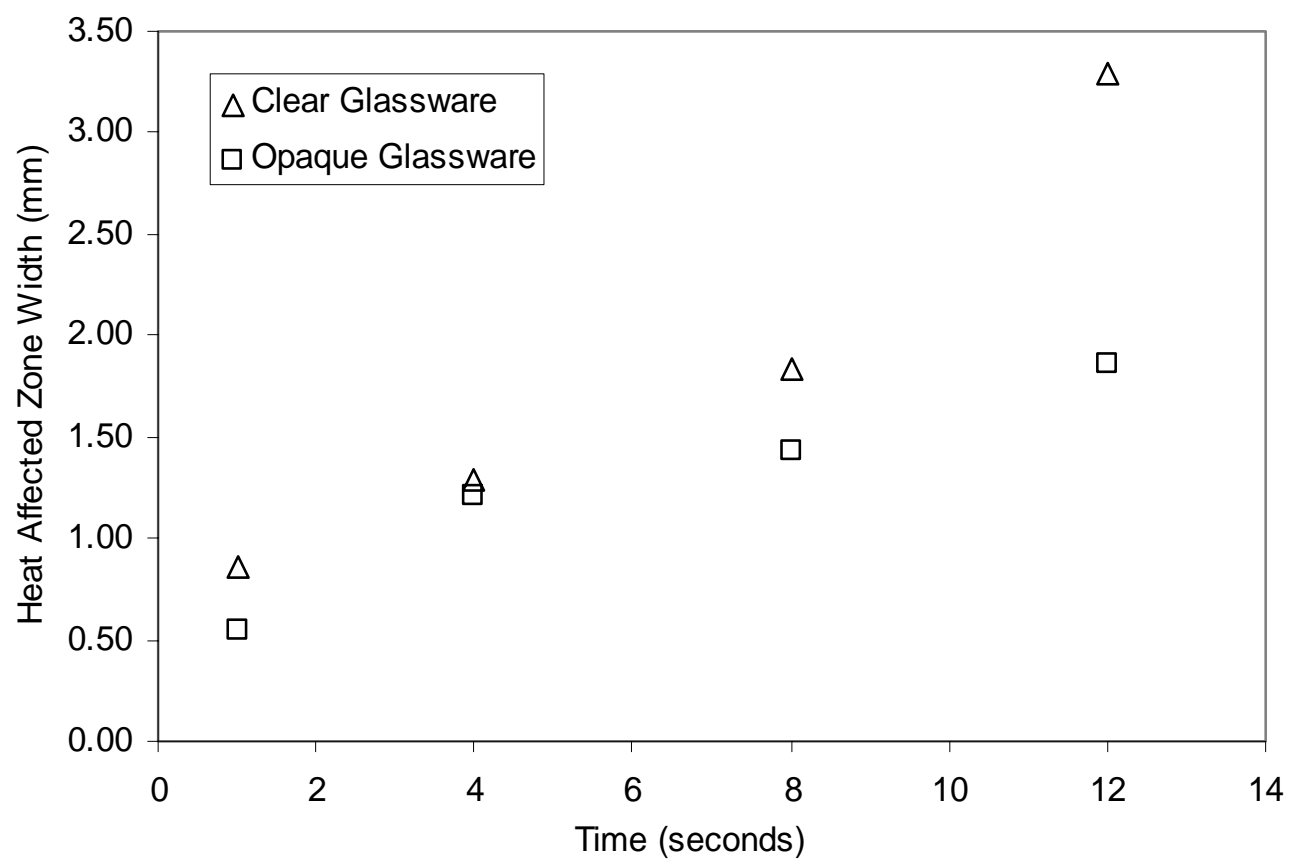

Figure 5.36 Heat Affected Zone Widths vs. Time

\subsubsection{Effect of Laser Focal Position}

The effect of the laser focal position was obtained from experiments using clear cylinder (ID 4 in Table 5.5). Operational parameters included a laser-firing time of 5 seconds and a preheating temperature at $600{ }^{\circ} \mathrm{C}$. There was no purge and no pulling force.

The data is listed in Table 5.14. Figure 5.37 and Figure 5.38 show the effect of focal position on the cutting process at two power levels. The focal position is either right in the surface or $2 \mathrm{~mm}$ below the glassware surface. It is concluded that the focal position has an effect on the cutting process. When the laser is below the glassware surface, it will produce a wider shallower groove and wider shallower melting zone. Therefore, in laser glass cutting, it is best that the focal position be kept at the glassware surface. Since a groove $(0.6 \mathrm{~mm}$ in width $)$ will be 
formed during the cutting, it might be necessary to track the focal position in the real time. If the groove depth is negligible compared to the depth of focus of the laser, there is no need to track the focal position.

Table 5.14 Effect of Focal Position on Cutting Process

\begin{tabular}{||c|c|c|c|c||}
\hline $\begin{array}{c}\text { LASER POWER } \\
(\mathrm{W})\end{array}$ & FOCUS POSITION & $\begin{array}{c}\text { GROOVE WIDTH } \\
(\mathrm{mm})\end{array}$ & $\begin{array}{c}\text { GROOVE DEPTH } \\
(\mathrm{mm})\end{array}$ & $\begin{array}{c}\text { MELTING ZONE } \\
\text { DEPTH (mm) }\end{array}$ \\
\hline \multirow{2}{*}{500} & On Surface & 0.47 & 0.84 & 0.91 \\
\cline { 2 - 5 } & Below Surface & 0.68 & 0.34 & 2.57 \\
\hline \multirow{2}{*}{1000} & On Surface & 0.90 & 0.46 & 2.34 \\
\cline { 2 - 5 } & Below Surface & 1.00 & 0.44 & \\
\hline
\end{tabular}

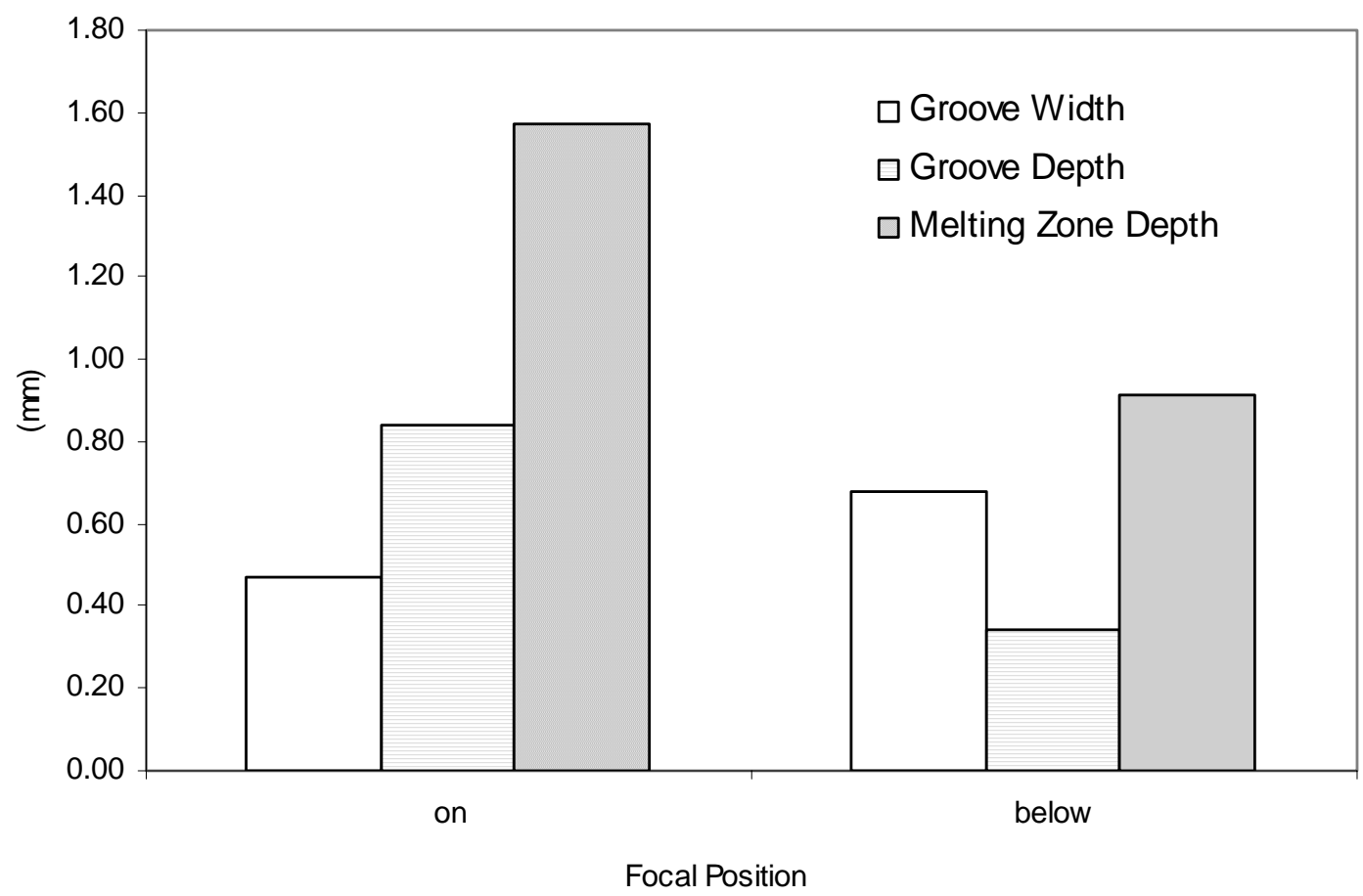

Figure 5.37 Effect of Focal Position on Cutting Process $(P=500 \mathrm{~W})$ 


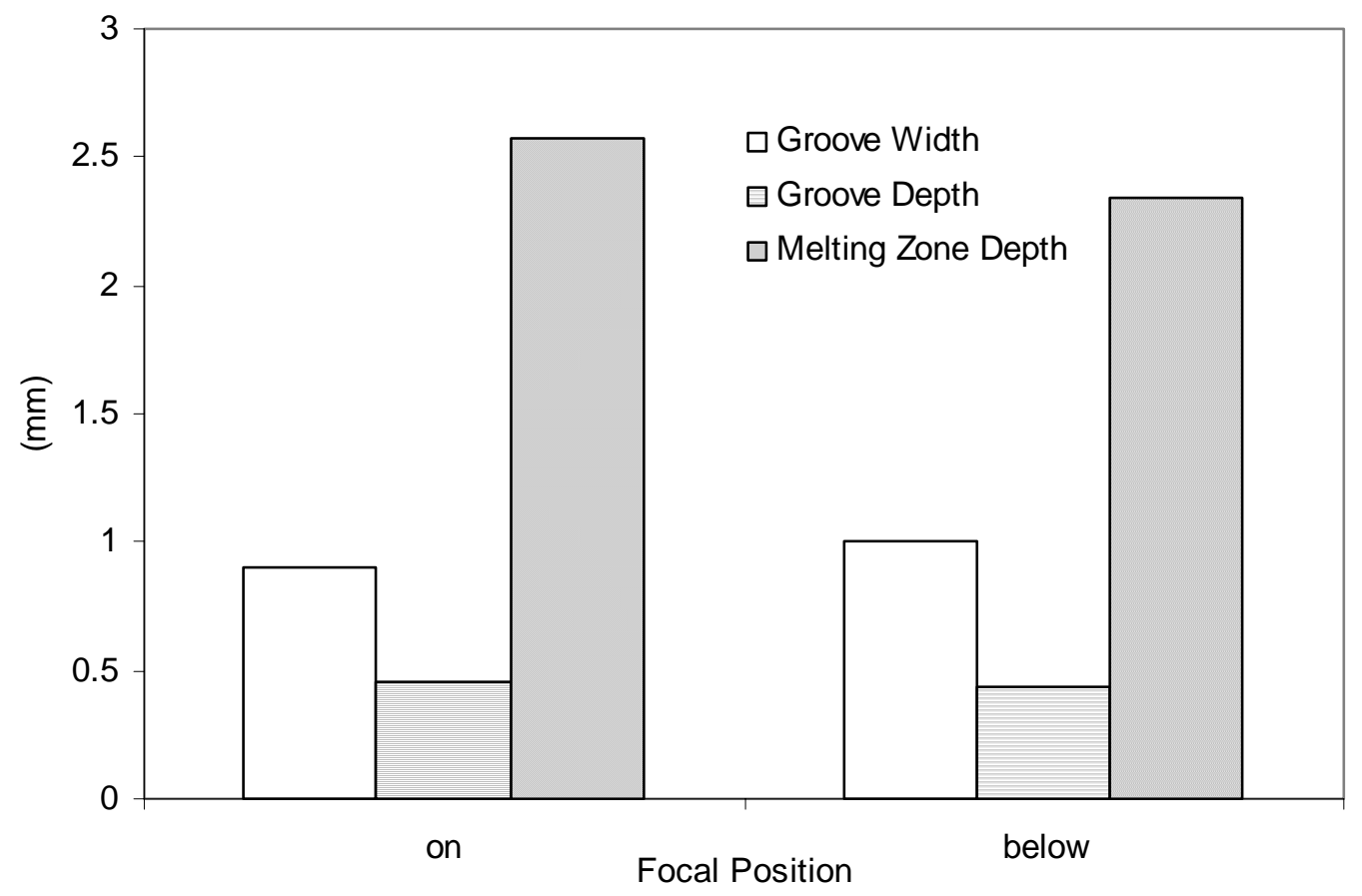

Figure 5.38 Effect of Focal Position on Cutting Process $(P=1000 \mathrm{~W})$

\subsubsection{Effect of Purge}

The idea of utilizing a purge is to limit glass melting to a certain extent and to a certain volume. Since the purge can cause the glass cutting relatively cool, the flow of liquid glass can be limited.

A cold air purge was tried in the laser glass cutting of wine bottle (ID 21 and ID 22 in Table 5.3). The laser power was at $600 \mathrm{~W}$, rotation speed at $1 \mathrm{r} / \mathrm{s}$ and preheating temperature at $600{ }^{\circ} \mathrm{C}$. The laser was fired for 10 seconds and stopped if and when the glassware cracked. The geometry of the formed groove was $0.35 \mathrm{~mm}$ in width and $0.88 \mathrm{~mm}$ in depth. This depth/width ration was 2.5 , which is the highest number obtained so far. It means that gas jet can help the 
laser glass cutting process to achieve straight and narrow cut. Also it was found that, with a gas jet, the bubbling could be dramatically reduced, if not totally eliminated.

Since the glassware is hot, a cold gas jet will likely cause the glassware to crack. Thus, it is required that the jet be hot to avoid cracking the glassware when it blows on the surface of the hot glassware. It is shown that a gas jet with a temperature of $400{ }^{\circ} \mathrm{C}$ is not only achievable using a heat gun, but also can avoid cracking glassware when it is applied.

More experiments with both cold and hot air purges were performed on clear cylinders (ID 5, ID 6 and ID 8 in Table 5.5). Sample ID 6 cracked during the experiment. Table 5.15 lists the data from micrograph measurements of the samples after the experiment. Hot air was produced by a heat gun with a custom-made cone attached to its head to form the narrow air flow. The temperature of air from the heat gun was around $400{ }^{\circ} \mathrm{C}$.

Table 5.15 Cutting Process Results from Experimenst with Purge

\begin{tabular}{||c|c|c|c|c|c|c||}
\hline PURGE & $\begin{array}{c}\text { LASER FIRING } \\
\text { TIME (Seconds) }\end{array}$ & $\begin{array}{c}\text { POWER } \\
(\mathrm{W})\end{array}$ & $\begin{array}{c}\text { GROOVE } \\
\text { WIDTH }(\mathrm{mm})\end{array}$ & $\begin{array}{c}\text { GROOVE } \\
\text { DEPTH }(\mathrm{mm})\end{array}$ & $\begin{array}{c}\text { MELTING DEPTH } \\
(\mathrm{mm})\end{array}$ & $\begin{array}{c}\text { HEAT AFFECTED } \\
\text { ZONE WIDTH (mm) }\end{array}$ \\
\hline Off & 10 & 400 & 0.45 & 0.17 & 2.46 & N/A \\
\hline Off & 5 & 400 & 0.31 & 0.21 & 2.06 & N/A \\
\hline Hot & 5 & 400 & 0.35 & 0.60 & 1.49 & N/A \\
\hline Off & 5 & 1000 & 0.40 & 0.28 & 2.00 & 1.30 \\
\hline \hline Cold Min & 5 & 1000 & 0.47 & 1.48 & 2.57 & 0.90 \\
\hline Cold Med & 5 & 1000 & 0.56 & 1.82 & 2.57 & 1.20 \\
\hline Cold Max & 5 & 1000 & 0.60 & 1.17 & 2.71 & \\
\hline
\end{tabular}


It was found that the groove formed by laser glass cutting was narrower when a purge was applied. The groove depth/width ratio was about 2 to 3 , while the ratio was usually less than 1 when no purge was applied. Application of a purge can also reduce the heat affected zone. The results did not show the significance there is a significant effect of purge on the melting depth. The exact relation of magnitude of purge to the cutting process still needs further investigation.

It should be mentioned that the purge was not well controlled in the experiments, and therefore, the effect of the purge is still not fully addressed. It seems that the purge will lower the quality of cutting edge, which was also stated in the literature by Chui [14].

\subsubsection{Discussion}

Repeating the experiment at a certain experimental condition and repeating the measurement for specimens can significantly increase the accuracy and the reliability of the experimental results. Design of experiment (DOE) to investigate single factor and multiple factors, as well as the statistical analysis methods like Analysis of Variance (ANOVA) and regression analysis were proposed in the dissertation proposal. However, due to the associated cost, the experiments were arranged in such a way that as many factors as possible could be investigated within the available time frame. As a result, only a few of the experiments performed at certain individual experimental conditions could be repeated and, as a result, the proposed DOE and ANOVA could not be applied during the experiment and thereafter. The reliability and accuracy of the experiment were taken into consideration during the experiments as well as the measurements thereafter. First, all the experimental conditions except for those 
parameters under investigation were kept constant from one experiment to another. Second, confirmation experiments were performed when investigating the cutting process and laser power effect. In Sample ID 3, two more cuts were performed to confirm by additional experiments on the laser power effect. Samples ID 9 and ID 13 were used to confirm the experiments with Samples ID 2 and ID 3, but they both cracked during the experiment. Third, if the experiments are independent from one trial to another (which is expected to be the case in laser glass cutting experiments), the random error in each trial of experiment can be assumed to have the identical distribution. In this case, regression analysis and significance test can help to eliminate these experimental random errors and measurement errors. Measurements of melting zone depth and heat affected zone were more reliable than the groove depth and groove width since, when measuring the melting zone depth and heat affected zone depth, straight lines were drawn first along the melting front or heating front and then the measurements were taken. This approach is equivalent to an approach that first measures multiple positions along the melting front or heating front and then computes the average of these multiple measurements.

An example of regression analysis was performed on the results to investigate the effect of laser power on the laser glass cutting. The linear regression analysis results were:

$$
\begin{array}{ll}
\mathrm{W}_{\mathrm{g}}=0.56+0.00032 \times \mathrm{P}, & \mathrm{R}=0.79, \mathrm{~F}=5.1(0.11), \mathrm{Std}=0.17 \\
\mathrm{D}_{\mathrm{g}}=0.45-0.00011 \times \mathrm{P}, & \mathrm{R}=0.91, \mathrm{~F}=14.8(0.03), \mathrm{Std}=0.03 \\
\mathrm{D}_{\mathrm{m}}=0.44+0.0098 \times \mathrm{P}, & \mathrm{R}=0.99, \mathrm{~F}=120.5(0.002), \mathrm{Std}=0.11
\end{array}
$$

where $\mathrm{W}_{\mathrm{g}}$ is the groove width, $\mathrm{D}_{\mathrm{g}}$ is the groove depth, $\mathrm{D}_{\mathrm{m}}$ is the melting depth, and $\mathrm{P}$ is the laser power. The statistics $\mathrm{R}$ show a strong relation between the laser power and the groove width, groove depth, and melting depth. The statistics F, when compared to the critical value in the 
parenthesis, show the significance of these relations. Std refers to the standard deviation from the predicted average value at a certain level of the laser power. The Std value represents the experimental and measurement random error.

This statistical analysis leads to the conclusion that, under the conditions to perform this experiment, laser power does have a significant effect on the groove width, groove depth and melting depth. What needs to be mentioned is that, since the data for this statistical analysis came from one sample, if there is a systematic error in this sample or in performing this experiment, the analysis is not able to recognize it. As future work, when the time and finance permit, more experiments on different samples but of the same type of glassware should be performed. 


\section{Control of Laser Glass Cutting Process}

\subsection{INTRODUCTION}

The cutting capability of the laser glass cutting machine cannot be fully utilized without process control. For the lab prototype machine, basic controls together with associated instrumentation are necessary for laser glass cutting.

Chapters 4 and 5 have investigated the operational parameters in laser glass cutting. These chapters identified that the laser power has a significant effect on the laser glass cutting. Laser focal position also has an effect on the laser glass cutting. It is best that the laser focal position be kept on the surface of the cutting ring to obtain a narrow and deep cut. The cutting ring surface is not a fixed surface during the laser glass cutting due to the continual vaporization of glass and the formation of the cutting groove.

Glassware rotation speed has an effect on laser glass cutting in terms of the groove depth during laser glass interaction, especially during the single-cycle laser glass interaction. It was indicated in Chapter 5 that the faster the glassware rotation, the deeper the groove depth. However, this effect became less significant in multi-cycle laser glass interaction. From a practical aspect, the glassware rotation speed cannot rotate too fast due to the mechanical limitation of the lathe. On the other hand, there is no obvious need to adjust the speed during multi-cycle laser glass cutting when the glassware rotation speed has already been set. The 
practice of laser cutting of sheet material where the laser power together with the relative speed between sheet material and laser determines the cutting process does require speed adjustment.

It was found that the pulling force is critical to the laser glass cutting. Initial glass temperature is also an important factor in laser glass cutting, since the laser cannot fire until the glassware temperature is above the annealing temperature of the glass. A gas purge to the cutting ring will also help the laser glass cutting. However, a purge was not thoroughly investigated.

Hence, four operation parameters in the laser glass cutting process were proposed for measurement and control:

- Measurement of glass preheating temperature;

- Control of laser power;

- Control of beam focal position;

- Control of pulling force.

The proposed process control system is comprised of two levels; namely, microprocessor based low-level controls (subsystem controllers), such as the three above listed controls, and a PC based high-level supervisory control (system controller). The high-level supervisory controller incorporates the process models that compute the operation parameters including laser power, beam focus-tracking position and the required pulling force. The high-level supervisory controller also has the human-machine interface and machine-machine interface. With these, system controller is able to take the customer inputs such as the glassware product size and production rates through human-machine interface, compute the operational parameters, and 
send the corresponding parameters as commands to the subsystem controllers through machinemachine interface.

In this chapter, the process control modeling is described first in Section 6.1. Then, the implementation of the subsystem controllers are described in Sections 6.2.1 to 6.2.5, followed by the description of the integration of these subsystems in Section 6.2.6. The system controller is described afterwards in Section 6.3. Finally, the application of this control system is described in Section 6.4; an example is included.

\subsection{Process Control Modeling}

Figure 6.1 shows the schematic of the laser glass cutting machine with the proposed controls. Figure 6.2 shows the block diagram representation of the control logic, where $\mathrm{T}$ is the temperature; $\mathrm{y}_{\mathrm{d}}$ and $\mathrm{y}_{\mathrm{a}}$ are the desired and actual production rates; $\mathrm{D}_{\mathrm{m}}$ is the predicted melting depth to be sent to the pulling force controller to control pulling force; $\mathrm{D}_{\mathrm{g}}$ is the predicted groove depth to be sent to laser beam motion controller to control beam focal position; and $\mathrm{P}$ is the desired laser power.

The successful process control depends on two technical challenges. The first challenge is the controller of each subsystem. The second challenge, more important, is the system controller that depends on the availability of three models: 1) a model to describe the relation between the glassware production rate and laser power, and describe the melting depth as a function of laser cutting time and laser power; 2) a model to describe the groove depth as a function of laser cutting time and laser power; and 3) a model to describe the required pulling force as a function of laser cutting time, glassware size, or even glassware mechanical properties. 


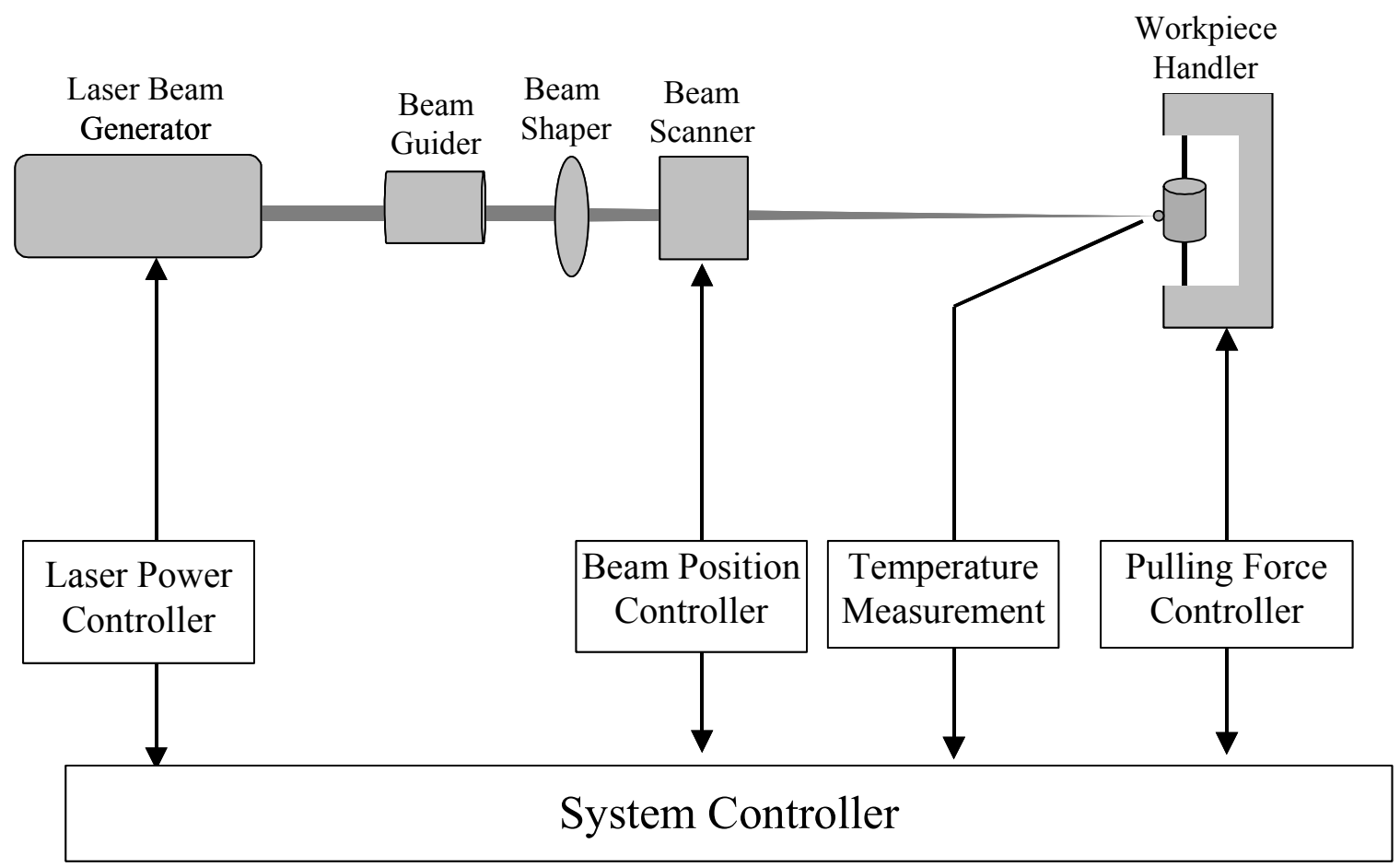

Figure 6.1 Schematic of Laser Glass Cutting Machine with Proposed Controls

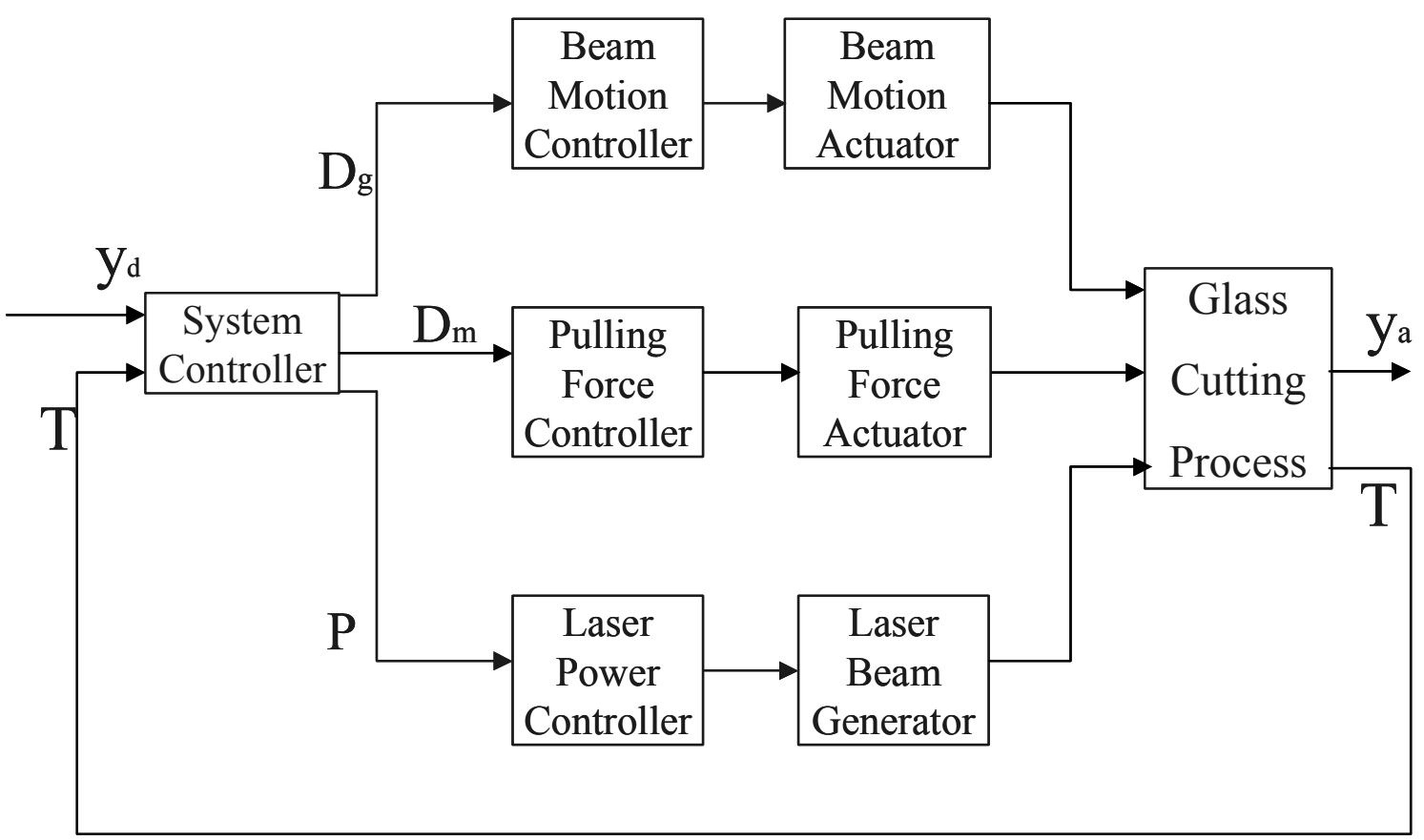

Figure 6.2 Control Logic of Laser Glass Cutting Process 
This section will focus on developing the first two of these three models. The approach to develop these two models is shown in Figure 6.3. The first model was developed based on the results from simulation. The second model was developed based on the micrograph measurement results.

Since pulling force was not fully investigated either in simulation or by experiment, the third model to describe the required pulling force as a function of laser cutting time, glassware size and mechanical properties was not developed.

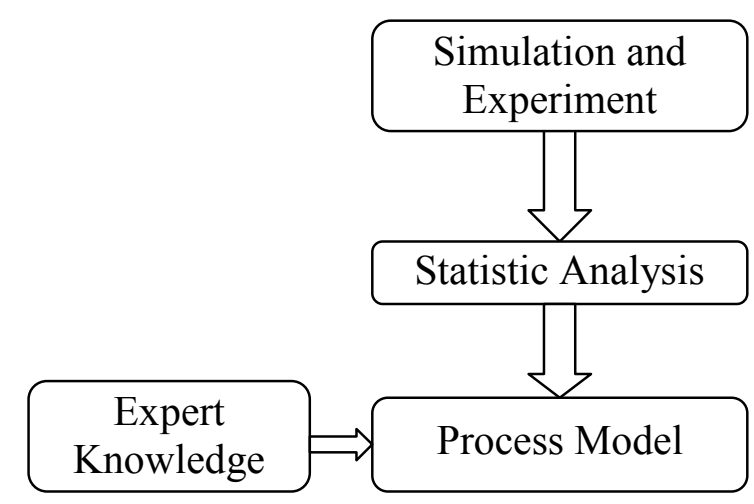

Figure 6.3 Approach to Develop Process Model

\subsubsection{Model to Predict Melting Depth}

A model to predict the melting depth is derived from the 3-D simulation results for the case where the glassware diameter was $95 \mathrm{~mm}$ and the thickness was $5 \mathrm{~mm}$. The data obtained from the simulation and used to derive this model are shown in the first three columns in Table 6.1. 
First, it was assumed that the model is in the form of

$$
D_{m}(P, t)=A_{0}\left(1-e^{-t / t_{0}}\right)
$$

where $D_{m}$ is the melting depth, $P$ is the laser power, $t$ is the laser firing time, $A_{0}$ is the constant and $\mathrm{t}_{0}$ is the time constant. Both $\mathrm{A}_{0}$ and $\mathrm{t}_{0}$ are unknown and need to be determined by the data in Table 6.1. The form of the model as shown in Equation 6.1 is a reasonable representation since all the thermal system is a first order system, and $D_{m}$ is 0 when $t$ is 0 .

Then $A_{0}$ and $t_{0}$ were found by trial and error by first giving a set of values to $A_{0}$ and $t_{0}$; Second, predict $\mathrm{D}_{\mathrm{m}}$ using each power level $\mathrm{P}$ and laser firing time $\mathrm{t}$ as shown in the first two columns of Table 6.1. Predicted values were shown in the fourth column of the Table 6.1. Third, calculate the error between the value predicted by this model and the value obtained from the simulation results. Errors were shown in the fifth column. Fourth, calculate mean and variance of the error as shown in the low end of the table. The mean and variance were used as criteria to optimize the $\mathrm{A}_{0}$ and $\mathrm{t}_{0}$. And fifth, adjust $\mathrm{A}_{0}$ and $\mathrm{t}_{0}$ and repeat above procedure. Repeat this process until the best $\mathrm{A}_{0}$ and $\mathrm{t}_{0}$ that make the both mean and variance minimal are found.

The model was found as

$$
D_{m}(P, t)=0.0045 \alpha\left(D_{0}, d_{0}\right) P\left(1-e^{-t / 15.5}\right)
$$

where $\mathrm{D}_{\mathrm{m}}$ is the melting depth in $\mathrm{mm}, \mathrm{P}$ is the laser power in $\mathrm{W}$, and $\mathrm{t}$ is the laser cutting time in seconds. The coefficient $\alpha\left(D_{0}, d_{0}\right)$ is used to adjust the model for other glassware geometry than a diameter of $95 \mathrm{~mm}$ and a thickness of $5 \mathrm{~mm}$, where $\mathrm{D}_{0}$ is the diameter of glassware and $\mathrm{d}_{0}$ is the thickness of the glassware. For glassware with a diameter of $95 \mathrm{~mm}$ and thickness of 5 $\mathrm{mm}, \alpha\left(D_{0}, d_{0}\right)$ is equal to 1 since no adjustment is needed. 
Table 6.1 Melting Depth Predicted by Simulation and by Process Model

\begin{tabular}{|c|c|c|c|c|}
\hline & \multicolumn{4}{|c|}{ Undetermined Coefficients: $\mathrm{A}_{0}=0.0045, \mathrm{t}_{0:}=15.5$} \\
\hline POWER & LASER CUTTING & $\mathrm{D}_{\mathrm{m}}(\mathrm{mm})$ & $\mathrm{D}_{\mathrm{m}}(\mathrm{mm})$ & ERROR (mm) \\
\hline (W) & TIME (SECONDS) & FROM SIMULATION & FROM PROCESS MODEL & \\
\hline 600 & 5 & 0.8 & 0.7 & 0.1 \\
\hline 600 & 10 & 1.1 & 1.3 & -0.2 \\
\hline 600 & 15 & 1.4 & 1.7 & -0.3 \\
\hline 600 & 20 & 1.6 & 2.0 & -0.4 \\
\hline 800 & 5 & 1.3 & 1.0 & 0.3 \\
\hline 800 & 10 & 1.8 & 1.7 & 0.1 \\
\hline 800 & 15 & 2.2 & 2.2 & 0 \\
\hline 800 & 20 & 2.4 & 2.6 & -0.2 \\
\hline 1000 & 5 & 1.6 & 1.2 & 0.4 \\
\hline 1000 & 10 & 2.3 & 2.1 & 0.2 \\
\hline 1000 & 15 & 3.0 & 2.8 & 0.2 \\
\hline 1000 & 20 & 3.3 & 3.3 & 0 \\
\hline & & & tistics: Mean $=0$. & riance $=0.06$ \\
\hline
\end{tabular}

The model as describe in Equation 6.2 is graphically shown in the Figure 6.4, assuming the geometrical adjustment coefficient $\alpha\left(D_{0}, d_{0}\right)$ is 1 . The predicted melting depths in laser glass cutting for the same size glassware $\left(D_{0}=95 \mathrm{~mm}\right.$ and $\left.d_{0}=5 \mathrm{~mm}\right)$ at several specific power levels and at several specific points in time are listed in the fourth column of the Table 6.1 for 
comparison. The error between the prediction and the results from the 3-D simulation is about \pm $0.2 \mathrm{~mm}$. This model is applicable to glassware of soda-lime glass, since the simulation was performed on this type of glassware.

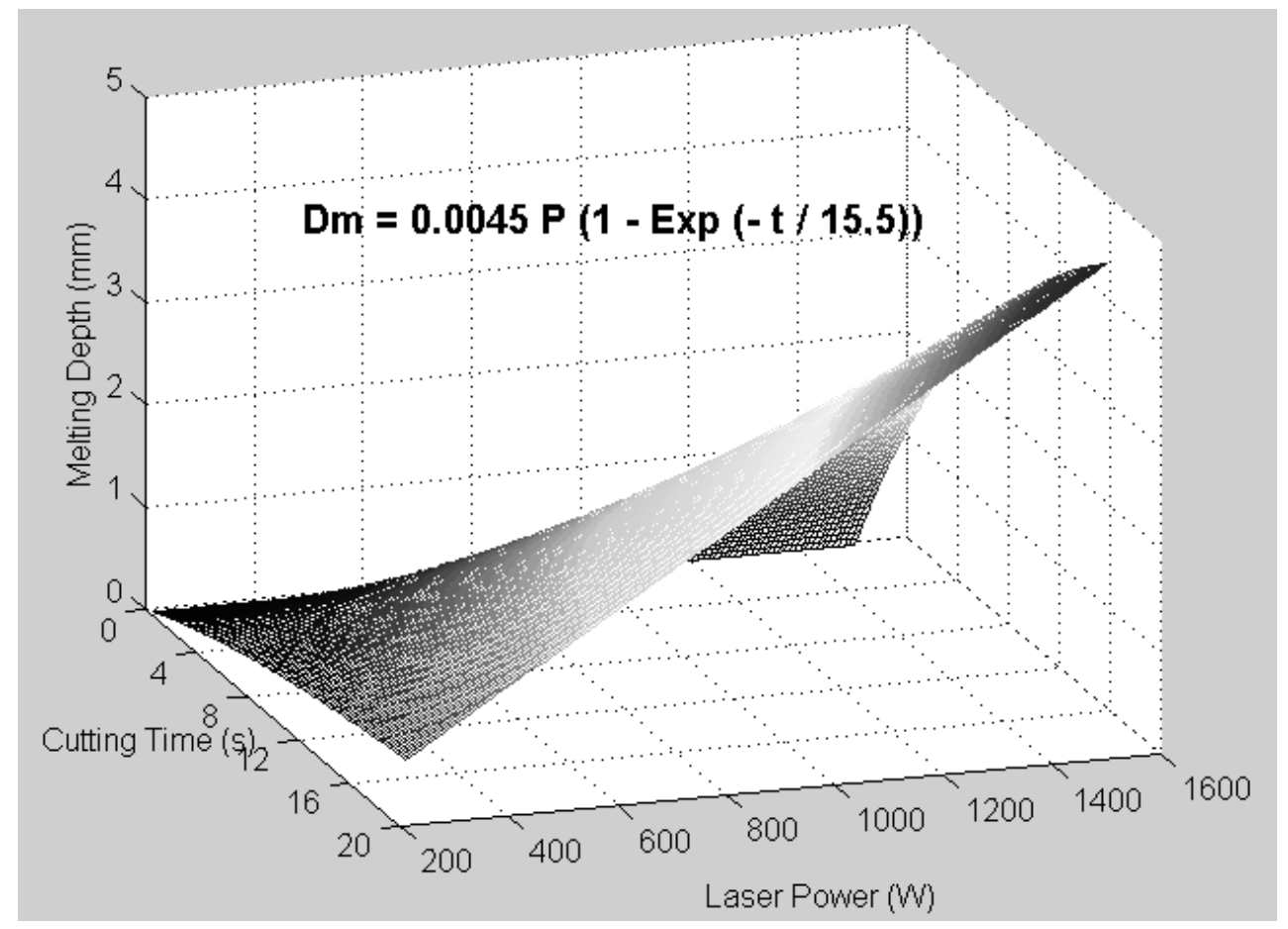

Figure 6.4 Melting Depth vs. Cutting Time and Laser Power

The expression for $\alpha\left(D_{0}, d_{0}\right)$ was constructed using the same approach as that to develop the model shown in Equation 6.2. The criteria is that the melting depth predicted by the new resultant model for a given $\mathrm{P}, \mathrm{D}_{0}$ and $\mathrm{d}_{0}$ should best fit the melting depth obtained from the simulation with the same parameters $\mathrm{P}, \mathrm{D}_{0}$ and $\mathrm{d}_{0}$. The melting depth data for the derivation of $\alpha\left(D_{0}, d_{0}\right)$ were obtained from two simulation cases, $\mathrm{D}_{0}=80 \mathrm{~mm}$ and $\mathrm{d}_{0}=5 \mathrm{~mm}$ for the first case, and $\mathrm{D}_{0}=80 \mathrm{~mm}$ and $\mathrm{d}_{0}=3 \mathrm{~mm}$ for the second case. Laser power for both cases was 1000 W. Table 6.2 lists the computed melting depths at 5, 10, 15 and 20 seconds. The function expression for $\alpha\left(D_{0}, d_{0}\right)$ was constructed as shown in Equation 6.3. 


$$
\alpha\left(D_{0}, d_{0}\right)=0.7 \times 10^{1-\frac{D_{0}}{95}}+0.3 \times 10^{1-\frac{d_{0}}{5}}
$$

For the same two cases, the melting depths predicted by the process model in Equation 6.2 and adjusted by the geometrical adjustment function in Equation 6.3 were also listed in the Table 6.2.

Table 6.2 Melting Depths Predicted by Simulation and by Process Model with Geometrical Adjustment

\begin{tabular}{||c|c|c|c|c||}
\hline \multirow{2}{*}{$\begin{array}{c}\text { LASER } \\
\text { CUTTING TIME }\end{array}$} & \multicolumn{2}{|c|}{$\mathrm{P}=1000 \mathrm{~W}, \mathrm{D}_{0}=80 \mathrm{~mm}, \mathrm{~d}_{0}=5 \mathrm{~mm}$} & \multicolumn{2}{c||}{$\mathrm{P}=1000 \mathrm{~W}, \mathrm{D}_{0}=80 \mathrm{~mm}, \mathrm{~d}_{0}=3 \mathrm{~mm}$} \\
\cline { 2 - 5 } & $\begin{array}{c}\mathrm{D}_{\mathrm{m}}(\mathrm{mm}) \\
\text { from Simulation }\end{array}$ & $\begin{array}{c}\mathrm{D}_{\mathrm{m}}(\mathrm{mm}) \\
\text { from Process Model }\end{array}$ & $\begin{array}{c}\mathrm{D}_{\mathrm{m}}(\mathrm{mm}) \\
\text { from Simulation }\end{array}$ & $\begin{array}{c}\mathrm{D}_{\mathrm{m}}(\mathrm{mm}) \\
\text { from Process Model }\end{array}$ \\
\hline 5 & 2.0 & 1.6 & 2.2 & 2.2 \\
\hline 10 & 3.0 & 2.8 & $>3.0$ & 3.8 \\
\hline 15 & 4.0 & 3.7 & $>3.0$ & 4.9 \\
\hline 20 & $>5.0$ & 4.3 & $>3.0$ & 5.7 \\
\hline
\end{tabular}

One fact in the simulation is the assumption that laser energy is absorbed by the glass by $100 \%$, which is the not the case in reality. It is estimated that only about $90 \%$ of the laser energy can be absorbed by the glassware. If this fact is taken into consideration, the model to predict the melting depth becomes

$$
D_{m}(P, t)=0.0045 \eta \alpha\left(D_{0}, d_{0}\right) P\left(1-e^{-t / 15.5}\right)
$$

where $\eta$ is the laser energy efficiency coefficient and is assumed to be 0.9 for $\mathrm{CO}_{2}$ laser glass interaction. 
This model is applied to predict the melting depth in laser glass cutting with soda-lime glassware, $D_{0}$ at $80 \mathrm{~mm}, \mathrm{~d}_{0}$ at $3 \mathrm{~mm}$ and $\mathrm{P}$ at $1000 \mathrm{~W}$. The prediction as well as the experimental results are shown in Figure 6.5 for comparison. The experiment results can also be found in Tables 5.9 and 5.11, or Figures 5.25 and 5.30.

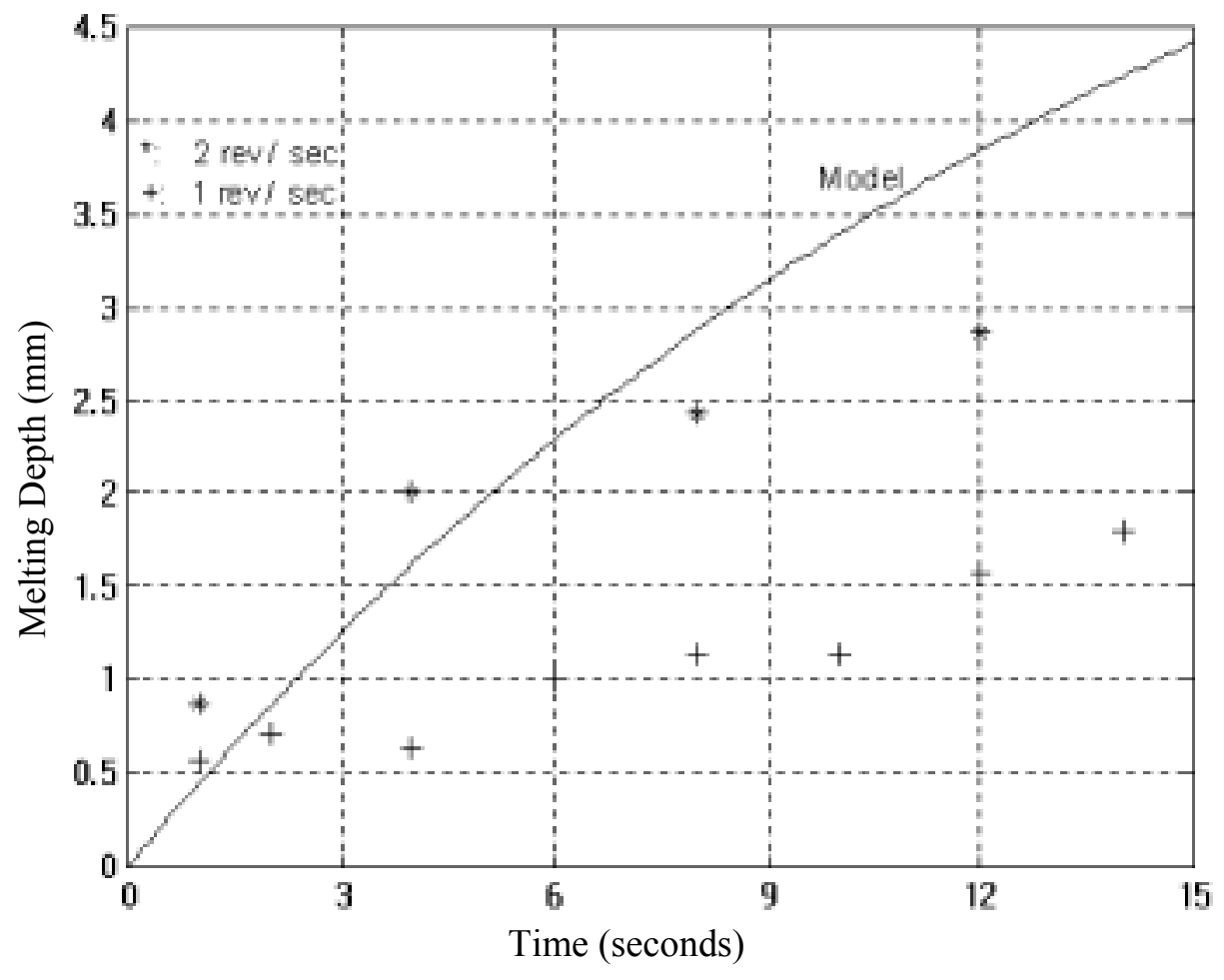

Figure 6.5 Comparison Between Model and Experimental Results

The model does predict the melting process, although the difference between the model prediction and the experimental results still exists. There are three factors contributing to the difference. First, in the simulation to predict the melting depth, it was assumed that laser energy is evenly distributed along the cutting ring, or rotation speed is infinite. Experiment results showed that rotation speed affects the melting depth as shown in Figure 5.30. It explains why the model curve is closer to the data points that resulted from $2 \mathrm{rev} / \mathrm{sec}$ laser glass cutting than 
the data points resulted from $1 \mathrm{rev} / \mathrm{sec}$ laser glass cutting. Second, the simulation did not take any vaporization into consideration, and assumed that the entire energy from the laser was used for heating and melting. However, in the experiments, vaporization did happen and did take away energy. Third, the temperature point used to determine the melting depth affects the value of melting depth, and thus affects the model, since the temperature gradient is very steep.

In a real application, this model has two types of uses. First, it can be used to determine the required laser power given the required glassware production rate. Second, given the required laser power, this model can predict the melting depth at a certain time in the laser glass cutting. The pulling force can further be predicted and controlled based on the melting depth.

The limitation of this model is that it varies when the glassware material properties change, meaning the model is glassware property-dependent. For glassware with a different material, the model has to be re-developed using the procedure shown in Figure 6.3 and based on simulation results with that geometry and material properties.

\subsubsection{Model to Track Cutting Groove Depth}

The model to predict the groove depth is given by Equation 6.5 and graphically shown in the Figure 6.6. It describes the temporal behavior of the cutting groove depth. It was derived from the micrograph measurement results of glass cut as shown in Table 6.3 using linear regression techniques. Glassware type used was clear cylinder. The operation parameters for this cut were $\mathrm{P}$ at $1000 \mathrm{~W}, \mathrm{D}_{0}$ at $95 \mathrm{~mm}, \mathrm{~d}_{0}$ at $5 \mathrm{~mm}$, and there was no purge and pulling force.

$$
D_{g}(P, t)=0.331-0.00011 P+0.027 t
$$


where $D_{g}$ is the cutting groove depth in $\mathrm{mm}$, $t$ is the laser cutting time in seconds, and $\mathrm{P}$ is the laser power in W.

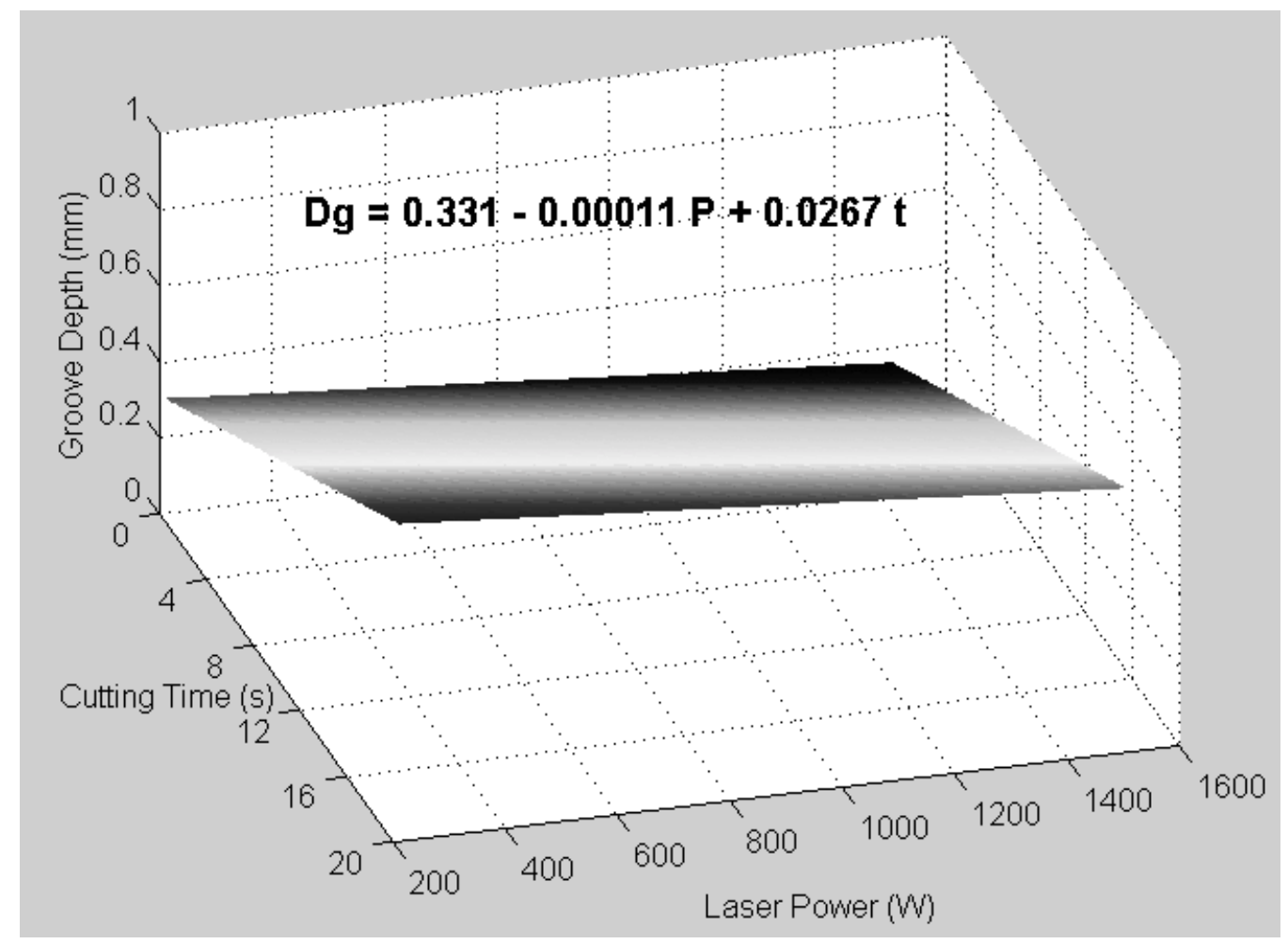

Figure 6.6 Cutting Groove Depth vs. Cutting Time and Laser Power

Table 6.3 Groove Depth Obtained from Experiments and Predicted by Process Model

\begin{tabular}{|c|c|c|c||}
\hline $\begin{array}{c}\text { LASER POWER } \\
(\mathrm{W})\end{array}$ & $\begin{array}{c}\text { LASER CUTTING TIME } \\
\text { (SECONDS) }\end{array}$ & $\begin{array}{c}\text { GROOVE DEPTH (mm) } \\
\text { FROM EXPERIMENTS }\end{array}$ & $\begin{array}{c}\text { GROOVE DEPTH (mm) } \\
\text { FROM PROCESS MODEL }\end{array}$ \\
\hline 400 & 5 & 0.44 & 0.42 \\
\hline 800 & 5 & 0.36 & 0.38 \\
\hline 1000 & 1 & 0.26 & 0.25 \\
\hline 1000 & 2 & 0.20 & 0.27 \\
\hline 1000 & 4 & 0.40 & 0.36 \\
\hline 1000 & 5 & 0.30 & \\
\hline
\end{tabular}




\begin{tabular}{||c|c|c|c||}
\hline 1000 & 6 & 0.50 & 0.38 \\
\hline 1000 & 8 & 0.32 & 0.44 \\
\hline 1000 & 10 & 0.54 & 0.49 \\
\hline 1000 & 12 & 0.46 & 0.54 \\
\hline 1000 & 14 & 0.64 & 0.60 \\
\hline 1500 & 5 & 0.29 & 0.30 \\
\hline 2000 & 5 & 0.26 & 0.24 \\
\hline
\end{tabular}

This model can be used to adjust the laser focus to keep the laser beam focused on the cutting ring; in other words, to track the cutting groove depth during the laser glass cutting process. However, since this model was based on the results of experiments on one type of glassware, the graph is not appropriate to be extended for the use in other types of glassware. The real time measurement of the glassware thickness was considered to be an effective way to track the cutting groove depth, however measurement using optical method was tried without success.

\subsection{SUBSYSTEM IMPLEMENTATIONS}

\subsubsection{Temperature Measurement Unit}

The Omega Model OS 554-V1-6 infrared-red (IR) sensor and temperature measurement unit, with a response time of $250 \mathrm{~ms}$, a spot size of $12.5 \mathrm{~mm}$ when positioned $250 \mathrm{~mm}$ from the glass surface and a measuring range of $-18{ }^{\circ} \mathrm{C}$ to $1371{ }^{\circ} \mathrm{C}\left(0\right.$ to $\left.2500{ }^{\circ} \mathrm{F}\right)$, was used in the lab 
prototype machine for temperature measuring purposes. The temperature unit with IR sensor is shown in Figure 6.7.

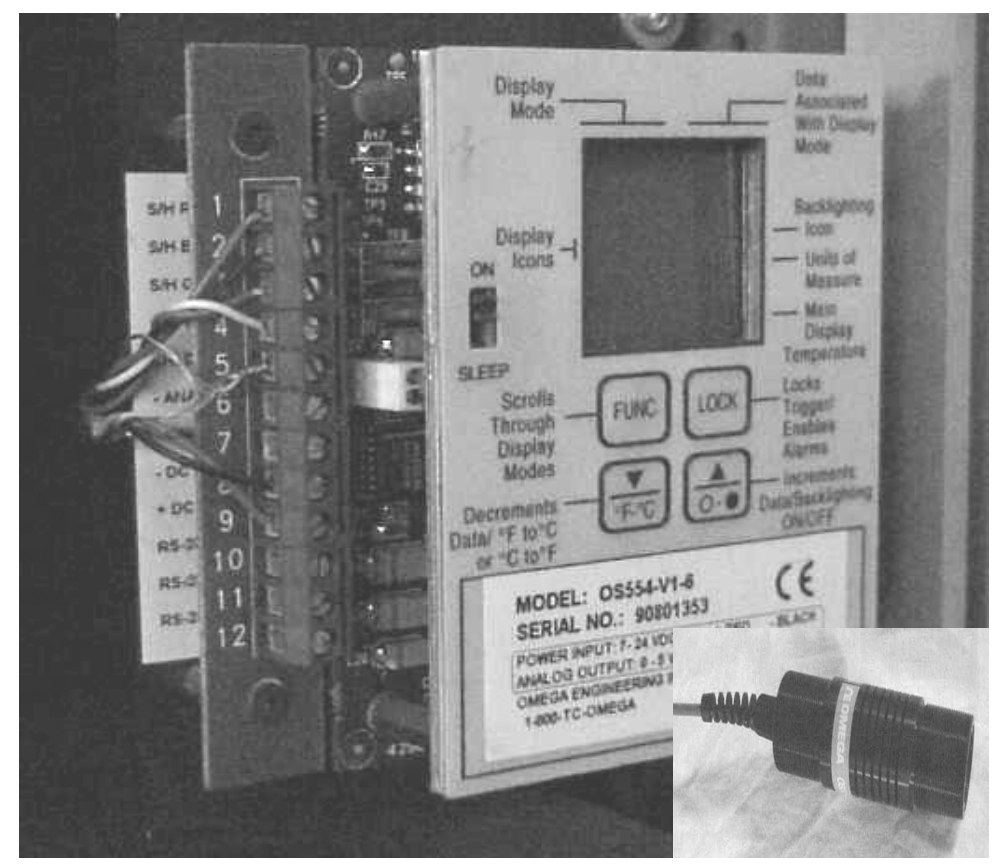

Figure 6.7 Temperature Measurement Unit with IR Sensor

Compared to the cutting ring width, which is about $4.2 \mathrm{~mm}$ (groove width of $0.6 \mathrm{~mm}$ plus adjacent strip width of $3.6 \mathrm{~mm})$, the sensor has a much larger spot size $(12.5 \mathrm{~mm})$ at its normal distance $(250 \mathrm{~mm})$ to the glassware surface; therefore, this unit has its limit in the measurement of the local temperature inside the cutting ring. Instead, it measures the average temperature of a larger area, and this average temperature is much lower than the local temperature inside the cutting ring during laser cutting, which could reach $3500{ }^{\circ} \mathrm{C}$ (predicted by the simulation). However, this limit is not a big problem in laser glass cutting, since the initial glassware temperature is of more concerns than the local temperature inside the cutting ring during laser cutting. This initial glassware temperature has to be measured and sent to the system controller 
for taking action on laser controller, since the laser can only fire when the initial glassware temperature is above its annealing temperature.

This unit has the ability to output the temperature information in either digital format or analog format. With this capability, it could be incorporated in the high-level control system. In the application, the analog signal $(0$ to $5 \mathrm{~V})$ output from the unit was connected to the $\mathrm{A} / \mathrm{D}$ channel of data acquisition board (DAQ) DT 9800 for digitization and data acquisition.

\subsubsection{Laser Power Controller}

Laser power is controlled by the Pulse Width Modulation (PWM) signal from UC-1000 Laser Power Control Unit as shown in Figure 6.8. The UC-1000 has an adjustment knob so that the power can be adjusted manually. The UC-1000 also accepts an analog voltage ( 0 to $10 \mathrm{~V}$ ) or analog current (4 to $20 \mathrm{~mA}$ ) input, $\mathrm{ANV} / \mathrm{C}$, for remote voltage/current signal to control the laser

power. In addition, the UC-1000 has an external gate signal input for remote laser on/off control. With these capabilities, the UC-1000 is not only able to control the laser power manually, but is also able to be incorporated in the high-level control system.

In the application, a 0 to $10 \mathrm{~V}$ voltage signal generated in DT 9800 through D/A channel was connected to $\mathrm{ANV} / \mathrm{C}$ input port of UC-1000 for the power magnitude control, and a digital signal also generated in the DT 9800 though a digital output channel was connected to the UC1000 external gate signal port to control the laser on or off. 


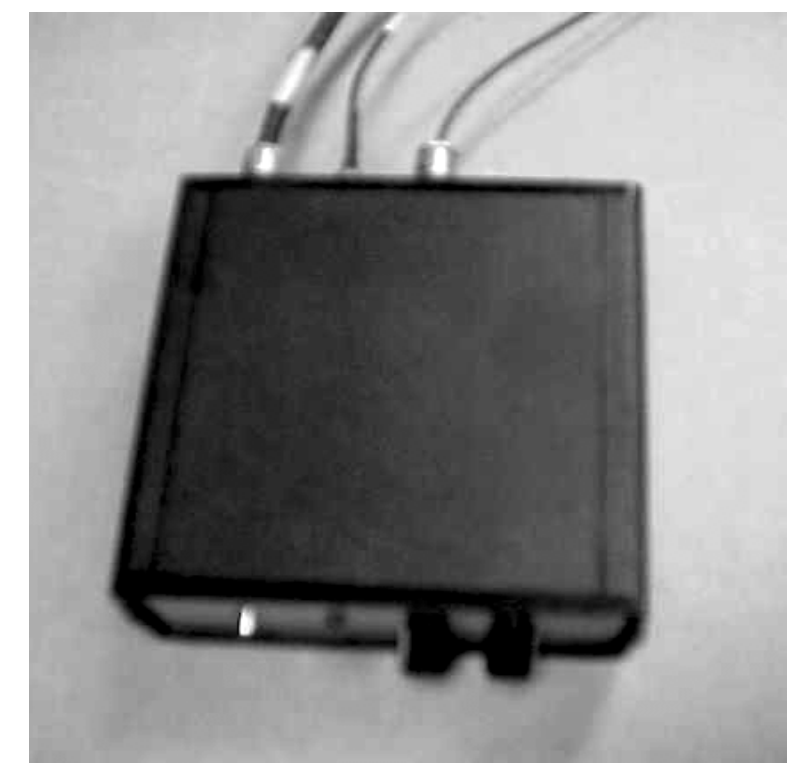

Figure 6.8 UC-1000 Laser Power Control Unit

As an example to show that the controller works, the response of the Synrad $100 \mathrm{~W}$ laser generator to step input was measured. The Model 201 Coherent Laser Power Meter was used to measure the laser power. The voltage analog output ( 0 to $1 \mathrm{~V}$ ) from the power meter was connected to the A/D channel in the DT 9800 for digitization and data acquisition. The response of this laser generator to the $10 \mathrm{~V}$ step input is shown in Figure 6.9. It was normalized with respect to the desired laser power output, which was $100 \mathrm{~W}$ and was corresponding to a $1 \mathrm{~V}$ peak analog output. Figure 6.10 shows the decaying response of laser power output when the off command was sent to the laser generator. It was found that the Synrad $100 \mathrm{~W}$ laser generator is a first-order system with a time constant of about 0.5 second. It has 0.3 second time delay in response to a step input. An estimation of the time constant and time delay for the laser generator from Figures 6.9 and 6.10 would not be accurate since the dynamics of the power meter was not taken into consideration. 


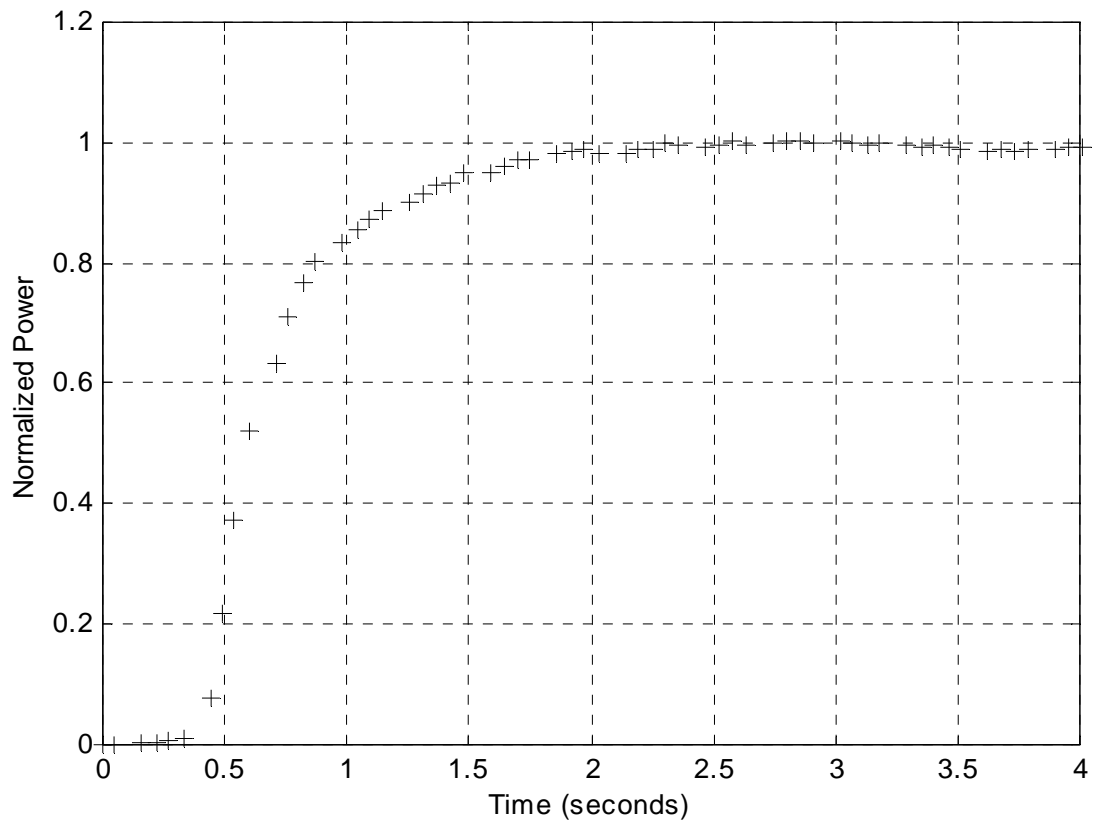

Figure 6.9 Response of Synrad 100 W Laser Generator to Step Input

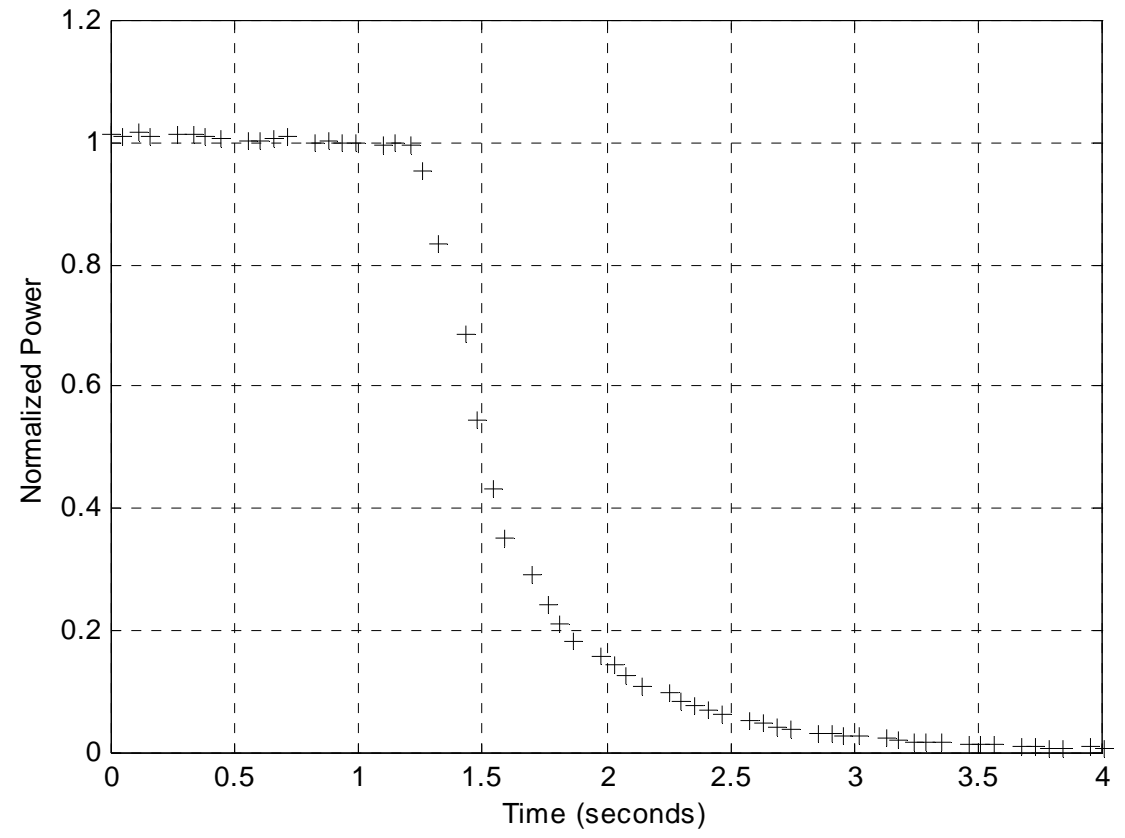

Figure 6.10 Decaying Response of Synrad 100 W Laser Generator 


\subsubsection{Laser Beam Positioning Controller}

After the beam has been delivered from the laser gun, it needs proper focus positioning for effective and precise cutting. This laser beam focus requirement was accomplished by a beam positioning system that includes two stepping motors and two translation platforms with embedded limit switches. These two stepper motors were controlled by the Motion Controller/Driver available from Velmex. This Velmex Controller/Driver is shown in Figure 6.11 and has the capability of driving two $1.8^{\circ}$ (200 steps/revolution) Permanent Magnet (PM) 5 amp/phase stepping motors. It is a message-based device and has the ability to communicate with the host computer via a RS 232 connection. With this capability, the system controller in the PC can control the motion of the laser beam by sending a command to the Velmex Motion Controller/Driver via the RS 232.

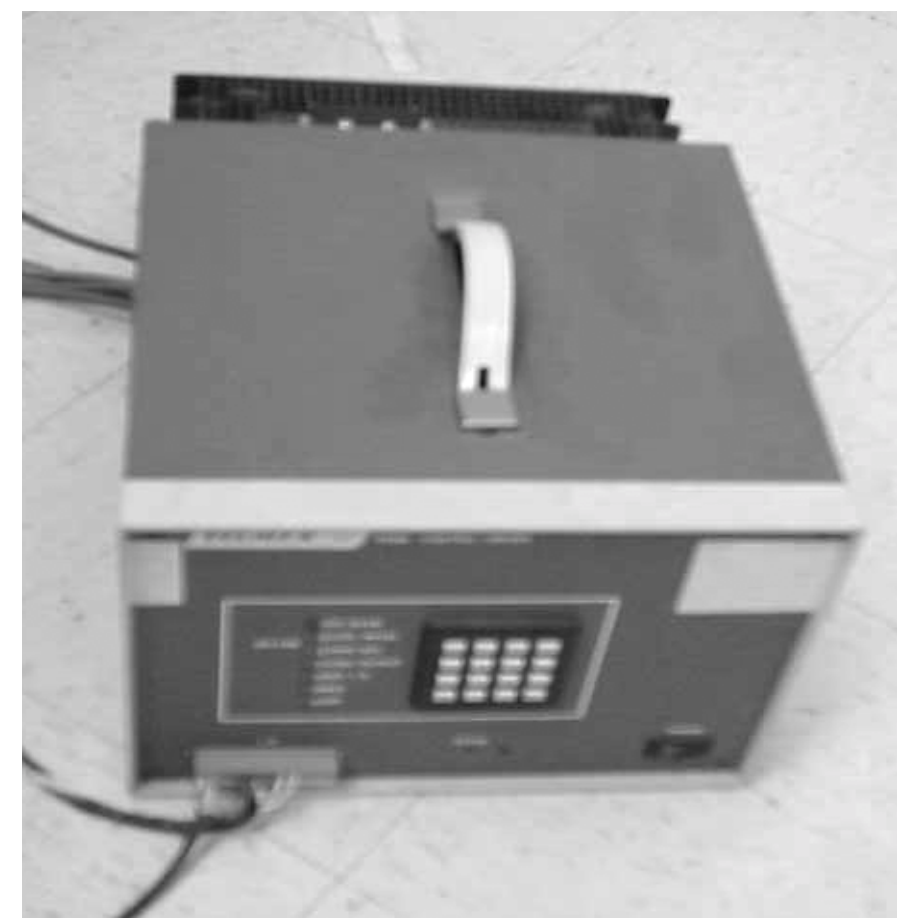

Figure 6.11 Velmex Motion Controller for Laser Beam Focus Position Control 
The pitch of the threaded shaft in the linear motion platform is $1 / 4$ inch (about $6.4 \mathrm{~mm}$ ), and the resolution of the stepper motor is 200 steps per revolution. Therefore, the linear positioning resolution of this laser beam position system is about $32 \mu \mathrm{m}$. The Velmex Motion Controller/Driver has the ability to drive a stepper motor at a speed of 2000 steps/second; therefore, the linear tracking velocity of this laser beam position system can reach 64 $\mathrm{mm} / \mathrm{second}$. Both the position resolution and tracking velocity are sufficient for the laser glass cutting process.

\subsubsection{Pulling Force Controller}

The DAEDAL MC 2000 Motion Controller with MS Series Drive shown in Figure 6.12 was used to control a stepper motor, which drives a spring-loaded pulling mechanism, so that by controlling the motion of stepper motor, the pulling force can be controlled. The pulling mechanism made by author is shown in Figure 5.3. The designed pulling force that can be produced by the pulling mechanism is 0 to $20 \mathrm{lb}$.

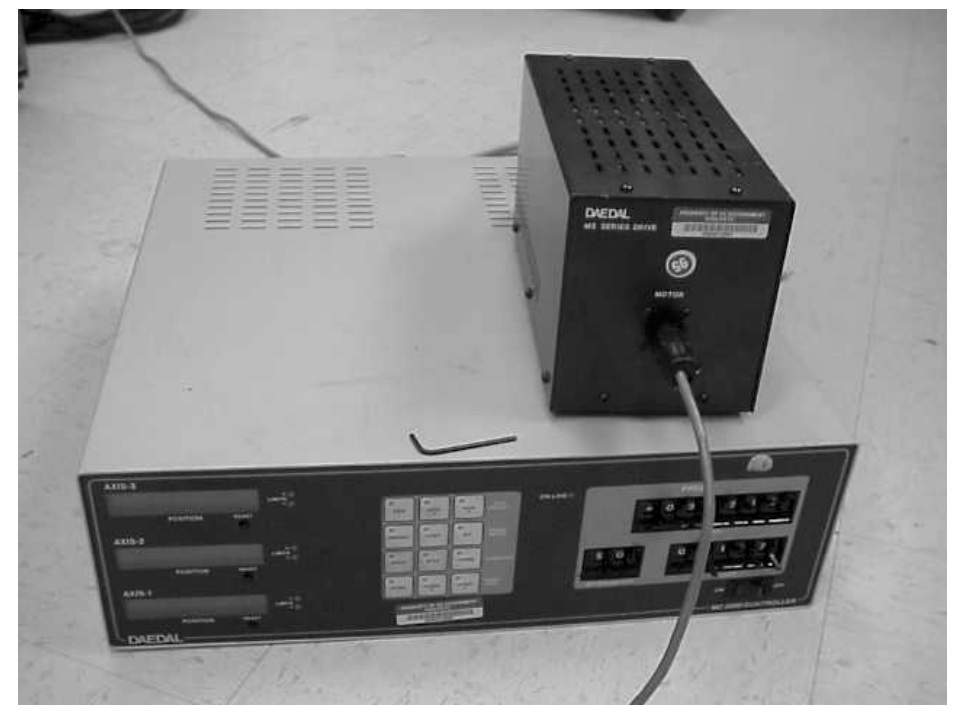

Figure 6.12 Motion Controller for Pulling Force Control 


\subsubsection{Data Acquisition Board}

The DT 9800 shown in Figure 6.13 is a data acquisition board (DAQ) from the Data Translation Company. It has the USB connection capability to communicate with a host computer. This DAQ has 12 bits resolution. Since the output range is 10 volts and the input range is 5 volts, output resolution is 0.0024 volts and the measurement resolution is 0.0012 volt.

The basic features of this DAQ include: 16 single-ended analog inputs or 8 differential analog inputs, 8 digital inputs, 8 digital outputs, 2 analog outputs, and 2 counters or timers. With these features, this DAQ is able to take care of most types of signal I/Os needed in laser glass cutting process, except for the message-based command signal, which is taken care by the RS 232.

In the application, this DAQ was used to integrate the subsystems and served as connection between the subsystem controllers and the system controller. The subsystems integrated through this DAQ include a temperature measurement unit and the laser power control unit.

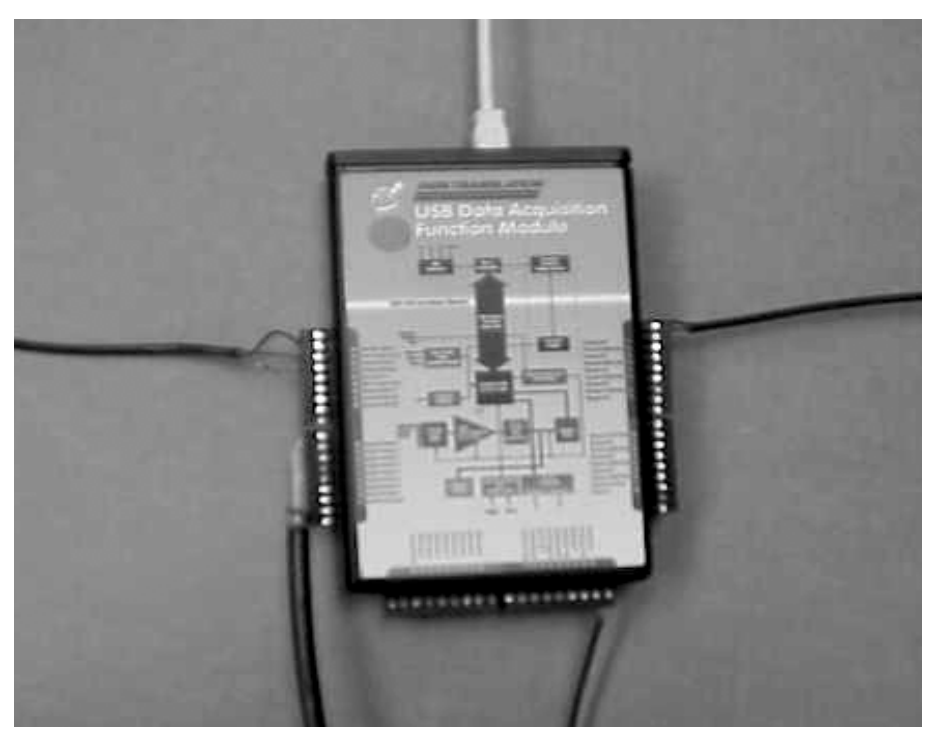

Figure 6.13 DT 9800 Data Acquisition Board 


\subsubsection{System Integration}

The measurement and controls discussed in Sections 6.2.1 to 6.2.4 were integrated with PC computer through an RS 232 and the DT 9800 with USB connection capability discussed in Section 6.2.5. The schematic of the integrated system is shown in Figure 6.14, and the physical implementation is shown in Figure 6.15. The Omega 554-V1-6 temperature measurement unit and the UC-1000 laser power control unit were connected to the DT 9800, and the DT 9800 was connected to the PC computer through the USB. The PC computer sends the power level command and laser firing on/off command to the UC-1000 through the DT 9800 D/A channel and digital output channel, respectively. The PC computer also receives the temperature information from the temperature measurement unit through the DT $9800 \mathrm{~A} / \mathrm{D}$ channel. The laser beam focus position control unit was connected to the PC through the RS 232. The pulling force control unit is to be integrated into the system through the DT 9800.

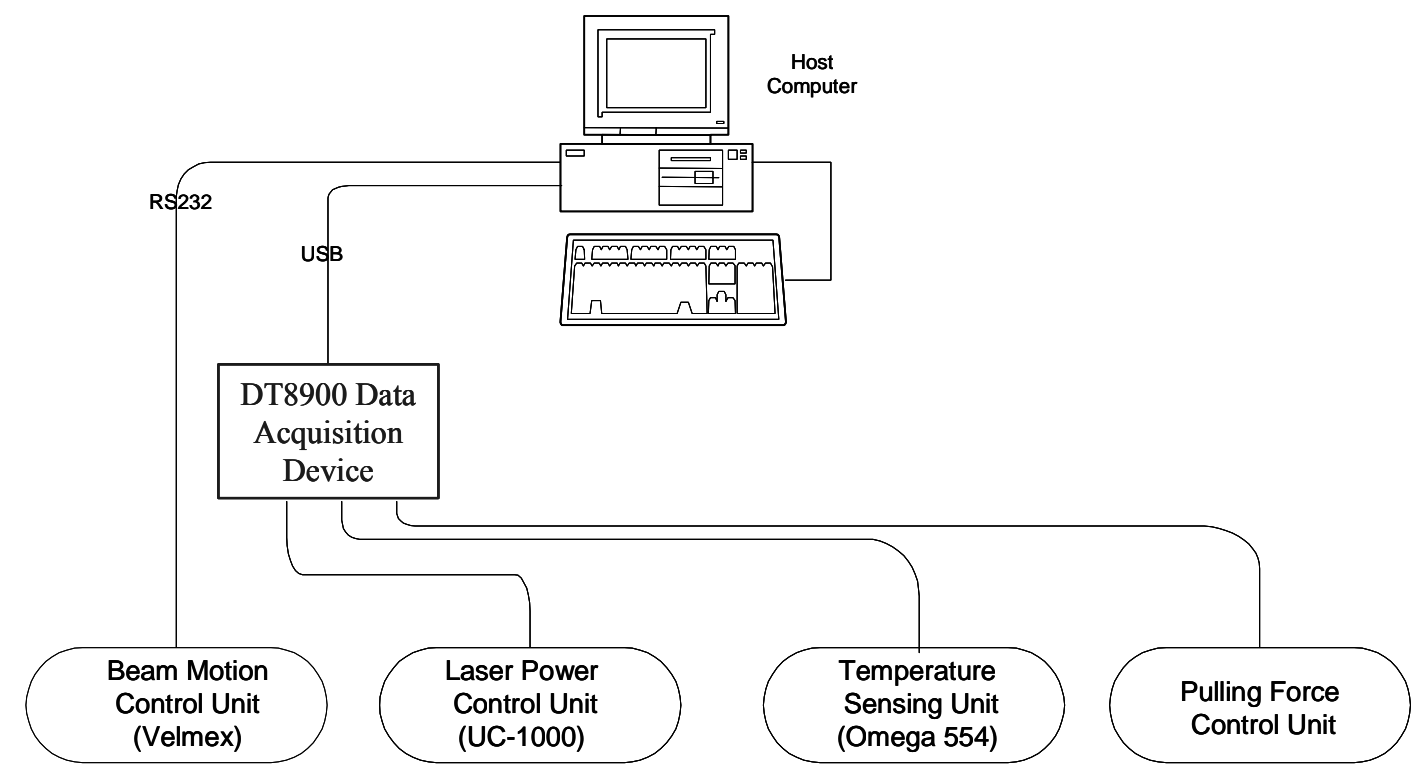

Figure 6.14 Schematic of Control System for Laser Glass Cutting 


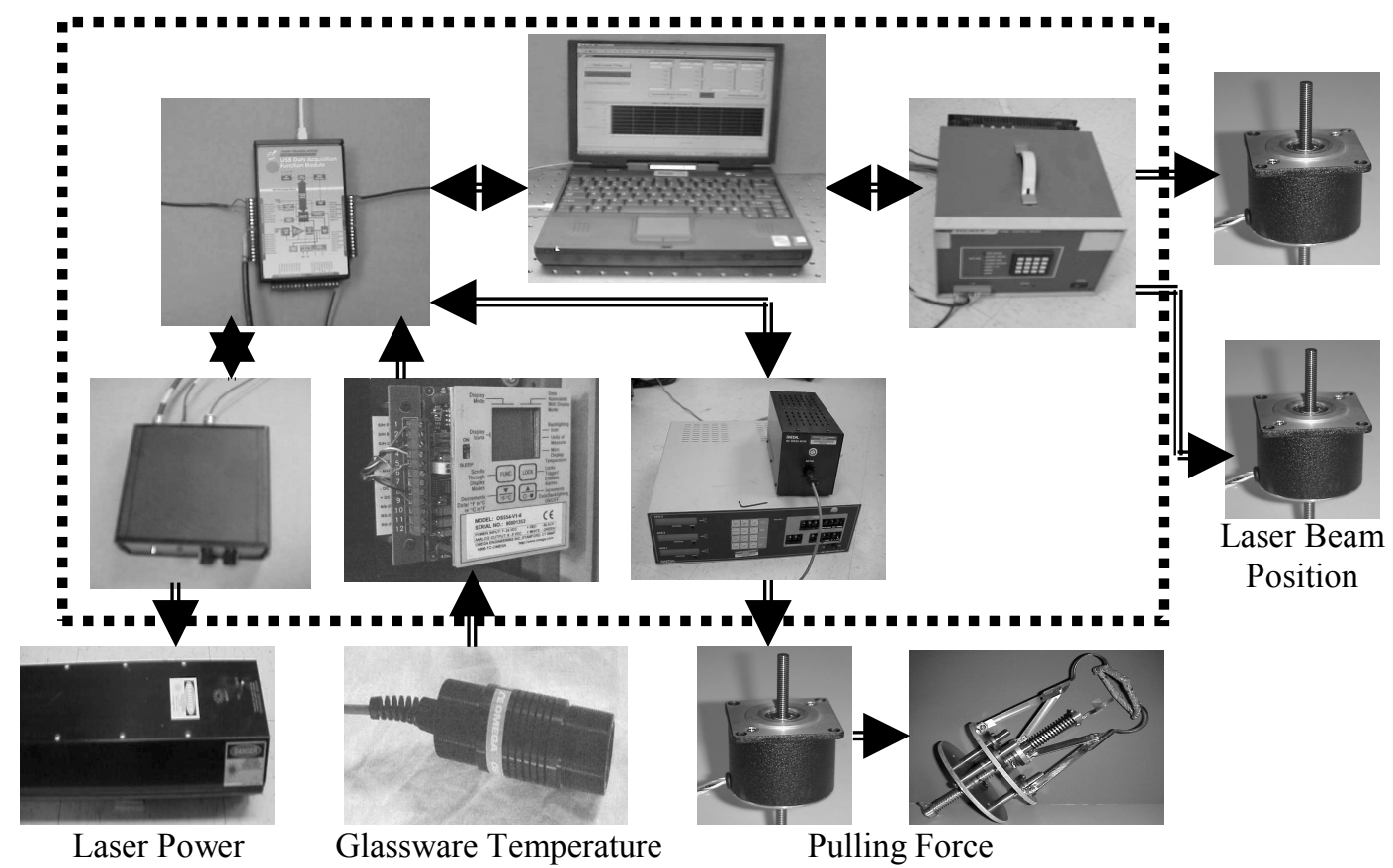

Figure 6.15 Physical Implementation of Control System for Laser Glass Cutting

\subsection{SYSTEM CONTROLLER IMPLEMENTATION}

The system controller was developed using HP VEE in a laptop computer. HP VEE is the programming software from Hewlett Packard Company, specially designed for instrumentation and control. The significant features of this software are first it is graphical programming and the strong capability to interface the hardware such as the DAQ.

There are three major functions of the system controller. First, it provides the humanmachine interface to take the user inputs for the laser glass cutting process and displays the laser glass cutting process information to the user. Second, it computes the operation parameters based on its incorporated models. Third, it provides the interface to the subsystems so that it is 
able to send the commands to the subsystems or receive the status information from the subsystems.

The user inputs include the glassware type, size and production rate. The outputs to the user include glassware temperature, laser firing status and firing time, laser beam focal position. Additional safety purpose interfaces such as laser emergency stop, and motion emergency termination are also provided to the user. The two models described in Sections 6.1.1 and 6.1.2 were incorporated in this system controller. These models are used to compute the required laser power, and laser beam focus tracking position based on the user input and the actual laser cutting time. The calculated values are then sent to the subsystems to be executed.

Figure 6.16 shows the graphical user interface (GUI) of this system controller. Figure 6.17 shows the block diagram behind the GUI. In the block diagram, blocks are used to represent various objects, and wires are used to represent data flow or operation sequence.

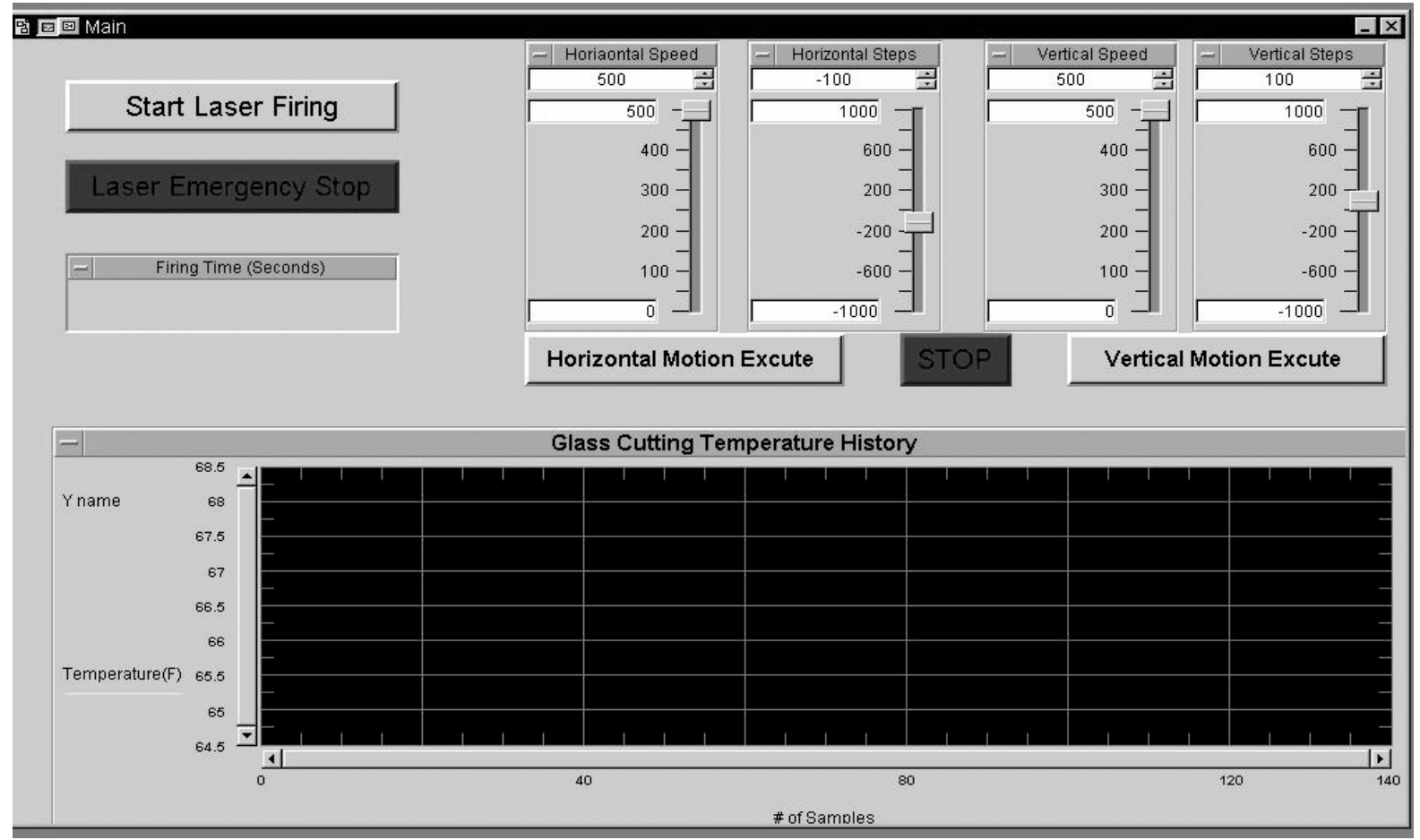

Figure 6.16 Visual Front Panel of System Control Software 


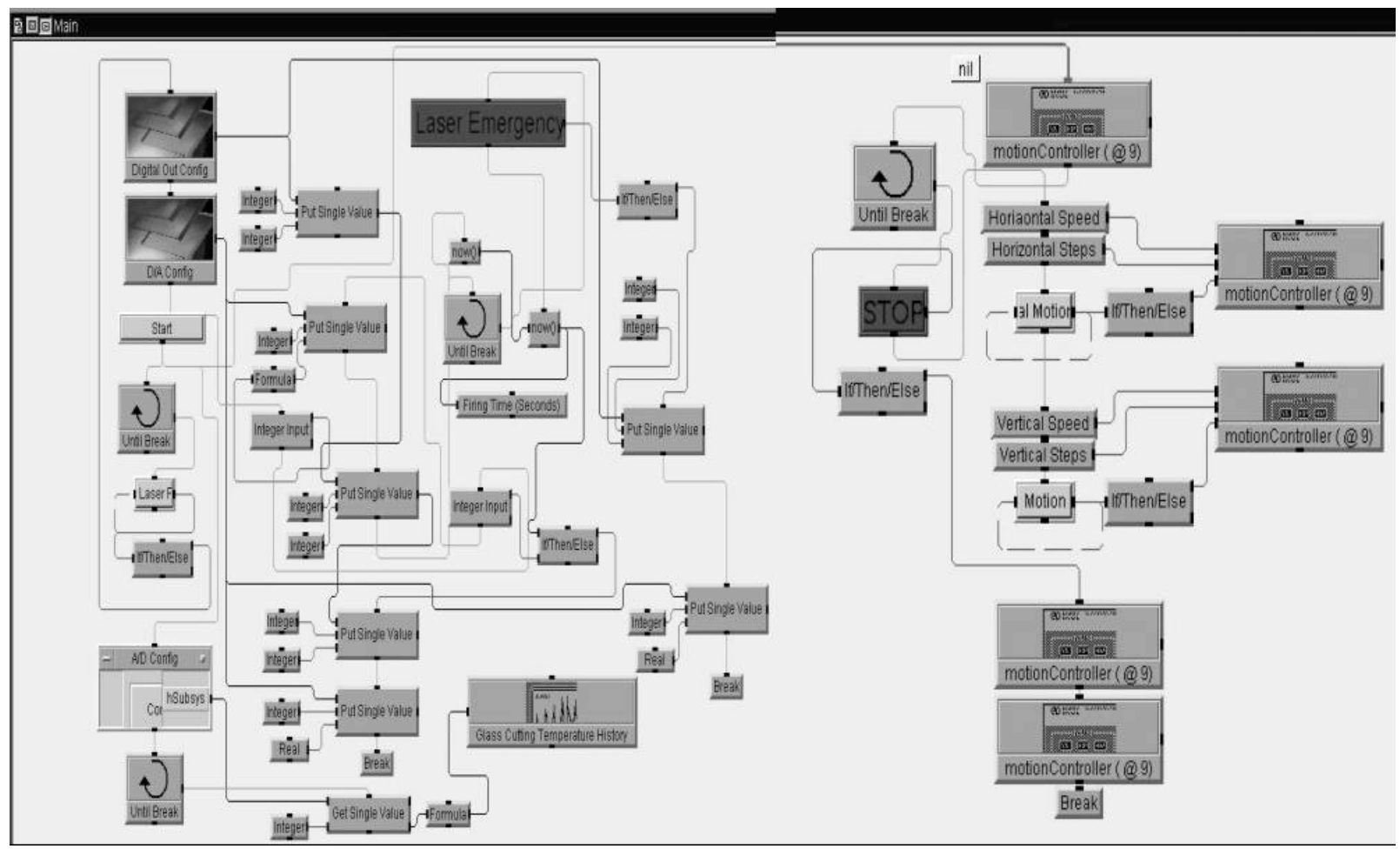

Figure 6.17 Block Diagram of System Control Software

\subsection{ApPlication}

In an actual industrial application, the first step would be to get the user input. The second step would be to calculate the required laser power and the pulling force. The third step would be to initialize the system such as move stepper motors to their home positions, zero the pulling force, etc. The fourth step would be to send a signal of the laser power level to the laser power controller. The fifth step would be to monitor the temperature and send a laser-firing command (gate signal) to the laser power controller to start the laser firing when the glassware temperature is above $5508 \mathrm{C}$. Then groove depth is continuously predicted and sent to beam 
motion controller for beam focus tracking. When the glassware is about to melt through based on the melting depth prediction, a pulling force command will be sent to pulling force controller.

As an example, supposed that it is proposed to cut glassware made of soda lime, with a diameter of $80 \mathrm{~mm}$, a thickness of $3 \mathrm{~mm}$, and at a production rate of 6 pieces per minute. After the system controller gets this information, it will choose the model for soda lime type glassware, and perform the following computations.

Using Equation 6.3 yields

$$
\alpha(80,3)=0.7 \times 10^{1-\frac{80}{95}}+0.3 \times 10^{1-\frac{3}{5}}=1.76
$$

Substituting $\alpha(80,3)=1.76, \eta=0.9, \mathrm{t}=10$ seconds and $\mathrm{D}_{\mathrm{m}}(\mathrm{P}, 10)=3 \mathrm{~mm}$ into Equation 6.4 yields

$$
P=\frac{3}{0.0045 \times 0.9 \times 1.76 \times\left(1-e^{-10 / 15.5}\right)}=885 \mathrm{~W}
$$

Let $\mathrm{P}=900 \mathrm{~W}$. This is the power level required for this particular laser glass cutting process. Substituting $\mathrm{P}=900 \mathrm{~W}, \eta=0.9$ and $\alpha(80,3)=1.76$ again into Equation 6.4 gives the melting depth $\mathrm{D}_{\mathrm{m}}$ as a function of time

$$
D_{m}(900, t)=6.42 \times\left(1-e^{-t / 15.5}\right)
$$

Substituting $\mathrm{P}=900 \mathrm{~W}$ into Equation 6.5 gives the groove depth $\mathrm{Dg}$ as a function of time

$$
D_{g}(900, t)=0.232+0.027 t
$$

Having computed the information for $\mathrm{P}$, as well as $\mathrm{D}_{\mathrm{m}}$ and $\mathrm{D}_{\mathrm{g}}$ as functions of time, the system controller is able to control the laser power by holding $\mathrm{P}=900 \mathrm{~W}$, to track the groove by sending $D_{g}(t)$ to the laser beam motion controller, and to control pulling force by sending $D_{m}(t)$ to the pulling force controller. 


\section{DISSERTATION SUMMARY, CONTRIBUTIONS AND FUTURE WORK}

\subsection{DisSERTATION SUMmary}

\subsubsection{Motivation}

The $\mathrm{CO}_{2}$ laser, which has a $10.6 \mu \mathrm{m}$ wavelength, has gained much attention in cutting glass due to its high absorption in glass. Depending on the laser beam intensity and the laser glass interaction duration, the dominant thermal phenomena could be heating, melting or vaporizing. This leads to the potential new methods of laser glass cutting besides the commonly mentioned cutting method by scoring and fracture; namely, glass cutting by melting and/or vaporizing.

Compared to glass cutting by scoring and fracture, glass cutting by melting and/or vaporizing has several potential advantages. It will eliminate the cracking issue since the glass will be cut while hot. It will eliminate the further processing, such as grinding and polishing, due to the clean and finished cut quality. The process is more controllable since the melting and vaporizing are more predictable than the fracture. 


\subsubsection{Objectives}

The four objectives of this dissertation were:

- Understand the thermal behavior of laser glass interaction;

- Identify the critical factors in laser glass cutting by melting and/or vaporizing;

- Determine the effect of critical factors on the cutting process;

- Develop the laser glass cutting control system and process control.

\subsubsection{Approaches}

The following seven approaches were taken to achieve the objectives:

- Model the laser glass interaction using classical 3D heat conduction theory;

a Develop a simulation software program in Visual C++ based on the 3D model and the R-C formulation of the finite difference method, and perform the simulation of laser glass interaction;

- Contribute to building the lab prototype of the laser glass cutting machine;

- Implement a control system based on the data acquisition device DT9800, and implement a system controller using HP VEE. Instrumentation and controls will include beam motion control, laser power control, pulling force control, and temperature measurement;

- Participate in systematic laser glass cutting experiments;

- Validate the simulation model by using experimental results and the melting depth as criteria;

- Develop the process control model and implement the model. 


\subsubsection{Results}

- Simulation provided information of instantaneous peak temperature, heat penetration, and temperature decay under certain conditions. Although a laser with a power of $100 \mathrm{~W}$ can produce a temperature of $3500{ }^{\circ} \mathrm{C}$, high enough to melt and vaporize the glass, it is not capable of melting through glass because of the very limited heat penetration.

a Simulation with a laser power of $1000 \mathrm{~W}$ and glassware diameter of $95 \mathrm{~mm}$ and thickness of $5 \mathrm{~mm}$ showed a melting penetration of $3.3 \mathrm{~mm}$ in $20 \mathrm{~s}$. This result indicated that a laser power of $1000 \mathrm{~W}$ is possibly required to cut glass of $95 \mathrm{~mm}$ in diameter and $5 \mathrm{~mm}$ in thickness within an acceptable time (a piece per minute).

- Experiments showed that $100 \mathrm{~W}$ laser is incapable of cutting through a typical glassware (diameter $>60 \mathrm{~mm}$, thickness $>2 \mathrm{~mm}$ ) by melting and/or vaporizing, although melting and vaporizing does happen in the process. It was found experimentally that a laser with a power of around $1000 \mathrm{~W}$ would be sufficient to cut typical glassware when using a pulling force mechanism.

- Experiments showed that a pulling force would enable a quick and stable separation of glassware from the moil in laser glass cutting.

- Both simulation and experiments showed that preheating is necessary in order to avoid cracking, and the experiments showed that preheating temperature is preferred to be $600{ }^{\circ} \mathrm{C}$ in order for a laser with a power of $1000 \mathrm{~W}$ to cut glass without cracking.

- Micrograph results showed that four distinct areas characterize the cutting edge induced by the laser glass interaction. The characteristic is sensitive to the thickness of glass and pulling force.

- Micrograph results showed that laser power has a significant effect on groove width, but has less effect on the cutting quality. Micrograph results showed that rotation speed has an effect on both cutting depth and cutting quality. Although rotation speed has an effect on groove 
width, this effect is diminished in the multi-path cutting process. Micrograph results showed that the laser beam focus position has an effect on the groove depth and width as well as the melting depth. It is best that the laser beam always be kept focused. Micrograph results showed that the hot gas purge could help to obtain narrow and deep groove.

\subsection{DisSERTATION CONTRIBUTIONS}

\subsubsection{Theoretical Contributions}

A simulation program called LGCSim based on a heat conduction model and the finite difference method was developed to simulate the thermodynamics and heat transfer of laser interaction with glassware. The model in the simulation program was validated by the agreement, in certain extent, between the melting depth predicted by the simulation and the melting depth measured by the micrograph equipment.

Temperature response and temperature distribution were computed from the simulation. The peak temperature $\left(3500{ }^{\circ} \mathrm{C}\right)$ and the melting depth computed from the simulation indicated the feasibility of laser glass cutting using the melting/vaporization method. The time constant for temperature decay after laser striking is about 0.02 second. The simulation results showed (see Figures 4.14, 4.27, 4.28, 4.29 and 4.30) that the required laser power for cutting glassware has to be about $1000 \mathrm{~W}$ for typical glassware $(60 \mathrm{~mm}$ to $150 \mathrm{~mm}$ in diameter and $2 \mathrm{~mm}$ to $5 \mathrm{~mm}$ in thickness). $100 \mathrm{~W}$ laser is not able to cut the typical glassware.

A parametric study based on simulation (see Figures 4.12, 4.13 and 4.14) found that laser power has a significant effect on laser glass cutting. Increasing the laser power facilitates the heat propagation into the glassware. Glassware size has an effect on the laser glass cutting too. 
Increasing either the glassware diameter or glassware thickness frustrates the heat propagation into the glassware. Glassware rotation speed has an effect on the uniformity of temperature distribution along the cutting ring. Increasing the glassware rotation speed produces a more uniform temperature distribution.

Models to predict the depth of melting and the depth of the groove for various levels of laser power were derived as shown in Equations 6.4 and 6.5, based on both simulation results and micrograph measurement results. The models enabled the prediction of required laser power for laser glass cutting under certain production rate. The models also enabled the prediction of melting depth and groove depth that are required for glassware pulling force control and laser beam motion control.

\subsubsection{Experimental Contributions}

Contributions were made to the design and construction of a lab prototype machine, including basic instrumentation and controls. This lab prototype machine has the functional capabilities required for laser glass cutting, including glassware holding, glassware rotating, glassware preheating, laser beam firing, laser power adjusting, and laser beam adjusting. This machine has the capability to cut small glassware with its installed $100 \mathrm{~W}$ laser, and to cut larger glassware when a higher power laser is incorporated; for example, the $4000 \mathrm{~W}$ laser at the LPC facility.

Feasibility of laser glass cutting using the melting and vaporizing method was verified by successfully cutting in the lab environment glass bottles as well as glassware from hand glass 
companies. The resultant cutting edges of some cuts were clean and finished, thus showed the achievability of a clean and finished cut by the laser glass cutting process.

Five critical process operation parameters in laser glass cutting were identified through the systematic glassware cutting experiments and then micrograph measurement of the cuts. 1) It was found that laser power is extremely important in laser glass cutting. While the low power laser is able to cut small size thin-wall glassware, a higher power laser (around $1000 \mathrm{~W}$ ) is needed to cut glassware of typical size (Diameter about $60 \mathrm{~mm}$ to $150 \mathrm{~mm}$, thickness about 2 $\mathrm{mm}$ to $5 \mathrm{~mm}$ ). The higher laser power will produce deeper melting with a shallower groove. 2) The initial glassware temperature is also critical. The laser should not fire before the glassware temperature is above the annealing temperature in order to avoid cracking. However, there is no evidence showing that the initial glassware temperature has any effect on the cutting process. 3) It was also found that the glassware rotation speed has an effect on the laser glass cutting. However, the rotation speed has to be limited since the glassware cannot sustain a large rotation momentum. Once the rotational speed is set, there is no need to adjust during laser glass cutting. 4) To achieve a narrow and deep cut, the laser beam is preferably kept focused, which was accomplished by the beam motion controller. 5) A gas purge (air or nitrogen) was helpful in achieving a narrow and deep cut. There are two major functions of a gas purge in the laser glass cutting process. First, it purges the induced vapor away during cutting, thus helping the laser penetration. Second, it limits the melting in the cutting ring surface, thus reducing the resealing problem. Unique to laser glass cutting is that the gas purge has to be hot $\left(\approx 500{ }^{\circ} \mathrm{C}\right)$ to avoid cracking the glassware. 


\subsection{RECOMMENDATIONS FOR FUTURE WORK}

Future work for the project falls into the following five categories:

- Model to predict pulling force

This model will basically be developed experimentally. The model should be able to predict the required pulling force in terms of the laser power, laser cutting time, glassware diameter, glassware wall thickness.

a Pulling force control

Pulling force control has to be implemented based on the current pulling force mechanism. The upper gripper of this mechanism should be modified so that it is more rigid to avoid slip along the glassware surface during pulling.

\section{口 System controller}

When the model for pulling force prediction and the new laser with a higher power level are available, the system controller can be implemented and thus control the laser glass cutting process in plant test.

- Simulation taking melting and/or vaporizing into consideration

The current simulation model only takes heat conduction into consideration, and the kinematics of melting and vaporizing were not a consideration due to the limitation in finite difference method and due to the lack of knowledge about the melting and vaporization mechanism. A different model such as composite model should be considered to incorporate melting and even vaporization, therefore providing not only more accurate temperature information, but also information such as the melting depth and the vaporization depth. 


\section{References}

[1] Energetics, Inc, Glass Technology Roadmap, September 1997

[2] E. Beyer and G. Herziger, "Recent Development in Laser Technology", Proceedings of the Conference, The Laser and the Electron Beam in Welding, Cutting, and Surface Treatment, State of the Art, 1991

[3] F. Dausinger, "Laser Hardening in Precision Components", $2^{\text {nd }}$, Symposium on Exploiting the Laser in Engineering Production, Coventry, G.B., 1984

[4] H.W. Bergmann, "The Influence of Exposure Time, Wavelength and Repetition Rate on the Quality of Surface Treatments of Metals With Excimer Laser", Proc, ISATA 1989

[5] K. Behler, et al, "Advances in Polarized Laser Beam Welding of Pipes", Harrah's Reno Nevada, 1989

[6] F. Dausinger, "Welding and Cutting with Controlled Polarization of Laser", Proceedings of the Conference, The Laser and the Electron Beam in Welding, Cutting, and Surface Treatment, State of the Art, 1991

[7] E. Beyer et al, "State of the Art in Laser Cutting with $\mathrm{CO}_{2}$ Lasers", ICALEO 1990

[8] J. Luxon and D. Parker, Industrial Laser and Their Applications, Second Edition, Prentice Hall, 1992

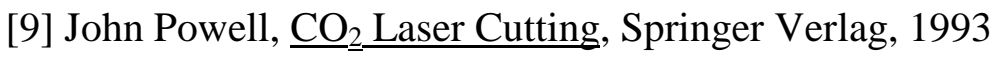

[10] Luciano E. Chaing, "3-D CNC Trajectory Interpolation Using Bresenham Algorithm", IEEE International Symposium on Industrial Electronics, IEEE, Santiago, Chile, May 25 -27, 1994 
[11] George W. Mclellan and Errol B. Shand, Glass Engineering Handbook, $3^{\text {rd }}$. Edition, McGraw-Hill Book Company, 1984

[12] J. P. Holman, Heat Transfer, $8^{\text {th }}$ Edition, McGraw-Hill, 1995

[13] R.M Lumley, "Controlled Separation of Brittle Materials Using a Laser", American Ceramic Society Bulletin, 48[9] 850-54, 1969

[14] Granger K. Chui, "Laser Cutting of Hot Glass", American Ceramic Society Bulletin. $514-18,1974$

[15] F.J. Grove, D.C. Wright, and F.M. Hamer, "Cutting of Glass with a Laser Beam", U.S. Patent 3.543.979, Dec. 1, 1970

[16] M.A. Finucane and I. Black, "CO 2 Laser Cutting of Stained Glass", The International Journal of Advanced Manufacturing Technology, 12:47-59, 1996

[17] Yu V. Khlopkov, “Laser Cutting of Glass for Color Filters for Television and Personal Computers", Glass and Ceramic, Vol. 51, Nos. 7-8, 1994

[18] Precision Technology Center (PTC), "Zero Width Cutting Technology", http://www.ptg.nu/products/owct/descrip.htm, 1999

[19] Verheyen, et al. “Glass Cutting”, U.S. 3.932.726, Jan. 13, 1976

[20] Walter Haefner, "Method of Working (Cutting) Glass with Absorbent by Laser Beam", U.S. Patent 3.453.097, July 1, 1969

[21] Frane W. Boddicker "Method and Device for Cutting Glass", U.S. Patent 4.468.534, Aug. 28, 1984

[22] Granger K Chui “Method of Cutting Glass with a Laser" U.S. Patent 3.885.943, May 27,1975 
[23] Granger K. Chui "Method of Laser Beam Cutting of a Ribbon of Hot Glass", U.S. Patent 3.930.825, Jan. 6, 1976

[24] Richard W. Meyer “Laser Beam Severing of a Rotating Article”, U.S. Patent 3.839.005, Oct. 1,1974

[25] Minakawa, Shiono, Nishihashi “Laser Beam Glass Cutting” U.S. Patent 4.682.003, July 21,1987

[26] H. Soodak, Effects of Heat Transfer Between Gases and Solids, Ph.D. Thesis, Duke University, Durham, NC, 1943

[27] H.G. Landau, "Heat Conduction in a Melting Solid", Q. Applied Math, 8, 81-94, 1950

[28] J.E. Rogerson and G.A. Chayt, "Total Melting Time in the Ablating Slab Problem", Journal of Applied Physics, 42, 2711-2713, 1971

[29] F W. Dabby and U-C. Paek, "High-Intensity Laser-Induced Vaporization and

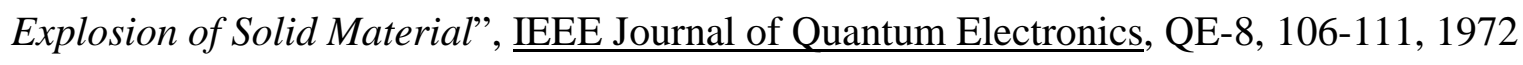

[30] M. Von Allmen, "Laser Drilling Velocity in Metals", Journal of Applied Physics, 47, $5460-5463,1976$

[31] H. E. Cline and T.R. Anthony, "Heat Treating and Melting Material with Scanning Laser or Electron Beam", Journal of Applied Physics, 48, 3895-3900, 1977

[32] J. Mazumder and W. M. Steen, "Heat Transfer Model for CW Laser Material Processing”, Journal of Applied Physics, 51, 941-947, 1980

[33] M.F Modest and H. Abakians, "Evaporative Cutting of a Semi-infinite Body with a Moving CW Laser", Trans. ASME 108, 602-607, 1986 
[34] S.C.Hsu, S. Chakravorty and R. Mehrabian, "Rapid Melting and Solidification of a Surface Layer", Metallurgy Transaction, 9B, June 1978

[35] S. Biyiki and M.F Modest, "Effect of Beam Expansion and Focusing on Evaporative Cutting with a Moving CW Laser", Journal of Heat Transfer, 110, 529-532, 1988

[36] C. Chan, J. Mazumder and M.M. Chen, "A Two Dimensional Transient Model for Convective in Laser Method Pool", Metallurgy Transaction, 15A, 2175-2184, 1984

[37] C. P. Grigoropoulos, S. E. Long, A. F. Emery and W.E. Dutcher, Jr. "Experimental and Computational Analysis of Laser Melting of Thin Silicon Films", National Heat Transfer Conference, HTD-Volume 113, Heat Transfer in Manufacturing and Materials Processing, 1989

[38] A. Minardi and P.J. Bishop, "Temperature Distribution within a Metal Subjected to Irradiation by a Laser of Spatially Varying Intensity", National Heat Transfer Conference, HTDVol. 113, Heat Transfer in Manufacturing and Materials Processing, 1989

[39] J.M. Glass, H.P.Groger, R.J. Churchill, J. W. Lindau and T.E.Diller, "Heat Transfer in Metallic Glasses during Laser Cutting", National Heat Transfer Conference, HTD-Vol. 113, Heat Transfer in Manufacturing and Materials Processing, 1989

[40] M.J. Kim, Z.H. Chen and P. Majumdar, "Finite Element Modeling of the Laser Cutting Process", Computers \& Structures, Vol.49, No. 2, 231-241, 1993

[41] B.S. Yilbas, A. Z. Sahin and R. Davies, "Laser Heating Mechanism including Evaporation Process Initiating Laser Drilling", International Journal of Mech. Tools Manufacturing, 35 1047-1062, 1995

[42] L. M. Yu, "Three-Dimensional Finite Element Modelling of Laser Cutting”, Journal of Materials Processing Technology, 63, 637-639, 1997 
[43] P. A. Atanasov and S. I. Gendjov, "Laser Cutting of Glass Tubing - a Theoretical Model", J. Phys. D: Appl. Phys., 20, 597-601, 1987

[44] Terry L. VanderWert, "Laser Processing Formed Metal Parts", Proceedings of the Conference, The Laser and the Electron Beam in Welding, Cutting, and Surface Treatment, State of the Art, 1991

[45] Christopher Hermanns, "Optimizing Cutting and Welding Processing by Controlling the Laser Beam”, Conference of Manufacturing'96, Laser in the Workpiece Session, 1996

[46] W. M. Steen, Laser Material Processing, Springer, London, 1991

[47] G. Chryssoloaris, Laser Machining, Springer, New York, 1991

[48] H. Kaebernick, A. Jeromin, P. Mathew, "Adaptive Control for Laser Cutting Using Striation Frequency Analysis", Annals of the CIRP, 137-140, 1998

[49] Lisa T. Bird, Mark A. Yvanovich "Automated Laser Cutting in Three Dimensions", NASA Tech Briefs, November 1995

[50] Christopher Hermanns, "Optimizing Cutting and Welding Processing by Controlling the Laser Beam”, Conference of Manufacturing'96, Laser in the Workpiece Session, 1996

[51] Huang, M.Y., Chatwin, C.R., "A knowledge Based Adaptive Control Environment for an Industrial Laser Cutting System", Optics and Laser in Engineering, 21:273-295, 1994

[52] Chryssolouris, G., Yablon, A., "Depth Prediction in Laser Machining With the Aid of Surface Temperature Measurements", Annals of the CIRP, 42/1:205-207, 1993

[53] Jorgenson, H. and Olsen, F.O, "Process Monitoring During Laser Cutting, Gas and Metal Vapor Lasers and Applications", Proc. of SPIE, 1412:198-208, 1991 
[54] Tonshoff, H.K., Overmeyer, L., "Process Control System in Laser Material Processing, Optical and Quantum Electronics", 27:1439-1447, 1995

[55] Luciano E. Chiang and Jorge Ramos G., "CNC Control of a Laser Cutting Machine", IEEE International Symposium on Industrial Electronics, IEEE, Santiago, Chile, May 25 -27, 1994

[56] Robert Dworkowski, Peter Wojcik, “Computer Control for a High Speed, Precision Laser Cutting System", Canadian Conference on Electrical and Computer Engineering, 1995

[57] Donald C. O'Shea, Elements of Modern Optical, John Wiley \& Sons Inc., 1985

[58] E. B. Shand, Technical Consultant, Glass Engineering Handbook, Second Edition, McGraw-Hill Book Company, Inc., 1958

[59] Liyun Zheng, John E. Sneckenberger, Tim McLaughlin, Steven D. Woodruff, "Modeling and Simulation of Laser Glass Interaction", ISATED Conference on Modeling and Simulation, Pittsburgh, May 2000

[60] Christopher Thompson, John E. Sneckenberger and Steven D. Woodruff, "Model of a Laser Glass Cutting Machine using Design of Experiments", ISATED Conference on Modeling and Simulation, Pittsburgh, May 2000

[61] Christopher Thompson, "Development of System Parameters for Enhanced Cutting and Finishing of Hand glass Using a CO2 Laser", Master Thesis, http://etd.wvu.edu/templates/showETD.cfm?recnum=1347, May 2000 


\section{APPENDIX A: 1-D Analytical Model for Laser Glass Cutting}

The 1-D model developed by Antanasov and S. I. Gendjov [43] for the laser cutting of a glass cylinder by melting is presented in this appendix.

The goal of the model was to find the temperature response of any point in the cutting ring to the multiple laser pulse inputs with finite length. This temperature is a temperature averaged along the thickness direction. The derivation of this model consists of solving the thermal conductivity equation. This model can be solved to give an explicit expression to predict the temperature at a certain location and at a certain point of time during the laser glass interaction.

The geometry of the glass cylinder to be laser cut is shown in Figure A.1. This cylinder glass with an external diameter $\mathrm{D}_{0}$ and a wall thickness $\mathrm{d}_{0}$ is rotated around its axis with a rotation period of $\tau$. The cylinder is preheated to a temperature $\mathrm{T}_{0}$ and is sustained at this temperature during the laser cutting. The cylinder's axis is in a vertical direction and the moil to be removed is at the bottom of the glassware. The laser beam is focused on the wall of the cylinder by a focal lens, forming a spot with glass surface dimensions $l \times 2 w_{0}$. It is assumed that the following relationship holds for the spot length 1 :

$$
D_{0} \geq l \geq w_{0} \sim d_{0}
$$

The laser spot can be approximated as an infinite uniform heat source along the y-axis, whose profile along the $\mathrm{z}$-axis is that of the laser beam along the same direction. The intensity profile of the laser beam along the z-axis is described by Equation A.2. 


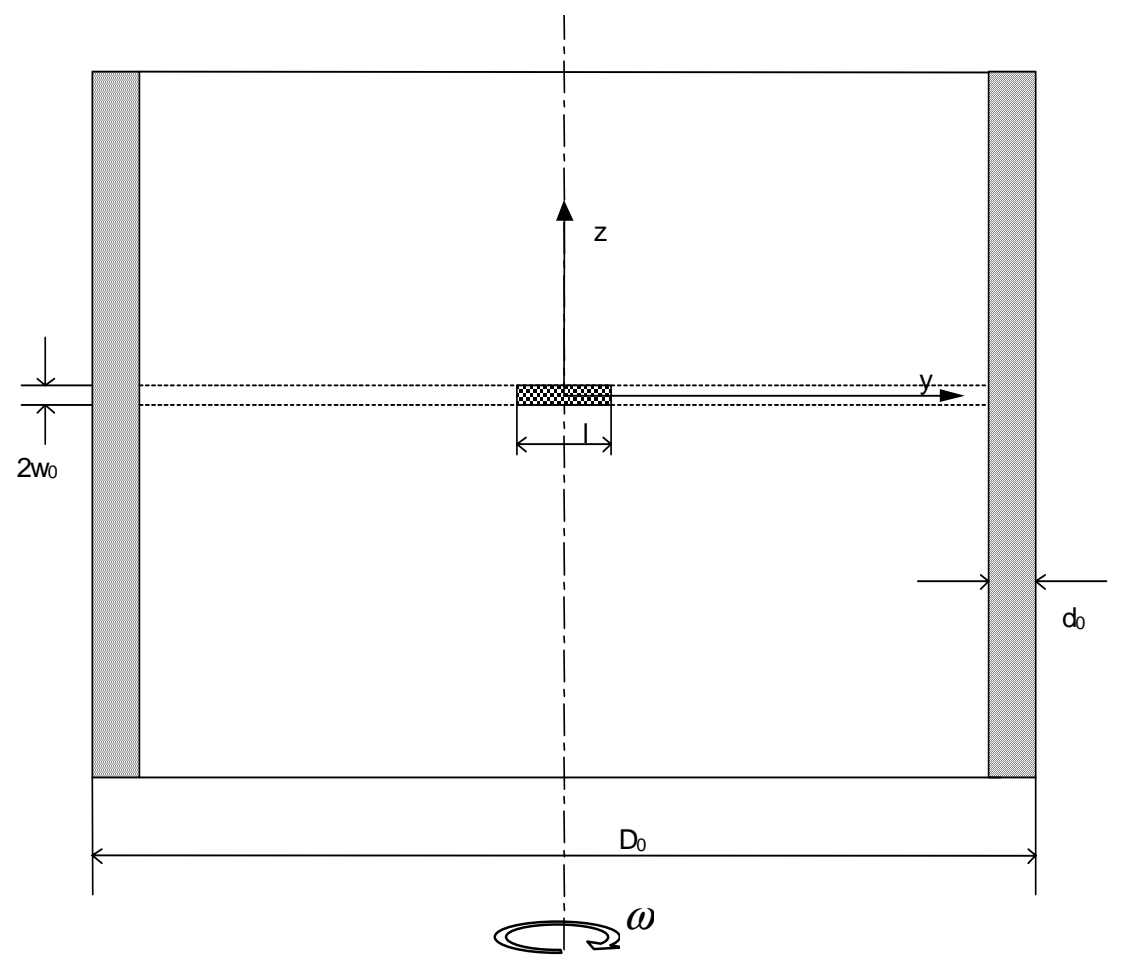

Figure A.1 Geometry of Laser Glass Interaction

$$
I(r)=I_{0} \exp \left(-2 r^{2} / w_{0}^{2}\right)
$$

The approximation of the laser spot as an infinite uniform heat source along the y direction is based on the relationship $l \gg>w_{0}$. Nevertheless, at any particular point of the cutting ring $\left(-w_{0}<z_{0}<w_{0}\right)$ this source can be considered as a pulsed source with a pulse length of $\tau_{p}=\left(l / \pi D_{0}\right) \tau$. The pulse length is determined by the laser glass interaction time, which is a function of laser spot dimension and the rotational velocity of the glass cylinder.

Let $\mathrm{N}$ pulses corresponding to $\mathrm{N}-1$ rotation periods $\tau$. In the $\mathrm{z}$ direction, it is assumed that there is no loss of heat away from the cutting ring. Moreover, in a time interval of the order of $\tau$, temperature uniformity is reached in the wall along the $\mathrm{z}$ direction, provided the following condition is satisfied: 


$$
\mathrm{d}_{0}<(4 a)^{1 / 2}
$$

where $a=k / C \rho$ is the thermal diffusivity of the material, with $k$ being the thermal conductivity, $C$ the thermal capacity, and $\rho$ the density of the glass. It can be assumed the temperature through the depth of the wall is uniform.

In order to represent the temperature after some pulse periods as a sum of the contributions of each pulse, one shall assume temperature-independent values. This can be done by averaging the physical quantities $k, C, \rho$, and therefore $a$, in the interval of $600{ }^{\circ} \mathrm{C}$ to 1500 ${ }^{\circ} \mathrm{C}$. In this temperature interval, the value of $a$ varies less than $\pm 30 \%$ with respect to its average value [57].

Solutions of the classical heat conduction equation can be written in a form using the solution for a point-like initial $\left(t=t^{\prime}\right)$ temperature profile, i.e., using the Green Function of this classical heat conduction equation.

$$
G\left(z-z^{\prime}, t-t^{\prime}\right)=\frac{1}{\sqrt{\pi\left[4 k\left(t-t^{\prime}\right)\right]^{1 / 2}}} \times \exp \left[-\left(\frac{z-z^{\prime}}{\left[4 k\left(t-t^{\prime}\right)\right]^{1 / 2}}\right)^{2}\right]
$$

under the boundary conditions $T(z= \pm \infty)=T_{0}$. It is convenient to use the following expression for the time interval

$$
\begin{aligned}
& \left(t-t^{\prime}\right)=(n-1+\xi) \tau \\
& \text { for } n=1,2, \ldots . N \text { and } 0<\xi \leq 1
\end{aligned}
$$

In this representation $\xi$ could be thought of as being the transformed coordinate $\theta=2 \pi \xi$, as long as one is free to assign $\xi=0$ to the point on the cutting ring which, at the moment $(n-1) \tau$, is at the leading end of the focused laser spot. 
In the above notation the general expression for the temperature in the cutting ring as a function of time can be written as

$$
T(z: N, \xi)=T_{0}+\sum_{n=1}^{N} \Delta T(n, \xi)
$$

where

$$
\Delta T(n, \xi)=\int_{-\omega_{0}}^{\omega_{0}} d z^{\prime} G\left[z-z^{\prime},(n-1+\xi) \tau\right] \times T^{\prime}\left(z^{\prime}, \tau_{p}\right)
$$

Here $T^{\prime}\left(z, \tau_{p}\right)$ is the change in the temperature profile at the end of a pulse with respect to its beginning. One still assumes independence of $T^{\prime}\left(z, \tau_{p}\right)$ on $i$; e.g. assuming that pulses heat up the cylinder in a uniform way.

Suppose that the characteristic length, corresponding to the duration of a single pulse, is significantly smaller than $w_{0}$, e.g. $\left(4 a \tau_{p}\right)^{1 / 2}<<w_{0}$. If so, then using Equation A.2 will give

$$
T^{\prime}\left(z, \tau_{p}\right) \underset{\tau_{p} \rightarrow 0}{\longrightarrow} \frac{I(z) \tau_{p}}{C \rho d_{0}}=\frac{I_{0} \tau_{p}}{C \rho d_{0}} \exp \left[-2\left(\frac{z}{w_{0}}\right)^{2}\right]
$$

Indeed, in this particular case, there holds another relationship, namely

$$
w_{0} \approx\left(4 a \tau_{p}\right)^{1 / 2}
$$

which makes it necessary to take into account the finite duration of the pulse. In order to do this, consider the solution of the thermal conductivity equation describing the heating of a thin semifinite plane by a source along the line $z=0$, having a uniform (along 0y axis) power density:

$$
T_{q}(z, t)=T_{0}+\frac{2 q}{k}(a t)^{1 / 2} \operatorname{ierfc}\left(\frac{z}{(4 a t)^{1 / 2}}\right)
$$


where the function ierfc(u) is defined as

$$
\operatorname{ierfc}(u)=\frac{1}{\pi} e^{-u^{2}}-u \times \operatorname{erfc}(u)
$$

where

$$
\operatorname{erfc}(u)=1-\frac{2}{\pi^{2}} \int_{0}^{u} e^{-t^{2}} d t
$$

In order to find $T^{\prime}\left(z, \tau_{p}\right)$, Equations A.2 and A.10 are used. At the same time $q=I\left(z^{\prime}\right) d z^{\prime} / d_{0}$ and $u=\left(z-z^{\prime}\right) /\left(4 a \tau_{p}\right)^{1 / 2}$ are defined, and $q$ is integrated over $z^{\prime}$. It is nearly impossible to take the integral, even approximately, by analytical means. In order to avoid the difficulties, while saving the main physical features of the solution, the original dependence of the temperature on the coordinate $\mathrm{z}$ at given time $t=\tau_{p}$ after the pulse's arrival time is replaced by the function

$$
g\left(z-z^{\prime}\right)=\left(\frac{2}{\pi}\right)^{1 / 2} \frac{1}{w_{p}} \exp \left[-2\left(\frac{z-z^{\prime}}{w_{p}}\right)^{2}\right]
$$

which is a normalized to an area of one redistribution function of the temperature, and whose half-width is equal to the half-width of $\operatorname{ierfc}(\mathrm{u}), w_{p} \approx 0.32\left(4 a \tau_{p}\right)^{1 / 2}$. Besides this, it is worth mentioning that if the half-width and maximum of the two functions are equal, they have almost equal areas.

Using Equations A.2 and A.13, an expression is obtained for the temperature profile change at the end of a single pulse: 


$$
\begin{aligned}
T^{\prime}\left(z, \tau_{p}\right) & \approx \frac{I_{0} \tau_{p}}{C \rho d_{0}} \times \int_{-\infty}^{\infty} d z^{\prime} \exp \left[-2\left(\frac{z^{\prime}}{w_{0}}\right)^{2}\right] \exp \left[-2\left(\frac{z-z^{\prime}}{w_{p}}\right)^{2}\right] \\
& =\frac{I_{0} \tau_{p} w_{0}}{C \rho d_{0} w} \exp \left[-2\left(\frac{z}{w}\right)^{2}\right]
\end{aligned}
$$

where $w^{2}=w_{0}^{2}+w_{p}^{2}$. The integration over $z^{\prime}$ is expanded to $\pm \infty$, which doesn't introduce a significant error because of satisfying the condition $w_{0}>w_{p}$ and the exponential behavior of the primary part of the function in this interval.

After substituting Equations A.14 into A.7 and after taking the integral using Equation A.6 an expression is obtained for the temperature of the cutting ring at $x=0$ after heating during the time for rotating the cylinder $N-1$ turns:

$$
T(0, N, \xi)=T_{0}+T_{1} S(N, \xi)
$$

where

$$
\begin{gathered}
T_{1}=0.84 \frac{P \tau}{C_{\rho} \pi D w_{0} d_{0}} \times \frac{1}{\left[1+\left(w_{p} / w_{0}\right)^{2}\right]^{1 / 2}} \\
S(N, \xi)=\sum_{n=1}^{N} \frac{1}{\left[1+\left(n-1+\xi^{\prime}\right) / \delta^{2}\right]^{1 / 2}} \times \operatorname{erf}\left[\left(2+2 \delta^{2} /\left(n-1+\xi^{\prime}\right)\right]^{1 / 2}\right.
\end{gathered}
$$

here,

$$
\begin{aligned}
& \xi^{\prime}=\xi-\frac{\tau_{p}}{\tau} \\
& \delta=\frac{w_{0}}{(4 a \tau)^{1 / 2}}\left[1+\left(w_{p} / w_{0}\right)^{2}\right]^{1 / 2}
\end{aligned}
$$


where $T(0, N, \xi)$ is the temperature at location 0 (cutting ring start point), $\mathrm{N}$ is the number of revolutions and $\xi$ is the time phase, $P$ is the laser power, $\tau$ is the period of rotation, $\tau_{p}$ is the laser pulse duration length, $w_{0}$ is the radius of laser focal spot, $D_{0}$ is the outside diameter of the glassware, $d_{0}$ is the thickness of the glassware, $C_{\rho}$ is the thermal capacity, and $a$ is the thermal diffusivity.

For the intended application the most important parameter is the duration of cutting and its dependence upon the absorbed laser power $\mathrm{P}$, e.g. the time $t_{c}(P)$ from the beginning of the laser heating until the partition of the glassware. The partition takes place one complete turn after the temperature $T(0: N, \xi)$ reaches the production temperature $T_{l}$ (above $T_{l}$ the glass is liquid)

$$
t_{c}(P)=t\left(P ; T_{l}\right)=N_{l} \tau
$$

where $N_{l}$ is the solution of the equation

$$
\left(T_{l}-T_{0}\right) / T_{l}=S\left(N_{l}, 1\right)
$$

It is estimated [43] that the additional (not compensated for by the gas burner that sustains the tube at $\mathrm{T}=\mathrm{T}_{0}$ ) convective heat losses from the cutting ring to the air do not exceed $6 \%$ of the absorbed laser power. The same upper limit was estimated for the additional radiated power. Since the total additional heat loss amount to less than $12 \%$, taking into account that this value is a high upper limit, they could be neglected. 


\section{APPENDIX B: \\ Peak Temperature and Decay Rate}

The purpose of this appendix is to justify the peak temperature and temperature decay rate that was obtained by the simulation. The justification was based on the calculation of thermodynamics and heat conduction in an element on the surface of the glassware.

The parameters used in this calculation include: laser power $(\mathrm{P}) 100 \mathrm{~W}$, rotation cycle $(\tau)$ 1 second, glassware diameter (D) $95 \mathrm{~mm}$, and ambient temperature $\left(\mathrm{T}_{\infty}\right) 50 \mathrm{C}$. Laser beam waist radius $\mathrm{w}_{0}$ is $0.1 \mathrm{~mm}$ and laser beam transmissibility index $\lambda_{0}$ is assumed to be $0.1 \mathrm{~mm}$. In the simulation, the element size is $3 \mathrm{~mm} \times 0.2 \mathrm{~mm} \times 0.1 \mathrm{~mm}$.

Assume that only the heat conduction along the radial direction ( $\mathrm{r}$ axis) happen, then the governing equation for this small element is

$$
C_{m} \frac{d T}{d t}=-k \times d A \frac{d T}{d r}+\dot{Q}
$$

where $\mathrm{T}$ is the temperature in $\mathrm{K}, \mathrm{t}$ is the time in second, $\mathrm{C}_{\mathrm{m}}$ is the thermal capacity (mass is considered), $\mathrm{k}$ is the thermal conductivity, $\mathrm{dA}$ is the heat conduction surface area of the small element, $\mathrm{r}$ is the radial axis, $Q$ is the heat input.

When comparing the element size to the beam waist radius $\mathrm{w}_{0}$ and transmissibility index $\lambda_{0}$, it can be concluded that during the period that laser is passing along this element, $100 \%$ of the radiation in circumferential direction, $86 \%$ in height direction and $73 \%$ in the thickness 
direction will be absorbed in this element. It is assumed that no reflection, heat convection and heat radiation happen. Therefore, the heat flow into this element is

$$
\dot{Q}=100 \times 86 \% \times 73 \%=62.8 \mathrm{~W}
$$

For soda lime glass, thermal capacity (C) is $840 \mathrm{~J} / \mathrm{kg} . \mathrm{K}$, density ( $\rho$ ) is $2440 \mathrm{~kg} / \mathrm{m}^{3}$, and thermal conductivity ( $\mathrm{k}$ ) is $0.88 \mathrm{~W} / \mathrm{m} . \mathrm{k}$. Substituting these figures into Equation B.1 yields

$$
\begin{aligned}
\frac{d T}{d t} & =\frac{-k \times d A}{C_{m}} \times \frac{d T}{d r}+\frac{\dot{Q}}{C_{m}} \\
& =\frac{-0.88 \times 3 \times 0.2 \times 10^{-6} \frac{d T}{d r}+62.8}{840 \times 2440 \times\left(3 \times 0.2 \times 0.1 \times 10^{-9}\right)} \\
& =-0.00429 \frac{d T}{d r}+510668.7
\end{aligned}
$$

where $\frac{d T}{d r}$ can be approximated as

$$
\frac{d T}{d r} \approx \frac{T-T_{1}}{\Delta r}
$$

where $T_{1}$ is the temperature of the element next to the element of concerns, $\Delta r$ is distance between two element. $T_{1}$ can be assumed to be the initial temperature, which is $873 \mathrm{~K}(600 \mathrm{C})$, and $\Delta \mathrm{r}$ is $0.1 \mathrm{~mm}$. Let $T^{\prime}=T-T_{1}$, then $d T=d T^{\prime}$. Substituting $T^{\prime}=T-T_{1}, d T=d T^{\prime}$ and Equation B.4 into Equation B.3 yields

$$
\begin{aligned}
\frac{d T^{\prime}}{d t} & =0.00429 \frac{T^{\prime}}{0.1 \times 10^{-3}}+510668.7 \\
& =42.9 T^{\prime}+510668.7
\end{aligned}
$$


Solving this differential equation given the initial condition $T^{\prime}(t=0)=0 K$ yields

$$
T^{\prime}=11903.6\left(1-e^{-42.9 t}\right)
$$

Then,

$$
T=-11903.6 e^{-t / 0.023}+12776.6
$$

When $\mathrm{t}=0.01$ second, the element will reach the peak temperature

$$
\begin{aligned}
& T_{\text {peak }}=-11903.6 e^{-t / 0.023}+12776.6 \\
& \quad=5069 K \quad(4796 C)
\end{aligned}
$$

Decaying rate of the temperature in this laser glass interaction is 0.023 second.

It needs mention that it is rough estimation. There are some assumptions in this calculation. First, $T_{1}$ is assumed to be constant, while in reality it will increase due to the energy input from laser and from heat conduction from the first element. Second, no conduction through other dimensions, while in reality there is heat conduction to both $\mathrm{z}$ direction and circumferential direction. Third, no convection and radiation were considered. Fourth, no vaporization was considered. Fifth, It is assumed that the $\lambda_{0}=0.1 \mathrm{~mm}$, means that most of the energy (73\%) was absorbed in the first element. Different $\lambda_{0}$ value will effect the calculation of the peak temperature and temperature decaying rate. 


\section{APPENDIX C: \\ Energy Loss Due to Heat Convection}

The purpose of this appendix is to justify the consideration of heat convection in the laser glass simulation. The justification was based on the calculation of heat convection occurred in the heat convection area of the element used in the simulation.

In the simulation of laser glass interaction, the value of heat convection coefficient $h_{c}$ was chosen to be $10 \mathrm{~W} / \mathrm{m}^{2} . \mathrm{K}$. Reference [12] states that heat convection coefficient between glass and air is $5 \sim 15 \mathrm{~W} / \mathrm{m}^{2}$.K. The heat loss due to heat convection is evaluated using the Equation C.1

$$
\dot{Q}_{h}=H_{c} \times d A \times\left(T_{s}-T_{\infty}\right)
$$

where $\mathrm{h}_{\mathrm{c}}$ is the heat coefficient, $\mathrm{dA}$ is the surface area of the element used in the simulation, $\mathrm{T}_{\mathrm{s}}$ is the temperature in the element and $\mathrm{T}_{\infty}$ is the ambient temperature.

It was found from the simulation that temperature in the surface element $\left(\mathrm{T}_{\mathrm{s}}\right)$ could be as high as $3500 \mathrm{C}$. The parameters used in the simulation to predict this $\mathrm{T}_{\mathrm{s}}$ include: laser power (P) $100 \mathrm{~W}$, rotation cycle $(\tau)$ second, glassware diameter (D) $95 \mathrm{~mm}$, and ambient temperature $\left(\mathrm{T}_{\infty}\right)$

$50 \mathrm{C}$. Laser beam waist radius $\mathrm{w}_{0}$ is $0.1 \mathrm{~mm}$ and laser beam transmissibility index $\lambda_{0}$ is assumed to be $0.1 \mathrm{~mm}$. In the simulation, the element size is $3 \mathrm{~mm} \times 0.2 \mathrm{~mm} \times 0.1 \mathrm{~mm}$. 
When comparing the element size to the beam waist radius $\mathrm{w}_{0}$ and transmissibility index $\lambda_{0}$, it can be concluded that during the period that laser is passing along a particular surface element, $100 \%$ of the radiation in circumferential direction, $86 \%$ in height direction and $73 \%$ in the thickness direction will be absorbed in this element. The duration of laser passing along the element $\left(\tau_{1}\right)$ is estimated by

$$
\tau_{1}=\tau \times \frac{3}{\pi \times D}=1 \times \frac{3}{\pi \times 95}=0.01 \text { Second }
$$

Therefore, the energy input $\left(Q_{\text {in }}\right)$ from laser is estimated as

$$
\mathrm{Q}_{\text {in }}=100 \times 86 \% \times 73 \% \times 0.01=0.63 \mathrm{~J}
$$

Substituting $\mathrm{h}_{\mathrm{c}}=10 \mathrm{~W} / \mathrm{m}^{2} . \mathrm{K}, \mathrm{dA}=3 \mathrm{~mm} \times 0.2 \mathrm{~mm}, \mathrm{~T}_{\mathrm{s}}=3500 \mathrm{C}, \mathrm{T}_{\infty}=50 \mathrm{C}$ into the Equation C.1 yields

$$
\begin{aligned}
\dot{Q}_{h} & =10 \times 3 \times 0.2 \times 10^{-6} \times(3500-50) \\
& =0.021 \mathrm{~W}
\end{aligned}
$$

Since this high rate heat convection can only happen in a short period of time (less than $\tau)$, mainly during the period that laser is passing along this small element, the energy loss due to heat convection

$$
Q_{h}<Q_{h} \times \tau=0.018 \mathrm{~J}
$$

Therefore, the percent of energy loss $\left(\eta_{\text {loss }}\right)$ due to the heat convection

$$
\eta_{\text {loss }}<\frac{Q_{h}}{Q_{\text {in }}}=\frac{0.021}{0.63}=3.3 \%
$$

Reference [43] states the energy loss due to convection will not exceed $6 \%$. 
For rotating cylinder, heat convection coefficient will be larger than $10 \mathrm{~W} / \mathrm{m}^{2} . \mathrm{k}$. Method in reference [Frank Kreith, Mark S. Bohn, "Principles of Heat Transfer", PWS Publishing Co] can be used to determine roughly the magnitude of $h_{c}$. In this method, it is assumed that cylinder is rotating horizontally, and temperature in the cylinder is uniform as shown in Figure C.1.

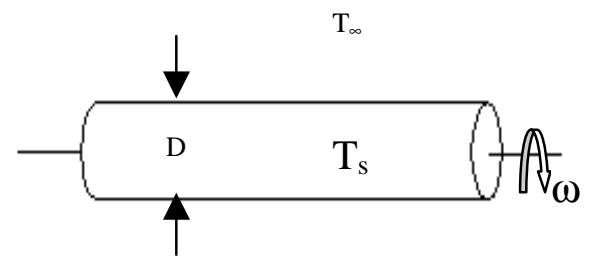

Figure C.1 Schematic to Represent the Rotating Cylinder

Equations used to estimate the heat convection coefficient include

$$
\begin{aligned}
& h_{c}=\frac{N_{u d} \times k}{D} \\
& N_{u d}=0.11 \times\left(0.5 R_{e w}^{2}+G_{r D} \times P_{r}\right)^{0.35} \\
& R_{e w}=\frac{\pi D^{2} \omega}{v} \\
& G_{r D}=g \times \beta\left(T_{s}-T_{\infty}\right) D^{3} / v^{2}
\end{aligned}
$$

where $N_{u d}$ is the Nusselt number, $R_{e w}$ is the peripheral-speed Reynolds number, $G_{r D}$ is the Grashof number, $P_{r}$ is the Prandtl number, $v$ is the viscosity, $\mathrm{k}$ is the thermal conductivity, D is the diameter of the glassware, $\omega$ is the rotation speed, $g$ is gravity accelerates, and $\beta$ is the thermal expansion coefficient. 
Substituting D $=95 \mathrm{~mm}, \omega=2 \pi \mathrm{rad} / \mathrm{sec}, v=1.80 \times 10^{-5}, \mathrm{~g}=9.8 \mathrm{~m} / \mathrm{s}^{2}, \beta=3.10 \times 10^{-3} \mathrm{k}^{-1}$, $\mathrm{k}=0.027 \mathrm{~W} / \mathrm{m} . \mathrm{k}$ into above equations yields

$$
\begin{aligned}
R_{e w} & =\frac{\pi \times(0.095)^{2} \times 2 \pi}{1.80 \times 10^{-5}}=1.43 \times 10^{8} \\
G_{r D} P_{r}= & 9.8 \times 3.10 \times 10^{-3} \times(3500-50) \times(0.095)^{3} /\left(1.80 \times 10^{-5}\right)^{2} \times 0.71 \\
= & 1.68 \times 10^{8} \\
h_{c}= & \frac{0.11 \times\left(0.5 \times\left(8.9 \times 10^{3}\right)+1.68 \times 10^{8}\right) \times 0.0270}{0.095} \\
& =25.5
\end{aligned}
$$

In this case, the heat loss due to hest convection is

$$
\begin{aligned}
\dot{Q}_{h} & =h_{c} \times d A \times\left(T_{s}-T_{\infty}\right) \\
& =25.5 \times 3 \times 0.2 \times 10^{-6} \times(3500-50) \\
& =0.53 \mathrm{~W}
\end{aligned}
$$

Since this high rate heat convection can only happen in a short period of time (less than $\tau)$, mainly during the period that laser is passing along this small element, the energy loss due to heat convection

$$
Q_{h}<\dot{Q}_{h} \times \tau=0.054 \mathrm{~J}
$$

Therefore, the percent of energy loss $\left(\eta_{\text {loss }}\right)$ due to the heat convection

$$
\eta_{\text {loss }}<\frac{Q_{h}}{Q_{\text {in }}}=\frac{0.054}{0.63}=8.6 \%
$$




\section{APPENDIX D: \\ Energy Loss Due to Heat Radiation}

The purpose of this appendix is to justify the consideration of heat radiation in the laser glass simulation. The justification was based on the calculation of percentage of heat radiation energy loss occurred in the radiation surface area of the element used in the simulation.

In the simulation of laser glass interaction, no radiation energy loss was considered. The heat loss due to heat radiation could be evaluated using the Equation D.1

$$
\dot{Q}_{r}=d A \times F \times \sigma \times\left(T_{s}^{4}-T_{\infty}^{4}\right)
$$

where $\mathrm{F}$ is the geometrical shape factor and is less than $1, \mathrm{dA}$ is the surface area of the element used in the simulation, $\sigma$ is the Boltsman Constant, $\mathrm{T}_{\mathrm{s}}$ is the temperature in the element and $\mathrm{T}_{\infty}$ is the ambient temperature.

It was found from the simulation that temperature in the surface element $\left(\mathrm{T}_{\mathrm{s}}\right)$ could be as high as $3500 \mathrm{C}$. The parameters in the simulation to predict this $\mathrm{T}_{\mathrm{s}}$ include: laser power $(\mathrm{P}) 100$ $\mathrm{W}$, rotation cycle $(\tau)$ second, glassware diameter $(\mathrm{D}) 95 \mathrm{~mm}$, and ambient temperature $\left(\mathrm{T}_{\infty}\right) 50 \mathrm{C}$. Laser beam waist radius $\mathrm{w}_{0}$ is $0.1 \mathrm{~mm}$ and laser beam transmissibility index $\lambda_{0}$ is assumed to be $0.1 \mathrm{~mm}$. In the simulation, the element size is $3 \mathrm{~mm} \times 0.2 \mathrm{~mm} \times 0.1 \mathrm{~mm}$.

When comparing the element size to the beam waist radius $\mathrm{w}_{0}$ and transmissibility index $\lambda_{0}$, it can be concluded that during the period that laser is passing along a particular surface element, $100 \%$ of the radiation in circumferential direction, $86 \%$ in height direction and $73 \%$ in 
the thickness direction will be absorbed in this element. The duration of laser passing along the element $\left(\tau_{1}\right)$ is estimated by

$$
\tau_{1}=\tau \times \frac{3}{\pi \times D}=1 \times \frac{3}{\pi \times 95}=0.01 \text { Second }
$$

Therefore, the energy input $\left(\mathrm{Q}_{\text {in }}\right)$ from laser is estimated as

$$
\mathrm{Q}_{\text {in }}=100 \times 86 \% \times 73 \% \times 0.01=0.63 \mathrm{~J}
$$

Since the majority of radiation energy loss happened in a short period of time (less than $\tau)$, mainly during the period that laser is passing along this small element and short period thereafter, when estimating the radiation energy loss, it is assumed that the temperature maintains $\bar{T}_{s}=2400 C$ for about 0.03 second as shown in Figure D.1.

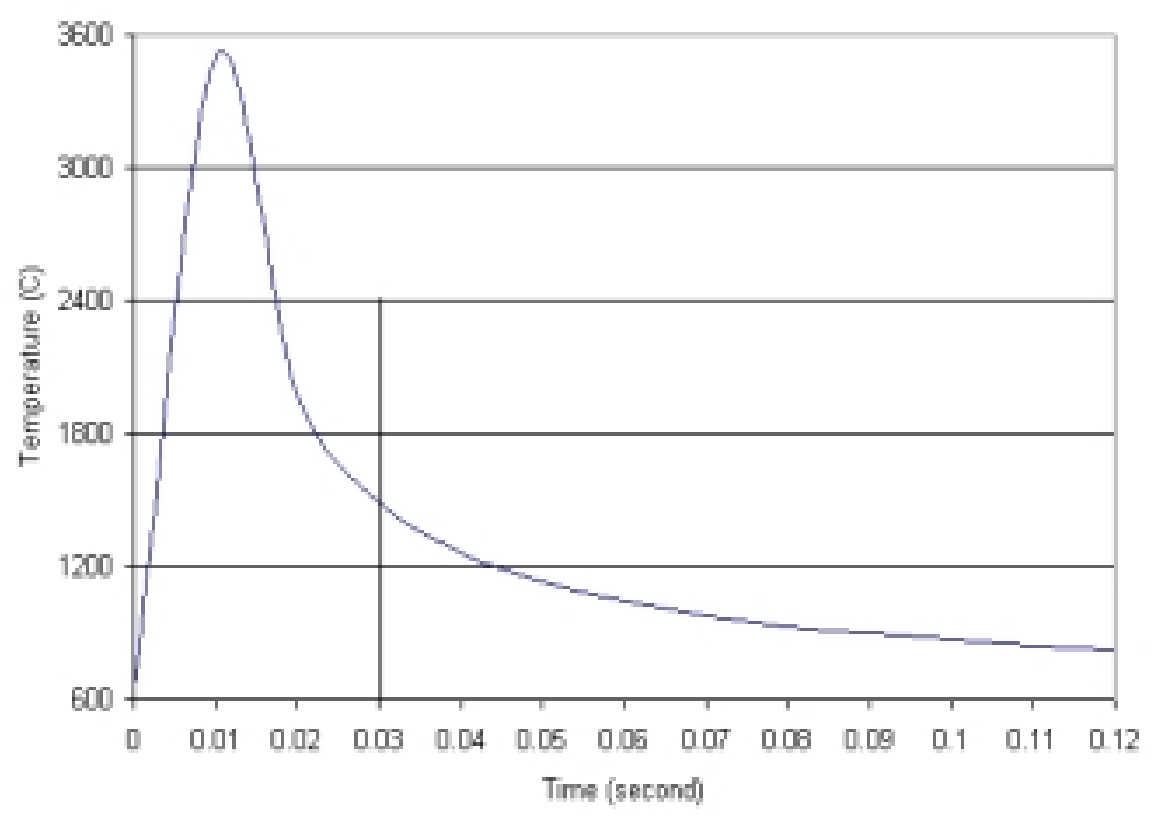

Figure D.1 Surface Temperature Response During Laser Glass Interaction 
Substituting $\mathrm{F}=1, \mathrm{dA}=3 \mathrm{~mm} \times 0.2 \mathrm{~mm}, \bar{T}_{s}=2400 C, \mathrm{~T}_{\infty}=50 \mathrm{C}$ into Equation D.1

yields

$$
\begin{gathered}
\dot{Q}_{r}=3 \times 0.2 \times 10^{-6} \times 1 \times 5.67 \times 10^{-8} \times\left((2400+273)^{4}-(50+273)^{4}\right) \\
=1.74 \mathrm{~W} \\
Q_{r} \approx \dot{Q}_{r} \times 0.03=0.053 \mathrm{~J}
\end{gathered}
$$

Therefore, the percent of energy loss $\left(\eta_{\text {loss }}\right)$ due to the heat radiation

$$
\eta_{\text {loss }}<\frac{Q_{h}}{Q_{\text {in }}}=\frac{0.053}{0.63}=8.3 \%
$$

Reference [43] states the energy loss due to radiation will not exceed $6 \%$. 


\section{VITA}

\section{Education}

Ph.D. in Mechanical Engineering, focus on Dynamic Systems and Controls

West Virginia University (WVU), Morgantown, WV, October 2000 (3.9/4.0 GPA)

MS in Mechanical Engineering, focus on Engines and Vehicles

Northern Jiaotong University (NJU), Beijing, China, April 1995 (87.0/100 GPA)

BS in Mechanical Engineering, focus on Thermodynamics and Engines

Northern Jiaotong University (NJU), Beijing, China, July 1992 (84.4/100 GPA)

\section{Research Experience}

Projects with Industry Group, MAE Department, WVU, Morgantown, WV

August 1998 - October 2000, $\quad$ Research Assistant

Center for Industrial Research Applications, WVU, Morgantown, WV

August 1997 - July 1998, Research Assistant

Research Center for Locomotive and Vehicles, NJU, Beijing, China

April 1995 - July 1997, $\quad$ Research Associate

Mechanical Engineering Department, NJU, Beijing, China

September 1992 - March $1995 \quad$ Research Assistant

\section{Teaching Experience}

Projects with Industry Group, MAE Department, WVU, Morgantown, WV

January 1999-present Teaching Assistant

Mechanical Engineering Department, NJU, Beijing, China

April 1995-July 1997

Teaching Assistant 